\author{
Universidade de São Paulo \\ Instituto de Física
}

\title{
Rotas de síntese e métodos de caracterização estrutural para sistemas de nanopartículas metálicas
}

\author{
Paulo Ricardo de Abreu Furtado Garcia
}

Orientador: Prof. Dr. Cristiano Luis Pinto de Oliveira

Tese de doutorado apresentada ao Instituto de Física da

Universidade de São Paulo, como requisito parcial para a obtenção do título de Doutor em Ciências.

São Paulo

2020 
FICHA CATALOGRÁFICA

Preparada pelo Serviço de Biblioteca e Informação do Instituto de Física da Universidade de São Paulo

Garcia, Paulo Ricardo de Abreu Furtado

Rotas de síntese e métodos de caracterização estrutural para sistemas de nanopartículas metálicas. São Paulo, 2020.

Tese (Doutorado) - Universidade de São Paulo. Instituto de Física. Depto. de Física Experimental

Orientador: Prof. Dr. Cristiano Luís Pinto de Oliveira

Área de Concentração: Física da Matéria Condensada

Unitermos: 1. Nanopartículas; 2. Espalhamento de raios $X$ à baixos ângulos; 3 . Síntese química; 4 . Nanotecnologia; 5 . Modelagem de dados. 


\author{
University of São Paulo \\ Physics Institute
}

\title{
Synthesis routes and structural characterization methods for metallic nanoparticle systems
}

\author{
Paulo Ricardo de Abreu Furtado Garcia
}

Supervisor: Prof. Dr. Cristiano Luis Pinto de Oliveira

Thesis submitted to the Physics Institute of the University of São Paulo in partial fulfillment of the requirements for the degree of Doctor of Science

São Paulo 



\section{Agradecimentos}

A realização desta tese de doutorado só foi possível graças à colaboração de diversas pessoas e entidades. Neste sentido, expresso minha gratidão a todos que me ajudaram a completar essa jornada.

Agradeço à toda a minha família, em especial à minha mãe Luzia, ao meu pai Hélio e à minha tia Elisa, tão fundamentais na minha vida. Agradeço a Isabella por sempre estar ao meu lado.

Agradeço ao meu orientador, Professor Cristiano Oliveira, pela orientação, por todo o aprendizado e pelas oportunidades.

Agradeço aos técnicos, estudantes e professores do Grupo de Fluidos Complexos. À Universidade de São Paulo.

Agradeço ao Prof. Dr. Matthias Epple e Dr. Oleg Prymak por todo o suporte prestado durante o excelente estágio que realizei na Universidade de Duisburg-Essen. Agradeço aos estudantes do grupo do Prof. Epple pela recepção e pelo auxílio durante os trabalhos realizados.

Agradeço às agências de fomento CAPES, CNPQ e FAPESP por todo o suporte financeiro concedido no financiamento de bolsas de estudo, equipamentos, participação em eventos científicos entre outros.

O presente trabalho foi realizado com apoio da Coordenação de Aperfeiçoamento de Pessoal de Nível Superior - Brasil (CAPES) - Código de Financiamento 001. 

“Toda a nossa ciência comparada com a realidade, é primitiva e infantil; e, no entanto, é a coisa mais preciosa que temos.

(Albert Einstein) 



\section{Resumo}

GARCIA, Paulo Ricardo de Abreu Furtado. Rotas de síntese e métodos de caracterização estrutural para sistemas de nanopartículas metálicas. 2020. 171 f. Tese (Doutor em Ciências) - Instituto de Física, Universidade de São Paulo, São Paulo, 2020 .

Devido às propriedades magnéticas, ópticas e elétricas, nanopartículas metálicas têm sido extensivamente estudadas para possíveis aplicações na produção de biossensores, separação de moléculas biológicas, técnicas de imagem, administração de medicamentos entre várias outras. Para tais aplicações, é crucial ter rotas de síntese otimizadas para a formação de partículas com morfologia e estrutura bem definidas. Neste trabalho, apresentamos um estudo sistemático de processos de síntese de nanopartículas bem como uma caracterização estrutural detalhada utilizando diversas técnicas experimentais. Experimentos in e ex situ possibilitaram a aquisição de dados desses sistemas durante e após o processo de formação das nanopartículas. A correlação dos resultados de espalhamento de raios X a baixo ângulo (SAXS) com outras técnicas experimentais permitiu a determinação de diversos parâmetros estruturais para os sistemas estudados e também demonstrou a complementaridade das diferentes técnicas utilizadas. Foi necessário o desenvolvimento de métodos avançados de modelagem de dados de SAXS, o que permitiu a obtenção de informações sobre características dos sistemas como tamanho médio, estado de agregação, polidispersidade entre outros parâmetros. A experiência em síntese de nanopartículas adquirida durante o projeto foi essencial para a implementação de uma rota de síntese de nanobastões de ouro com baixa polidispersão de tamanho. Além das informações estruturais obtidas para os diversos sistemas investigados nesta tese, obtivemos um conjunto de métodos experimentais e teóricos que podem ser aplicados a diversos tipos de sistemas.

Palavras chave: Modelagem. SAXS. Nanopartículas. Estrutura. Síntese. 



\begin{abstract}
GARCIA, Paulo Ricardo de Abreu Furtado. Synthesis routes and structural characterization methods for metallic nanoparticle systems. 2020. $171 \mathrm{f}$. Thesis (Doctorate in Sciences) - Physics Institute, São Paulo University, São Paulo, 2020.

Due to their magnetic, optical and electrical properties, metallic nanoparticles have been extensively studied for applications in biosensor production, separation of biological molecules, imaging techniques, drug delivery among many others. For such applications, it is crucial to have optimized synthesis routes for the formation of particles with well-defined morphology and structure. In this work, we present a systematic study of nanoparticle synthesis processes as well as a detailed structural characterization using several experimental techniques. In and ex situ experiments enabled the acquisition of data from these systems during and after the nanoparticle formation process. The correlation of small angle X-ray scattering (SAXS) results with other experimental techniques allowed the determination of several structural parameters for the studied systems and also demonstrated the complementarity of the different techniques used. It was necessary to develop advanced methods of SAXS data modeling, which allowed obtaining information about characteristics of the systems such as average size, aggregation state, polydispersity among other parameters. The experience in nanoparticle synthesis acquired during the project was essential for the implementation of a gold nanorods synthesis route with low polydispersity. In addition to the structural information obtained for the various systems investigated in this thesis, we obtained a set of experimental and theoretical methods that can be applied to several types of systems.
\end{abstract}

Keywords: Modeling. SAXS. Nanoparticles. Structure. Synthesis. 



\section{Lista de figuras}

Figura 1 - (a) Taça de Lycurgus and (b) imagem de TEM da espada de Damasco. Barra de escala: 5nm. Fontes: (FREESTONE et al., 2007; Reibold M. et al., 2006). . . . . . . . . . . . . . . . . 31

Figura 2 - Efeito Faraday-Tyndall. . . . . . . . . . . . . . . . 32

Figura 3 - Representação de processos de síntese top-down e bottom-up. Fonte: Adaptada de Habiba et al. (2014). . . . . . . . . . . . . . . . . . . . . 32

Figura 4 - Reação química que ocorre durante a formação de nanopartículas de ouro. Método Turkevich. Ácido cloroaúrico + citrato trissódico + água. Fonte:(ZHAO; LI; ASTRUC, 2013) . . . . . . . . . . . . . . . 34

Figura 5 - Energia livre de Gibbs em função do raio. . . . . . . . . . . . . . . 37

Figura 6 - Representação dos processos de geração, nucleação e crescimento de átomos ilustrados através concentração em função do tempo (XIA et

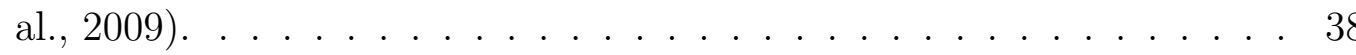

Figura 7 - (a) Diagrama esquemático mostrando os cinco monocristais que formam o decaedro e $(b, c)$ imagens de alta resolução de TEM de cristais decaédricos de prata. Fonte: Xia et al. (2009). . . . . . . . . . . . . 40

Figura 8 - Diagrama esquemático de um experimento de espalhamento/difração de raios X usando geometria de transmissão. . . . . . . . . . . . . . . . . 41

Figura 9 - Interação de uma onda incidente $\left(\mathbf{k}_{\mathbf{0}}\right)$ com o potencial $\varphi\left(\mathbf{r}^{\prime}\right)$ localizado no ponto P resultando na geração de onda esférica. . . . . . . . . . . . 43

Figura 10 - Vetor de transferência de momento do espaço recíproco (q), vetores de onda dos feixes incidente $\left(\mathbf{k}_{\mathbf{0}}\right)$ e espalhado $(\mathbf{k}) \ldots \ldots . . . . . .44$

Figura 11 - Ilustração da Lei de Bragg. . . . . . . . . . . . . . . . . . . . . 52

Figura 12 - Representação de uma estrutura cristalina cúbica, mostrando os parâmetros de rede $a, b, c, \alpha, \beta$ e $\gamma \ldots \ldots \ldots \ldots$

Figura 13 - Espectroscopia de correlação de fótons: (a) homódino e (b) heteródino. 57 
Figura 14 - (a)Diagrama esquemático do aparato experimental de espectroscopia uvvis, (b) representação da ressonância plasmônica de superfície localizada e (c) espectro Uv-vis de uma amostra de nanopartículas de prata. A imagem do espectrômetro na figura (a) está disponível em: (OCEAN OPTICS, 2019).

Figura 15 - Diagrama esquemático de um microscópio eletrônico. Fonte: Adaptado de (SPECTROSCOPY, 2019) . . . . . . . . . . . . .

Figura 16 - Diagrama mostrando as posições da lente e abertura abjetivas na formação de imagens de campo escuro e claro. Na figura (A) o feixe transmitido, na direção do eixo ótico, é captado para a formação de imagens de campo escuro. Nas (B) e (C) o feixe espalhado é captado formando imagens de campo claro. Em (B) o feixe incidente está na mesma direção do eixo ótico enquanto que em (C) o feixe incidente é posicionado em uma direção $2 \theta$ em relação ao eixo ótico. Fonte: Williams e Carter (2009). . . . . . . . . . . . . . . . .

Figura 17 - (a) Diagrama esquemático do disco do equipamento de DCS e (b) distribuição de diâmetros de uma amostra de nanopartículas de prata. Figura (a) esta disponível em: (CPS INSTRUMENTS EUROPE, 2019).

Figura 18 - Diagrama esquemático da síntese de nanopartículas de prata. Neste diagrama, $t$ é o tempo de reação. . . . . . . . . . . . . . . 68

Figura 19 - Diagrama esquemático da síntese de nanopartículas de ouro e prata. Neste diagrama, $t$ é o tempo de reação. . . . . . . . . . . . . . . 68

Figura 20 - Diagrama esquemático da síntese de nanopartículas de paládio-ouro. . . 70 Figura 21 - Diagrama esquemático da síntese de nanobastões de ouro. Neste diagrama, $t$ é o tempo de reação. . . . . . . . . . . . . . . .

Figura 22 - Diagrama esquemático da síntese modificada de nanobastões de ouro.

Neste diagrama, $t$ é o tempo de reação. . . . . . . . . . . . . . . . 72

Figura 23 - (a) Nanostar ${ }^{\circledR}$ com a atualização do sistema de colimação da Xenocs e (b) Xenocs Xeuss ${ }^{\circledR} \ldots \ldots \ldots \ldots \ldots \ldots$. . . . . . . . . . . . . . . . .

Figura 24 - Imagens do equipamento de SAXS Xeuss 10m. . . . . . . . . . . . . 74

Figura 25 - Dados de WAXS do corundum e indexação dos picos de difração. . . . 75

Figura 26 - Imagens do aparato experimental utilizado no experimento in situ realizado no LNLS. . . . . . . . . . . . . . . . . . . . 77 
Figura 27 - (a) Diagrama esquemático e (b) imagem do aparato in situ. . . . . . . 78

Figura 28 - O aparato in situ (a) antes e (b) depois da atualização. . . . . . . . . . 79

Figura 29 - Imagem do equipamento de DLS NanoBrook 90Plus. . . . . . . . . . . 80

Figura 30 - Imagem do equipamento de XRD Bruker D8 Advance. Fonte: (UNIVERSITY OF DUISBURG-ESSEN, 2019) . . . . . . . . . . . . . 80

Figura 31 - Imagem do equipamento de espectroscopia Uv-vis. . . . . . . . . . . . 81

Figura 32 - Imagem do microscópio eletrônico JEOL 2100. Fonte: (IPEN - INSTITUTO DE PESQUISAS ENERGÉTICAS E NUCLEARES, 2019). . 82

Figura 33 - Imagem centrífuga de disco DC 24000 . Fonte: (CPS INSTRUMENTS EUROPE, 2019) . . . . . . . . . . . . . . . 83

Figura 34 - Imagem do menu do programa Rexpace. . . . . . . . . . . . . . . . . . 84

Figura 35 - Fluxograma do algoritmo do método de Monte Carlo utilizado na modelagem dos dados de SAXS. Nesta figura, $\alpha$ é o critério de convergência. 86

Figura 36 - Dados de SAXS dos (a) nanobastões e (c) nanodiscos de prata, dados de WAXS dos (b) nanobastões e (d) nanodiscos de prata. Fonte: Adaptado de Garcia et al. (2019). . . . . . . . . . . . . . . . . . . 90

Figura 37 - Imagens de TEM dos (esquerda) nanodiscos e (direita) nanobastões de prata. Fonte: Garcia et al. (2019). . . . . . . . . . . . . . . . . . . 90

Figura 38 - Gráficos de SWAXS: (a) dados experimentais de SAXS e curva de ajuste, (b) distribuições de raios calculadas usando os dados SAXS e (c) dados experimentais de WAXS. Fonte: Adaptado de Garcia et al. (2019). . . . 92

Figura 39 - Amostras de nanopartículas de prata (da esquerda para direita): Ag2, Ag10, Ag15, Ag19, Ag30, Ag35, Ag50, Ag120 e Ag210. . . . . . . . . . 94

Figura 40 - Caracterizações estruturais de alíquotas de nanopartículas de prata com diferentes tempos de reação: (a) espectroscopia Uv-vis (a absorbância está normalizada pelo valor máximo da curva), (b) DLS, (c) WAXS e

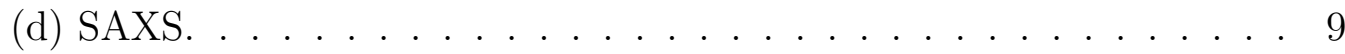

Figura 41 - Imagem de HAADF-STEM e mapa de EDX das nanopartículas núcleocasca de paládio-ouro. Barras de escala são 7 nm. Fonte: Adaptado de (ROSTEK et al., 2018). . . . . . . . . . . . . . . . 100 
Figura 42 - Dados de SAXS in situ: Evolução temporal da (a) intensidade de espalhamento e (b) raio médio do sistema de nanopartículas núcleocasca de Pd-Au. Para maior clareza, nem todas as curvas de intensidade são exibidas. Fonte: Adaptado de (ROSTEK et al., 2018). ...... . 101

Figura 43 - Evolução temporal dos (a) fatores de escala e (b) raios de giro de agregados da amostra de nanopartículas de PdAu. . . . . . . . . . . 102

Figura 44 - Evolução temporal da (a) intensidade de espalhamento de SAXS, (b) raio médio pesado por volume, (c) polidispersidade relativa $(\sigma / R$, em que $\mathrm{R}$ e $\sigma$ são o raio médio pesado por volume e o desvio padrão da distribuição, respectivamente) e (d) frações de volume durante a síntese das nanopartículas de prata. Fonte: Figuras (a), (b) e (d) foram adaptadas de: (GARCIA et al., 2020). . . . . . . . . . . . . 106

Figura 45 - (a) Gráfico log-log do raio médio pesado por número em função do tempo de síntese, (b) imagens de TEM mostrando nanopartículas grandes (esquerda) e pequenas (direita) com distâncias interplanares de 2,34 $\AA$, (c) espectros Uv-vis de alíquotas de nanopartículas de prata coletadas em 24, 36, 54 e 72 minutos de síntese; e (d) difratograma de XRD de uma alíquota obtida no final da síntese. Fonte: Adaptado de (GARCIA et al., 2020). . . . . . . . . . . . . . . . . . . 108

Figura 46 - Gráficos das caracterizações realizadas no Laboratorio Nacional de Luz Síncotron. Evolução temporal da (a) intensidade de espalhamento de SAXS, (b) raio médio pesado por volume, (c) polidispersidade $(\sigma)$ e (d) frações de volume durante a síntese das nanopartículas de prata. . . . . 110

Figura 47 - Gráfico log-log do raio médio pesado por número em função do tempo de síntese de nanopartículas de prata. Síntese realizada no LNLS. . . . 111

Figura 48 - Gráficos da evolução temporal da (a) intensidade de espalhamento de SAXS, raio médio pesado por volume em escalas linear e logarítmica (b, c) e (d) fator de escala de agregados. Fonte: Adaptado de (GARCIA et al., 2020) . . . . . . . . . . . . . . . . . . 113 
Figura 49 - Caracterizações da alíquota de nanopartículas de ouro-prata retirada ao final da síntese. (a) imagem de TEM, (b) histograma de distribuição de tamanhos calculado usando as imagens de TEM, (c) dados de XRD com refinamento de Rietveld e (d) espectros Uv-vis. O histograma foi produzido pelo pesquisador Dr. Wagner Wlysses. Fonte: Adaptado de (GARCIA et al., 2020) . . . . . . . . . . . . . . 116

Figura 50 - Dados de SAXS de nanobastões de ouro. (a) Dados experimentais e curva teórica da intensidade de espalhamento, evolução temporal do (b) raio médio, (c) comprimento médio e (d) polidispersidade relativa $(\sigma / R)$. Os símbolos são os dados experimentais e as linhas são linhas de tendência $(\mathrm{b}, \mathrm{c}, \mathrm{d})$ ou curvas de ajuste $(\mathrm{a}) \ldots$. . . . . . . . . . . 118

Figura 51 - Imagens de TEM de diferentes alíquotas de nanobastões de ouro. . . . 119

Figura 52 - Evolução temporal da (a) razão de aspecto e (b) espectro Uv-vis de nanobastões de ouro. A linha na figura (a) é uma linha de tendência. . 120

Figura 53 - Intensidade de espalhamento de SAXS de amostras de nanobastões centrifugada e não centrifugada. . . . . . . . . . . . . . . . . . . . 122

Figura 54 - Curvas de SAXS das amostras de CTAB. . . . . . . . . . . . . . . . 124

Figura 55 - Histogramas das distribuições de raio de alíquotas de nanopartículas de prata obtidas em (a) 7 e (b) 72 minutos de síntese. . . . . . . . . . . 138

Figura 56 - Micrografias de TEM e distribuição de tamanhos de alíquotas de nanopartículas de prata obtidas em (a) 24 minutos, (b) 36 minutos e (c) 72 minutos de síntese. . . . . . . . . . . . . . . . . . . 138

Figura 57 - Evolução temporal da distribuição de raios de nanopartículas de prata durante experimento in situ. . . . . . . . . . . . . . . . . . . . . 139

Figura 58 - Evolução temporal da distribuição de raios de nanopartículas de ouroprata durante experimento in situ.. . . . . . . . . . . . . . . 139 


\section{Lista de tabelas}

Tabela 1 - Fatores de forma (ZEMB; LINDNER, 2002) . . . . . . . . . . . 49

Tabela 2 - Distância interplanares. . . . . . . . . . . . . . . 55

Tabela 3 - Parâmetros estruturais de amostras de nanobastões e nanoplaquetas de

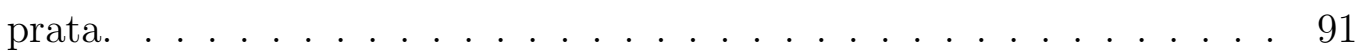

Tabela 4 - Parâmetros estruturais de nanoligas de ouro-prata. . . . . . . . . . 93

Tabela 5 - Parâmetros estruturais de nanopartículas de prata sintetizadas com diferentes tempos de reação. . . . . . . . . . . . . . . . . . . . . . . 98

Tabela 6 - Parâmetros estruturais das amostras de nanobastões de ouro centrifugada e não centrifugada. . . . . . . . . . . . . . . . . . 123

Tabela 7 - Parâmetros estruturais calculados para soluções de CTAB com diferentes concentrações. . . . . . . . . . . . . . . . . . 124

Tabela 8 - Parâmetros estruturais de nanopartículas de prata calculados usando as micrografias TEM. . . . . . . . . . . . . . . . . 139

Tabela 9 - Parâmetros estruturais das alíquotas de nanobastões de ouro obtidas em diferentes tempos de reação. . . . . . . . . . . . . . . . . . . . 140 
Sumário

$1 \quad$ Introdução $\ldots \ldots \ldots \ldots \ldots$

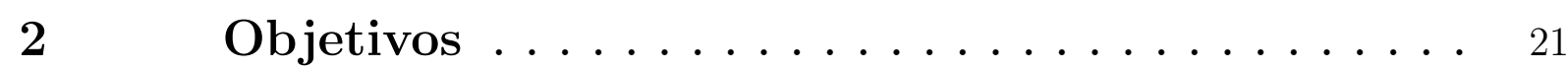

$3 \quad$ Publicações . . . . . . . . . . . . . . 22

4 Métodos de minimização . . . . . . . . . . . 23

4.1 Modelagem e o conceito de qui-quadrado . . . . . . . . 23

$4.2 \quad$ O teste qui-quadrado $\left(\chi^{2}\right) \ldots \ldots \ldots \ldots$

$4.3 \quad$ O método de mínimos quadrados . . . . . . . . 25

4.3.1 Os métodos de Gauss-Newton e gradiente descendente. . 25

4.4 Método de Levenberg-Marquardt . . . . . . . . . . . 27

5 Conceitos de síntese e formação de nanopartículas

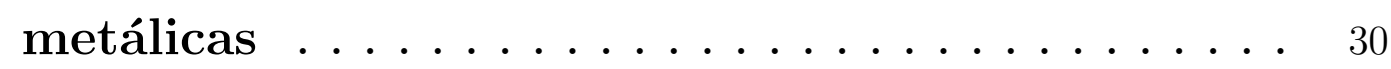

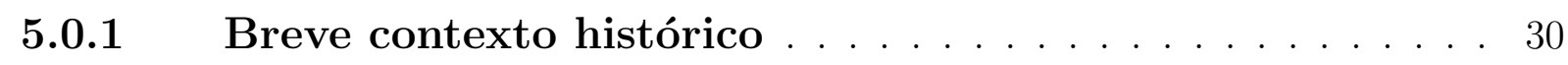

5.0.2 Conceitos básicos de síntese de nanopartículas . . . . . . 32

5.0.3 Mecanismo de crescimento . . . . . . . . . . . . . 35

6 Técnicas de caracterização e métodos de análise . 41

6.1 Espalhamento de raios $\mathbf{X}$ a baixo ângulo . . . . . . . . 41

6.1.1 Princípios de espalhamento: Primeira aproximação de Born . . . . . . . . . . . . . . . . . . . . . . 44 42

6.1.2 Intensidade de espalhamento e função de distribuição de pares de distância . . . . . . . . . . . . . . . 46

6.1.3 Modelagem dos fatores de forma e estrutura de um sistema de partículas . . . . . . . . . . . . . . . 48

6.2 Difração de $\operatorname{raios} \mathbf{X} \ldots \ldots \ldots \ldots 2$

6.3 Espalhamento dinâmico de luz . . . . . . . . . . 56

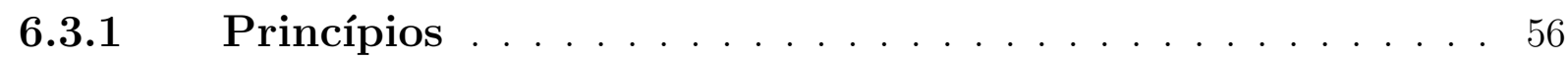

6.3.2 Funçao de autocorrelação temporal da intensidade . . . 57

6.3.3 A função de autocorrelação de um sistema polidisperso . 58 
6.3.4 Modelagem . . . . . . . . . . . . . . . . . . . . . 59

6.4 Espectroscopia no ultravioleta-visível e ressonância plasmônica de superfície localizada . . . . . . . . . . 60

6.4.1 Ressonância plasmônica de superfície localizada . . . . . . 61

6.5 Microscopia eletrônica de transmissão . . . . . . . . . . . 62

6.6 Sedimentação Centrífuga Diferencial . . . . . . . . . . 65

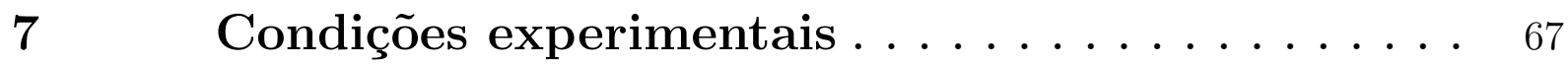

$7.1 \quad$ Síntese de nanopartículas de prata . . . . . . . . . . 67

7.2 Síntese de nanopartículas de ouro-prata . . . . . . . 68

7.3 Síntese de nanopartículas de paládio-ouro . . . . . . . . 69

7.4 Síntese de nanobastões de ouro . . . . . . . . . . . . 70

$7.5 \quad$ SAXS e WAXS . . . . . . . . . . . . . . . . . 72

7.6 Caracterizações por SAXS realizadas no Laboratório

Nacional de Luz Síncotron (LNLS) . . . . . . . . . 76

$7.7 \quad$ Aparato in situ de SAXS . . . . . . . . . . . . . . 77

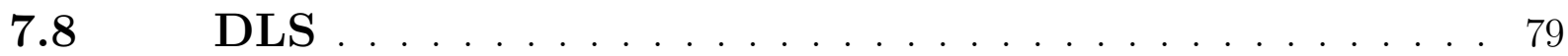

$7.9 \quad$ Difração de raios $\mathrm{X} \ldots \ldots \ldots \ldots$. . . . . . . 80

7.10 Espectroscopia no ultravioleta e visível . . . . . . . . . 81

$7.11 \quad$ TEM . . . . . . . . . . . . . . . . . . 81

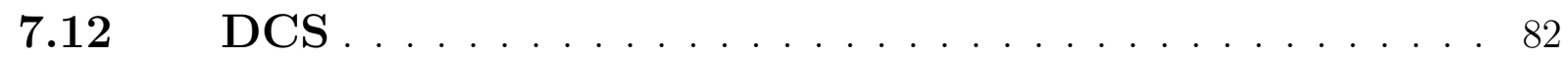

7.13 Programas de análise desenvolvidos durante o projeto 83

7.14 Colaboração com pesquisadores da Universidade de Duisburg-Essen . . . . . . . . . . . . . . . . 87

$8 \quad$ Resultados e discussão . . . . . . . . . . . . . . . . . 89

8.1 Nanopartículas de diferentes formas e composições . . 89

8.2 Estudo ex situ de nanopartículas de prata . . . . . . . . 93

8.3 Estudo in situ de nanopartículas de paládio-ouro . . . 99

8.4 Estudo in situ de nanopartículas de prata . . . . . . . . 103

8.5 Estudo in situ de nanopartículas de prata realizado no Laboratorio Nacional de Luz Síncotron . . . . . . . . . 109

8.6 Estudo in situ de nanopartículas de ouro-prata . . . . 112 
8.7 Investigação estrutural de nanobastões de ouro . . . 116

8.7.1 Estudo de micelas de CTAB . . . . . . . . . . . . . . . . 121

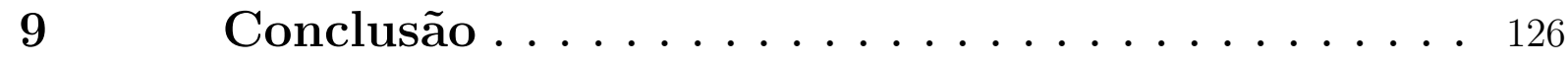

$\operatorname{Referências~}^{1} \ldots \ldots \ldots \ldots \ldots \ldots$

$\begin{array}{ll}\text { APENNDICES } & 135\end{array}$

Apêndice A-Conteúdo complementar . . . . . . 136

A.1 A equação de Carpena . . . . . . . . . . . . . . . 136

A.2 $\mathrm{O}$ fator de escala de agregados $\mathbf{S c}^{\mathrm{G}} \ldots \ldots \ldots 136$

Apêndice B-Dados complementares ....... 138

$\begin{array}{ll}\text { ANEXOS } & 141\end{array}$ 


\section{Introdução}

Nanopartículas são partículas que tem dimensões no intervalo de 1 a 100 nanometros. Devido a propriedades como grande área superficial, nanopartículas inorgânicas possuem uma vasta possibilidade de aplicação em diversos campos. Nanopartículas de sílica podem atuar como suporte catalítico, molde para a produção de nanofios de materiais nobres para aplicações em microeletrônica, molde para a produção de nanofios de carbono e adjuvante imunológico onde atuam no sistema "drug delivery" (HAN; KIM; STUCKY, 2000; WU; BEIN, 1994; MERCURI et al., 2006). Nanopartículas de materiais nobres, das quais destacam-se nanopartículas de ouro e prata, vêm sendo muito estudadas atualmente em virtude de suas propriedades óticas, elétricas e magnéticas; o que as tornam interessantes para aplicações nas áreas de produção de biossensores, separação de moléculas biológicas, técnicas de imageamento, drug delivery entre várias outras (EUSTIS; EL-SAYED, 2006b).

Para as aplicações de nanopartículas citadas anteriormente é crucial obter cristais com morfologia e estrutura bem definidos, mas isso tem se mostrado um desafio em diversos casos. Nesse regime, há uma ênfase cada vez maior no meio científico de se relacionar a morfologia final dos sistemas de nanopartículas aos parâmetros experimentais da rota de síntese escolhida através da análise de seu crescimento ultra estrutural e cristalográfico (BANERJEE et al., 2014; RISTIG et al., 2015). Assim, busca-se obter um maior controle de parâmetros estruturais, como forma e distribuição de tamanho, para tornar a aplicação desses materiais mais eficaz, além de possivelmente contribuir para o conhecimento sobre os mecanismos físico-químicos responsáveis pela formação e crescimento das nanopartículas.

O conhecimento sobre quais fatores influenciam a morfologia final pode ser adquirido rastreando-se parâmetros específicos da síntese como tamanho de domínio, tamanho de cristalito, tamanho de partícula e inomogeneidades de forma (RISTIG et al., 2015). Neste âmbito, métodos experimentais que permitam a caracterização destas propriedades devem ser utilizados. O estudo de rotas de síntese de nanopartículas metálicas através da caracterização estrutural de nanopartículas com diferentes formas e simetrias é o tema central desta tese de doutorado.

Especificamente, pretende-se investigar o processo de nucleação e crescimento de nanopartículas metálicas sintetizadas por "wet chemical synthesis". As nanopartículas podem ser compostas por diversos metais ( $\mathrm{Ag}, \mathrm{Au}, \mathrm{Pt}, \mathrm{Pd}$, etc) e ligas. Dependendo do metal ou liga escolhido, as partículas formam cristais com geometrias diferentes. A caracterização 
destes sistemas é feito utilizando-se técnicas experimentais diretas e indiretas de caracterização, em particular técnicas de espalhamento de raios X e luz, em diversos estágios da síntese desses materiais com o objetivo de correlacionar propriedades morfológicas e estruturais de sistemas de nanopartículas metálicas aos parâmetros experimentais das rotas de síntese.

Entre os métodos mais utilizados para a caracterização de nanopartículas estão técnicas de espalhamento e difração e métodos de microscopia como microscopia eletrônica de transmissão (TEM, Transmission Electron Microscopy) e microscopia eletrônica de varredura (SEM, Scanning Electron Microscopy). Essas técnicas de microscopia são importantes porque fornecem uma imagem direta (espaço real) do sistema possibilitando a aquisição de informações sobre tamanhos, morfologia, homogeneidades, etc, de forma direta. No entanto, experimentos de TEM e SEM requerem, em geral, um elaborado processo de preparo da amostra para a execução das medidas. O número de partículas estudadas por estas técnicas é, em geral, relativamente pequeno, restringindo-se, no máximo, a alguns milhares. Além disso, as imagens representam projeções bidimensionais das partículas e a eventual sobreposição pode tornar a análise das imagens ainda mais complexas (BORCHERT et al., 2005). Métodos de espalhamento a baixo ângulo (usando raios X ou nêutrons) fornecem informações sobre o sistema de maneira indireta, do espaço recíproco. Para obter informações estruturais dos dados são necessárias técnicas de análise e modelagem bem como otimizações numéricas. Apesar disso, os dados obtidos por métodos de espalhamento representam uma média sobre um número muito grande de partículas (> $10^{5}$ partículas $/ \mathrm{mm}^{3}$ ), fornecendo informações representativas sobre o ensemble de partículas. Em geral, informações estatísticas sobre forma e tamanho e a análise dos dados pode ser realizada de maneira mais rápida que nos casos de experimentos de TEM e SEM (BORCHERT et al., 2005). Técnicas de microscopia e espalhamento podem ser combinadas para fornecer informações complementares sobre os sistemas estudados (OLIVEIRA, 2011).

Para a análise dos dados, além de ferramentas computacionais disponíveis na literatura, foram desenvolvidas e implementadas metodologias para modelagem de dados experimentais para sistemas nanoestruturados. Para a aplicação desses modelos adaptados aos sistemas estudados, um programa escrito em $\mathrm{C}++$ foi desenvolvido e otimizado. Esse programa foi utilizado para realizar as análises de dados experimentais obtidos durante o projeto. As técnicas de modelagem de dados de SAXS aplicadas ao sistemas de 
nanopartículas e a correlação de diferentes técnicas experimentais são bastante exploradas nesta tese.

Um estudo sistemático de rotas e processos de síntese de nanopartículas feitas de metais nobres (prata, ouro, paládio) foi realizado neste projeto de doutorado. Através da combinação de diversas técnicas experimentais, em particular SAXS, foi possível investigar e caracterizar o processo de síntese in situ, utilizando aparatos experimentais e computacionais desenvolvidos durante o projeto.

Como será apresentado a seguir, diversos resultados inéditos foram obtidos, o que permitiu publicações de artigos em revistas de alto impacto. 


\section{Objetivos}

O objetivo geral deste trabalho é realizar investigações estruturais de rotas de síntese de nanopartículas metálicas para a obtenção de informações detalhadas sobre a formação e morfologia final das nanopartículas.

Os objetivos específicos são:

- Investigar e implementar diferentes rotas de síntese de nanopartículas metálicas.

- Desenvolver o aparato experimental para acompanhamento in situ de processos de síntese.

- Desenvolver ferramentas teóricas e computacionais de modelagem de dados.

- Correlacionar dados de diversos experimentos para uma melhor compreensão do processo de síntese.

- Otimizar as rotas de síntese investigadas. 


\section{Publicações}

Algumas investigações realizadas durante o curso deste projeto foram publicadas em artigos de revistas científicas. Essas publicações são descritas a seguir e estão incluídas na seção de anexos.

Garcia, P. R. A. F., Prymak, O., Grasmik, V., Pappert, K., Wlysses, W., Otubo, L., Epple M., Oliveira, C. L. P. An in situ saxs investigation of the formation of silver nanoparticles and bimetallic silver-gold nanoparticles in controlled wet-chemical reduction synthesis. Nanoscale Adv., RSC, v. 2, p. 225, 2020.

Garcia, P. R. A. F., Loza, K., Daumann, S., Grasmik, V., Pappert, K., Rostek, A., Helmlinger, J., Prymak, O., Heggen, M., Epple, M., Oliveira, C. L. P. Combining small-angle x-ray scattering and x-ray powder diffraction to investigate size, shape and crystallinity of silver, gold and alloyed silver-gold nanoparticles. Brazilian Journal of Physics, v. 49, n. 2, p. 183-190, 2019.

Rostek, A., Breisch, M., Loza, K., Garcia, P. R. A. F., Oliveira, C. L. P., Prymak, O., Heggen, M., Koeller, M., Sengstock, C., Epple, M. Wet-chemical synthesis of pd-au coreshell nanoparticles $(8 \mathrm{~nm})$ : From nanostructure to biological properties. ChemistrySelect, Wiley Online Library, v. 3, n. 17, p. 4994-5001, 2018. 


\section{Métodos de minimização}

Este capítulo apresenta o método de minimização usado para modelar a maior parte dos dados experimentais analisados neste trabalho. O procedimento descrito é o algoritmo proposto por Kenneth Levenberg e Donald Marquardt (LEVENBERG, 1944; MARQUARDT, 1963) para minimização da quantidade qui-quadrado $\left(\chi^{2}\right)$ para modelos não lineares.

\subsection{Modelagem e o conceito de qui-quadrado}

Um modelo pode ser considerado como uma abstração matemática de um sistema real descrito por meio de um conjunto de equações (GARCIA, 2005). Um modelo matemático é sempre uma aproximação de um sistema, portanto, nunca fornece a descrição completa dos fenômenos observados. Através da interpolação dos dados experimentais, modelos matemáticos podem ser usados para descrever como um determinado processo evolui ao longo do tempo, fornecendo informações sobre características do sistema que podem não ser acessíveis por observações diretas.

Um modelo consiste em um conjunto de equações matemáticas que buscam descrever um determinado fenômeno. Essas funções dependem de um conjunto de variáveis. Pela otimização dessas variáveis, obtém-se os parâmetros do modelo que fornecem a melhor descrição do fenômeno observado.

Existem duas abordagens principais para a estimativa do melhor modelo teórico que descreve um dado observável: os métodos de Máxima Verossimilhança (Maximum Likelihood Estimation, MLE) e Mínimos Quadrados (Least Squares Method, LSM). Para o método de máxima verossimilhança, o conjunto de parâmetros que melhor descreve o observável é aquele cuja probabilidade de obter os dados experimentais é a mais alta (PRESS et al., 1996). Para o método dos mínimos quadrados, o conjunto de parâmetros que melhor descreve o observável é aquele para o qual a soma dos quadrados das diferenças entre os valores experimentais e do modelo teórico (resíduos) é mínima (BEVINGTON; ROBINSON, 2003).

As próximas seções tratam do método dos mínimos quadrados já que este foi o método de minimização usado neste projeto. 


\subsection{O teste qui-quadrado $\left(\chi^{2}\right)$}

Considere-se as coordenadas $\left(x_{i}, y_{i}\right)$ como a abcissa e a ordenada de um conjunto de $N$ observações. Dado um conjunto de $M$ parâmetros $\boldsymbol{a}=\left\{a_{1}, a_{2}, \ldots, a_{\mathrm{M}}\right\}$ de um modelo $f\left(x_{i} ; \boldsymbol{a}\right)$ e assumindo que os erros estatísticos das ordenadas seguem uma distribuição normal centrada em $y_{i}$, os parâmetros que melhor descrevem as observações são, de acordo com o método dos mínimos quadrados, aqueles que minimizam a função qui-quadrado definida pela expressão:

$$
\chi^{2}=\sum_{i=1}^{N}\left[\frac{y_{i}-f\left(x_{i} ; \boldsymbol{a}\right)}{\sigma_{i}}\right]^{2}
$$

onde $\sigma_{i}$ é o desvio padrão da observação de índice $i$. A diferença $y_{i}-f\left(x_{i} ; \boldsymbol{a}\right)$ é chamada de resíduo.

O valor do parâmetro $a_{k}$ para o qual $\chi^{2}$ é mínimo ocorre quando $\partial \chi^{2} / \partial a_{k}=0$, portanto:

$$
\sum_{i=1}^{N}\left[\frac{y_{i}-f\left(x_{i} ; \boldsymbol{a}\right)}{\sigma_{i}^{2}}\right]\left[\frac{\partial f\left(x_{i} ; \boldsymbol{a}\right)}{\partial a_{k}}\right]=0 \quad k=1,2 \cdots M
$$

Para estimativa do quão bem o conjunto de parâmetros descreve os dados experimentais é conveniente usar o qui-quadrado reduzido $\left(\chi_{\text {red }}^{2}\right)$. Essa quantidade é definida como o $\chi^{2}$ dividido pelo número de graus de liberdade do sistema.

O número de graus de liberdade de uma estimativa está relacionado à quantidade de informação utilizada para o cálculo. Mais precisamente, o número de graus de liberdade do sistema é definido, no âmbito da estatística, como o número de observações (pontos experimentais) menos o número de variáveis do modelo $(N-M)$. Assim, o $\chi_{\text {red }}^{2}$ é escrito como (BEVINGTON; ROBINSON, 2003):

$$
\chi_{\text {red }}^{2}=\frac{\chi^{2}}{N-M}
$$

A definição do qui-quadrado reduzido permite uma estimativa da qualidade do ajuste ponderada pela quantidade de dados experimentais e pela complexidade do modelo.

No processo de minimização, valores do vetor $\boldsymbol{a}$ para os quais o modelo descreve os dados satisfatoriamente são alcançados quando $\chi_{\text {red }}^{2} \approx 1$. Valores muito maiores que a unidade podem indicar dados imprecisos, estimativa incorreta das incertezas ou escolha incorreta do modelo teórico proposto. Valores muito menores que a unidade podem ser 
indicativos de incertezas super estimadas ou imprecisões experimentais (BEVINGTON; ROBINSON, 2003).

\subsection{O método de mínimos quadrados}

Quando o modelo é linear em relação aos parâmetros de ajuste $\boldsymbol{a}$ ele pode ser expresso, de forma geral, pela seguinte equação (PRESS et al., 1996):

$$
f\left(x_{i} ; \boldsymbol{a}\right)=\sum_{k=1}^{M} a_{k} X_{k}\left(x_{i}\right)
$$

$X_{k}\left(x_{i}\right)$ são funções arbitrárias de $x_{i}$, geralmente chamadas de funções base.

A aplicação de funções lineares na equação 2 para a minimização do $\chi_{\text {red }}^{2}$ resulta em uma série de equações lineares acopladas em relação aos parâmetros $a_{k}$. Esse conjunto de equações pode ser resolvido diretamente utilizando-se ferramentas analíticas. Neste caso, o método aplicado para a minimização do $\chi_{\text {red }}^{2}$ para modelos lineares é conhecido como regressão linear (PRESS et al., 1996).

No entanto, se o modelo é uma função não linear, as equações acopladas não são lineares e, portanto, não podem ser resolvidas por ferramentas analíticas simples. Nesse caso, o sistema de equações deve ser resolvido iterativamente no método conhecido como regressão não linear (BEVINGTON; ROBINSON, 2003).

Existem várias estratégias para encontrar o valor mínimo do parâmetro $\chi_{\text {red }}^{2}$ para um modelo não linear. Uma das estratégias mais utilizadas é o algoritmo Levenberg-Marquardt (LEVENBERG, 1944; MARQUARDT, 1963), que combina os métodos de Gauss-Newton e gradiente descendente. Esses métodos são descritos nas seções a seguir.

\subsubsection{Os métodos de Gauss-Newton e gradiente descendente}

O método de Gauss-Newton baseia-se no fato de que, suficientemente próximo do mínimo global, a função $\chi^{2}(\boldsymbol{a})$ pode ser aproximada pelos primeiros termos de sua expansão de Taylor $^{1}$ (PRESS et al., 1996):

$$
\chi^{2} \approx \chi^{2}\left(\boldsymbol{a}_{\mathbf{o}}\right)+\Delta \boldsymbol{a} \cdot \nabla \chi^{2}\left(\boldsymbol{a}_{\mathbf{o}}\right)+\frac{1}{2} \Delta \boldsymbol{a}\left[\nabla^{2} \chi^{2}\left(\boldsymbol{a}_{\mathbf{o}}\right)\right] \Delta \boldsymbol{a}
$$

1 O termo $\boldsymbol{a}_{\mathbf{o}}$ refere-se a um conjunto de valores dos parâmetros $\boldsymbol{a}$ que estão próximos aos valores $\boldsymbol{a}_{\boldsymbol{m} \boldsymbol{i n}}$ que minimizam a função $\chi^{2}$. 
onde $\Delta \boldsymbol{a}=\boldsymbol{a}_{\min }-\boldsymbol{a}_{\mathbf{o}}$.

Tomando o gradiente de $\chi^{2}(\boldsymbol{a})$, negligenciando os termos de terceira ordem e igualando a zero, temos:

$$
\nabla \chi^{2}\left(\boldsymbol{a}_{\mathbf{o}}\right)+\Delta \boldsymbol{a} \cdot \boldsymbol{H}\left[\chi^{2}\left(\boldsymbol{a}_{\mathbf{o}}\right)\right]=0
$$

onde $\boldsymbol{H}$ é a matriz hessiana. Isolando $\Delta \boldsymbol{a}$ :

$$
\begin{array}{r}
\Delta \boldsymbol{a}=\boldsymbol{H}^{-1}\left[\chi^{2}\left(\boldsymbol{a}_{\mathbf{o}}\right)\right]\left[-\nabla \chi^{2}\left(\boldsymbol{a}_{\mathbf{o}}\right)\right] \\
\boldsymbol{a}_{\text {min }}=\boldsymbol{a}_{\mathbf{o}}+\boldsymbol{H}^{-1}\left[\chi^{2}\left(\boldsymbol{a}_{\mathbf{o}}\right)\right]\left[-\nabla \chi^{2}\left(\boldsymbol{a}_{\mathbf{o}}\right)\right]
\end{array}
$$

Essas equações podem ser convenientemente escritas em notação matricial:

$$
\left(\begin{array}{c}
a_{1} \\
a_{2} \\
\vdots \\
a_{M}
\end{array}\right)_{\min }=\left(\begin{array}{c}
a_{1} \\
a_{2} \\
\vdots \\
a_{M}
\end{array}\right)_{0}+\left(\begin{array}{cccc}
\frac{\partial^{2} \chi^{2}}{\partial a_{1}^{2}} & \frac{\partial^{2} \chi^{2}}{\partial a_{1} \partial a_{2}} & \cdots & \frac{\partial^{2} \chi^{2}}{\partial a_{1} \partial a_{M}} \\
\frac{\partial^{2} \chi^{2}}{\partial a_{2} \partial a_{1}} & \frac{\partial^{2} \chi^{2}}{\partial a_{2}^{2}} & \cdots & \frac{\partial \chi^{2}}{\partial a_{2} \partial a_{M}} \\
\vdots & \vdots & \ddots & \vdots \\
\frac{\partial^{2} \chi^{2}}{\partial a_{M} \partial a_{1}} & \frac{\partial^{2} \chi^{2}}{\partial a_{M} \partial a_{2}} & \cdots & \frac{\partial^{2} \chi^{2}}{\partial a_{M}{ }^{2}}
\end{array}\right)^{-1} \times\left(\begin{array}{c}
-\frac{\partial \chi^{2}}{\partial a_{1}} \\
-\frac{\partial \chi^{2}}{\partial a_{2}} \\
\vdots \\
-\frac{\partial \chi^{2}}{\partial a_{M}}
\end{array}\right)
$$

Os termos da matriz hessiana e o gradiente são expressos como:

$$
\begin{aligned}
\frac{\partial \chi^{2}}{\partial a_{k}} & =-2 \sum_{i=1}^{N} \frac{\left[y_{i}-f\left(x_{i} ; \boldsymbol{a}\right)\right]}{\sigma_{i}^{2}} \frac{\partial f\left(x_{i} ; \boldsymbol{a}\right)}{\partial a_{k}} \quad k=1,2, \cdots, M \\
\frac{\partial^{2} \chi^{2}}{\partial a_{k} \partial a_{l}} & =-2 \sum_{i=1}^{N} \frac{1}{\sigma_{i}^{2}}\left\{\frac{\partial f\left(x_{i} ; \boldsymbol{a}\right)}{\partial a_{k}} \frac{\partial f\left(x_{i} ; \boldsymbol{a}\right)}{\partial a_{l}}-\left[y_{i}-f\left(x_{i} ; \boldsymbol{a}\right)\right] \frac{\partial^{2} f\left(x_{i} ; \boldsymbol{a}\right)}{\partial a_{k} \partial a_{l}}\right\} \\
& \approx-2 \sum_{i=1}^{N} \frac{1}{\sigma_{i}^{2}} \frac{\partial f\left(x_{i} ; \boldsymbol{a}\right)}{\partial a_{k}} \frac{\partial f\left(x_{i} ; \boldsymbol{a}\right)}{\partial a_{l}} \quad k, l=1,2, \cdots, M
\end{aligned}
$$

O termo de segunda ordem da equação 10 é negligenciado porque, à medida que $\chi^{2}$ se aproxima do mínimo, o fator $\left[y_{i}-f\left(x_{i} ; \boldsymbol{a}\right)\right]$ tende a expressar a incerteza aleatória de cada ponto, de modo que a soma sobre os $N$ pontos tende a zero. Isso faz com que a derivada de segunda ordem de $f\left(x_{i}, \boldsymbol{a}\right)$ se torne muito pequena e desprezível (PRESS et al., 1996).

É comum remover o fator 2 desta equação e definir os fatores $\alpha$ e $\beta$ :

$$
\alpha_{k l}=\frac{1}{2} \frac{\partial^{2} \chi^{2}}{\partial a_{k} \partial a_{l}}
$$




$$
\beta_{k}=-\frac{1}{2} \frac{\partial \chi^{2}}{\partial a_{k}}
$$

De maneira que a equação 6 pode ser reescrita na forma de equações lineares:

$$
\sum_{l=1}^{M} \alpha_{k l} \Delta a_{l}=\beta_{k}
$$

O método de Gauss-Newton é eficiente apenas quando os valores de entrada $\boldsymbol{a}_{\mathbf{o}}$ correspondem a $\chi^{2}$ próximos ao mínimo. Quando o valor $\chi^{2}$ está relativamente longe do mínimo, a aproximação de segunda ordem (equação 5) deixa de ser válida. Nesse caso, outro método é necessário.

Uma alternativa é utilizar o chamado método do gradiente descendente (PRESS et al., 1996). Esse método consiste em, partindo de um conjunto de valores iniciais $\boldsymbol{a}_{\mathbf{o}}$, encontrar os valores $\boldsymbol{a}_{\boldsymbol{m i n}}$ avançando na direção oposta ao vetor gradiente da função $\chi^{2}$ calculado em $\boldsymbol{a}_{\mathbf{o}}$ :

$$
\boldsymbol{a}_{\min }=\boldsymbol{a}_{\mathbf{o}}+C \times\left[-\nabla \chi^{2}\left(\boldsymbol{a}_{\mathbf{o}}\right)\right]
$$

onde $C$ é uma constante.

Em termos de $\beta$, esta equação assume a forma:

$$
\Delta a_{l}=C \times \beta_{l}
$$

Assim, temos duas aproximações: uma válida para os valores de $\chi^{2}$ próximo ao mínimo (Gauss-Newton) e outra para os valores de $\chi^{2}$ longe do mínimo (gradiente descendente). Esta é a base do Método de Levenbert-Marquardt, que será descrito a seguir.

\subsection{Método de Levenberg-Marquardt}

O método Levenberg-Marquardt combina os métodos de Gauss-Newton e gradiente descendente de maneira eficiente e elegante. A constante $C$ do método gradiente descendente é o módulo do passo em direção a $\boldsymbol{a}_{\boldsymbol{m i n}}$, enquanto que o gradiente fornece a direção. Se compararmos as equações 7 e 14, veremos que as componentes da matriz hessiana do método de Gauss-Newton fornecem alguma informação sobre a ordem de magnitude da constante da equação 14 (PRESS et al., 1996). 
Conforme proposto por Marquardt (MARQUARDT, 1963), os métodos do gradiente descendente e Gauss-Newton podem ser combinados através da definição de uma nova matriz $\alpha^{\prime}$ :

$$
\begin{array}{lr}
\alpha_{k l}^{\prime} \equiv \alpha_{k l}(1+\lambda) & \text { se } k=l \\
\alpha_{k l}^{\prime} \equiv \alpha_{k l} & \text { se } k \neq l
\end{array}
$$

$\lambda$ é uma constante. A equação 13 é reescrita na forma:

$$
\sum_{l=1}^{M} \alpha_{k l}^{\prime} \Delta a_{l}=\beta_{k}
$$

Neste método uma série de iterações é feita ajustando-se o valor de $\lambda$. Quando $\lambda$ é grande, a matriz $\alpha^{\prime}$ se torna diagonalmente dominante e o método converge para o método do gradiente descendente, tornando a equação 17 mais próxima da equação 15 . Por outro lado, quando o valor $\lambda$ é pequeno, temos $\alpha^{\prime} \approx \alpha$ e o método converge para o método Gauss-Newton, tornando a equação 17 semelhante à equação 13.

No início do algoritmo, um valor inicial de $\lambda$ menor que a unidade é definida. Em seguida, os valores de entrada para $\boldsymbol{a}_{\mathbf{o}}$ são definidos e a equação 17 é resolvida para encontrar novos valores para $\boldsymbol{a}$. A qualidade do ajuste em relação aos novos valores $\boldsymbol{a}$ é então avaliada com base em $\chi_{\text {red }}^{2}$. Abaixo estão as etapas do algoritmo (PRESS et al., 1996):

- Escolha dos valores iniciais para $\boldsymbol{a}\left(\boldsymbol{a}=\boldsymbol{a}_{\mathbf{o}}\right)$.

- Cálculo de $\chi_{\text {red }}^{2}(\boldsymbol{a})$.

- $\star$ Resolução das equações lineares 17 para $\Delta \boldsymbol{a}$.

- Cálculo de $\chi_{\text {red }}^{2}(\boldsymbol{a}+\Delta \boldsymbol{a})$.

- Se $\chi_{r e d}^{2}(\boldsymbol{a}+\Delta \boldsymbol{a}) \geq \chi_{\text {red }}^{2}(\boldsymbol{a}), \lambda$ é aumentado por um fator 10 e o algoritmo retorna para $\star$.

- Se $\chi_{r e d}^{2}(\boldsymbol{a}+\Delta \boldsymbol{a})<\chi_{r e d}^{2}(\boldsymbol{a}), \lambda$ é diminuído por um fator $10, \boldsymbol{a}=\boldsymbol{a}_{\mathbf{o}}+\Delta \boldsymbol{a}$ e o algoritmo retorna para $\star$.

As equações lineares 17 são também chamadas de equações normais e métodos como decomposição linear LU e eliminação de Gauss-Jordan podem ser empregados para a encontrar a solução (PRESS et al., 1996). 
Uma vez iniciado esse processo iterativo, uma condição de convergência é necessária para interromper o processo quando uma solução estatisticamente desejada é alcançada. Essa condição pode ser, por exemplo, o decréscimo de $\chi_{\text {red }}^{2}$ por um fator de $10^{-3}$ ou um número máximo de iterações (10, por exemplo).

A variância de cada parâmetro é determinada a partir dos elementos diagonais da matriz de covariância, que é igual à matriz $\alpha$ inversa (PRESS et al., 1996):

$$
\begin{gathered}
{[C]_{j k}=[\alpha]_{j k}^{-1}} \\
\sigma^{2}\left(a_{k}\right)=[C]_{k k}
\end{gathered}
$$




\section{Conceitos de síntese e formação de nanopartículas metálicas}

Nesta seção, é apresentada uma descrição básica sobre os mecanismos de formação de nanopartículas. Existem várias rotas de síntese e protocolos experimentais disponíveis na literatura para a produção de diferentes tipos de nanopartículas (EALIAS; SARAVANAKUMAR, 2017).

De acordo com as recomendações sobre a definição de nanomaterial adotadas pela União Europeia em 2011, "nanomaterial" se refere à:

"A natural, incidental or manufactured material containing particles, in an unbound state or as an aggregate or as an agglomerate and where, for $50 \%$ or more of the particles in the number size distribution, one or more external dimensions is in the size range 1 nm-100 nm." (BLEEKER et al., 2013).

Em outras palavras, nanopartículas são todos os tipos de partículas com pelo menos uma dimensão no intervalo de 1 a 100 nm. Elas podem ter diferentes composições (como metais, cerâmica, carbono) e formas (como esferas, barras, placas, cubos, etc.) (JEEVANANDAM et al., 2018).

\subsubsection{Breve contexto histórico}

Em 1959, o físico americano Richard P. Feynman, laureado com o Prêmio Nobel em 1965, apresentou sua famosa palestra "Há muito espaço lá embaixo", apresentando ideias e conceitos de nanociência (SANCHEZ; SOBOLEV, 2010). Em sua palestra, Feynman previu possibilidades extraordinárias de manipulação de átomos e moléculas individuais, lançando a idéia revolucionária de manipulação da matéria em escalas extremamente pequenas.

Embora o termo "nanotecnologia" tenha sido usado pela primeira vez só em 1974 por Norio Taniguchi, pesquisador da Universidade de Tóquio, o exemplo mais antigo conhecido de material inorgânico nanoestruturado data do século IV. O cálice romano de vidro chamado de "taça de Lycurgus" (FREESTONE et al., 2007) tem uma característica peculiar: parece vermelho ou verde, dependendo do ângulo de incidência da luz. A presença de quantidades muito pequenas de ouro e prata coloidais são responsáveis por esse efeito.

Outro exemplo interessante são as "espadas de Damasco", fabricadas no século XVIII na Índia antiga. Descobriu-se que as lâminas de aço dessas espadas contêm nanotubos 
de carbono. Essa característica, não encontrada no aço europeu antigo, é o resultado de um sofisticado tratamento termomecânico de forja e recozimento do material (Reibold M. et al., 2006).

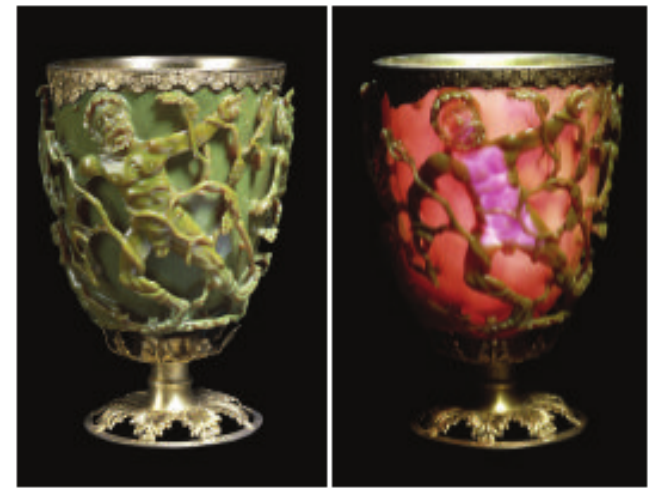

(a)

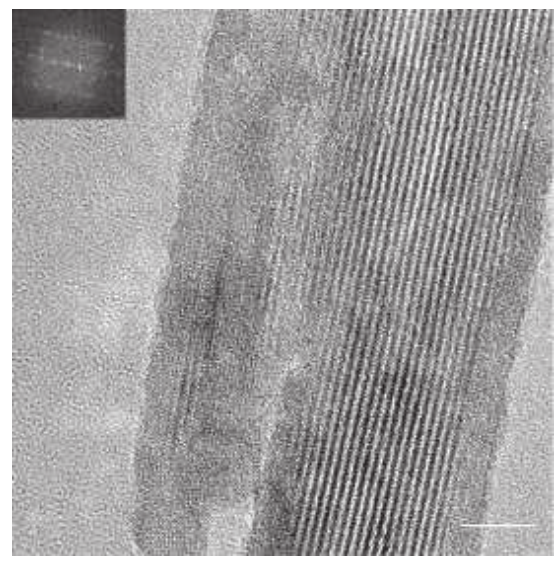

(b)

Figura 1 - (a) Taça de Lycurgus and (b) imagem de TEM da espada de Damasco. Barra de escala: 5nm. Fontes: (FREESTONE et al., 2007; Reibold M. et al., 2006).

Nanopartículas metálicas foram reportadas pela primeira vez há mais de 150 anos. Michael Faraday produziu acidentalmente uma amostra de colóides de ouro enquanto trabalhava com filmes finos. Faraday percebeu que folhas finas de ouro pareciam ter cores diferentes em relação à luz transmitida e à luz refletida. Ele então conduziu experimentos sobre a interação entre luz e matéria na década de 1850, analisando o comportamento da luz transmitida através de filmes finos de ouro.

Faraday produziu um líquido com aspecto avermelhado durante o processo de lavagem dos filmes. Esse fluido tinha uma propriedade única: quando era iluminado, um cone de luz bem definido era produzido através do fluido. Faraday explicou esse efeito dizendo que o fluido continha nanopartículas de ouro, pequenas demais para serem vistas, que espalhavam a luz.

Esse fenômeno ficou conhecido como efeito Faraday-Tyndall e, de fato, é um exemplo das propriedades ópticas das nanopartículas metálicas. Para explicar os efeitos de cor de colóides de ouro, o físico alemão Gustav Mie desenvolveu sua famosa teoria de espalhamento de luz por partículas esféricas (WRIEDT, 2012). O efeito Faraday-Tyndall está representado na figura 2. 


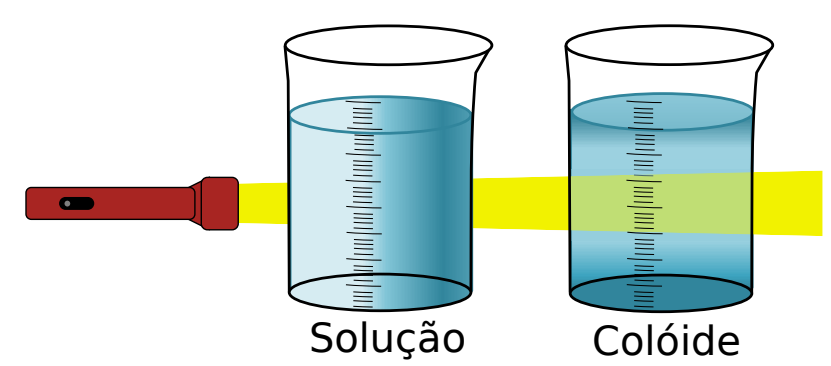

Figura 2 - Efeito Faraday-Tyndall.

\subsubsection{Conceitos básicos de síntese de nanopartículas}

As rotas de síntese de nanoapartículas podem ser classificadas em duas grandes categorias: bottom-up e top-down (SANCHEZ; SOBOLEV, 2010; EALIAS; SARAVANAKUMAR, 2017). Na categoria bottom-up (também denominada como métodos físicos), as nanopartículas são produzidas através da fragmentação sucessiva de um material macroscópico. Moagem, litografia e a ablação a laser são exemplos de abordagens top-down comumente utilizados, entre muitas outras.

Na categoria bottom-up (também conhecida como método químico), as nanopartículas são produzidas em processos envolvendo reações químicas. Neste método os átomos são os blocos de construção das nanopartículas. Exemplos de abordagens de síntese bottom-up são Sol-gel e deposição química a vapor, entre outros. A figura 37 a seguir mostra um diagrama representativo dessas duas categorias de síntese.

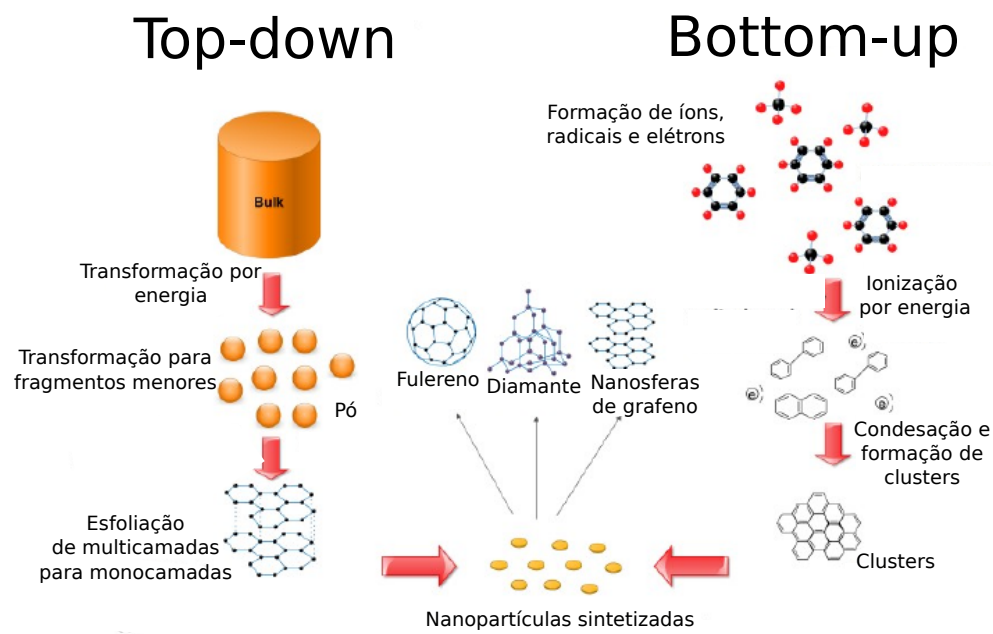

Figura 3 - Representação de processos de síntese top-down e bottom-up. Fonte: Adaptada de Habiba et al. (2014). 
O método "wet chemical synthesis" é um conjunto bem estabelecido de rotas de síntese bottom-up. Esse tipo de síntese geralmente é realizada em temperatura relativamente baixa, usando equipamentos de laboratório relativamente simples, o que o torna barato e amplamente utilizado. Frequentemente, as nanopartículas têm a tendência de se agregar durante o processo de formação, formando grandes conjuntos de agregados/aglomerados durante a síntese. Uma maneira de resolver esse problema é utilizar moléculas específicas que recobrem a superfície das nanopartículas e reduzem sua tensão superficial (NGUYEN, 2013). Essa moléculas, chamadas de agentes passivadores, evitam o crescimento excessivo e a aglomeração por meio de interação estérica com as nanopartículas. Exemplos de agentes passivadores são polímeros, como polivinilpirrolidona (PVP), surfactantes, como brometo de cetil trimetil amônio (CTAB) e ácidos, como citrato e ácido tânico, entre muitos outros.

Outra característica importante da síntese de nanopartículas é o conceito de agentes redutores. Um agente redutor é um composto que doa elétrons para a formação de átomos neutros que irão compor as nanopartículas. Citrato de sódio, glicose e PVP, entre muitos outros, são exemplos de reagentes comumente usados como agentes redutores.

Xia et al. (2009) reportam o uso de PVP como agente redutor na síntese de nanopartículas de prata. Esse polímero é responsável por causar a redução dos íons $A g+$, que são gerados durante a fase de decomposição do precursor, resultando na formação de aglomerados triméricos que evoluem para partículas triangulares.

Na rota de síntese de nanopartículas de ouro conhecida como método Turkevich (TURKEVICH; STEVENSON; HILLIER, 1951), citrato de sódio é utilizado como agente redutor e passivador. Este método baseia-se na redução dos íons $\mathrm{Au}^{3+}$ em átomos de $\mathrm{Au}$, usando agentes redutores como citrato de sódio ou ácido ascórbico (SHAH et al., 2014). A figura 4 mostra a interação entre o precursor de ouro (ácido cloroaúrico), o agente redutor/passivador (citrato trissódico) e o solvente (água), resultando na formação da nanopartícula encapada com citrato, conforme descrito no artigo de Zhao, Li e Astruc (2013). Citrato de sódio também pode ser usado para a síntese de nanopartículas de prata. Lea (1889) reportou a primeira rota de síntese de nanopartículas de prata usando citrato como agente redutor.

Em um processo típico de síntese bottom-up, os íons de prata são produzidos durante o processo de solvatação do precursor de prata:

$$
\mathrm{AgNO}_{3}(s)+\mathrm{H}_{2} \mathrm{O}(l)=\mathrm{Ag}^{+}(a q)+\mathrm{NO}_{3}^{-}(a q)
$$



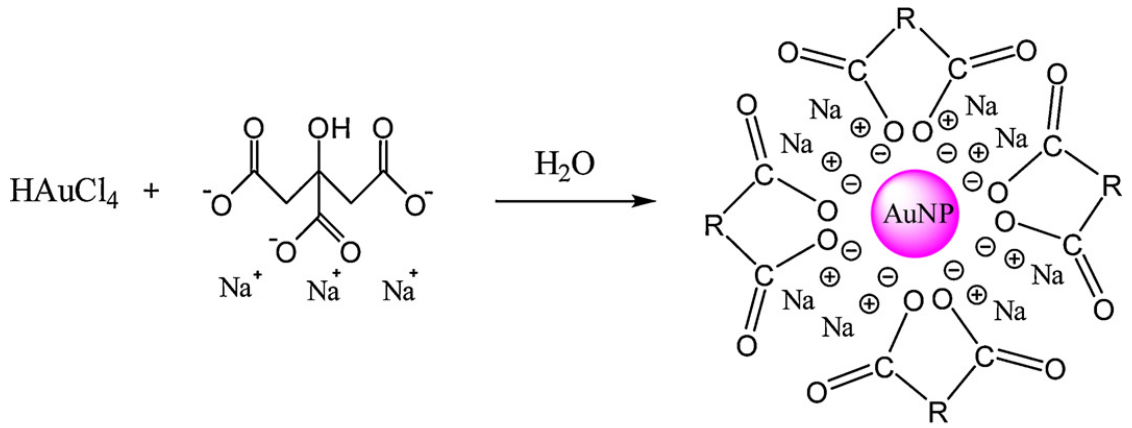

$\mathrm{R}=\stackrel{\mathrm{C}}{\mathrm{C}}=\mathrm{O}-_{\mathrm{C}_{2}-}^{\mathrm{H}_{2}-}$

Figura 4 - Reação química que ocorre durante a formação de nanopartículas de ouro. Método Turkevich. Ácido cloroaúrico + citrato trissódico + água. Fonte:(ZHAO; LI; ASTRUC, 2013).

Como é mostrado nesta equação, a redução dos precursores pode ocorrer em meio aquoso. Várias rotas de síntese de nanopartículas de prata promovem a redução de nitrato de prata $\left(\mathrm{AgNO}_{3}\right)$ em meio aquoso para a geração de íons de prata. Wang et al. (2005) relata duas possíveis reações que ocorrem em uma síntese de nanopartículas de prata usando PVP como agente passivador e água como solvente:

$$
\begin{aligned}
& \mathrm{Ag}^{+}+\mathrm{PVP} \rightarrow \mathrm{Ag}(\mathrm{PVP})^{+} \\
& \mathrm{CH}_{2} \mathrm{OH}-(\mathrm{CHOH})_{4}-\mathrm{CHO}+2[\mathrm{Ag}(\mathrm{PVP})]^{+}+2 \mathrm{OH}^{-} \\
& \rightarrow \mathrm{CH}_{2} \mathrm{OH}-(\mathrm{CHOH})_{4}-\mathrm{COOH}+2 \mathrm{Ag}(\mathrm{PVP}) \downarrow+\mathrm{H}_{2} \mathrm{O} \\
& \quad 2 \mathrm{Ag}^{+}+2 \mathrm{OH}^{-} \rightarrow \mathrm{Ag}_{2} \mathrm{O}+\mathrm{H}_{2} \mathrm{O} \\
& \quad \mathrm{Ag}_{2} \mathrm{O}+\mathrm{CH}_{2} \mathrm{OH}-(\mathrm{CHOH})_{4}-\mathrm{CHO}+2 \mathrm{PVP} \\
& \quad \rightarrow \mathrm{CH}_{2} \mathrm{OH}-(\mathrm{CHOH})_{4}-\mathrm{COOH}+2 \mathrm{Ag}(\mathrm{PVP}) \downarrow
\end{aligned}
$$

De acordo com Wang et al. (2005), na primeira etapa da equação 21 os íons $\mathrm{Ag}^{+}$ juntam-se às moléculas de PVP formando íons mais complexos. Os grupos hidroxilas reagem com a glucose por adição nucleofílica produzindo íons de gluconato que, por sua vez, reduzem os íons de prata resultando em átomos de neutros.

Nas reações descritas pela equação 22, o grupo hidroxila reage com os íons de prata formando $\mathrm{Ag}_{2} \mathrm{O}$. Esta molécula então reage com as moléculas de glicose e PVP formando moléculas de prata cobertas com PVP. 
Também é possível usar álcool como solvente (ou meio). No método poliol a redução do precursor metálico acontece em meio alcoólico, geralmente um poliálcool que age simultaneamente como meio dispersante, solvente e agente redutor (SUN; XIA, 1991).

A redução de íons de prata também pode ocorrer através de uma corrente elétrica. No método de síntese eletrolítica, a redução dos íons de prata ocorre através da eletrólise, como escrito na equação 23. A eletrólise é o processo no qual uma reação química não espontânea é induzida por uma corrente elétrica.

$$
A g^{+}+e^{-} \rightarrow A g^{0}
$$

O meio é sujeito a uma diferença de potencial aplicada entre dois eletrodos. Os elétrons são então extraídos dos átomos de prata e atraídos para o ânodo. Os cátions de prata migram para o cátodo onde são reduzidos. A formação das nanopartículas é iniciado através da aglomeração dos átomos de prata (CHEON et al., 2011).

\subsubsection{Mecanismo de crescimento}

De maneira geral, o processo de síntese é constituído por três etapas básicas: nucleação, evolução dos núcleos para sementes e crescimento das sementes para nanocristais (XIA et al., 2009). As sementes são definidas como algo maior que os núcleos e que não sofrem variação de forma. Thanh, Maclean e Mahiddine (2014) descrevem a nucleação como o processo em que as sementes atuam como modelos para o crescimento do cristal.

A teoria clássica da nucleação (classical nucleation theory, CNT) é uma descrição matemática abrangente do processo de nucleação. Essa abordagem puramente termodinâmica foi desenvolvida originalmente para descrever a condensação de vapores para a fase líquida e foi posteriormente estendida para outras fases. A CNT descreve um sistema de duas fases e está fundamentado na minimização da energia livre de Gibbs $(\Delta G)$ durante a formação das sementes. A energia livre total de Gibbs é a soma das energias livres associadas à superfície e ao volume. Para uma semente esférica com raio $r$, a forma mais simples de $\Delta G$ é (POLTE, 2015):

$$
\Delta G=4 \pi r^{2} \gamma-\frac{4}{3} \pi r^{3}\left|\Delta G_{\nu}\right|
$$


nessa equação, $\gamma$ é a energia livre de superfície por unidade de área e $\Delta G_{\nu}$ é a energia livre associada ao "bulk" por unidade de volume.

O termo à esquerda da equação 24 é a energia livre superficial e o termo à direita é a energia livre associada ao volume. Devido ao sinal negativo na equação 24 , a energia livre do "bulk" diminui a energia livre total. A competição entre as energias livres de superfície e volume gera um valor máximo de $\Delta G$ para um raio crítico $r_{c}$. Esse valor máximo é chamado de energia de ativação $\Delta G_{c}$. Resolvendo $d \Delta G / d r=0$ para $r$, o raio crítico pode ser determinado:

$$
r_{c}=\frac{2 \gamma}{\Delta G_{\nu}}
$$

O crescimento de pequenos aglomerados (clusters) com raio menor que $r_{c}$ é desfavorecido e esses clusters tendem a dissolver. Clusters com raio maior que $r_{c}$ têm seu crescimento favorecido (POLTE, 2015).

A energia livre crítica $\Delta G_{c}$ correspondente ao raio crítico é chamada de energia de ativação. A substituição de $r_{c}$ na equação 24 leva à expressão de $\Delta G_{c}$ :

$$
\Delta G_{c}=\frac{16 \pi \gamma^{3}}{\Delta G_{\nu}}
$$

A taxa de nucleação de $\mathrm{N}$ partículas em relação ao tempo $t$ pode ser determinada através da equação de Arrenius:

$$
\frac{d N}{d t}=A \exp \left(-\frac{\Delta G_{c}}{k_{B} T}\right)
$$

onde $A$ é uma constante, $k_{B}$ é a constante de Boltzmann e $T$ é a temperatura.

As equações 24-27 são válidas para os casos onde o processo de nucleação ocorre de forma aleatória e espontânea, chamada de nucleação homogênea. Porém, a nucleação pode não ocorrer uniformemente no meio de reação. Na nucleação heterogênea, a nucleação ocorre apenas em locais favoráveis, como a superfície do recipiente de reação, impurezas, superfícies de partículas, etc (POLTE, 2015; THANH; MACLEAN; MAHIDDINE, 2014). Nesses locais, a energia superficial efetiva é menor, aumentando a probabilidade de ocorrer a nucleação (POLTE, 2015). Embora a nucleação heterogênea ocorra com mais frequência do que a nucleação homogênea, supõe-se que ambas ocorram durante a síntese (POLTE, 2015). 


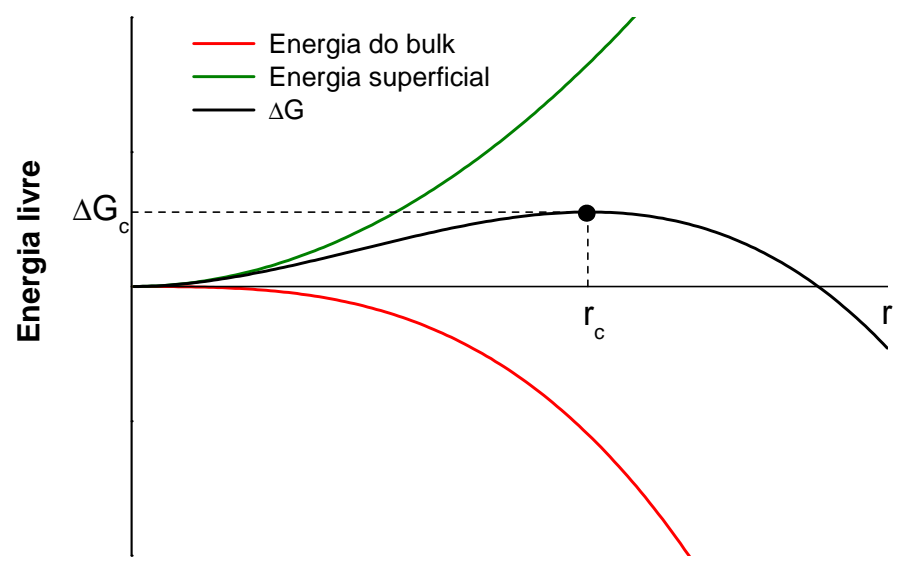

Figura 5 - Energia livre de Gibbs em função do raio.

Originalmente, o CNT foi desenvolvido para descrever a nucleação em sistemas supersaturados (formação de fase líquida em gases em condições de supersaturação). LaMer e Dinegar (1950) foram os primeiros a usar os conceitos de CNT para estudar a síntese de nanopartículas. Em um artigo sobre a síntese de sóis de enxofre usando tiossulfato de sódio como precursor, os autores propõem um mecanismo de formação de nanopartículas no qual a concentração de metal aumenta rapidamente durante o estágio de decomposição do precursor (LAMER; DINEGAR, 1950). Quando a concentração atinge um valor próximo à condição de supersaturação, os átomos começam a se aglomerar e formar pequenos núcleos. Então, esses núcleos começam a crescer rapidamente, diminuindo a concentração de átomos do precursor metálico do meio. Se a concentração de átomos no meio de reação cair rapidamente para um valor abaixo do valor de saturação, o processo de nucleação será interrompido. À medida que o precursor continua a se decompor em átomos de metal, os núcleos continuam a crescer continuamente abastecidos pelos átomos presentes na solução até que o equilíbrio entre os átomos da superfície dos núcleos e os átomos da solução seja alcançado. A figura 6 ilustra esse processo em função da concentração de átomos do precursor.

Lamer considerou o mecanismo de formação de nanopartículas em termos de dois processos distintos: nucleação e crescimento (LAMER; DINEGAR, 1950; POLTE, 2015). De acordo com Polte (2015), o modelo formulado por Lamer não é capaz de prever a evolução da distribuição de tamanho durante o processo de formação. Outras teorias foram propostas para explicar a formação de nanopartículas, várias delas baseadas nos chamados 


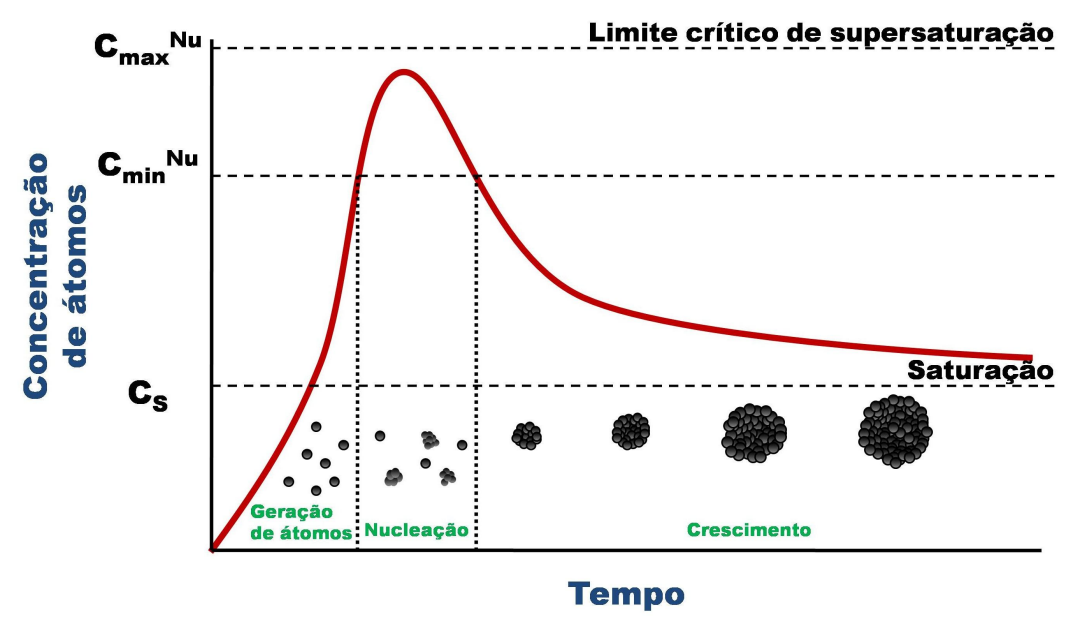

Figura 6 - Representação dos processos de geração, nucleação e crescimento de átomos ilustrados através concentração em função do tempo (XIA et al., 2009).

amadurecimento de Ostwald (Ostwald ripening, OR) e coalescência dinâmica (dynamic coalescence, DC).

Reportado em um artigo publicado em 1900 (OSTWALD, 1900), o amadurecimento de Ostwald é um mecanismo pelo qual as partículas com raio menor que um valor crítico são dissolvidas enquanto as partículas com raio maior que o valor crítico continuam crescendo. A contribuição teórica mais importante para a teoria do amadurecimento de Ostwald foi feita por Lifshitz e Slyozov (LIFSHITZ; SLYOZOV, 1961) e posteriormente por Wagner (WAGNER, 1961) no desenvolvimento da chamada teoria LSW. Eles fizeram uma previsão quantitativa da evolução temporal de um sistema de partículas.

De acordo com a definição da IUPAC em química de colóides, a coalescência é o fenômeno no qual ocorre "O desaparecimento do limite entre duas partículas (geralmente gotículas ou bolhas) em contato" (EVERETT, 1972). Na coalescência dinâmica duas partículas ou aglomerados se fundem após colisão e formam um novo domínio, o que causa uma redução na energia superficial total do sistema.

Algumas abordagens assumem que o aumento do raio médio das nanopartículas segue uma função exponencial. O expoente dessa função pode ser relacionado à ocorrência de coalescência e amadurecimento de Ostwald (HARADA; IKEGAMI, 2016; HARADA; KATAGIRI, 2010):

$$
R(t) \approx t^{\alpha}
$$

Geralmente, o valor do fator $\alpha$ está entre 1 e 1/3. A teoria clássica LSW prevê que, se o crescimento das partículas for governado pelo amadurecimento de Ostwald, então 
$\alpha=1 / 3$. Por outro lado, já foi demonstrado que para um sistema simples de nanopartículas onde o processo de crescimento é coalescência dinâmica o expoente $\alpha=1 / 2$ (CONTI et al., 2002).

Até agora, as propriedades termodinâmicas e como elas influenciam a evolução dos sistemas de nanopartículas foram abordadas. Além de aspectos termodinâmicos, outra característica importante da síntese química é a cinética das reações ${ }^{1}$. Controlando a cinética das reações, é possível obter formas de partículas que não são favorecidas termodinamicamente, ou seja, que não correspondem ao caminho que minimiza a energia livre interfacial do sistema.

Xia et al. (2009) cita um caso onde cinco monocristais assumem a forma de decaedro durante a fase de crescimento. Esses decaedros podem ser considerados como uma junção de cinco monocristais tetraédricos, como mostrado na figura 7. Como cada tetraedro contribui com um ângulo de 70,53 graus o cristal apresenta uma fenda de 7,35 graus. Durante o processo de crescimento o cristal aumenta sua área e, portanto, também a área da fenda. Esse aumento da área da fenda tem um custo energético fazendo com que esse cristal seja termodinamicamente favorável apenas em escalas de tamanho relativamente pequenas. Porém, essa energia extra da fenda pode ser compensada através da minimização da energia superficial total ${ }^{2}$. Se as sementes expandem muito rápido resultados teóricos demonstram que o crescimento da área superficial total não consegue contrabalancear a energia gasta com o crescimento da fenda e o resultado é a formação de um monocristal.

Todavia, se a expansão é lenta a formação de múltiplas sementes poliédricas prevalecerá em detrimento de apenas monocristais pois elas podem se manter mais estáveis sob longo períodos de tempo em pequenos tamanhos. Isso é geralmente feito controlando-se a taxa de decomposição do precursor.

\footnotetext{
1 "Cinética das reações" é o ramo da química que estuda a influência dos parâmetros de síntese na velocidade das reações químicas.

2 Isso é feito maximizando a área do plano (111).
} 
a)

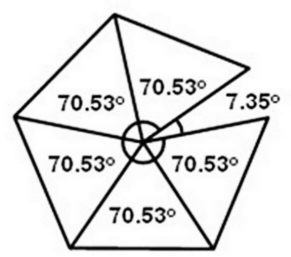

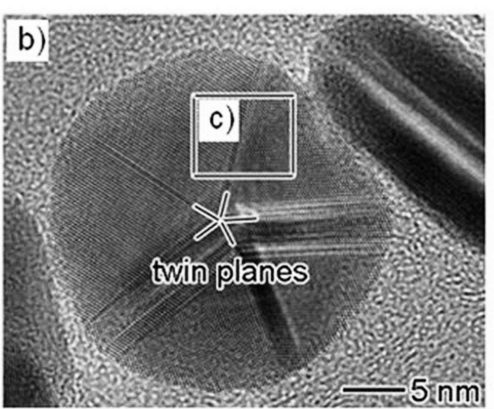

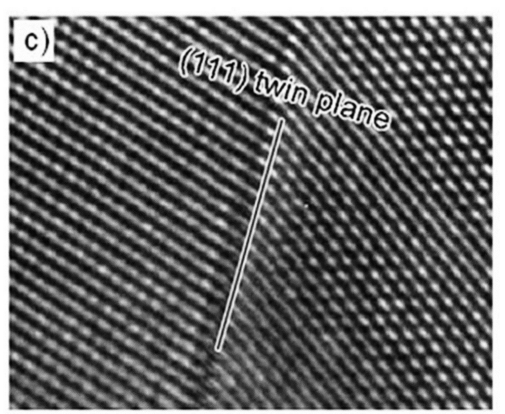

Figura 7 - (a) Diagrama esquemático mostrando os cinco monocristais que formam o decaedro e (b,c) imagens de alta resolução de TEM de cristais decaédricos de prata. Fonte: Xia et al. (2009). 


\section{Técnicas de caracterização e métodos de análise}

Técnicas de difração e espalhamento são usadas para o estudo da matéria em diversas escalas de tamanho e podem ser usadas para se obter informações estruturais sobre sistemas de nanopartículas. Há diversas formas de se realizar esses experimentos.

Espalhamento de raios X a baixo ângulo (small angle X-ray scattering, SAXS), espalhamento dinâmico de luz (dynamic light scattering, $D L S$ ) e microscopia eletrônica de transmissão (transmission electron microscopy, TEM) foram utilizados neste trabalho para a obtenção de informações sobre a morforlogia, forma, tamanho e polidispersão. Difração de raios X (X-ray diffraction, $X R D$ ) e espalhamento de raios $\mathrm{X}$ a alto ângulo (wide angle $X$-ray scattering, WAXS) foram utilizados para obtenção de informações sobre a estrutura cristalina interna e espectroscopia ultra-violeta e visível (violet-visible spectroscopy, $U V$-Vis) foi utilizado para a análise da ressonância plasmônica localizada das nanopartículas.

\subsection{Espalhamento de raios $\mathrm{X}$ a baixo ângulo}

Um experimento típico de espalhamento utilizando geometria de transmissão é exibido na figura 8. A amostra é submetida a um feixe monocromático incidente com comprimento de onda $\lambda$.

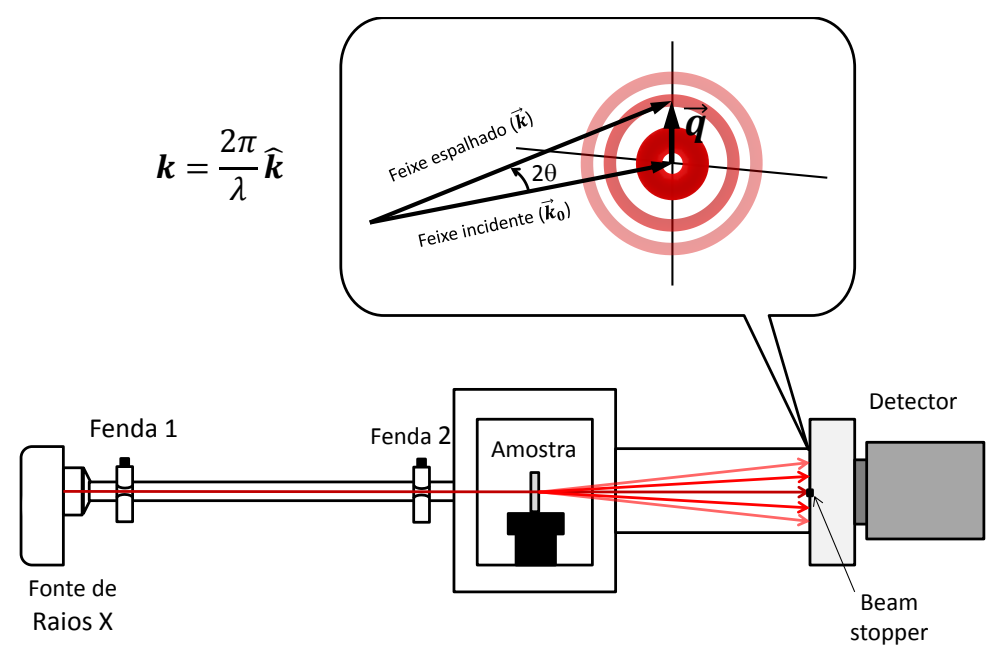

Figura 8 - Diagrama esquemático de um experimento de espalhamento/difração de raios $\mathrm{X}$ usando geometria de transmissão. 
Uma fração do feixe incidente $\mathbf{k}_{\mathbf{0}}$ é espalhada na direção $2 \theta$ pelos centros espalhadores da amostra. A relação entre a intensidade do feixe espalhado $\mathbf{k}$ e a direção de espalhamento carrega informações estruturais sobre as partículas constituintes do sistema. A direção de espalhamento pode ser expressa em termos do vetor de transferência de momento do espaço recíproco q, que é definido como a diferença dos vetores de onda do feixe espalhado (k) e incidente $\left(\mathbf{k}_{\mathbf{0}}\right)$.

Experimentos de espalhamento realizados usando ângulos detecção muito pequenos (ou q muito pequenos ) são denominados pela sigla SAS (small angle scattering). Se o feixe for composto por nêutrons, o experimento será chamado Espalhamento de nêutrons a baixos ângulos (small angle neutrons scattering, $S A N S$ ) e se for composto por raios $\mathrm{X}$ chamado espalhamento de raios $X$ a baixo ângulo. É possível também utilizar luz visível na técnica conhecida como Espalhamento estático de luz (static light scattering, SLS). Porém, diferentemente das outras, esta técnica é realizada utilizando-se ângulos mais altos. Como o comprimento de onda da luz visível é maior, a região do espaço recíproco também é observada para valores muito pequenos de $q$.

Na próxima seção princípios básicos da teoria de espalhamento são abordados, incluindo os conceitos de amplitude e intensidade de espalhamento. As derivações são feitas usando ferramentas de mecânica quântica e podem ser encontradas em detalhes nos livros de Feigin e Svergun (1987) e Sakurai e Napolitano (2011).

\subsubsection{Princípios de espalhamento: Primeira aproximação de Born}

Considere-se uma onda plana monocromática $\psi_{i}(\mathbf{r})$ interagindo com um potencial situado no ponto $P$ da figura 9 . A equação que descreve a evolução espacial dessa onda é:

$$
\psi_{i}(\mathbf{r})=A_{0} e^{-i \mathbf{k}_{\mathbf{0}} \cdot \mathbf{r}} \quad \text { no qual } \quad\left|\mathbf{k}_{\mathbf{0}}\right|=\frac{2 \pi}{\lambda}
$$

onde $\lambda$ é o comprimento de onda

Uma onda secundária é gerada como resultado da interação entre $\psi_{i}(\mathbf{r})$ e o potencial $\varphi(\mathbf{r})$. Essa onda, por sua vez, interage com outros centros espalhadores do material, produzindo ondas terciárias que interagem com outros centros espalhadores gerando outras ondas e assim por diante. 
Se o potencial $\varphi(\mathbf{r})$ for suficientemente fraco, as ondas espalhadas terão o mesmo comprimento de onda incidente ${ }^{1}$. Os cálculos geralmente são feitos considerando-se apenas as ondas secundárias, já que as ondas de ordem superior podem ser negligenciadas sem perda generalidade. Este procedimento é conhecido como primeira aproximação de Born (FEIGIN; SVERGUN, 1987).

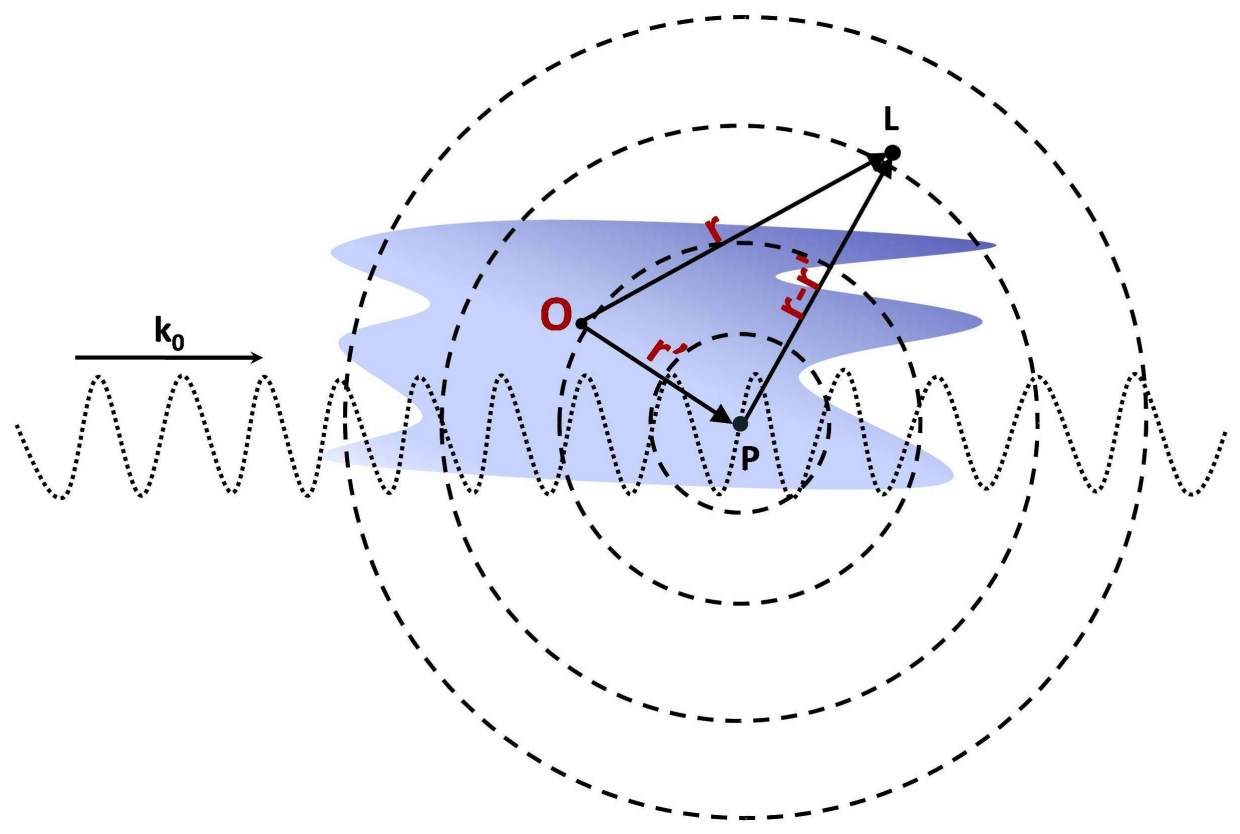

Figura 9 - Interação de uma onda incidente $\left(\mathbf{k}_{\mathbf{0}}\right)$ com o potencial $\varphi\left(\mathbf{r}^{\prime}\right)$ localizado no ponto $\mathrm{P}$ resultando na geração de onda esférica.

A evolução desse sistema é governada pela equação de Schrödinger que, para este problema, é escrita como (SAKURAI; NAPOLITANO, 2011):

$$
\left(\hat{H}_{0}+\hat{V}\right)|\psi\rangle=E|\psi\rangle \quad \text { with } \quad \hat{H}_{0}|\phi\rangle=E|\phi\rangle
$$

nesta equação $\hat{H}_{0}$ é o operador energia cinética, $\hat{V}$ é o operador energia potencial, $E$ é a energia total, $|\psi\rangle$ é o auto-estado da partícula que interage com o potencial $\varphi\left({ }^{\prime} \mathbf{r}\right)$ e $|\phi\rangle$ é o auto-estado de uma partícula livre. A solução dessa equação, quando a aproximação de primeira ordem é considerada, consiste em dois termos distintos (FEIGIN; SVERGUN, 1987):

$$
\psi^{(0)}(\mathbf{r})+\psi^{(1)}(\mathbf{r})=\frac{e^{i \mathbf{k}_{0} \cdot \mathbf{r}}}{(2 \pi)^{3 / 2}}-\frac{2 m}{4 \pi \hbar^{2}} \int \frac{e^{i \mathbf{k}\left(\mathbf{r}-\mathbf{r}^{\prime}\right)}}{\left|\mathbf{r}-\mathbf{r}^{\prime}\right|} e^{i \mathbf{k}_{\mathbf{0}} \cdot \mathbf{r}^{\prime}} \varphi\left(\mathbf{r}^{\prime}\right) \mathbf{d} \mathbf{r}^{\prime}
$$

1 Neste caso diz-se que o espalhamento é elástico. 


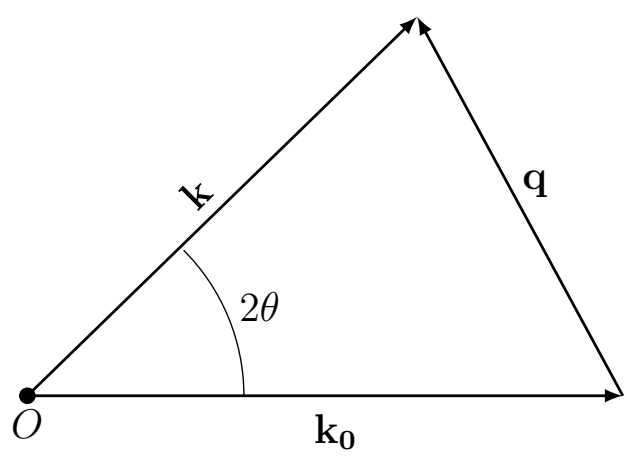

Figura 10 - Vetor de transferência de momento do espaço recíproco $(\mathbf{q})$, vetores de onda dos feixes incidente $\left(\mathbf{k}_{\mathbf{0}}\right)$ e espalhado $(\mathbf{k})$.

As ordens de grandeza envolvidas em experimentos de espalhamento são tais que $r \gg r^{\prime}$. Assim, assumindo que $\left|\mathbf{r}-\mathbf{r}^{\prime}\right| \approx r$, tem-se:

$$
\psi^{(0)}(\mathbf{r})+\psi^{(1)}(\mathbf{r})=\frac{e^{i \mathbf{k}_{\mathbf{0}} \cdot \mathbf{r}}}{(2 \pi)^{3 / 2}}-\frac{2 m}{4 \pi \hbar^{2}} \frac{e^{i \mathbf{k} \cdot \mathbf{r}}}{r} \int e^{-i\left(\mathbf{k}-\mathbf{k}_{\mathbf{0}}\right) \cdot \mathbf{r}^{\prime}} \varphi\left(\mathbf{r}^{\prime}\right) \mathbf{d} \mathbf{r}^{\prime}
$$

O primeiro termo dessa equação é a função de uma onda plana que se propaga na direção da onda incidente $\mathbf{k}_{\mathbf{0}}$ e representa a função de onda da partícula incidente. O segundo termo, que é a função de onda da partícula espalhada, é a função de uma onda esférica multiplicada por um termo integral e um termo constante. Considerando a equação geral de uma onda esférica, a equação 32 pode ser escrita como (SAKURAI; NAPOLITANO, 2011; FEIGIN; SVERGUN, 1987):

$$
\begin{gathered}
\psi^{(0)}(\mathbf{r})+\psi^{(1)}(\mathbf{r})=\frac{e^{i \mathbf{k}_{\mathbf{0}} \cdot \mathbf{r}}}{(2 \pi)^{3 / 2}}+\frac{e^{i \mathbf{k} \cdot \mathbf{r}}}{r} f(\mathbf{q}) \\
f(\mathbf{q}) \equiv-\frac{2 m}{4 \pi \hbar^{2}} \int e^{-i \mathbf{q} \cdot \mathbf{r}^{\prime}} \varphi\left(\mathbf{r}^{\prime}\right) \mathbf{d} \mathbf{r}^{\prime}
\end{gathered}
$$

O vetor de transferência de momento do espaço recíproco q é definido como a diferença entre os vetores $\mathbf{k}_{\mathbf{0}}$ e $\mathbf{k}$ (figura 10):

$$
\mathbf{q}=\mathbf{k}-\mathbf{k}_{\mathbf{0}} \quad \text { onde }|\mathbf{q}|=\frac{4 \pi}{\lambda} \operatorname{sen} \theta
$$

Esses resultados mostram que o resultado da interação entre a onda plana $\psi(\mathbf{r})$ e o potencial de espalhamento $\varphi\left(\mathbf{r}^{\prime}\right)$ é a geração de uma onda plana $\psi(\mathbf{r})^{(0)}$ e uma onda esférica $\psi(\mathbf{r})^{(1)}$ com amplitude $f(\mathbf{q})$.

A equação 34 mostra que a amplitude de espalhamento é na verdade a transformada de Fourier do potencial $\varphi\left(\mathbf{r}^{\prime}\right)$ em relação à variável $\mathbf{q}$ vezes o fator constante $\left(-2 m / 4 \pi \hbar^{2}\right)$. 
Então, aplicando a Transformada de Fourier Inversa, temos a expressão para o potencial $\varphi\left(\mathbf{r}^{\prime}\right)$ :

$$
\varphi\left(\mathbf{r}^{\prime}\right)=\frac{\hbar}{4 \pi^{2} m} \int f\left(\mathbf{r}^{\prime}\right) e^{i \mathbf{q r}^{\prime}} \mathbf{d q}
$$

Se o potencial de espalhamento $\varphi\left(\mathbf{r}^{\prime}\right)$ é relativamente fraco, o potencial se estende na região espacial limitada pela superfície da partícula. Assim, nesse caso, $\varphi\left(\mathbf{r}^{\prime}\right)$ equivale a forma da partícula.

Uma informação relevante sobre o sistema é o número de partículas espalhadas atravessando uma determinada região do espaço em uma determinada direção por unidade de tempo e área. Considerando uma região com área diferencial $d \sigma$ subtendendo um ângulo sólido diferencial $d \Omega$, a fração de partículas espalhadas é (SAKURAI; NAPOLITANO, 2011):

$$
\begin{aligned}
\frac{d \sigma}{d \Omega}(\mathbf{q}) d \Omega & =\frac{\text { Número de partículas espalhadas em uma região } d \Omega \text { por unidade de tempo }}{\text { Número de partículas incidentes cruzando uma área unitária por unidade de tempo }} \\
& =\frac{\mathbf{j}_{\text {scattered }} r^{2} d \Omega}{\mathbf{j}_{\text {incident }}}
\end{aligned}
$$

onde $\mathbf{j}$ é o fluxo de probabilidade, também chamado de corrente de probabilidade ${ }^{2}$.

O numerador da equação 37 é o fluxo de probabilidade diferencial de partículas espalhadas. A razão entre as correntes de probabilidade de partículas espalhadas e incidentes é igual ao módulo ao quadrado da amplitude de espalhamento sobre $r^{2}$ (SAKURAI; NAPOLITANO, 2011), assim, pode-se concluir que:

$$
\frac{d \sigma}{d \Omega}(\mathbf{q}) d \Omega=|f(\mathbf{q})|^{2} d \Omega \Longrightarrow \frac{d \sigma}{d \Omega}(\mathbf{q})=I(\mathbf{q})=|f(\mathbf{q})|^{2}
$$

Se $f(\mathbf{q})$ for a amplitude da onda esférica, a variável $d \sigma(\mathbf{q}) / d \Omega$ é a seção de choque diferencial de espalhamento e também é chamada de intensidade de espalhamento experimental $I(\mathbf{q})$ (FEIGIN; SVERGUN, 1987).

2 A corrente de probabilidade $j$ é um parâmetro que informa o fluxo de probabilidade por unidade área e tempo. Para mais detalhe ver (SAKURAI; NAPOLITANO, 2011). 


\subsubsection{Intensidade de espalhamento e função de distribuição de pares de distância}

Na seção anterior, foi demonstrado como uma partícula, descrita por uma dada função de onda, interage com um potencial $\varphi(\mathbf{r})$ associado a um centro espalhador.

Em experimentos reais de espalhamento, a amplitude de espalhamento não pode ser medida diretamente, pois é definida no espaço complexo. Somente a intensidade de espalhamento, definida na equação 38 como o quadrado da amplitude de espalhamento, pode ser medida diretamente.

O padrão de difração/espalhamento observado é produzido pela interferência das ondas espalhadas. Como mencionado anteriormente, para SAXS, os centros espalhadores dessas ondas são nuvens de elétrons.

Como o número de elétrons na amostra é muito grande e eles não possuem uma localização definida, é conveniente trabalhar com o conceito de densidade eletrônica.

Seja $\rho(\mathbf{r})$ a densidade eletrônica e considerando por simplicidade o prefator constante da amplitude de espalhamento igual à unidade (FEIGIN; SVERGUN, 1987), o potencial de espalhamento $\varphi(\mathbf{r})$ é equivalente à distribuição de densidade eletrônica no espaço tridimensional, expressa pela equação da amplitude de espalhamento:

$$
f(\mathbf{q})=\int \rho(\mathbf{r}) e^{-i \mathbf{q r}} \mathbf{d} \mathbf{r}
$$

Considerando que a amplitude de espalhamento é a Transformada de Fourier da função de densidade eletrônica, a intensidade de espalhamento pode ser escrita como (OLIVEIRA, 2011):

$$
\begin{aligned}
I(\mathbf{q}) & =f(\mathbf{q}) \cdot f(\mathbf{q})^{*}=F(\rho(\mathbf{r})) \cdot F(\rho(\mathbf{r}))^{*} \\
& =F(\rho(\mathbf{r}) * \rho(-\mathbf{r}))=\int_{V} e^{i \mathbf{q} \cdot \mathbf{r}} \mathbf{d} \mathbf{r} \int_{V} \rho\left(\mathbf{r}^{\prime}\right) \rho\left(\mathbf{r}^{\prime}+\mathbf{r}\right) \mathbf{d} \mathbf{r}^{\prime} \\
& =\int_{V} \int_{V} \rho\left(\mathbf{r}^{\prime}\right) \rho\left(\mathbf{r}^{\prime}+\mathbf{r}\right) e^{i \mathbf{q} \cdot \mathbf{r}} \mathbf{d} \mathbf{r} \mathbf{d} \mathbf{r}^{\prime}
\end{aligned}
$$

$F$ nessa equação se refere a Transformada de Fourier.

2 O teorema da convolução é usado nessa equação 40: $F\{f * g\}=F\{f\} \cdot F\{g\}$. 
A integral de volume do produto entre as densidades eletrônicas é conhecida como função de autocorrelação ou função de Patterson (FEIGIN; SVERGUN, 1987) e é geralmente indicada pela letra grega $\gamma$ :

$$
\gamma(\mathbf{r})=\int_{V} \rho\left(\mathbf{r}^{\prime}\right) \rho\left(\mathbf{r}^{\prime}+\mathbf{r}\right) \mathbf{d} \mathbf{r}^{\prime}
$$

A intensidade de espalhamento de uma única partícula pode ser expressa em termos de $\gamma(\mathbf{r})$. Considerando que a partícula está orientada aleatoriamente, isso pode ser feito através da média da equação 40 sobre o ângulo sólido $\Omega$ :

$$
\begin{aligned}
& I_{1}(q)=\left\langle f(\mathbf{q})_{1}^{2}\right\rangle_{\Omega}=\left\langle\int_{V} \int_{V} \rho\left(\mathbf{r}^{\prime}\right) \rho\left(\mathbf{r}^{\prime}+\mathbf{r}\right) e^{i \mathbf{q} \cdot \mathbf{r}} \mathbf{d} \mathbf{r d} \mathbf{r}^{\prime}\right\rangle_{\Omega}=\int_{V} \gamma(\mathbf{r})\left\langle e^{i \mathbf{q} \cdot \mathbf{r}}\right\rangle_{\Omega} \mathbf{d r} \mathbf{r} \\
& =\frac{1}{4 \pi} \int_{V} \gamma(\mathbf{r}) \frac{\sin (q r)}{q r} d \mathbf{r}=\int_{0}^{\infty} r^{2} d r \int_{0}^{4 \pi} \frac{1}{4 \pi} \gamma(\mathbf{r}) d \omega \frac{\sin (q r)}{q r}
\end{aligned}
$$

de maneira que $I_{1}(q)$ pode ser escrito como:

$$
I_{1}(q)=4 \pi \int_{0}^{\infty} \gamma(r) \frac{\operatorname{sen}(q r)}{q r} r^{2} d r \quad \text { onde } \quad \gamma(r)=\frac{1}{4 \pi} \int_{0}^{4 \pi} \gamma(\mathbf{r}) d \omega=\langle\rho(\mathbf{r}) * \rho(-\mathbf{r})\rangle_{\Omega}
$$

onde $\gamma(r)$ é a função de autocorrelação média. Esta função pode ser interpretada como a probabilidade de encontrar um ponto dentro da partícula a uma distância $r$ de outro ponto dentro da mesma partícula (ZEMB; LINDNER, 2002).

A equação 43 revela que a intensidade média de espalhamento é a Transformada de Fourier ${ }^{3}$ do fator $p(r)=r^{2} \gamma(r)$. O fator $p(r)$ é chamado função de distribuição de pares de distância e corresponde a um histograma de pares de distância do interior da partícula multiplicado por $r^{2}$ (ZEMB; LINDNER, 2002; OLIVEIRA, 2011). Essa função é especialmente útil quando informações sobre dimensão e forma das partículas não estão previamente disponíveis.

A função $p(r)$ forma um par de Transformadas de Fourier com a intensidade:

$$
I_{1}(q)=4 \pi \int_{0}^{\infty} p(r) \frac{\operatorname{sen}(q r)}{q r} d r \quad \Longleftrightarrow \quad p(r)=\frac{r}{2 \pi^{2}} \int_{0}^{\infty} q^{2} I_{1}(q) \frac{\operatorname{sen}(q r)}{q r} d q
$$

3 Considerando que $\left\langle e^{i \mathbf{q} \cdot \mathbf{r}}\right\rangle_{\Omega}=\frac{1}{4 \pi} \int_{0}^{4 \pi} e^{i \mathbf{q} \cdot \mathbf{r}} d \Omega=\frac{\operatorname{sen}(q r)}{q r}$. 
A função $p(r)$ é nula para distâncias que correspondem a pontos externos à partícula pois nessa região o produto $\langle\rho(\mathbf{r}) * \rho(-\mathbf{r})\rangle$ é nulo, o que faz com $\gamma(r)$ também seja nula. Sendo assim, a função $p(r)$ pode fornecer diretamente a máxima dimensão da partícula espalhadora.

Existem diversos métodos de modelagem para se obter informações estruturais sobre as partículas que compõem o sistema a partir de dados de SAXS. A função $p(r)$ é especialmente importante quando não se tem informações prévias sobre a forma e dimensões das partículas e pode ser calculada a partir do método da transformada indireta de Fourier (IFT) (GLATTER; KRATKY, 1982). Outra possível abordagem consiste em calcular analiticamente as contribuições dos fatores de forma e estrutura e usar estes modelos para o ajuste de dados experimentais. Porém essa abordagem exige que se tenha conhecimento prévio sobre a forma e interação das partículas espalhadoras.

A abordagem empregada neste trabalho é o método dos fatores de forma e estrutura, sobre o qual trata a seção a seguir.

\subsubsection{Modelagem dos fatores de forma e estrutura de um sistema de partículas}

Na seção 6.1.2, o espalhamento devido a uma única partícula é discutida. Para um sistema de partículas espalhadoras, a intensidade de espalhamento é capaz de fornecer informações sobre forma e tamanho médios, bem como informações sobre a interação entre elas. Essas informações são fornecidas pelo chamado fator de forma $P(q)$ e fator de estrutura $S(q)$.

Nesse caso, é geralmente assumido que as orientações e posições das partículas não estão correlacionadas. Portanto, essas duas contribuições podem ser desacopladas e expressas separadamente por um fator de forma $P(\mathbf{q})$, que descreve a forma e as dimensões das partículas, e um fator de estrutura $S(\mathbf{q})$, que descreve as interações partícula-partícula. Considerando um sistema de $N$ partículas, a intensidade de espalhamento pode ser escrita como (ZEMB; LINDNER, 2002):

$$
I(q)=N\left\langle f(0)^{2}\right\rangle\langle P(\mathbf{q})\rangle\langle S(\mathbf{q})\rangle \quad \text { where } \quad\langle P(\mathbf{q})\rangle=\frac{\left\langle f(\mathbf{q})^{2}\right\rangle}{\left\langle f(0)^{2}\right\rangle}
$$


as médias podem ser realizadas em relação à polidispersidade de tamanho, composição, etc. Para sistemas diluídos, a interação entre partículas pode ser negligenciada e, portanto, $S(\mathbf{q})=1$.

Mais especificamente, o fator de forma $P(\mathbf{q})$ pode fornecer informações sobre anisotropia, dimensões, polidispersidade e contraste de densidade eletrônica. O fator de estrutura $S(\mathbf{q})$ pode fornecer informações sobre estado de agregação, estado de oligomerização, cristalinidade, etc.

Existem várias expressões analíticas e semi analíticas para fatores de forma disponíveis na literatura. A tabela 2 lista alguns exemplos para formas geométricas simples usados nos estudos reportados neste trabalho.

Tabela 1 - Fatores de forma (ZEMB; LINDNER, 2002).

\begin{tabular}{|c|c|}
\hline Description & $P(q)$ \\
\hline $\begin{array}{l}\text { Esfera homogênea } \\
\qquad \text { Raio }=R\end{array}$ & $P_{s p h}(q, R)=\left\{\frac{3[\operatorname{sen}(q R)-q R \cos (q R)]}{(q R)^{3}}\right\}^{2}$ \\
\hline $\begin{array}{l}\text { Elipsoide de revolução } \\
\text { Semi-axes }=R, R, \epsilon R\end{array}$ & $\begin{aligned} P_{e l l}(q, R, \epsilon) & =\int_{0}^{\pi / 2} P_{s p h}[q, r(R, \epsilon, \alpha)] \operatorname{sen} \alpha d \alpha \\
r(R, \epsilon, \alpha) & =R\left(\operatorname{sen}^{2} \alpha+\epsilon^{2} \cos ^{2} \alpha\right)^{1 / 2}\end{aligned}$ \\
\hline $\begin{array}{c}\text { Elipsoide com seção } \\
\text { elíptica; Semi-eixos }=A, B \\
\text { Comprimento }=L\end{array}$ & $\begin{array}{c}P_{\text {ele }}(q, A, B, L)=\frac{2}{\pi} \int_{0}^{\pi / 2} \int_{0}^{\pi / 2}\left\{\frac{2 J_{1}[q r(A, B, \phi, \alpha)]}{q r(A, B, \phi, \alpha)} \frac{\operatorname{sen}(q L \cos \alpha / 2)}{q L \cos \alpha / 2}\right\}^{2} d \phi \operatorname{sen} \alpha d \alpha \\
r(A, B, \phi, \alpha)=\left(A^{2} \operatorname{sen}^{2} \phi+B^{2} \cos ^{2} \phi\right)^{1 / 2} \operatorname{sen} \alpha\end{array}$ \\
\hline $\begin{array}{c}\text { Cilindro } \\
\text { Raio }=R ; \text { comprimento }=L\end{array}$ & $P_{c y l}(R, L)=\int_{0}^{\pi / 2}\left[\frac{2 J_{1}(q R \operatorname{sen} \alpha)}{q R \operatorname{sen} \alpha} \frac{\operatorname{sen}(q L \cos \alpha / 2)}{q L \cos \alpha / 2}\right] d \alpha$ \\
\hline $\begin{array}{c}\text { Cilindro longo } \\
\text { Raio }=R ; \text { comprimento }=L\end{array}$ & $\begin{array}{c}P_{L c y}(R, L)=P_{M O D}(q) \cdot P_{R O D}(q) \\
=\left[\frac{J_{1}(q R)}{q R}\right]^{2} \cdot\left[2 \operatorname{Si}(q L) /(q L)-4 \operatorname{sen}^{2}(q L / 2) /(q L)^{2}\right]\end{array}$ \\
\hline
\end{tabular}

$J_{1}$ é a função de Bessel de primeira ordem, $P_{M O D}$ e $P_{R O D}$ são os fatores de forma da seção transversal circular e da haste infinitamente fina, respectivamente. $\operatorname{Si}(x)=\int_{0}^{x} t^{-1} \operatorname{sen}(t) d t$.

Em relação aos fatores de estrutura, existem apenas algumas expressões analíticas e semi analíticas disponíveis para esferas, cilindros e algumas partículas flexíveis, como cadeias gaussianas. A maioria das expressões foi deduzida utilizando conceitos de mecânica estatística e mecânica de fluidos.

Um modelo de fator de estrutura frequentemente usado descreve o potencial de interação de esferas rígidas (ZEMB; LINDNER, 2002). Nesta abordagem, as partículas interagem umas com as outras como esferas rígidas com raio médio de interação $R_{H S}$. Se 
a distância entre os centros for maior que $2 R_{H S}$, a interação será nula. A expressão para $S(q)$ é calculada de acordo com a aproximação de Percus-Yevick (ZEMB; LINDNER, 2002; PERCUS; YEVICK, 1958):

$$
S_{P}(q)=\frac{1}{1+24 \eta G\left(2 R_{H S} q\right) /\left(2 R_{H S} q\right)}
$$

onde $R_{H S}$ é o raio de interação e $\eta$ é a fracão de volume de esferas rígidas.

A fração de volume de esferas rígidas é definida como $\eta=V_{H S} \bar{N}$, na qual $V_{H S}$ é o volume da esferas rígidas e $\bar{N}$ é a fração de número de esferas rígidas e $G(A)$ são:

$$
\begin{aligned}
G(A)= & \frac{\alpha(\operatorname{sen} A-A \cos A)}{A^{2}}+\frac{\beta\left[2 A \operatorname{sen} A+\left(2-A^{2}\right) \cos A-2\right]}{A^{3}}+ \\
& \frac{\gamma\left\{-A^{4} \cos A+4\left[\left(3 A^{2}-6\right) \cos A+\left(A^{3}-6 A\right) \operatorname{sen} A+6\right]\right\}}{A^{5}}
\end{aligned}
$$

os fatores $\alpha, \beta$ e $\gamma$ são:

$$
\alpha=\frac{(1+2 \eta)^{2}}{(1-\eta)^{4}} \quad \beta=\frac{-6 \eta(1+\eta / 2)^{2}}{(1-\eta)^{4}} \quad \gamma=\frac{\eta \alpha}{2}
$$

As contribuições de agregados de nanopartículas podem ser determinadas por um fator de estrutura que depende do raio de giro dos agregados. Esse fator de estrutura considera que a região da curva da intensidade de espalhamento para $q \rightarrow 0$ é dominada pelos agregados, como determina a lei de Guinier. A expressão que descreve a contribuição de agregados com $\mathrm{N}$ tamanhos característicos é escrita como (OLIVEIRA; MONTEIRO; NETO, 2014):

$$
S_{G}\left(q, S c_{i}^{G}, R G_{i}\right)=1+\sum_{i=1}^{N} S c_{i}^{G} \cdot e^{-\frac{q^{2} R G_{i}}{3}}
$$

$S c_{i}^{G}$ é o fator de escala e $R G_{i}$ é o raio de giro dos agregados de índice $i$. Se os agregados são esféricos, o raio da esfera pode ser calculado por:

$$
R=\sqrt{\frac{5}{3}} R G
$$

Os fatores de escala $S c_{i}^{G}$ são equivalentes à razão entre a intensidade de espalhamento dos agregados e as nanopartículas na origem $(q=0)$ :

$$
S c_{i}^{G}=\frac{I_{i}^{A g g}(0)}{I^{N P}(0)}
$$


mais detalhes sobre esta equação são fornecidos no apêndice A.2.

Ao analisar um sistema contendo partículas com tamanhos diferentes, uma abordagem frequentemente empregada é modelar a distribuição de raios utilizando uma função matemática. A curva dessas funções geralmente apresenta formato de pico. Uma das funções de distribuição mais usadas é a chamada função Schulz-Zimm (ZEMB; LINDNER, 2002) $D(R)$ :

$$
D(R,\langle R\rangle, z)=\left(\frac{z+1}{\langle R\rangle}\right) \frac{R^{z}}{\Gamma(z+1)} \exp \left(-(z+1) \frac{R}{\langle R\rangle}\right)
$$

com

$$
\int_{0}^{\infty} D(R) d R=1
$$

$\langle R\rangle$ é o raio médio da distribuição e $z$ está relacionado à polidispersidade relativa do raio $\sigma /\langle R\rangle$ por $z=1 /(\sigma /\langle R\rangle)^{2}$.

Uma vez que a função $D(R)$ é conhecida, o raio médio pode ser determinado através da seguinte relação:

$$
\left\langle R_{i}\right\rangle=\left(\int_{0}^{\infty} R^{j} D(R) d R\right)^{1 / j}
$$

nesta equação, se $j=1$ a média é ponderada por número ( $i=$ número), se $j=3$ a média é ponderada por volume ( $i=$ volume) e se $j=6$ a média é ponderada por intensidade $(i=$ intensidade).

As médias nas expressões da intensidade de espalhamento (equação 45) levam a perda de informações e, consequentemente, a perda de resolução dos dados. A falta de informação gera degenerescência no perfil de SAXS e, consequentemente, os dados experimentais podem ser igualmente bem descritos por diferentes modelos teóricos.

Portanto, frequentemente é necessário escolher uma entre várias soluções possíveis para um dado problema de espalhamento; um critério de seleção se faz necessário. Uma maneira de abordar essa questão é a chamada Navalha de Occam (Occam's Razor), também chamada de princípio da parcimônia ${ }^{4}$. De acordo com Martin e Hine (2015), o princípio da parcimônia é "O princípio no qual a explicação mais aceitável de uma ocorrência, fenômeno ou evento é a mais simples, envolvendo o menor número de entidades, suposições ou mudanças". Em outras palavras, o modelo mais simples que descreve com 
êxito uma observação é escolhido. Como Ockham supostamente escreveu (GARRISON, 1997): "Entidades não devem ser multiplicadas além do necessário". Na prática, dados de espalhamento devem sempre ser correlacionados com outros resultados teóricos ou experimentais de modo a minimizar a ambiguidade e indicar o modelo mais provável.

\subsection{Difração de raios $\mathrm{X}$}

Em experimentos de difração de raios X, os fótons de raios X são elasticamente espalhados por átomos dispostos em uma rede cristalina ordenada. Como os feixes de raios X espalhados estão em fase, em determinadas condições poderá haver interferência construtiva na interação entre os feixes espalhados, resultando em picos na curva de intensidade espalhamento (RAMACHANDRAN; BEAUDOIN, 2000).

Esta técnica é geralmente aplicada em estudos cristalográficos da amostra uma vez que se baseia na análise dos máximos de interferência formados pela difração da rede cristalina. A estrutura cristalina pode ser considerada como um conjunto de planos cristalinos paralelos de átomos. A figura 11 mostra dois vetores de onda em fase espalhados por planos cristalinos separados por uma distância $d$ :

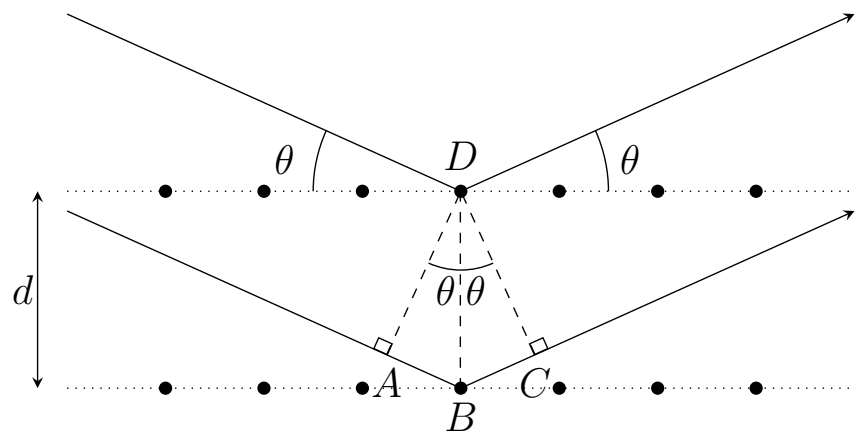

Figura 11 - Ilustração da Lei de Bragg.

O feixe espalhado pelo plano inferior percorre uma distância adicional $\overline{A B C} \mathrm{em}$ relação ao feixe espalhado pelo plano superior. Pode ser visto na figura 11 que a distância $\overline{A B}$ é igual à distância $\overline{B C}$. Este fato é matematicamente expresso como:

$$
\begin{aligned}
& \overline{A B}=\overline{B C}=d \operatorname{sen} \theta \\
& \overline{A B C}=2 d \operatorname{sen} \theta
\end{aligned}
$$

onde $d$ é a distância interplanar e $\theta$ é o ângulo de incidência. 
Só haverá interferência construtiva entre esses dois vetores de onda se a diferença de caminho $\overline{A B C}$ for igual a um múltiplo inteiro do comprimento de onda do feixe incidente. Assim, as ondas estarão em fase novamente depois de cruzar a linha $\overline{C D}$ somente se a seguinte relação for satisfeita:

$$
n \lambda=2 d \operatorname{sen} \theta
$$

$n$ é um número inteiro positivo. Essa equação é conhecida como lei de Bragg (CULLITY, 1956).

Como as distâncias entre os átomos na rede cristalina estão compreendidas na faixa de tamanhos coberta pela técnica, picos de intensidade surgem no difratograma como resultado do espalhamento de diferentes planos cristalinos (com diferentes distâncias interplanares $d$ ), conforme previsto pela lei de Bragg.

No caso de técnicas de difração, o vetor q assume valores discretos, uma vez que descreve as posições dos átomos na rede cristalina no espaço recíproco e é expresso em termos de índices de Miller ( $h k l$ ) (MORELHÃO, 2016):

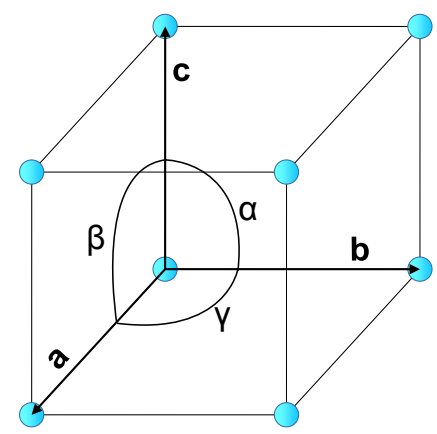

Figura 12 - Representação de uma estrutura cristalina cúbica, mostrando os parâmetros de rede $a, b, c, \alpha, \beta$ e $\gamma$.

$$
\mathbf{q}_{\mathbf{h k l}}=h \mathbf{a}^{*}+k \mathbf{b}^{*}+l \mathbf{c}^{*}
$$


onde $\mathbf{a}^{*}, \mathbf{b}^{*}$ e $\mathbf{c}^{*}$ são os vetores primitivos da rede no espaço recíproco. Os vetores da rede recíproca estão relacionados aos vetores da rede no espaço direto pela seguinte relação:

$$
\begin{aligned}
& \mathbf{a}^{*}=2 \pi \frac{\mathbf{b} \times \mathbf{c}}{V_{c e l}} \\
& \mathbf{b}^{*}=2 \pi \frac{\mathbf{c} \times \mathbf{a}}{V_{c e l}} \\
& \mathbf{c}^{*}=2 \pi \frac{\mathbf{a} \times \mathbf{b}}{V_{c e l}}
\end{aligned}
$$

onde $V_{c e l}=\mathbf{a} \cdot(\mathbf{b} \times \mathbf{c})$ é o volume da célula unitária.

A intensidade total é proporcional ao módulo quadrático da amplitude de espalhamento total do sistema $F(\mathbf{q})$ :

$$
I(\mathbf{q}) \propto I_{T h}|F(\mathbf{q})|^{2}
$$

$I_{T h}$ é a intensidade de espalhamento Thomson devido a um elétron (MORELHÃO, 2016). Na área de cristalografia, $F(\mathbf{q})$ é chamado de fator de estrutura.

O fator de estrutura de uma rede cristalina contendo $\mathrm{N}$ átomos é expressa como:

$$
F\left(\mathbf{q}_{h k l}\right)=\sum_{j=1}^{N} f_{j}(\mathbf{q}) e^{i \mathbf{q}_{h k l} \cdot \mathbf{r}_{j}}=\sum_{j=1}^{N} f_{j}(\mathbf{q}) e^{2 \pi i\left(h x_{j}+k y_{j}+l z_{j}\right)}
$$

onde $f_{j}(\mathbf{q})$ é o fator de espalhamento atômico e $x y z$ são coordenadas relativas das posições atômicas na célula unitária.

O fator de espalhamento atômico é calculado da mesma forma como indicado na equação 11. No entanto, como átomos são muito pequenos, estes fatores de espalhamento atômico variam suavemente para os comprimentos de onda típicos usados em experimentos de XRD.

Um plano cristalino é definido por um conjunto de três pontos não colineares da rede cristalina. A distância entre esses planos, chamada de distância interplanar, em uma determinada direção $(h k l)$ aparece na expressão da lei de Bragg ( $d$ na equação 56). Se a lei de Bragg for combinada com a expressão de $q$ (equação 35), tem-se:

$$
d_{h k l}=\frac{2 \pi}{q_{h k l}}
$$

O tamanho de domínio cristalino, também chamado de tamanho de cristalito, está relacionado à largura do pico de difração. Sendo $\Delta q_{h k l}$ a largura a meia altura do pico de 
difração de índices $h k l$ em função de q, o tamanho de cristalito $D$ correspondente é dado pela equação de Scherrer (INGHAM; TONEY, 2014):

$$
D=b \frac{2 \pi}{\Delta q_{h k l}}
$$

onde $b$ é uma constante.

A distância interplanar é uma função dos parâmetros de rede. A tabela 2 mostra essa relação para algumas redes de Bravais (EDINGTON, 1975):

Tabela 2 - Distância interplanares.

\begin{tabular}{|c|c|c|}
\hline Rede & Parâmetros & Distância interplanar \\
\hline cúbica & $a=b=c ; \alpha=\beta=\gamma=90^{\circ}$ & $d_{h k l}=\frac{a}{\sqrt{h^{2}+k^{2}+l^{2}}}$ \\
\hline Tetragonal & $a=b \neq c ; \alpha=\beta=\gamma=90^{\circ}$ & $d_{h k l}=\left[\frac{h^{2}+k^{2}}{a^{2}}+\frac{l^{2}}{c^{2}}\right]^{-1 / 2}$ \\
\hline Hexagonal & $a=b \neq c ; \alpha=\beta=90^{\circ} ; \gamma=120^{\circ}$ & $d_{h k l}=\left[\frac{4}{3} \frac{\left(h^{2}+h k+k^{2}\right)}{a^{2}}+\frac{l^{2}}{c^{2}}\right]^{-1 / 2}$ \\
\hline Ortorrombica & $a \neq b \neq c ; \alpha=\beta=\gamma=90^{\circ}$ & $d_{h k l}=\left(\frac{h^{2}}{a^{2}}+\frac{k^{2}}{b^{2}}+\frac{l^{2}}{c^{2}}\right)^{-1 / 2}$ \\
\hline
\end{tabular}

As amostras de nanopartículas globulares de prata e ouro investigadas nesta tese possuem uma rede cristalina interna cúbica de face centrada. As principais reflexões observadas no padrão de difração dessa fase são devidas aos planos (111) para $2 \theta \approx 38^{\circ}$, (200) para $2 \theta \approx 44^{\circ},(220)$ para $2 \theta \approx 64^{\circ}$ e $(311)$ para $2 \theta \approx 77^{\circ}$.

Juntamente com o fator de estrutura, outros fatores podem ser considerados no cálculo da intensidade difratada e geralmente são incluídos como prefatores da equação 59. Correções como polarização, orientação preferencial e multiplicidade de reflexões são exemplos dessas correções.

$$
I(\mathbf{q})=M(\mathbf{q}) L p(\mathbf{q}) P o(\mathbf{q})|F(\mathbf{q})|^{2}
$$

onde $M(\mathbf{q})$ é a multiplicidade das reflexões, $L p(\mathbf{q})$ é a polarização de Lorentz e $P o(\mathbf{q})$ é o fator correção de orientação preferencial. A modelagem de $I(\mathbf{q})$ é descrita em detalhes na publicação de Will (2006). 


\subsection{Espalhamento dinâmico de luz}

\subsubsection{Princípios}

O espalhamento dinâmico de luz, ou espectroscopia de correlação de fótons (PCS), é uma técnica baseada na análise de flutuações da intensidade de espalhamento relacionadas ao movimento Browniano das partículas em suspensão (ZEMB; LINDNER, 2002).

Em um experimento típico de DLS (figura 13), a amostra é submetida a um laser monocromático. Parte do feixe é espalhada pelas partículas em suspensão na amostra. A intensidade de espalhamento registrada pelo detector flutua ao longo do tempo devido ao movimento aleatório das partículas espalhadoras. O correlator então calcula a correlação temporal da intensidade de espalhamento registrada pelo detector.

Existem dois métodos diferentes para realizar experimentos DLS: homódino e heteródino. No modo homódino, exibido na figura 13a, a intensidade de espalhamento medida é correlacionada com ela mesma e a distribuição de frequências é proporcional ao quadrado da intensidade da luz espalhada $\left(\left\langle I_{S}^{2}\right\rangle\right)$. No modo heteródino, mostrado na figura 13b, o feixe espalhado é correlacionado com um feixe de referência, que é uma fração do feixe incidente desviado diretamente para o detector por lentes altamente refletivas. Nesse caso, a distribuição de frequências é proporcional ao produto da intensidade do feixe de referência com a intensidade do feixe de espalhamento $\left(\left\langle I_{S} I_{0}\right\rangle\right)$.

A configuração heteródino tem a vantagem de permitir medições de amostras com concentrações mais altas de partículas e com aglomerados de forma mais eficiente que o homódino. Isso é possível porque a correlação feita com o feixe de referência proporciona um ganho de sinal, aumentando assim a intensidade do feixe que chega ao detector, tornando a técnica mais sensível ao espalhamento menos intenso de partículas menores. Todos os dados DLS apresentados neste trabalho foram coletados em um equipamento utilizando a configuração homódino. Esta configuração é a mais comumente utilizada em equipamentos comerciais de DLS. 


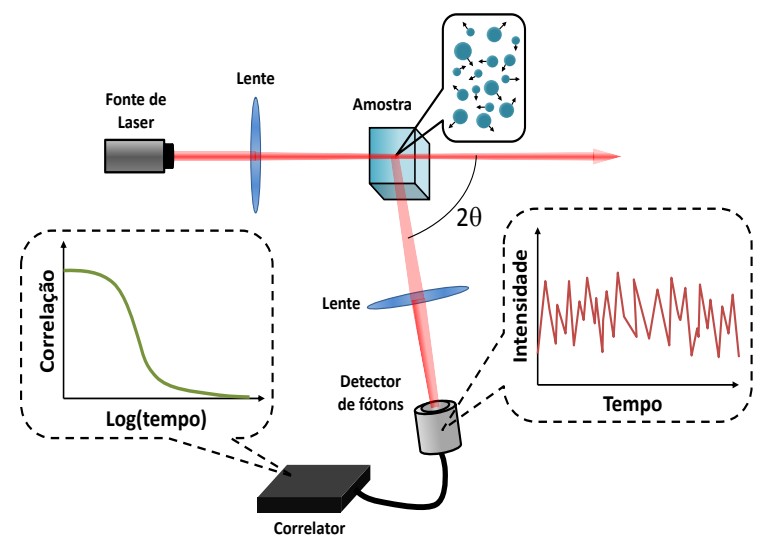

(a)

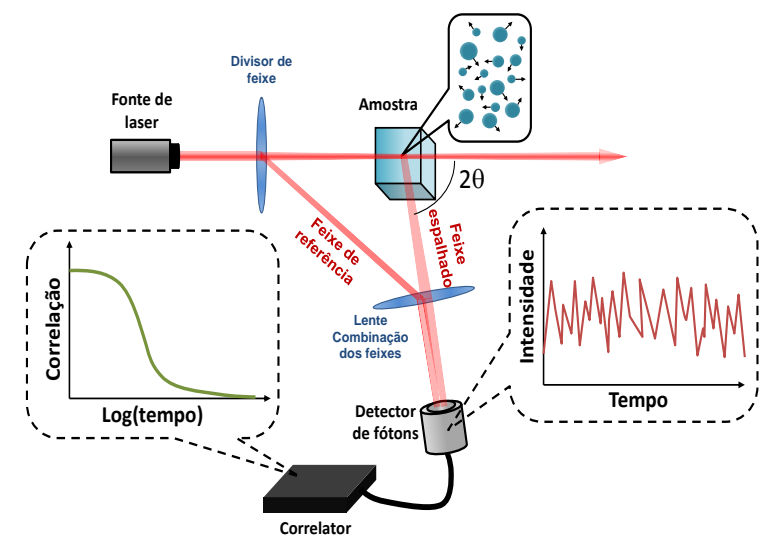

(b)

Figura 13 - Espectroscopia de correlação de fótons: (a) homódino e (b) heteródino.

\subsubsection{Funçao de autocorrelação temporal da intensidade}

A autocorrelação temporal da intensidade de espalhamento é o parâmetro de interesse em experimentos de DLS pois carrega informações sobre os tamanhos típicos do sistema de partículas. A função de autocorrelação de um sistema de partículas é definida como a média da convolução da intensidade em um dado momento " $t$ " com a intensidade medida em um momento posterior $t+\tau$ (ZEMB; LINDNER, 2002).

$$
g^{(2)}(\tau)=\langle I(t) I(t+\tau)\rangle=\lim _{T \rightarrow \infty} \frac{1}{2 T} \int_{-T}^{T} I(t) \cdot I(t+\tau) d t
$$

$g^{(2)}(\tau)$ é chamada de função de autocorrelação da intensidade de segunda ordem não normalizada, pois é proporcional ao quadrado do campo elétrico (e, portanto, à intensidade).

Pode ser demonstrado que a função de autocorrelação de intensidade pode ser expressa como uma função de decaimento exponencial (ZEMB; LINDNER, 2002). Para um sistema de partículas idênticas que não interagem, $g^{(2)}(\tau)$ é escrito pela relação de Siegert (ZEMB; LINDNER, 2002):

$$
g^{(2)}(\tau)=B+\beta \cdot\left|g^{(1)}(\tau)\right|^{2}=B+\beta \cdot e^{-2 \Gamma_{0} \tau}
$$

onde $B$ é uma constante, $\beta$ é um parâmetro experimental e $\Gamma_{0}$ é a taxa de decaimento. 
A função $g^{(1)}(\tau)$ é a autocorrelação temporal do campo elétrico e é definida como a convolução do campo elétrico em um momento $t$ com o campo elétrico em um momento posterior $t+\tau$ :

$$
g^{(1)}(\tau)=\frac{\left\langle E(\mathbf{q}, t) E^{*}(\mathbf{q}, t+\tau)\right\rangle}{\langle I(\mathbf{q}, t)\rangle}
$$

A taxa de decaimento é dada em função do módulo do vetor de espalhamento q e da constante de difusão $\left(D_{0}\right)$ pela relação $\Gamma_{0}=\tau^{-1}=q^{2} D_{0}$. Para DLS, o módulo do vetor $q$ leva em conta o índice de refração $n$ do meio $^{5}$ :

$$
q=\frac{4 \pi}{\lambda} n \operatorname{sen} \theta
$$

Uma vez determinada a constante de difusão, o raio hidrodinâmico pode ser calculado usando a equação de Stokes-Einsten (ZEMB; LINDNER, 2002; EINSTEIN, 1905):

$$
D_{0}=\frac{k_{B} T}{6 \pi \eta R_{H}} \quad \rightarrow \quad \Gamma=\frac{q^{2} k_{B} T}{6 \pi \eta R_{H}}
$$

$k_{B}$ é a constante de Boltzmann, $T$ é a temperatura, $\eta$ é a viscosidade do fluido e $R_{H}$ é o raio hidrodinâmico ou raio de Stokes ${ }^{6}$.

A equação de Stokes-Einsten é deduzida para um sistema de esferas com raio $R_{H}$. Portanto, $R_{H}$ é o raio da esfera equivalente, ou seja, o raio de um sistema de esferas que resultaria no mesmo coeficiente de difusão observado.

\subsubsection{A função de autocorrelação de um sistema polidisperso}

A extrapolação para um sistema polidisperso é feito pela soma das contribuições individuais das nanopartículas para a intensidade de espalhamento (e, portanto, para a autocorrelação total da intensidade). Considere-se um sistema de N partículas com raios $R_{1}, R_{2}, \ldots, R_{N}$ e frações de número $A_{1}, A_{2}, \ldots, A_{N}$. Devido aos diferentes tamanhos de

5 Para SAXS, $n \approx 1$.

6 Conforme a nanopartícula se move, ela carrega uma camada fina formada por partículas menores do fluido que aderem à superfície das partículas devido ao potencial elétrico entre as partículas e essas moléculas. Como esta camada influencia a difusão, o raio hidrodinâmico equivale a soma do raio da partícula com a espessura dessa camada. 
partícula, cada partícula contribui com taxas de decaimento $\Gamma_{1}, \Gamma_{2}, \ldots, \Gamma_{N}$. A função de autocorrelação de primeira ordem é dada pela soma dessas contribuições:

$$
g^{(1)}(\tau)=\sum_{i=1}^{N} A_{i} e^{-\Gamma_{i} \tau} \quad \text { onde } \quad \sum_{i=1}^{N} A_{i}=1
$$

Como o número de partículas de amostras reais é muito grande, o conjunto de taxas de decaimento pode ser expresso como uma função de distribuição contínua. Para um grande número de partículas de diferentes tamanhos, assumindo o limite para $N \rightarrow \infty$, a equação 69 assume a forma:

$$
g^{(1)}(\tau)=\int_{0}^{\infty} G(\Gamma) e^{-\Gamma \tau} d \Gamma \quad \text { onde } \quad \int_{0}^{\infty} G(\Gamma) d \Gamma=1
$$

$G(\Gamma)$ é a função de distribuição de taxas de decaimento.

Como a taxa de decaimento está diretamente relacionada ao raio hidrodinâmico através da equação 68 , determinar $G(\Gamma)$ implica em determinar a distribuição de raios hidrodinâmicos $F\left(R_{H}\right)$.

\subsubsection{Modelagem}

Interessantemente, uma análise mais detalhada da equação 70 mostra que a autocorrelação do campo $g^{(1)}(\tau)$ é na verdade a transformada de Laplace da distribuição de taxas de decaimento $G(\Gamma)$, então o problema consiste em executar a transformada inversa de Laplace de $g^{(1)}(\tau)$ para encontrar $G(\Gamma)$.

Pode-se demonstrar que esse problema inverso é matematicamente mal-posto (SCOTTI et al., 2015), o que significa que pode não haver uma solução única $G(\Gamma)$ para um determinado $g^{(1)}(\tau)$. Como consequência, métodos comuns de minimização podem resultar em soluções indesejáveis, como valores negativos e tendências oscilatórias.

Provencher (1982) propôs uma solução a esse problema formulando um método padrão de mínimos quadrados com a adição de um termo de restrição. Este procedimento é baseado na minimização do funcional (SCOTTI et al., 2015; PROVENCHER, 1982):

$$
V(\alpha)=\left\|g_{\text {teórico }}^{(2)}[G(\Gamma)]-g_{\text {experimental }}^{(2)}\right\|^{2}+\alpha^{2}\|\omega-\Omega G(\Gamma)\|^{2}
$$

o primeiro termo dessa equação é a norma residual e o segundo termo abrange as condições de restrição. O parâmetro $\alpha$ é o regularizador que define o peso das restrições e seu valor 
é geralmente definido manualmente, $\omega$ é um termo que inclui conhecimento prévio do sistema e, nos casos mais simples, $\omega=0$. Finalmente, $\Omega$ é a matriz de restrições.

Existem várias possibilidades de escolha para as restrições. A abordagem muito comum é definir $\Omega$ como a segunda derivada em relação a $\tau$ (SCOTTI et al., 2015).

\subsection{Espectroscopia no ultravioleta-visível e ressonância plasmônica de superfície localizada}

Espectroscopia é o estudo da interação da radiação com a matéria relacionada à dependência do comprimento de onda da radiação. Espectroscopia abrange uma ampla área de técnicas analíticas e nesta seção são abordados alguns conceitos da modalidade de espectroscopia que usa radiação ultravioleta e visível.

A Figura 14a mostra um diagrama esquemático do aparato experimental utilizado para as caracterizações por Uv-vis feitas neste projeto. A fonte de deutério-tungstênio produz um feixe de radiação policromático com comprimento de onda na faixa que vai do visível até o ultravioleta. O feixe é transportado por fibras óticas para o porta-amostras, onde interage com a amostra.

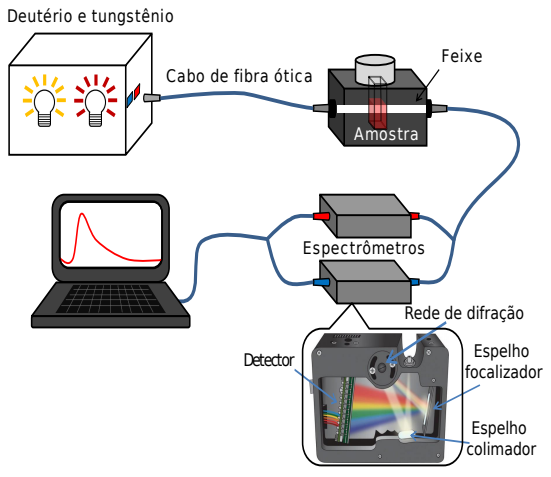

(a)

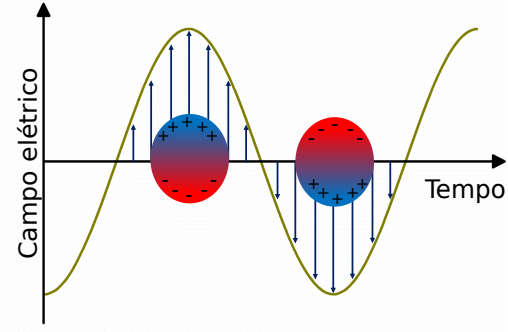

(b)

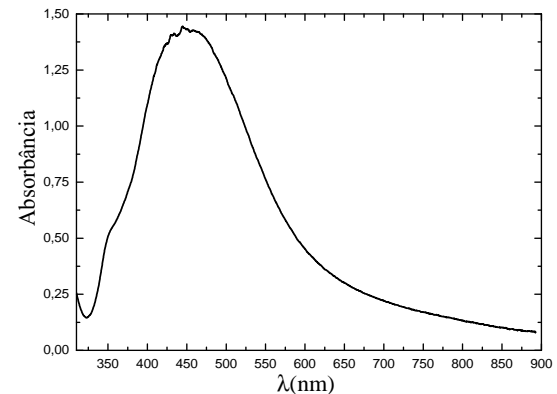

(c)

Figura 14 - (a)Diagrama esquemático do aparato experimental de espectroscopia uv-vis, (b) representação da ressonância plasmônica de superfície localizada e (c) espectro Uv-vis de uma amostra de nanopartículas de prata. A imagem do espectrômetro na figura (a) está disponível em: (OCEAN OPTICS, 2019).

O feixe transmitido é transportado para os espectrômetros de fótons (um para detecção de baixos e outro para detecção de altos comprimentos de onda), onde seus 
componentes são separados de acordo com o comprimento de onda e detectados. Um espectro Uv-vis típico de nanopartículas de prata é mostrado na figura 14c.

A atenuação do feixe incidente ocorre devido à absorbância e espalhamento da radiação. Assim, a intensidade do feixe incidente $I_{0}$ pode ser escrita como $I_{0}=I_{T}+I_{A}+I_{S}$, na qual os subscritos $T, A$ e $S$ referem-se à transmissão, absorbância e espalhamento, respectivamente. A absorbância depende da concentração das espécies absorventes e do comprimento do caminho ótico (distância percorrida pelo feixe ao atravessar a amostra), de acordo com a lei de Beer-Lambert.

\subsubsection{Ressonância plasmônica de superfície localizada}

Nanopartículas metálicas mostram uma propriedade única quando irradiadas por luz na faixa do visível e ultravioleta. As oscilações do campo elétrico da radiação causam uma oscilação coletiva dos elétrons da banda de condução. Em oposição, a nuvem de elétrons experimenta uma força restauradora decorrente da atração de Coulomb entre os elétrons e o núcleo e da repulsão entre outros elétrons. Essa condição de oscilação coerente é chamada de ressonância plasmônica de superfície localizada (LSPR) (WIEDERRECHT, 2010) e é representada na figura 14b.

O fenômeno é chamado "localizado" porque, no caso de nanopartículas com tamanho muito menor que o comprimento de onda da radiação, os plasmons ficam confinados à superfície das nanopartículas, o que limita as oscilações a uma frequência específica (WIEDERRECHT, 2010). A frequência de ressonância depende da constante dielétrica do material, que por sua vez muda com o comprimento de onda da radiação.

A relação entre as constantes dielétricas do sistema e o espectro plasmônico pode ser elucidada pela compreensão do comportamento do campo elétrico externo ao redor de uma partícula sujeita a uma onda eletromagnética. O campo elétrico externo pode ser determinado resolvendo-se as equações de Maxwell usando a teoria de Mie (MAYER; HAFNER, 2011; WIEDERRECHT, 2010). Sob condições e limites específicos, o campo elétrico em um ponto com coordenadas $x y z$ na região externa e próximo à superfície de uma partícula esférica é:

$$
E_{\text {out }}(x, y, z, \lambda)=E_{0} \hat{\mathbf{z}}-\left[\frac{\epsilon_{\text {in }}(\lambda)-\epsilon_{\text {out }}(\lambda)}{\epsilon_{\text {in }}(\lambda)+2 \epsilon_{\text {out }}(\lambda)}\right] \times a^{3} E_{0}\left[\frac{\hat{\mathbf{z}}}{r^{3}}-\frac{3 z}{r^{5}}(x \hat{\mathbf{x}}+y \hat{\mathbf{y}}+z \hat{\mathbf{z}})\right]
$$


$E_{0}$ é o campo elétrico da onda eletromagnética incidente, $\epsilon_{i n}$ é a constante dielétrica da partícula, $\epsilon_{\text {out }}$ é a constante dielétrica do meio, $a$ é o raio da esfera e $\lambda$ é o comprimento de onda da onda eletromagnética. A equação 72 mostra a dependência do campo elétrico $E_{\text {out }} \operatorname{com} \epsilon$ e $\lambda$.

A condição de ressonância ocorre quando $E_{\text {out }}(x, y, z, \lambda)$ é máximo, que por sua vez ocorre quando $\epsilon_{i n}(\lambda) \approx 2 \epsilon_{\text {out }}(\lambda)$. Essa é a condição básica para a ressonância plasmônica e demonstra a dependência do LSPR em relação às características dielétricas do sistema. Para nanopartículas de prata e ouro, essa condição ocorre para comprimentos de onda no espectro visível.

O espectro LSPR é sensível às propriedades estruturais das nanopartículas, exibindo uma curva de extinção que depende da forma e do tamanho (WIEDERRECHT, 2010). A dependência do LSPR das propriedades dielétricas do sistema permite a sua aplicação no desenvolvimento de sensores. As variações nas constantes dielétricas, e portanto no índice de refração, do meio devido às interações próximas à superfície das nanopartículas podem ser detectadas pela observação direta da variação das bandas de ressonância plasmônica (MAYER; HAFNER, 2011).

\subsection{Microscopia eletrônica de transmissão}

A microscopia eletrônica proporcionou um grande avanço para a ciência dos materiais (ESCALANTE; SIERRA, 2019). De fato, esta técnica impulsionou o progresso de diversas áreas de pesquisa.

A microscopia eletrônica surgiu como um aprimoramento do microscópio óptico, cuja resolução é limitada pelo comprimento de onda da luz visível. O conceito básico é que, como os elétrons têm comprimentos de onda muito menores que a luz visível, as imagens produzidas usando elétrons podem ter resolução muito maiores, chegando à escala atômica ${ }^{7}$.

A ideia de usar elétrons para a construção de imagens foi consolidada por Knoll e Ruska com a construção do primeiro microscópio eletrônico. Em uma publicação de 1923, eles reportaram a construção de lentes eletrônicas e mostraram as primeiras imagens

$7 \quad$ A resolução do microscópio ótico pode atingir $200 \mathrm{~nm}$, enquanto a resolução de um microscópio eletrônico pode atingir $2 \AA$. Assim, a resolução de um microscópio eletrônico tem a mesma ordem de grandeza das distâncias entre átomos. 
publicadas de um microscópio eletrônico (KNOLL; RUSKA, 1932). Em 1986, eles receberam o Prêmio Nobel por este trabalho (WILLIAMS; CARTER, 2009).

A figura 15 mostra as diversas partes que compõem um microscópio eletrônico. Os elétrons são gerados em uma fonte chamada de pistola ou canhão de elétrons. A fonte é composta por um cátodo de hexaboreto de lantânio (Lab6) ou tungstênio em forma de "V". O comprimento de onda $\lambda$ dos elétrons produzidos na fonte é dado pela equação de De Broglie:

$$
\lambda=\frac{h}{2 m_{0} e V\left(1+\frac{e V}{2 m_{0} c^{2}}\right)^{2}}
$$

onde $e V$ é o potencial elétrico que acelera os elétrons, $m_{0}$ é a massa de repouso do elétron, $h$ é constante de Planck e $c$ é a velocidade da luz.

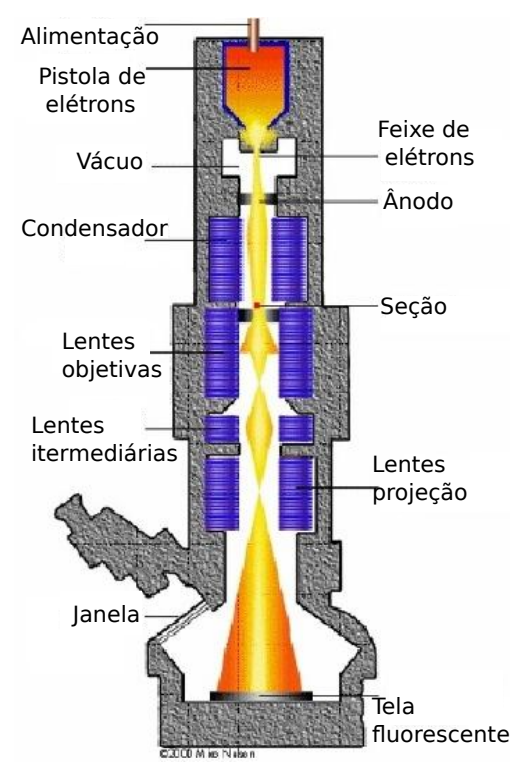

Figura 15 - Diagrama esquemático de um microscópio eletrônico. Fonte: Adaptado de (SPECTROSCOPY, 2019).

Após deixar o cátodo, os elétrons são acelerados e passam por um sistema de lentes magnéticas, chamadas lentes condensadoras, para ajustar as dimensões do feixe às condições de medição. A pistola de elétrons e a lente de condensação compreendem o chamado sistema de iluminação.

O feixe então atinge o porta-amostras, onde interage com a amostra. Após atravessála, o feixe é ampliado por outro sistema de lentes e direcionado à uma placa fluorescente, filme fotográfico ou tela onde produz uma imagem (sistema de imagem). 
Geralmente, as imagens de TEM são formadas por elétrons transmitidos, com a abertura objetiva posicionada na direção do eixo óptico do microscópio. Nesse caso, os pontos na imagem onde não há amostra são formados por elétrons não espalhados. Como o número de elétrons não espalhados é muito maior que o número de elétrons espalhados, esses pontos serão pontos brilhantes, enquanto os pontos que representam a amostra serão pontos escuros. Por esse motivo, essa modalidade é conhecida como imagem de campo claro.

Outra possibilidade é posicionar a abertura objetiva em um certo ângulo em relação ao eixo ótico para detectar apenas elétrons espalhados. Desta forma, diferentemente do caso anterior, os pontos brilhantes da imagem corresponderão à região onde há amostra, enquanto as regiões sem amostra serão representadas por pontos escuros. Essa modalidade é chamada de imagem de campo escuro.
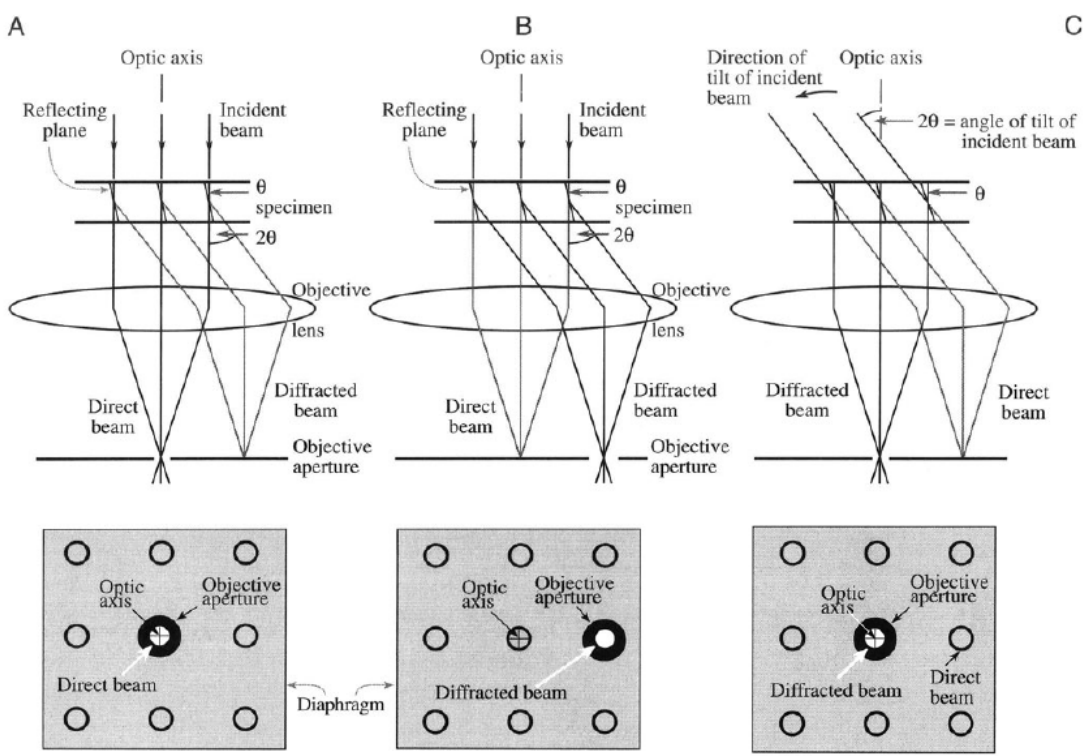

Figura 16 - Diagrama mostrando as posições da lente e abertura abjetivas na formação de imagens de campo escuro e claro. Na figura (A) o feixe transmitido, na direção do eixo ótico, é captado para a formação de imagens de campo escuro. Nas (B) e (C) o feixe espalhado é captado formando imagens de campo claro. Em (B) o feixe incidente está na mesma direção do eixo ótico enquanto que em (C) o feixe incidente é posicionado em uma direção $2 \theta$ em relação ao eixo ótico. Fonte: Williams e Carter (2009). 


\subsection{Sedimentação Centrífuga Diferencial}

A sedimentação centrífuga diferencial (differential centrifugal sedimentation, DCS) é uma técnica utilizada para a determinação da distribuição de tamanhos de nanopartículas através de um método de sedimentação.

O equipamento consiste em um disco preenchido com um fluido que possui um gradiente de densidade. A amostra em solução é injetada através de um orifício no centro do disco rotativo (ponto de injeção). As partículas, imersas no líquido, são então arrastadas para a borda do disco com diferentes velocidades, dependendo de seus tamanhos. A figura 17 mostra uma representação do disco e uma curva de distribuição de tamanhos obtida para uma amostra de nanopartículas de prata.

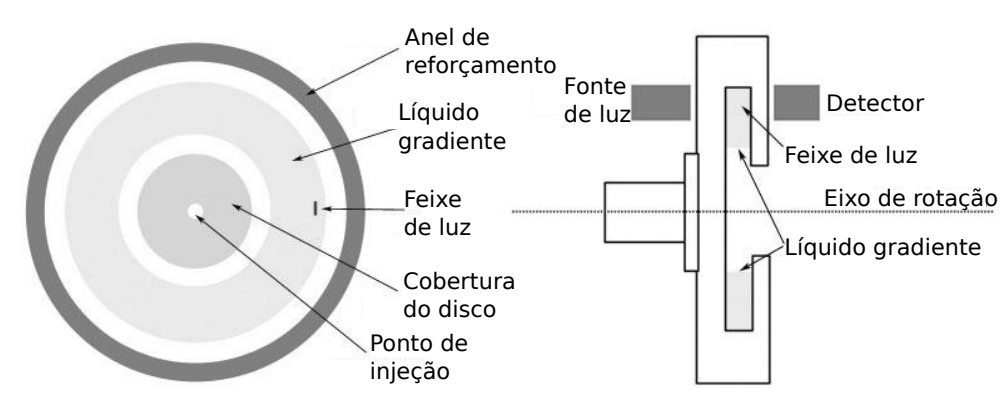

(a)

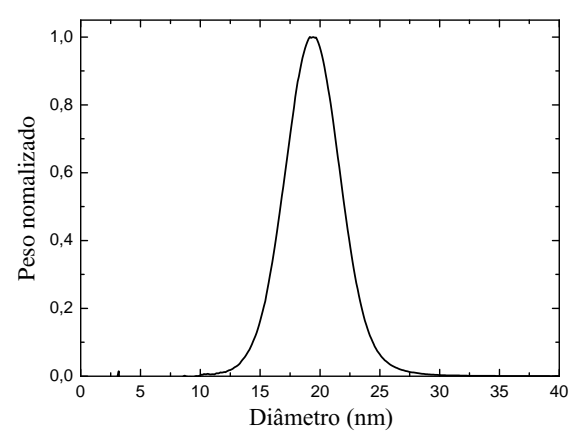

(b)

Figura 17 - (a) Diagrama esquemático do disco do equipamento de DCS e (b) distribuição de diâmetros de uma amostra de nanopartículas de prata. Figura (a) esta disponível em: (CPS INSTRUMENTS EUROPE, 2019).

Se o fluido satisfaz um conjunto de condições de contorno, Stokes demonstrou que as partículas se movem a uma velocidade constante (STOKES et al., 1901). Essas condições são:

- Partículas são esféricas.

- A velocidade de sedimentação é baixa o bastante para que o fluxo não seja turbulento.

- As partículas do soluto são muito maiores que as partículas constituintes do fluido (solvente).

- O volume de fluido é essencialmente infinito se comparado ao volume das partículas. 
Sob essas condições, a lei de Stokes pode ser usada para deduzir o tamanho das partículas (ISO13318-1, 2001; ISO13318-2, 2007; BRAUN et al., 2011):

$$
D=\sqrt{\frac{18 \eta \ln \left(R_{f} / R_{0}\right)}{\omega^{2}\left(\rho_{p}-\rho_{f}\right)} \frac{1}{t}}
$$

onde $D$ é o tamanho da partícula, $\eta$ é a viscosidade do fluido, $R_{f}$ é o raio final de rotação, $R_{0}$ é o raio inicial de rotação, $\rho_{p}$ é a densidade de massa da partícula, $\rho_{f}$ é a densidade de massa do fluido, $\omega$ é a velocidade de rotação e $t$ é o tempo necessário para as partículas sedimentarem de $R_{0}$ a $R_{f}$ (onde atingem o detector).

Quando as partículas se aproximam da borda externa do disco elas atravessam uma região iluminada pelo feixe de luz do detector. Uma parte desse feixe é espalhado. A distribuição de tamanho das partículas é então calculada com base no tempo decorrido de sedimentação e na diminuição da intensidade da luz do feixe usando a teoria de Mie.

Como mencionado anteriormente, o fluido gradiente é necessário para garantir que as partículas da amostra sedimentem conforme previsto pela lei de Stokes. A amostra é composta por um grande número de partículas em solução. Se um fluido homogêneo for usado (como por exemplo água), as partículas sedimentarão rapidamente, se comportando como um fluido de alta densidade e não como partículas individuais suspensas em um fluido de menor densidade, conforme descrito pela lei de Stokes. Nesse caso, não há uma relação clara entre o tamanho da nanopartículas e a velocidade de sedimentação. Esse fenômeno é conhecido como streaming.

O gradiente de densidade evita esse efeito, uma vez que as camadas sucessivamente mais densas sob as partículas durante a sedimentação tornam o processo mais estável, possibilitando a aplicação da lei de Stokes. 


\section{Condições experimentais}

Neste capítulo são descritas as condições experimentais dos métodos de caracterização e rotas de síntese utilizadas neste trabalho.

\subsection{Síntese de nanopartículas de prata}

A rota de síntese de nanopartículas de prata a seguir é descrita em detalhes no artigo de Banerjee et al. (2014).

Inicialmente, $16 \mathrm{~g}$ de glicose e $8 \mathrm{~g}$ de PVP foram dissolvidos em $320 \mathrm{~mL}$ de água deionizada. Essa solução foi aquecida a $90{ }^{\circ} \mathrm{C}$ e mantida em agitação magnética. Em seguida, $4 \mathrm{~g}$ de nitrato de prata foram dissolvidos em $8 \mathrm{~mL}$ de água deionizada e esta solução foi adicionada à primeira solução. A velocidade de agitação foi então aumentada.

Em seguida, alíquotas dessa solução foram retiradas e imediatamente resfriadas com gelo para interromper a evolução das nanopartículas. Essas alíquotas foram centrifugadas a 29400 g por 30 minutos e redispersas em água desionizada três vezes.

De acordo com Wang et al. (2005), as reações que ocorrem durante esta síntese são as reações descritas nas equações 21 e 22 .

Para as amostras de nanopartículas de prata sintetizadas durante o estágio do autor da tese na universidade de Duisburg-Essen, o PVP foi adquirido da Sigma Aldrich ${ }^{\circledR}$, o nitrato de prata da Carl-Roth ${ }^{\circledR}$ e a glicose da Fluka ${ }^{\circledR}$. A água ultra-pura foi obtida pelo instrumento ELGA Purelab ${ }^{\circledR}$.

Todos os produtos químicos utilizados na síntese realizada no IFUSP foram adquiridos da Sigma Aldrich e a água ultra-pura obtida pelo sistema Milli-Q ${ }^{\circledR}$. A figura 18 mostra o diagrama esquemático da síntese. 


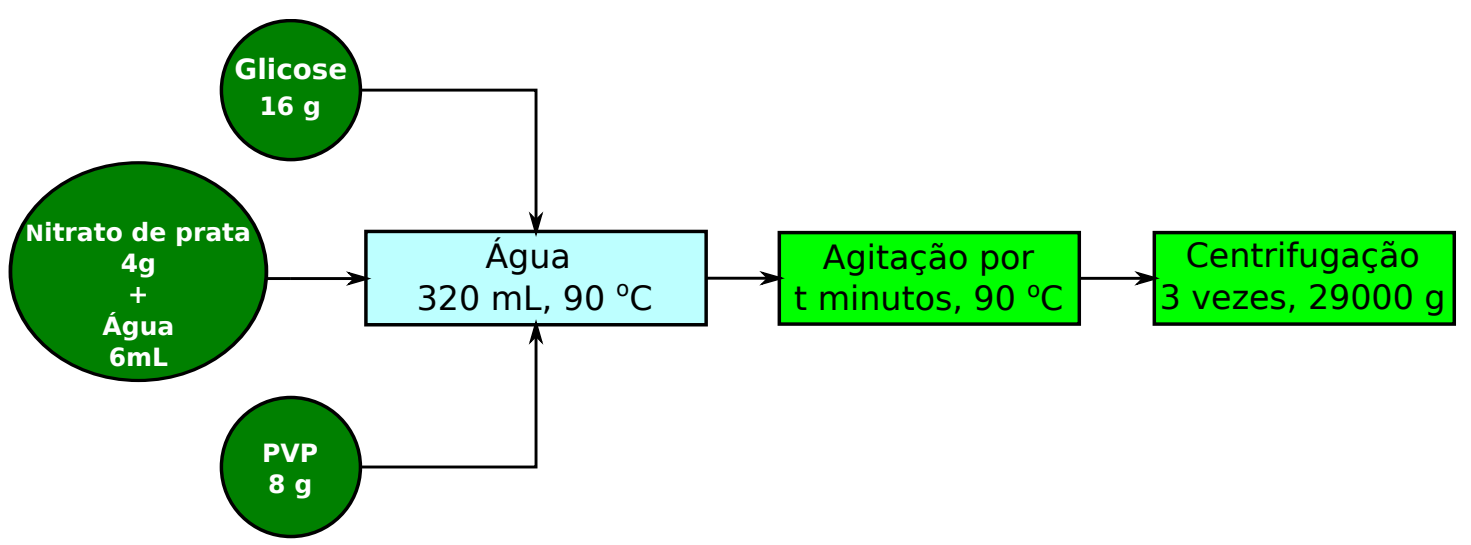

Figura 18 - Diagrama esquemático da síntese de nanopartículas de prata. Neste diagrama, $t$ é o tempo de reação.

\subsection{Síntese de nanopartículas de ouro-prata}

Para a síntese das nanopartículas de ouro-prata, $300 \mathrm{~mL}$ de água ultra pura foram aquecidos a cerca de $70{ }^{\circ} \mathrm{C}$. Em seguida, nitrato de prata $(1,5 \mathrm{~mL} ; 10 \mathrm{mM} ; 15 \mu \mathrm{mol})$ e cloreto de ouro (III) trihidratado $(1,5 \mathrm{~mL} ; 10 \mathrm{mM} ; 15 \mu \mathrm{mol})$ foram adicionados e a mistura foi submetida à agitação magnética vigorosa. Na sequência, uma solução aquosa de citrato trissódico dihidratado $(3 \mathrm{~mL} ; 58 \mathrm{mM} ; 174 \mu \mathrm{mol})$ foi rapidamente adicionada, iniciando as reações de formação das nanopartículas. A composição molar prata:ouro é $\mathrm{Ag}: \mathrm{Au}=50: 50$. A figura 19 mostra um diagrama desta síntese.

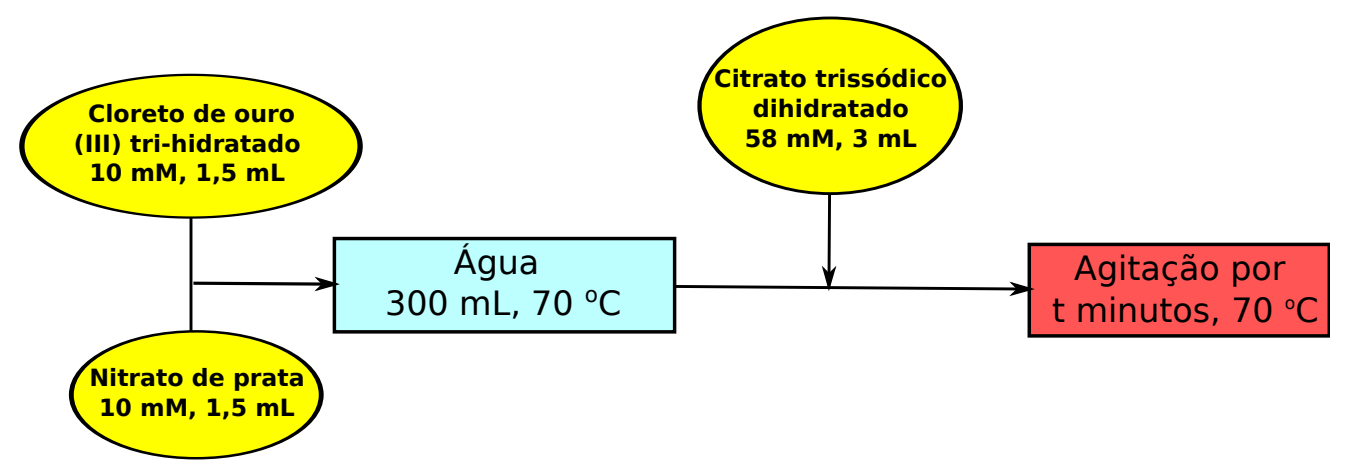

Figura 19 - Diagrama esquemático da síntese de nanopartículas de ouro e prata. Neste diagrama, $t$ é o tempo de reação. 


\subsection{Síntese de nanopartículas de paládio-ouro}

As nanopartículas núcleo-casca de paládio-ouro sintetizadas neste trabalho são descritas na publicação de Rostek et al. (2018). Para o experimento in situ, a síntese foi realizada em duas etapas. Primeiro, os núcleos de paládio foram formados e caracterizados, depois o precursor de ouro foi adicionado e medidas foram realizadas durante a formação da casca. Essa síntese foi realizada pela pesquisadora da Universidade de Duisburg-Essen Dr. Kateryna Loza em um laboratório do Grupo de Fluidos Complexos.

\section{Formação das sementes de paládio}

Os núcleos, também chamados de sementes, de paládio foram preparados misturandose $600 \mathrm{mg}(3 \mathrm{mM})$ de glicose e $50 \mathrm{mg}(0,125 \mu \mathrm{mol})$ de PVP em $50 \mathrm{~mL}$ de água deionizada. A solução foi aquecida a cerca de $70{ }^{\circ} \mathrm{C}$. Em seguida, foram adicionados $5 \mathrm{~mL}$ de solução aquosa de $\mathrm{PdCl}_{2}$ e a mistura de reação foi agitada por 1 hora.

\section{Formação das cascas de ouro}

Para a formação das cascas de ouro, $5 \mathrm{~mL}$ de $\mathrm{HAuCl}_{4}(0,05 \mathrm{mmol} \mathrm{Au})$ foram rapidamente adicionados e a mistura foi mantida sob agitação magnética por mais 50 minutos. Um diagrama esquemático dessa rota de síntese é exibido na figura 20 . 


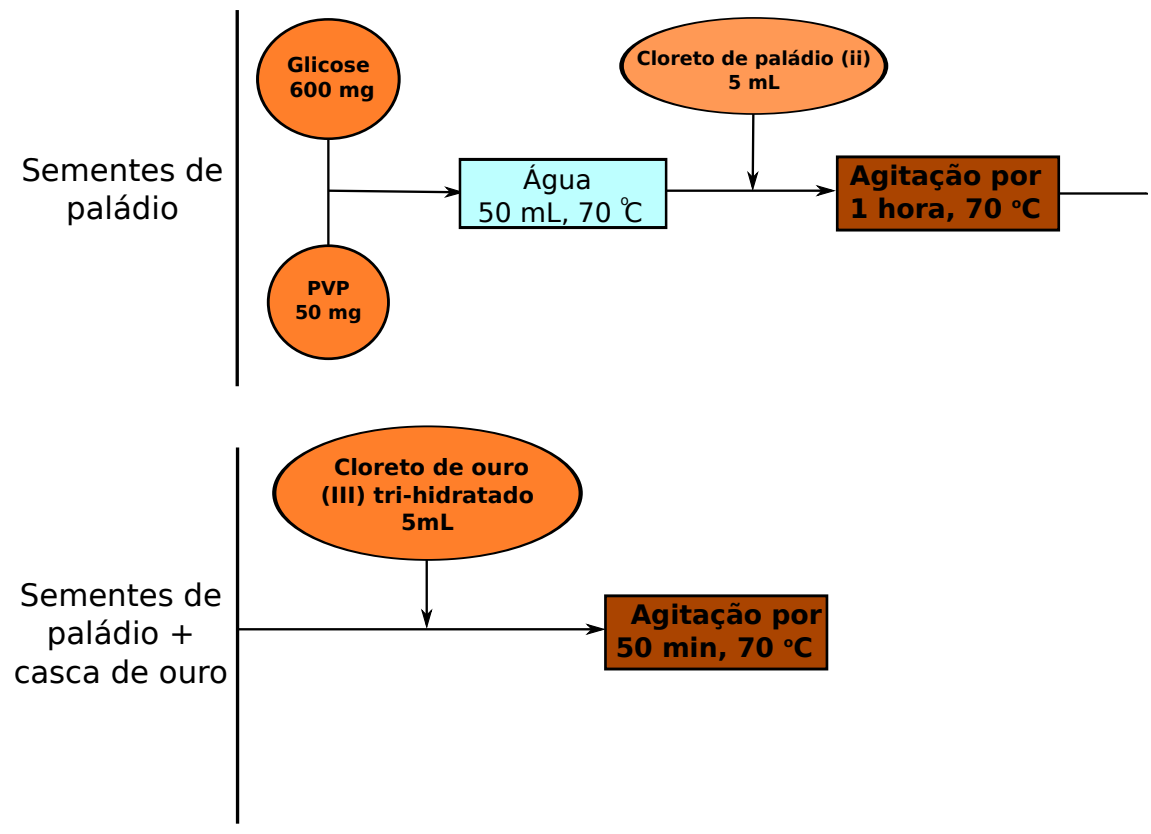

Figura 20 - Diagrama esquemático da síntese de nanopartículas de paládio-ouro.

\subsection{Síntese de nanobastões de ouro}

A síntese dos nanobastões de ouro investigados neste trabalho é descrita na publicação de Morasso et al. (2015). Essa síntese é realizada em duas etapas: a síntese das sementes de ouro e a preparação da solução de crescimento. A síntese foi realizada pelo autor desta tese e pelo pesquisador Dr. Wagner Wlysses.

Para a preparação das sementes, uma solução aquosa de brometo de cetiltrimetilamônio (cetrimonium bromide, CTAB) foi preparada (200 mM). Esta solução foi mantida em banho de ultrassom a $40{ }^{\circ} \mathrm{C}$ para garantir a dissolução completa do CTAB. Em seguida, $5 \mathrm{~mL}$ dessa solução foram misturados com $5 \mathrm{~mL}$ de $0,5 \mathrm{mM}$ de $\mathrm{HAuCl}_{4}$ a uma temperatura constante de $27^{\circ} \mathrm{C}$. A mistura foi mantida em agitação usando barras magnética. Em seguida, $600 \mu \mathrm{L}$ de $\mathrm{NaBH}_{4}(10 \mathrm{mM})$, previamente dissolvido em água a $4{ }^{\circ} \mathrm{C}$, foram adicionados à mistura e mantidos sob agitação vigorosa por 20 minutos.

A preparação da solução de crescimento foi iniciada com a adição de $220 \mathrm{mg}$ de hidroquinona em $50 \mathrm{~mL}$ de uma solução aquosa $50 \mathrm{mM}$ de CTAB a $40^{\circ} \mathrm{C}$. Essa solução foi mantida em banho de ultrassom e após a completa dissolução dos reagentes a temperatura foi reduzida para $27^{\circ} \mathrm{C}$. Em seguida, foram adicionados $2 \mathrm{~mL}$ de uma solução aquosa de $\mathrm{AgNO}_{3}(4 \mathrm{mM})$ e $50 \mathrm{~mL}$ de uma solução aquosa de $\mathrm{HAuCl}_{4}(1 \mathrm{mM})$ sob agitação 
magnética vigorosa. Imediatamente após essas adições, $120 \mu \mathrm{L}$ da solução de semente foram adicionados. Esta solução final foi mantida sob agitação vigorosa durante cerca de 1 hora.

As alíquotas coletadas durante o tempo de reação foram centrifugadas a 10000 rpm por 10 minutos e dispersas novamente em água. A figura 21 mostra um diagrama esquemático da síntese.
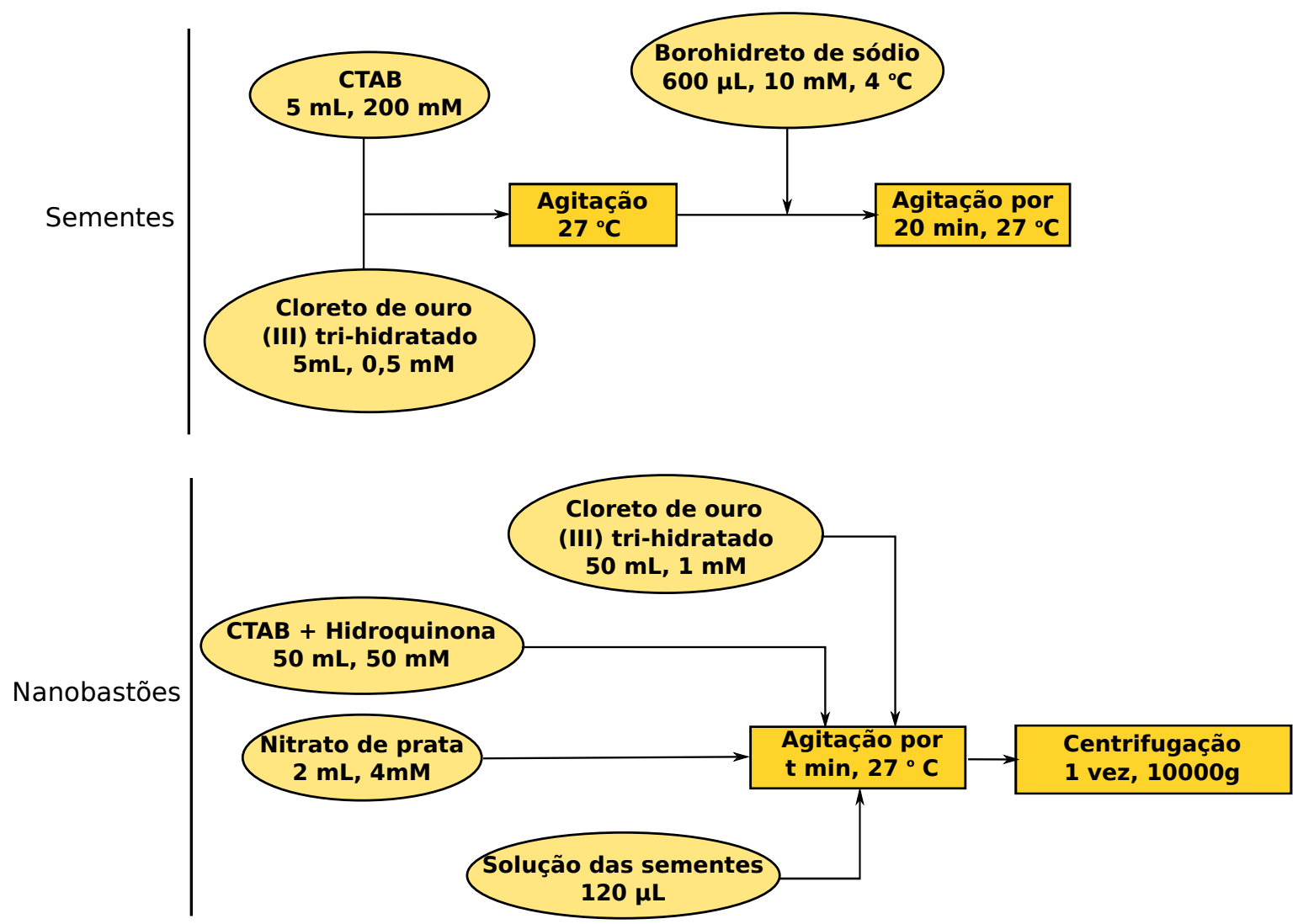

Figura 21 - Diagrama esquemático da síntese de nanobastões de ouro. Neste diagrama, $t$ é o tempo de reação.

\section{Síntese modificada}

Com o objetivo de tornar mais lento o processo de crescimento dos nanobastões, uma modificação da rota de síntese descrita na seção anterior foi implementada com sucesso. A modificação foi feita na solução de ouro preparada para a solução de crescimento, conforme descrito a seguir: 
A preparação da solução de crescimento começou com a adição de $220 \mathrm{mg}$ de hidroquinona em $50 \mathrm{~mL}$ de solução $50 \mathrm{mM}$ de CTAB a $40{ }^{\circ} \mathrm{C}$ em banho de ultrassom. Após a dissolução completa do CTAB, a temperatura foi reduzida para $27^{\circ} \mathrm{C}$.

Separadamente, $20 \mathrm{~mL}$ da solução de $\mathrm{HAuCl}_{4}(1 \mathrm{mM})$ foram misturados com $1 \mathrm{~mL}$ de CTAB. A solução mudou a cor de amarelo para laranja. Posteriormente, mais $30 \mathrm{~mL}$ da solução $\mathrm{HAuCl}_{4}$ foram adicionados a esta solução laranja. Em seguida, $2 \mathrm{~mL}$ da solução de $\mathrm{AgNO}_{3}(4 \mathrm{mM})$ e a solução de ouro alaranjada previamente preparada foram misturadas com 49 ml da solução de CTAB + hidroquinona sob agitação vigorosa. Imediatamente após, foram adicionados $120 \mu \mathrm{L}$ da solução de semente. Esta solução final foi mantida sob agitação vigorosa durante um tempo longo. Um diagrama esquemático dessa síntese é mostrado na figura 22.

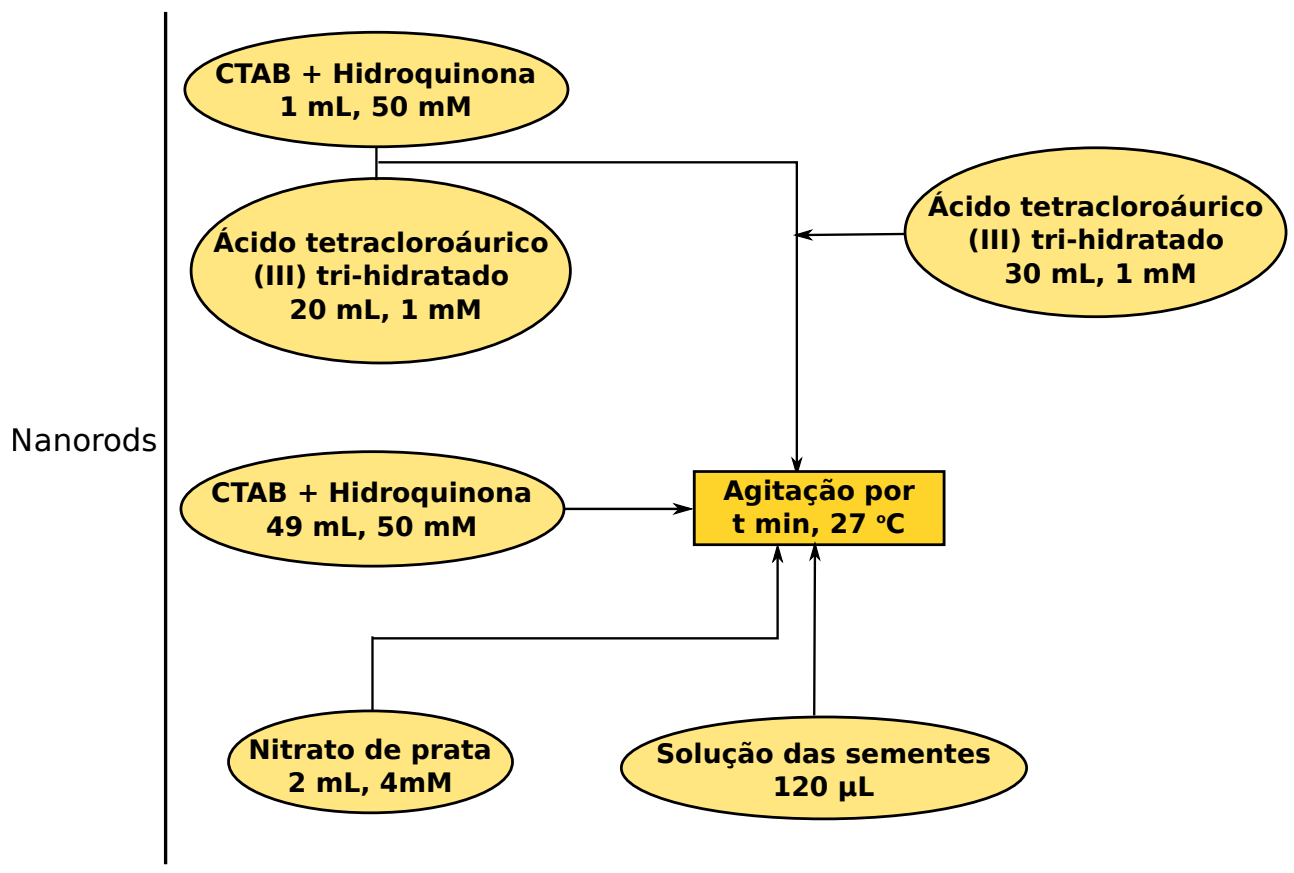

Figura 22 - Diagrama esquemático da síntese modificada de nanobastões de ouro. Neste diagrama, $t$ é o tempo de reação.

\subsection{SAXS e WAXS}

No IFUSP existem três equipamentos de SAXS em laboratório: Um Nanostar ${ }^{\circledR}$ Bruker e dois Xeuss ${ }^{\circledR}$-Xenocs. A presença desses equipamentos, em conjunto com os pesquisadores e cientistas que atuam nestes temas, fazem do IFUSP uma referência em nível nacional e internacional. 
As medições de SAXS e WAXS foram realizadas usando um comprimento de onda de radiação na borda $\mathrm{Cu} \mathrm{K} \alpha, \lambda=1,54 \AA$. O módulo de transferência de momento do espaço recíproco $q=4 \pi \operatorname{sen} \theta / \lambda$ no qual $2 \theta$ é o ângulo de espalhamento. A distância amostra-detector foi de 0,169 m para as caracterizações realizadas por WAXS. Para as caracterizações por SAXS diferentes distâncias amostra-detector foram utilizadas.

\section{Nanostar}

Nanostar ${ }^{\circledR}$ possui uma fonte de alta intensidade Microfocus Genix3D ${ }^{\circledR}$ e um sistema de colimação de fendas scaterless slits. Esses acessórios proporcionaram um aumento de quarenta vezes no fluxo do feixe se comparado à configuração anterior (tubo convencional +3 pinholes para colimação). As fendas scaterless slits são motorizadas para que o alinhamento do sistema e o ajuste do tamanho do feixe sejam procedimentos automatizados. O equipamento possui um detector bidimensional a gás Vantec2000 ${ }^{\circledR}$ Bruker. Na configuração padrão (distância amostra-detector de 0,67 m) tem-se uma intensidade de $5 \times 10^{7}$ fotons $/ \mathrm{mm}^{2} / \mathrm{s}$. Uma foto do equipamento é mostrada na figura $23(\mathrm{a})$.

\section{Xeuss}

O equipamento de SAXS Xeuss ${ }^{\circledR}$ é complementar ao Nanostar ${ }^{\circledR}$ em vários aspectos, pois permite a fácil montagem dos acessórios em uma mesa óptica. Além disso, possui uma fonte microfoco e um sistema de colimação semelhante ao instalado no Nanostar, fornecendo o mesmo fluxo de fótons.

Este equipamento possui um detector bidimensional de estado sólido Pilatus ${ }^{\circledR} 300 \mathrm{k}$ para medições de SAXS. Recentemente, outros acessórios foram adquiridos, entre eles uma câmara de vácuo com um detector WAXS Pilatus ${ }^{\circledR} 100 \mathrm{k}$. Este laboratório é o primeiro no Brasil a ser capaz de realizar medições simultâneas SAXS-WAXS. A figura 23(b) mostra uma imagem desse equipamento. 


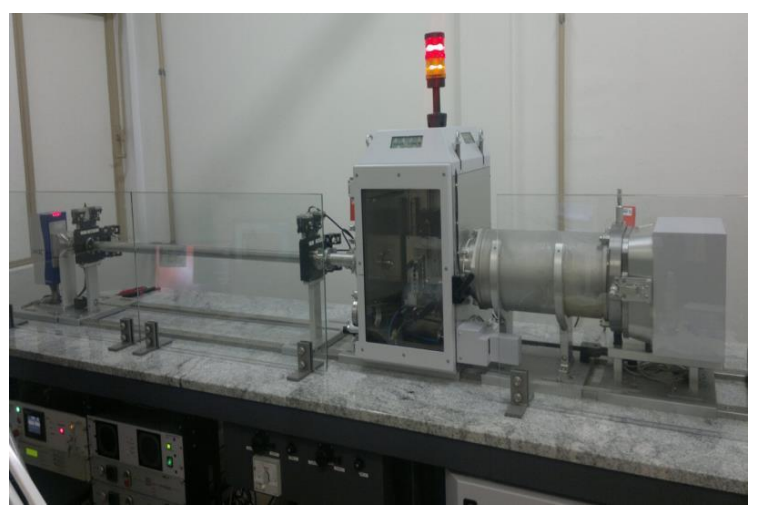

(a)

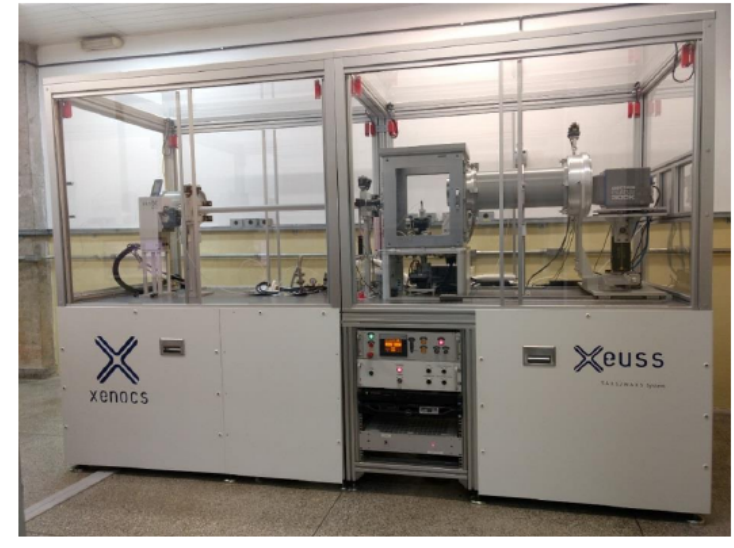

(b)

Figura 23 - (a) Nanostar ${ }^{\circledR}$ com a atualização do sistema de colimação da Xenocs e (b) Xenocs Xeuss ${ }^{\circledR}$.

\section{Xeuss 10m}

O equipamento Xeuss $10 \mathrm{~m}$ possui 3 fontes de raios $\mathrm{X}$ motorizada ( $\mathrm{Cu}, \mathrm{Mo}, \mathrm{Cr}$ ), um detector Pilatus $300 \mathrm{k}$ e ótica multicamada 2D de reflexão única. A distância amostradetector pode ser definida de 0,2 a 6,5 metros. Este equipamento pode atingir um grande número de intervalos de q podendo variar entre 0.001 a $6 \AA^{-1}$, praticamente, 4 ordens de grandeza. Os dois equipamentos de SAXS Xeuss compõem o Equipamento Multiusuário FAPESP (EMU), aberto a usuários para utilização. A página da web deste equipamento é https://portal.if.usp.br/emu. A figura 24 mostra uma imagem deste instrumento.

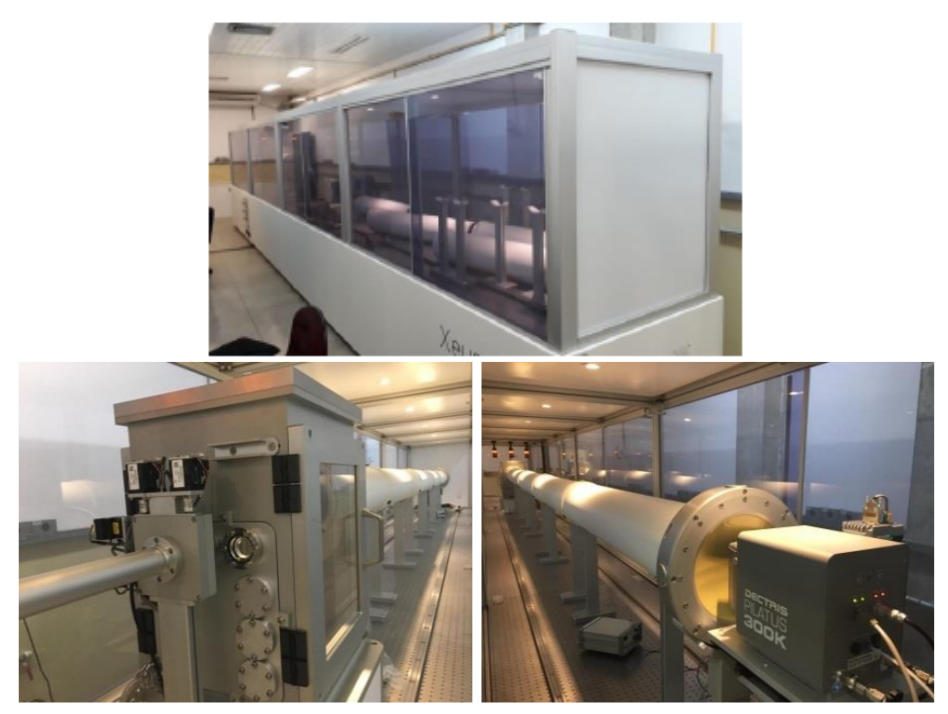

Figura 24 - Imagens do equipamento de SAXS Xeuss 10m. 


\section{Tratamento de dados de SAXS/WAXS}

O tratamento dos dados de SAXS e WAXS foi realizado usando o software SuperSAXS, escrito por Oliveira et al. (2009). Após a integração da imagem de espalhamento, o fundo foi descontado subtraindo-se uma medida do capilar preenchido com água para as amostras da solução, duas folhas de mica ou kapton para as amostras de pó. Medidas de carvão vítreo foram utilizadas para a correção do espalhamento residual do beam-stopper nos dados de SAXS. Em alguns casos, os dados foram normalizados para escala absoluta usando água como padrão. A equação usada para o tratamento dos dados é (OLIVEIRA, 2011):

$$
I_{\text {Treated }}(q)=\left[\frac{I_{s}(q)}{\Phi_{s} T_{s} t_{s}}-\frac{I_{b}(q)}{\Phi_{b} T_{b} t_{b}}-\frac{I_{n}(q)}{t_{n}\left(\Phi_{s} T_{s}-\Phi_{b} T_{b}\right)}\right] \frac{1}{I_{s h}(q)} \frac{d \Sigma / d \Omega_{\text {water }, 20^{\circ} C}}{I(0)_{\text {water }, 20^{\circ} \mathrm{C}}}
$$

o subscrito $s$ refere-se à amostra, $b$ ao fundo, $n$ ao ruído, $s h$ à sombra do beam-stopper e $d \Sigma / d \Omega_{\text {water }}=0,01632 \mathrm{~cm}^{-1}$ é a seção de choque de espalhamento teórica da água a $20{ }^{\circ} \mathrm{C}$.

O alargamento dos picos de difração nos dados WAXS devido à configuração experimental do equipamento Xeuss foi determinada através de uma medida de corundum $\left(\mathrm{Al}_{2} \mathrm{O}_{3}\right)$. Como o tamanho do domínio do corundum é conhecido, é possível determinar o alargamento instrumental. A figura 25 mostra a análise desta amostra.

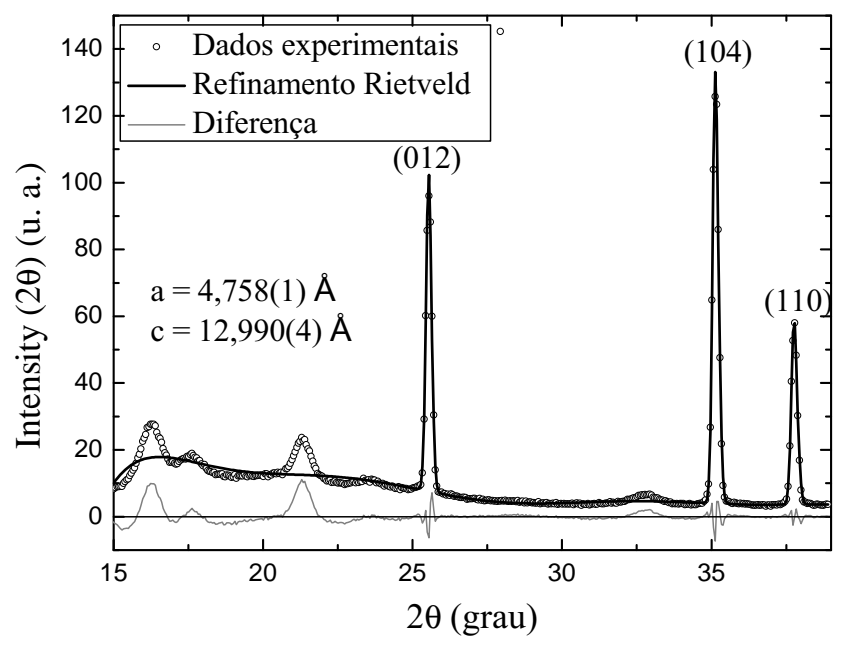

Figura 25 - Dados de WAXS do corundum e indexação dos picos de difração.

A partir desta análise, foi determinado que o fator de alargamento da largura à meia altura é FWHM =0,241 ${ }^{\circ}$. Esse valor é consideravelmente maior que os valores geralmente 
obtidos usando difratômetros padrão $\left(\approx<0.1^{\circ}\right)$. Por outro lado, o equipamento é capaz de realizar medições de SAXS e WAXS simultaneamente.

Uma vez conhecido o fator de alargamento, a largura relacionada ao domínio cristalino $\Delta$ pode ser determinado:

$$
\Delta=\sqrt{\Delta_{e x p}^{2}-F W H M^{2}}
$$

$\Delta_{e x p}$ é a largura do pico medida experimentalmente.

O procedimento de determinação do alargamento dos picos de difração nos dados de WAXS descrito nessa seção foi realizado pelo pesquisador da Universidade de DuisburgEssen Dr. Oleg Prymak.

\subsection{Caracterizações por SAXS realizadas no Laboratório Nacional de Luz Síncotron (LNLS)}

O experimento in situ reportado na seção 8.5 foi realizado na linha de luz SAXS1 do Laboratório Nacional de Luz Síncotron (LNLS). O porta amostras é composto por uma célula com dimensões $1 \times 4 \times 8 \mathrm{~mm}^{3}$ e duas janelas de mica (CAVALCANTI et al., 2004). O comprimento de onda da radiação foi de $\lambda=1,48 \AA$. A distância amostra-detector foi ajustada em 3,2 m, fornecendo um intervalo de q de 0,039 a 1,4987 $\mathrm{nm}^{-1}$. Os dados de espalhamento 2D foram coletados em um detector Pilatus 300k (Dectris, Baden, Suíça). A figura 26 mostra imagens do aparelho in situ, descrito na seção 7.7, utilizado nos experimentos realizados no LNLS. 


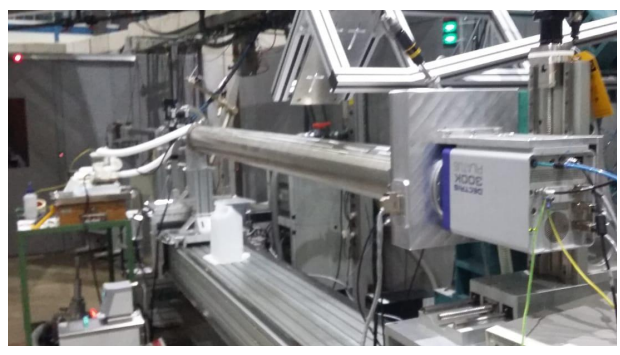

(a)

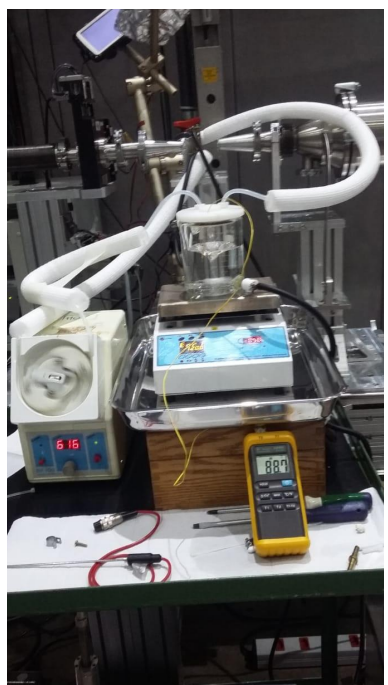

(b)

Figura 26 - Imagens do aparato experimental utilizado no experimento in situ realizado no LNLS.

\subsection{Aparato in situ de SAXS}

As experiências in situ foram realizadas usando um reator de vidro de parede dupla (cujo volume é de cerca de $500 \mathrm{~mL}$ ). Esse reator possui uma tampa de PTFE com conexões para os tubos de entrada e saída para circulação de amostra. A temperatura de síntese no reator e no suporte da amostra foi mantida por um banho de óleo de silicone em circulação. O porta amostra usado consiste em um capilar de quartzo colado em uma camisa de aço inoxidável conectada aos tubos de entrada e saída de amostra. A solução de reação, sob agitação vigorosa usando barras magnéticas no reator, foi bombeada continuamente para o suporte da amostra por uma bomba peristáltica. Os tubos que transportam a amostra foram isolados termicamente e o volume total dentro desses tubos era de cerca de $20 \mathrm{~mL}$.

Em todos os experimentos in situ, as medidas de SAXS começaram logo após a adição do último reagente, quando a formação das nanopartículas tem início. As imagens bidimensionais de espalhamento foram obtidas em intervalos de 1 minuto. 


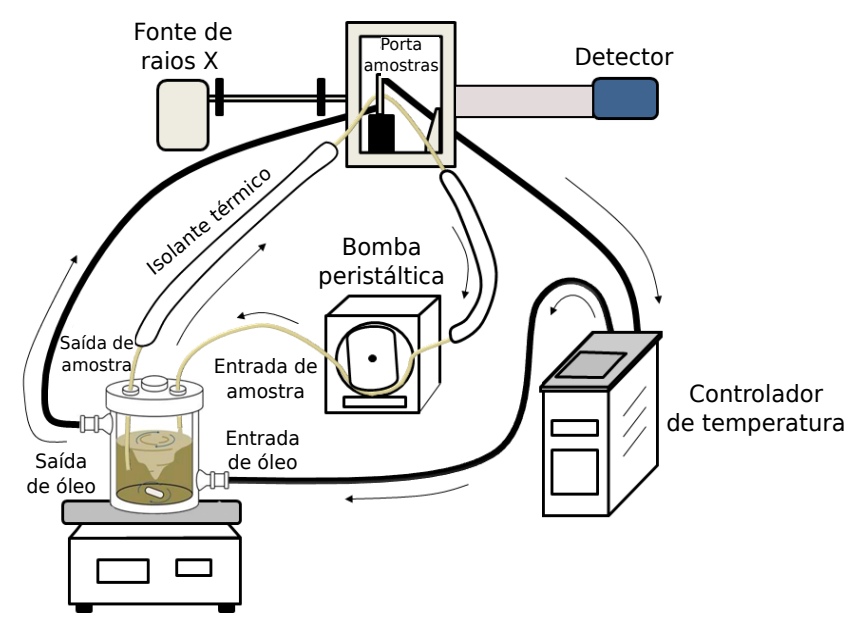

(a)

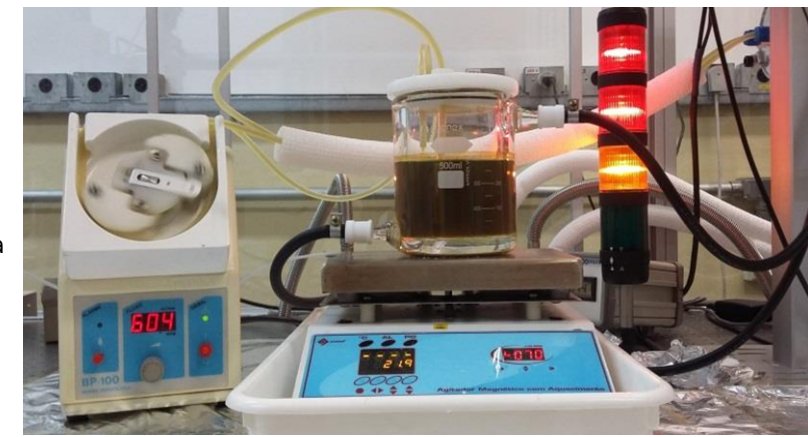

(b)

Figura 27 - (a) Diagrama esquemático e (b) imagem do aparato in situ.

\section{Atualização do aparato in situ}

A figura 28 mostra as imagens do aparelho in situ na configuração atual. No entanto, o estado atual desse conjunto é resultado de diversas melhorias realizadas durante o projeto de doutorado.

No início, a amostra estudada era sintetizada em um béquer de vidro borossilicato de $500 \mathrm{ml}$, colocado em um recipiente de vidro Pyrex ${ }^{\circledR}$ com óleo de banho térmico aquecido por uma placa térmica. Nesta configuração inicial, o béquer era coberto com um vidro de relógio.

Algumas experiências foram realizadas usando essa configuração e percebemos que era necessário um melhor controle de temperatura. Foi então que três reatores de vidro de parede dupla foram adquiridos para substituir o béquer. Tampas específicas feitas de Teflon foram projetadas para esses reatores. A figura mostra as representações do aparato in situ antes e depois dessas modificações. 


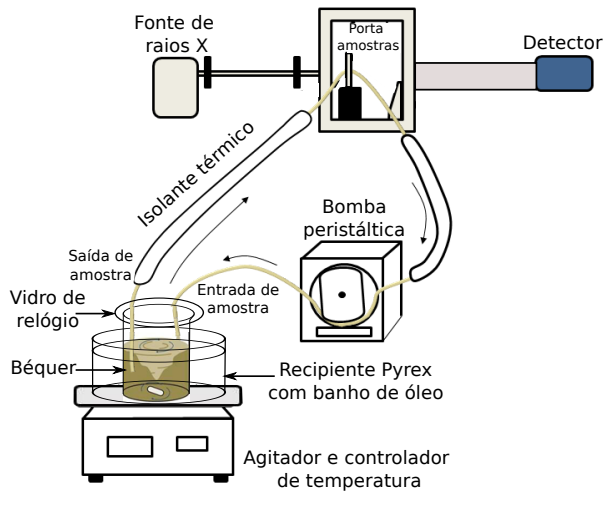

(a)

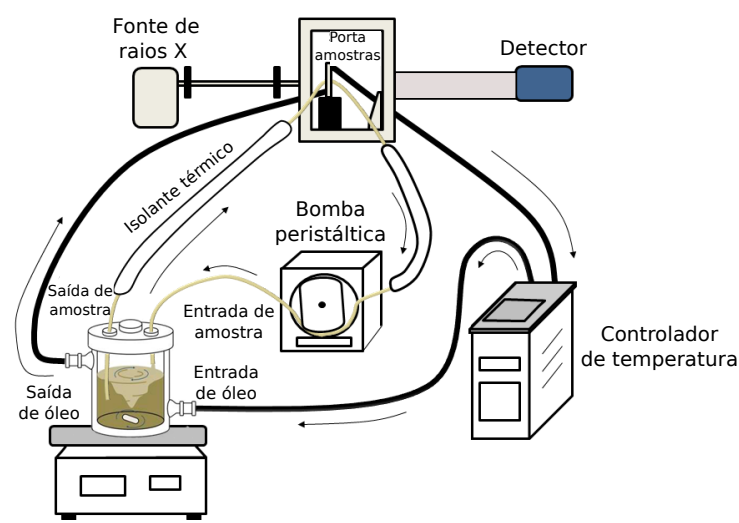

(b)

Figura 28 - O aparato in situ (a) antes e (b) depois da atualização.

O reator de paredes duplas proporcionou um melhor isolamento térmico da solução de reação. As conexões dos tubos de entrada e saída do reator de vidro permitiram o uso de um aquecedor julabo ao invés de uma placa térmica para a manutenção da temperatura. Essa mudança representou um grande avanço pois o aquecedor julabo é capaz de manter a temperatura de síntese de maneira mais eficiente que a placa térmica utilizada configuração anterior. O mesmo é válido para as tampas de Teflon, que proporcionaram uma melhor vedação do recipiente da amostra durante a reação.

\subsection{DLS}

Para as caracterizações por DLS, foi utilizado um equipamento Brookhaven NanoBrook 90Plus particle size analyzer. As medidas foram realizadas em temperatura ambiente $\left(\approx 24^{\circ} \mathrm{C}\right)$ com ângulo de espalhamento de 90 graus. O comprimento de onda nominal do laser é $640 \mathrm{~nm}$. As amostras foram solubilizadas em cerca de $1 \mathrm{~mL}$ de água e colocadas em uma cubeta de plástico. Uma imagem do equipamento, situado no IFUSP, é mostrada na figura 29 . 


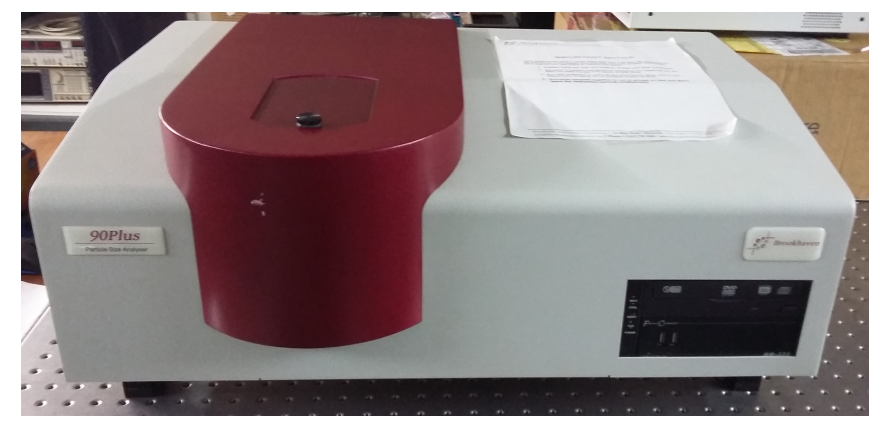

Figura 29 - Imagem do equipamento de DLS NanoBrook 90Plus.

\subsection{Difração de raios $\mathrm{X}$}

As caracterizações por XRD foram realizadas usando um difratômetro Bruker D8 Advance situado na Universidade de Duisburg-Essen. Este equipamento utiliza radiação $\mathrm{Cu} \mathrm{K \alpha}(\lambda=1,54 \AA ; 40 \mathrm{kV} ; 40 \mathrm{~mA})$ e geometria de Bragg-Brentano. As amostras foram secas em um monocristal de silício para minimizar o espalhamento e caracterizadas até um ângulo máximo de 90 graus com passo de 0,003 graus por um intervalo de tempo de 6 segundos cada. A análise das fases foi realizada no software Diffrac Suite EVA V1.2 (Bruker). O software TOPAS 4.2 (Bruker) foi utilizado para o refinamento de Rietveld. Os dados do ICDD Ag (\#04- 0783) e AgCl (\#31-1238) foram utilizados para descrever os padrões de prata e cloreto de prata, respectivamente.

Todos os dados de XRD reportados neste trabalho foram coletados e analisados pelo pesquisador Dr. Oleg Prymak.

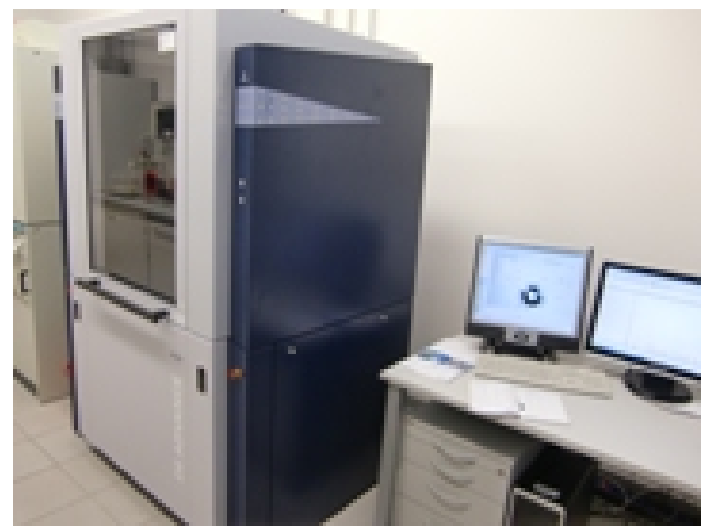

Figura 30 - Imagem do equipamento de XRD Bruker D8 Advance. Fonte: (UNIVERSITY OF DUISBURG-ESSEN, 2019). 


\subsection{Espectroscopia no ultravioleta e visível}

As caracterizações por espectroscopia no ultravioleta e visível foram realizadas usando um espectrômetro Ocean Optics USB400 e uma fonte de luz Mikropack DH-2000BAL. Os dados foram coletados para comprimentos de onda variando de 178 a $893 \mathrm{~nm}$. As amostras foram dispersas em $1 \mathrm{~mL}$ de água em cubetas de plástico. Este equipamento, situado no IFUSP, é mostrado na figura 31.

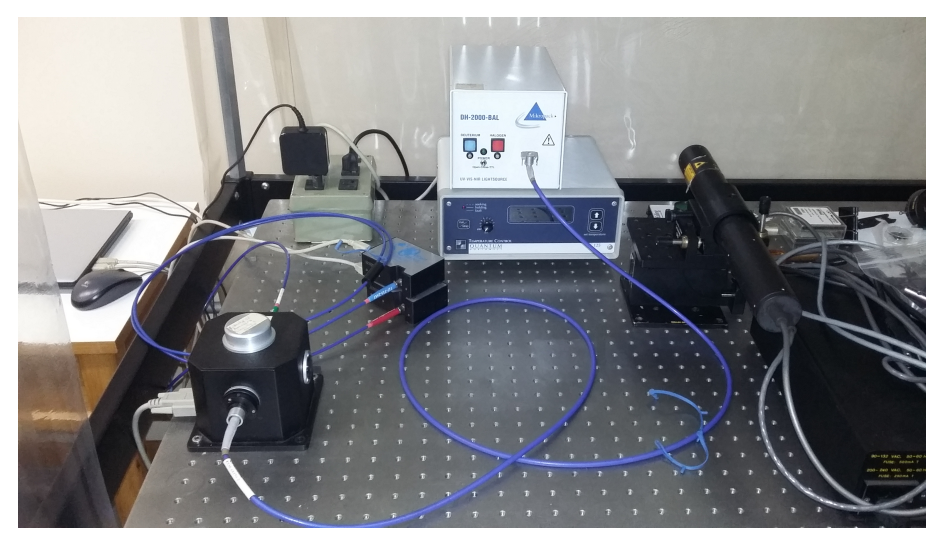

Figura 31 - Imagem do equipamento de espectroscopia Uv-vis.

\subsection{TEM}

Algumas imagens de TEM apresentadas neste trabalho foram obtidas pela Dra. Larissa Otubo, do Instituto de Pesquisas Energéticas e Nucleares (IPEN), usando um instrumento JEOL 2100 operando a $200 \mathrm{kV}$. Este equipamento possui um filamento de hexaboreto de lantâneo $\mathrm{LaB}_{6}$, uma peça polar de alta resolução (HR) e um sistema de espectroscopia de raios X por energia dispersiva (EDS) (detector Thermo EDS). Algumas gotículas da amostra, previamente dispersa em água, foram colocadas em uma grade de cobre com filme de colódio revestido com carbono. Uma foto deste equipamento é mostrado na figura 32. 


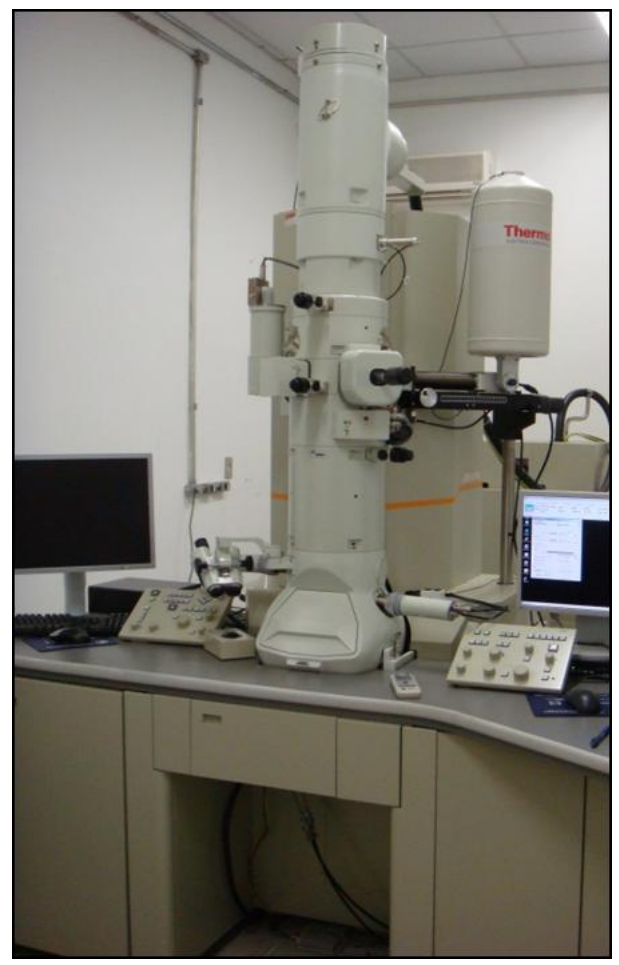

Figura 32 - Imagem do microscópio eletrônico JEOL 2100. Fonte: (IPEN - INSTITUTO DE PESQUISAS ENERGÉTICAS E NUCLEARES, 2019).

\subsection{DCS}

As caracterizações por sedimentação centrífuga diferencial foram realizadas em uma centrífuga de disco DC 24000 da CPS Instruments, situada na Universidade de Duisburg-Essen. A velocidade de rotação foi de $24000 \mathrm{rpm}$. O gradiente de densidade, composto por duas soluções de sacarose ( $8 \%$ em peso e $24 \%$ em peso), foi coberto com 0,5 mL de dodecano para estabilizar a solução gradiente. Poli (cloreto de vinil) (PVC), fornecido pela CPS Instruments ${ }^{\circledR}$, foi utilizado como padrão para a calibração. O volume de amostra utilizado para as medidas foi cerca de $100 \mu \mathrm{L}$. Uma imagem desse equipamento e mostrado na figura 33. As curvas de distribuição de diâmetros foram calculadas pelo mesmo programa da CPS Instruments responsável pela operação do equipamento. 


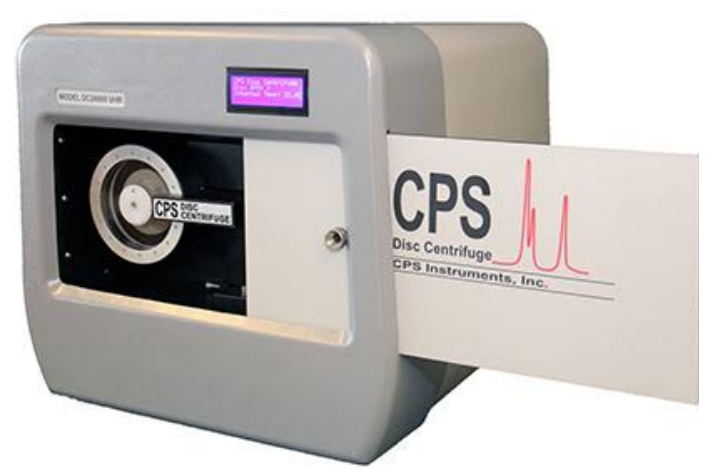

Figura 33 - Imagem centrífuga de disco DC 24000 . Fonte: (CPS INSTRUMENTS EUROPE, 2019).

\subsection{Programas de análise desenvolvidos durante o projeto}

Durante o desenvolvimento deste projeto de doutorado, alguns programas de análise foram desenvolvidos para a implementação dos métodos de modelagem utilizados nas análises estruturais realizadas.

\section{Rexpace}

O programa Rexpace, baseado em outro programa escrito em FORTRAN ${ }^{\circledR}$, fornecido pelo orientador desta tese, foi escrito em $\mathrm{C}++$ para o sistema operacional Linux.

Este programa usa o método de mínimos quadrados não-linear Levenberg-Marquardt, descrito em detalhes no capítulo 2, e a plataforma gráfica Gnuplot ${ }^{\circledR}$ (WILLIAMS; KELLEY; many others, 2010) para a realização dos gráficos. Qualquer modelo pode ser facilmente implementado ou alterado no código fonte.

Este programa é usado para a modelagem dos fatores de forma e estrutura, método esse descrito em detalhes na seção 6.1.3. Uma imagem do menu é mostrada na figura 34: 


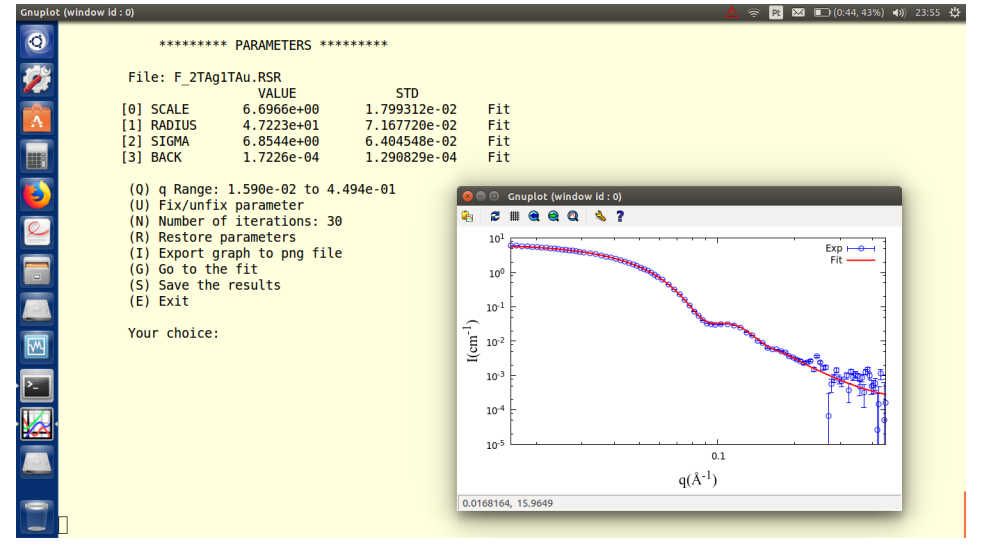

Figura 34 - Imagem do menu do programa Rexpace.

A equação da intensidade de espalhamento teórica usada para modelar a maioria dos dados é escrita como:

$$
I(q)=S c\left[\int_{0}^{\infty} V^{2} P(q, R) D(R,\langle R\rangle, \sigma) d R\right] S_{G}\left(q, S c^{G}, R G\right) S_{H S}\left(q, \eta, R_{H S}\right)+B
$$

onde $S c$ é o fator de escala, $V$ é o volume da nanopartícula, $P(q, R)$ é o fator de forma, $D(R,\langle R\rangle, \sigma)$ é a função de distribuição de raios Schulz-Zimm e $B$ é uma constante que descreve o fundo. Os parâmetros deste modelo são detalhados no capítulo 6 .

Para a modelagem dos dados da nanopartículas de prata e ouro-prata a equação 77 foi usada considerando-se um fator de forma de esferas, escrito na tabela 2. Já para os dados das amostras de CTAB um fator de forma de elipsoides de revolução núcleo-casca foi considerado:

$$
I_{m i c}(q)=S c_{m i c}\left[\int_{0}^{\infty} P_{m i c}\left(q, R_{c}, R_{s}, \epsilon\right) D\left(R_{c},\left\langle R_{c}\right\rangle, \sigma_{c}\right) d R_{c}\right] S_{H S}\left(q, \eta, R_{H S}\right)+B
$$

onde $R_{c}$ é o raio do núcleo, $R_{s}$ é o raio da casca, $\epsilon$ é a excentricidade e $P_{m i c}\left(q, R_{c}, R_{s}, \epsilon\right)$ é o fator de forma dos elipsoides núcleo-casca:

$$
P_{m i c}\left(q, R_{c}, R_{s}, \epsilon\right)=\int_{0}^{\pi / 2} F_{C S}\left[q, r\left(R_{c}, R_{s}, \epsilon, \alpha\right)\right]^{2} \sin \alpha d \alpha
$$

onde $r(R, \epsilon, \alpha)=R\left(\sin ^{2} \alpha+\epsilon^{2} \cos ^{2} \alpha\right)^{1 / 2}$ e $F_{C S}\left[q, r\left(R_{c}, R_{s}, \epsilon, \alpha\right)\right]$ é dado por:

$$
F_{C S}\left[q, r\left(R_{c}, R_{s}, \epsilon, \alpha\right)\right]=\frac{1}{M}\left[V\left(R_{c}\right) F_{s p h}\left(q, R_{c}\right)+\left(\frac{\Delta \rho_{c s}}{\Delta \rho_{c}}\right) V\left(R_{s}\right) F_{s p h}\left(q, R_{c s}\right)\right]
$$


$F_{s p h}\left(q, R_{c}\right)$ é o módulo da amplitude de espalhamento de esferas, $V(R)$ é o volume da esfera, $\Delta \rho_{c s}$ é o contraste de densidade eletrônica entre o núcleo e a casca, $\Delta \rho_{c}$ é contraste de densidade eletrônica do núcleo e $M=V\left(R_{c}\right)+\left(\Delta \rho_{c s} / \Delta \rho_{c}\right) V\left(R_{s}\right)$ é a massa de espalhamento.

Os dados de SAXS de algumas amostras de nanobastões de ouro analisados na seção 8.7 carregam informações sobre as micelas de CTAB presentes na solução. Portanto, o modelo usado considera que a intensidade de espalhamento teórica total é a soma da intensidade de espalhamento dos nanobastões de ouro com a intensidade de espalhamento das micelas de CTAB:

$$
\begin{aligned}
& I(q)=I_{c y l}(q)+I_{N I m i c}(q)+B \\
& =S c \int_{0}^{\infty} V^{2}(R, L) P_{c y l}(q, R, L) D(R,\langle R\rangle, \sigma) d R+I_{N I m i c}(q)+B
\end{aligned}
$$

onde $R$ é o raio, $L$ é o comprimento, $\sigma$ é a polidispersidade, $V(R, L)$ é o volume e $P_{c y l}(q, R, L)$ é o fator de forma dos cilindros (tabela 2). A intensidade de espalhamento das micelas não interagentes $I_{N I m i c}(q)$ é igual à equação 78 considerando $S_{H S}\left(q, \eta, R_{H S}\right)=1$ $\left[I_{N I m i c}(q)=I_{m i c}(q)\right.$ para $\left.S_{H S}\left(q, \eta, R_{H S}\right)=1\right]$.

\section{Programa de Monte Carlo}

Outro programa desenvolvido para a modelagem dos dados SAXS utiliza um método de Monte Carlo para a minimização do qui-quadrado. Nesta abordagem, a intensidade de espalhamento é descrita por uma equação discreta. Este programa também usa a plataforma gráfica Gnuplot ${ }^{\circledR}$. Para um sistema de N partículas espalhadoras esféricas, a intensidade de espalhamento é expressa como (PAUW et al., 2013):

$$
I(q)=S c\left(\frac{4 \pi}{3}\right)^{2} \sum_{i=1}^{N}\left|F_{s p h}\left(q R_{i}\right)\right|^{2} R_{i}^{(6-p c)}+B
$$

$S c$ é o fator de escala, $F_{s p h}\left(q R_{i}\right)$ é o módulo da amplitude de espalhamento de esferas, $R$ é o raio, $B$ é o fundo e $p c$ é um parâmetro de estabilização.

A distribuição de esferas que resulta no melhor ajuste dos dados experimentais é encontrada por tentativa e erro. Inicialmente, um conjunto de $\mathrm{N}$ partículas com raios $\boldsymbol{R}=\left\{R_{1}, R_{2}, \cdots, R_{N}\right\}$ é gerado. Então, um raio $R_{i}$ é escolhido aleatoriamente e seu valor é alterado para um novo valor aleatório dentro de um intervalo de valores determinado. 
Em seguida, as constantes $S c$ e $B$ que fornecem o melhor ajuste para o novo conjunto $\boldsymbol{R}$ são calculadas usando o método de mínimos quadrados linear. Então, a intensidade de espalhamento (equação 82) é recalculada e a qualidade do ajuste é avaliada. Se a qualidade do ajuste for melhor, o novo $R_{i}$ será aceito. Se houver piora na qualidade do ajuste, a alteração será rejeitada e $R_{i}$ será retornado para o valor anterior. Este processo é repetido até que a distribuição de raios das $\mathrm{N}$ partículas que satisfaça um determinado critério de convergência seja alcançado. A figura 35 mostra um fluxograma do algoritmo.

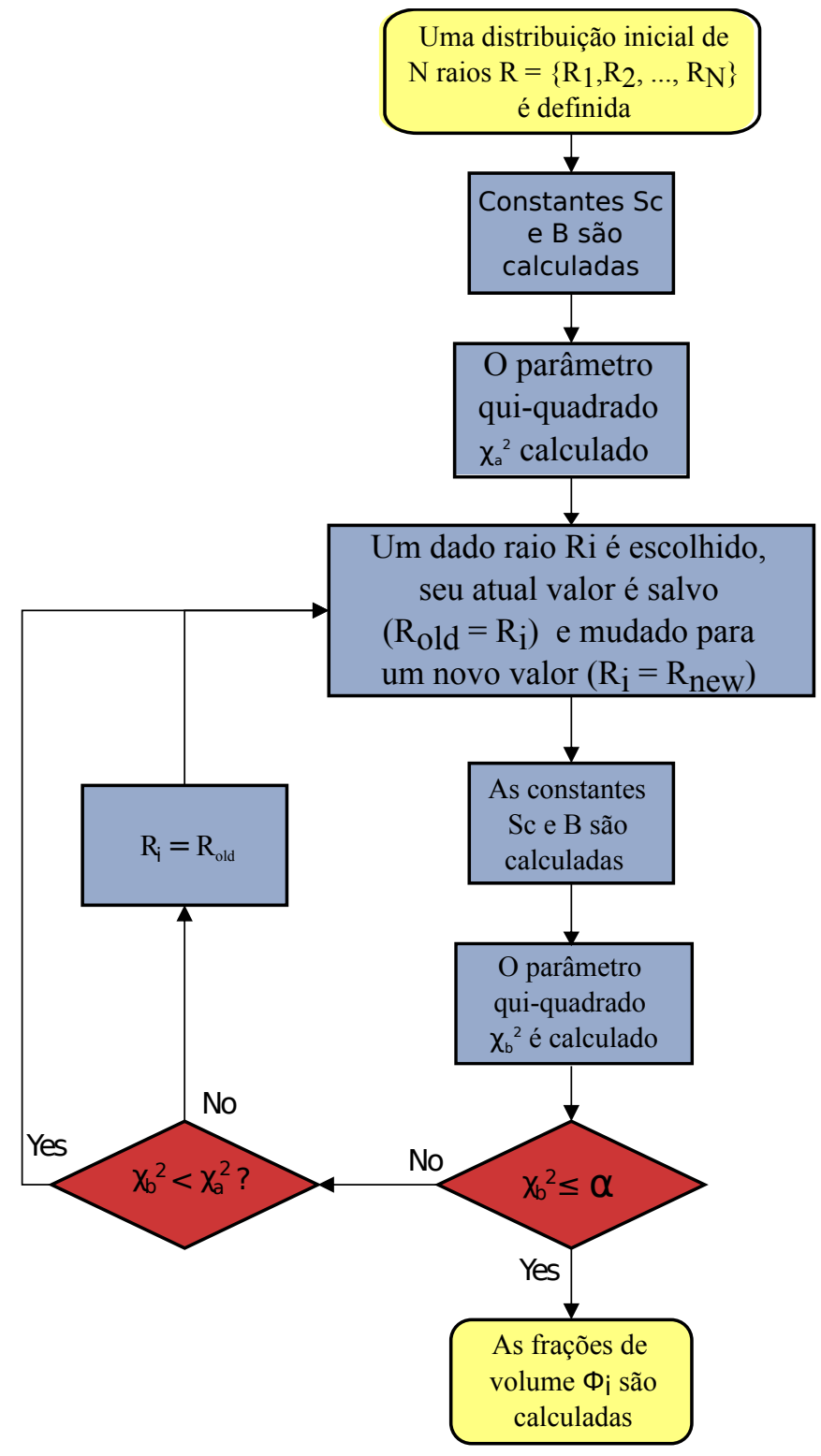

Figura 35 - Fluxograma do algoritmo do método de Monte Carlo utilizado na modelagem dos dados de SAXS. Nesta figura, $\alpha$ é o critério de convergência. 
A contribuição de fração de volume parcial de cada esfera com raio $R_{i}, \phi_{i}$ é (PAUW et al., 2013):

$$
\phi_{i}=S c \frac{4 \pi}{3} \frac{R_{i}^{\left(3-p_{c}\right)}}{\Delta \rho^{2}}
$$

Para calcular as incertezas estatísticas na distribuição de raios, são gerados cem distribuições de raios $\left(R_{i}, \phi_{i}\right)$. A distribuição final de raios é a média dessas cem distribuições.

Um exemplo de histograma de distribuição de raio calculado usando este método pode ser visto na figura 55 .

Uma vez que o histograma da distribuição de raios pesado por volume é obtida, a distribuição pesada por número pode ser calculada dividindo-se o valor da altura de cada barra da distribuição pesada por volume $V_{i}$ pelo cubo do raio correspondente $\left(V_{i} /\left(\frac{4 \pi}{3} R_{i}^{3} \pi\right)\right.$.

\subsection{Colaboração com pesquisadores da Universidade de Duisburg- Essen}

No início de 2015, foi estabelecida a colaboração do Prof. Dr. Cristiano L. P. Oliveira com pesquisadores do departamento de Química Inorgânica da Universidade de Duisburg-Essen (UDE). O grupo liderado por Matthias Epple desenvolve pesquisas em síntese e funcionalização de nanopartículas inorgânicas, síntese e caracterização de nanopartículas bimetálicas, aplicação de biomateriais, entre outras.

Dois projetos relacionados a esta colaboração foram aprovados. Um foi financiado pela Fundação Amparo a Pesquisa do Estado de São Paulo (FAPESP). Este projeto permitiu a visita do Dr. Prymak ao Instituto de Física de São Paulo (IFUSP) por um período de 15 dias para estabelecer o início da colaboração científica. O outro é um projeto CAPES-DAAD (2015-2018) que financiou visitas científicas de professores e alunos de ambos os grupos.

O grupo do Prof. Epple tem uma vasta experiência em síntese de nanopartículas e análise de difração de raios X, enquanto o grupo do Prof. Oliveira tem uma vasta experiência em métodos de caracterização usando técnicas de espalhamento. Os principais objetivos desta parceria são adquirir conhecimentos sobre o mecanismo de formação de nanopartículas e rotas de síntese, desenvolvimento de metodologias de modelagem de dados para as nanopartículas estudadas e correlação entre diferentes técnicas de caracterização. Realizei um estágio no grupo do Prof. Epple de 1 de novembro de 2016 a 31 de outubro 
de 2017. Por um período de um ano, adquiri experiência nos métodos de síntese de nanopartículas metálicas e análise de dados. Os resultados mais importantes obtidos durante o estágio são apresentados nesta tese.

A primeira participação do autor desta tese em trabalhos relacionados a esta colaboração foi a análise SAXS e WAXS de várias amostras de nanopartículas de metal sintetizadas em Essen por estudantes do grupo alemão. Entre 2015 e 2018 dois estudantes da UDE visitaram o IFUSP, pelo menos uma vez a cada ano, por períodos de 1 a 2 semanas. Várias experiências foram realizadas durante essas visitas.

Entre os experimentos realizados estão experimentos SAXS in situ com nanopartículas de prata, ouro-prata e paládio-ouro. Uma dessas experiências foi realizada no LNLS. 


\section{Resultados e discussão}

Neste capítulo são apresentados os principais estudos realizados durante este doutorado. Os estudos consistem em análises estruturais realizadas de sistemas de nanopartículas de prata, ouro e paládio. Parte das sínteses, caracterizações e análise de dados foi realizada na Universidade de Duisburg-Essen, durante o estágio do autor desta tese no Grupo do Prof. Dr. Matthias Epple. Outra parte foi realizada nos laboratórios do Grupo de Fluidos Complexos. Como mencionado anteriormente, algumas imagens de TEM mostradas nas seções a seguir foram produzidas no Instituto de Pesquisas Energéticas e Nucleares.

\subsection{Nanopartículas de diferentes formas e composições}

Esta seção apresenta uma investigação sistemática de sistemas de nanopartículas de prata e ouro-prata usando medidas simultâneas de SAXS/WAXS (SWAXS). Este estudo está dividido em duas partes: nanopartículas de prata com diferentes formas (bastões e discos) e nanopartículas globulares de ligas de ouro-prata com diferentes composições. Os resultados de SWAXS são correlacionados à dados de TEM e XRD.

A síntese das amostras e a coleta dos dados de TEM e XRD foram feitas pelo grupo alemão. Nossa participação neste estudo consistiu na coleta, tratamento e análise dos dados de SWAXS. Os resultados obtidos foram publicados no artigo de Garcia et al. (2019). Os dados de SWAXS foram coletados usando o equipamento Xeuss, descrito na seção 7.5. A distância amostra-detector das medidas de SAXS foi de 0,7 m.

\section{Bastões e discos}

A modelagem dos dados de SAXS forneceu informações sobre o comprimento e raio médio dos sistemas de nanopartículas. Os nanobastões de prata foram modelados como um sistema polidisperso de cilindros longos [equação 77 com fator de forma de cilindros longos e $\left.S_{H S}\left(q, \eta, R_{H S}\right)=S_{G}\left(q, S c^{G}, R G\right)=1\right]$. Os dados dos nanodiscos de prata foram modelados assumindo um sistema polidisperso de cilindros curtos com seção transversal elíptica [equação 77 com fator de forma dos cilindros elípticos e $S_{H S}\left(q, \eta, R_{H S}\right)=$ $\left.S_{G}\left(q, S c^{G}, R G\right)=1\right]$. Os dados de SWAXS e as imagens de TEM dessas nanopartículas são mostrados nas figuras 36 e 37, respectivamente. 

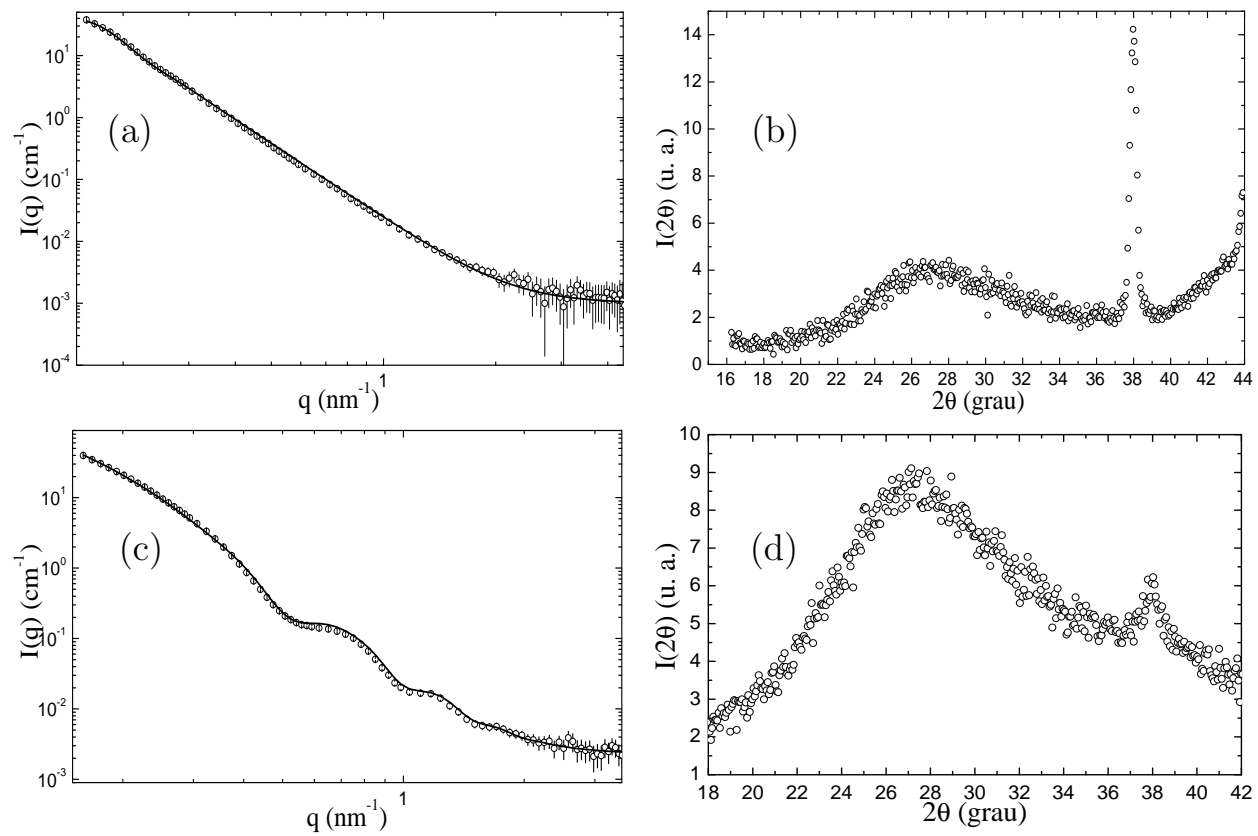

Figura 36 - Dados de SAXS dos (a) nanobastões e (c) nanodiscos de prata, dados de WAXS dos (b) nanobastões e (d) nanodiscos de prata. Fonte: Adaptado de Garcia et al. (2019).
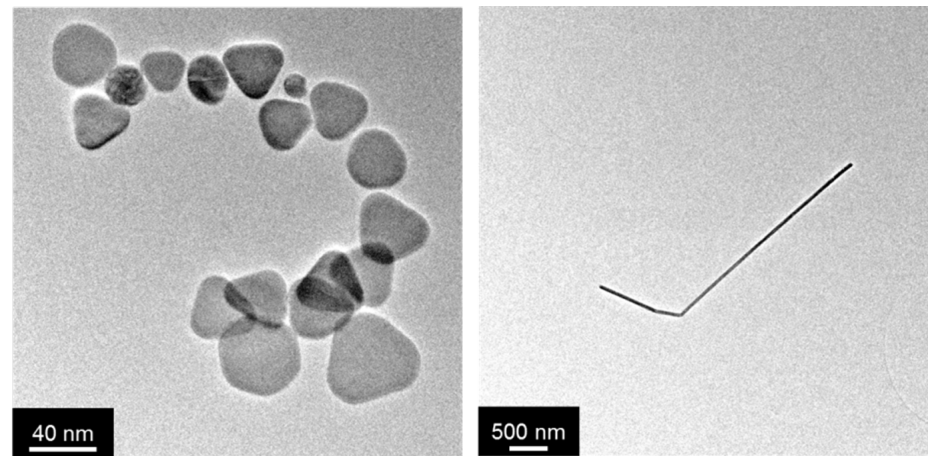

Figura 37 - Imagens de TEM dos (esquerda) nanodiscos e (direita) nanobastões de prata. Fonte: Garcia et al. (2019).

A tabela 3 mostra todos os parâmetros dos modelos teóricos de SAXS aplicados. Como pode ser visto, o raio médio determinado por SAXS está em bom acordo com o tamanho médio obtido pelas imagens TEM para ambas as amostras. A modelagem do comprimento $(\mathrm{L})$ e raio $(\mathrm{R})$ médio é difícil para os nanobastões, uma vez que os comprimento típico dessas nanopartículas, evidenciado pela imagem de TEM, é muito maior que a resolução máxima das caracterizações por SAXS $\left(D_{\max }=\pi / q_{\min } \approx 20 \mathrm{~nm}\right)$. O raio médio, por sua vez, tem um valor pouco maior que a resolução máxima da técnica. 
Como consequência, o modelo teórico de espalhamento tem um grau relativamente alto de degenerescência em relação aos parâmetros $L$ e $R$. Por isso, o valor do parâmetro $L$ foi fixado para o valor obtido por TEM para a modelagem dos dados dos nanobastões.

Essa limitação não ocorre para a modelagem dos dados de SAXS dos discos de prata, cujas dimensões estão compreendidas no intervalo de tamanhos observados pela técnica, com exceção do eixo $A$. Para esta amostra, o comprimento do cilindro $L$ obtido por SAXS é comparável ao calculado por TEM. Curiosamente, esse valor está muito próximo ao tamanho de cristalito obtido por XRD e WAXS. Os dados do XRD e WAXS dessa amostra são comparáveis.

No entanto, não há acordo entre o tamanho de cristalito determinado por XRD e WAXS para os nanobastões. Essa diferença pode ser explicada pela influência de diferentes procedimentos de preparação de amostras nos dados experimentais, pois os dados de TEM e SAXS foram coletados utilizando-se diferentes lotes de amostras.

Tabela 3 - Parâmetros estruturais de amostras de nanobastões e nanoplaquetas de prata.

\begin{tabular}{|c|c|c|c|c|c|}
\hline \multirow{2}{*}{ Amostra } & \multicolumn{2}{|c|}{ SAXS } & TEM & WAXS & XRD \\
\hline & Fator de Forma & Parâmetros (nm) & \multicolumn{3}{|c|}{ Parâmetros (nm) } \\
\hline Nanobastões & Cilindros longos & $\begin{array}{c}\mathrm{R}=28,7(2) \\
\sigma_{R}=5,3(1) \\
\mathrm{L}=20.10^{3} \text { (Fixo) }\end{array}$ & $\begin{aligned} \mathrm{D} & =100(50) \\
\mathrm{L} & \approx 20.10^{3}\end{aligned}$ & $\begin{array}{c}\mathrm{d}=0,2369(2) \\
\mathrm{C}_{\mathrm{S}}=30(2)\end{array}$ & $\mathrm{C}_{\mathrm{S}}=117(2)$ \\
\hline Nanodiscos & Cilindros elípticos & $\begin{array}{c}\mathrm{A}=46(5) \\
\mathrm{B}=26(2) \\
\sigma_{A}=4(2) \\
\sigma_{B}=2(1) \\
\mathrm{L}=12,3(4)\end{array}$ & $\begin{array}{c}\mathrm{D}=40(20) \\
\mathrm{L}=16\end{array}$ & $\begin{array}{c}\mathrm{d}=0,2368(1) \\
\mathrm{C}_{\mathrm{S}}=12(2)\end{array}$ & $\mathrm{C}_{\mathrm{S}}=15(1)$ \\
\hline
\end{tabular}

$\mathrm{R}$ é o raio médio dos cilindros longos, $\sigma_{R}$ é a polidispersidade do raio, L é o comprimento médio dos cilindros, $\mathrm{D}$ é o diâmetro médio, d é a distância interplanar, $\mathrm{C}_{\mathrm{S}}$ é o tamanho de cristalito, A e B são os eixos médios dos cilindros elípticos e $\sigma_{A}$ e $\sigma_{B}$ são as polidispersidades dos eixos A e B, respectivamente.

\section{Nanoligas de ouro-prata}

Nesta seção a influência de diferentes proporções de ouro e prata nas características estruturais de sistemas de nanopartículas bimetálicas é investigada. Amostras em pó de nanoligas com diferentes proporções molares de precursores de ouro e prata foram 
sintetizadas e caracterizadas. Os resultados de SWAXS foram comparados aos resultados obtidos por DCS fornecidos pelo grupo alemão.

Os dados de SAXS foram modelados usando a equação 77 com o fator de forma de esferas. Em amostras em pó, as partículas estão muito mais próximas umas das outras se comparadas à amostras em solução. Assim, geralmente as posições das nanopartículas estão correlacionadas. Essa interação entre partículas foi descrita através do fator de estrutura de Percus-Yevick. Além disso, foi necessário incluir um termo para descrever o espalhamento de agregados usando o fator de estrutura Guinier ${ }^{1}$.

Os resultados de SAXS concordam satisfatoriamente com os resultados de DCS publicados na tabela 1 do artigo de Garcia et al. (2019). Curiosamente, o raio de interação $R_{H S}$ e as frações de volume de esferas rígidas $\eta$ das nanoligas de ouro e prata apresentam valores maiores se comparados com as amostras puras de prata e de ouro. Isso indica que as correlações espaciais entre as nanopartículas das nanoligas ouro-prata são maiores do que as correlações para amostras de apenas ouro e apenas prata. O maior valor do parâmetro $R_{H S}$ pode estar principalmente relacionado à maior polidispersidade das nanoligas. As curvas e os dados de SWAXS são mostrados na figura 38 e na tabela 4, respectivamente.

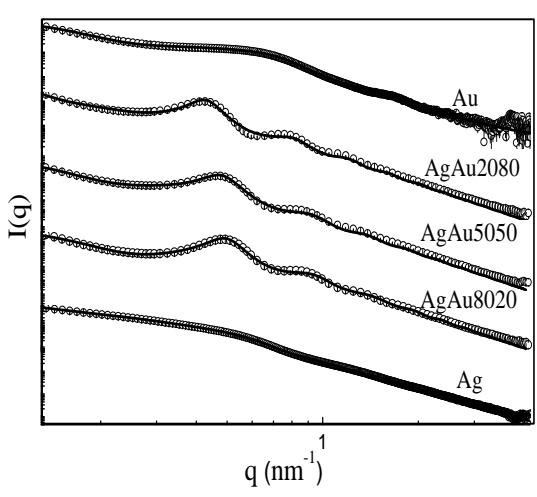

(a)

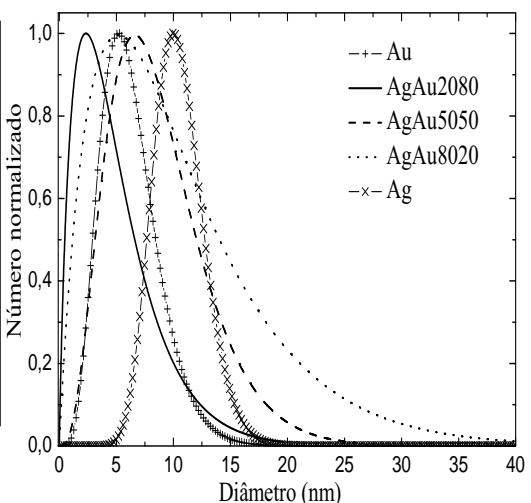

(b)

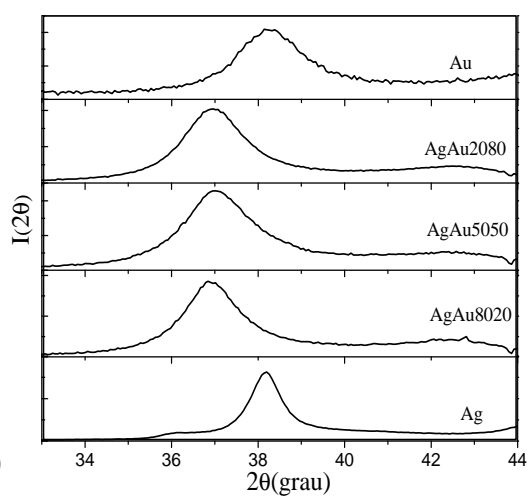

(c)

Figura 38 - Gráficos de SWAXS: (a) dados experimentais de SAXS e curva de ajuste, (b) distribuições de raios calculadas usando os dados SAXS e (c) dados experimentais de WAXS. Fonte: Adaptado de Garcia et al. (2019).

$\overline{1}$ Mais informações sobre fatores de estrutura podem ser encontradas na seção 6.1.3. 
Tabela 4 - Parâmetros estruturais de nanoligas de ouro-prata.

\begin{tabular}{|c|c|c|c|c|c|c|c|c|}
\hline \multirow[b]{2}{*}{ Amostra } & \multirow[b]{2}{*}{$\begin{array}{l}\text { Composição } \\
\text { Prata:Ouro }\end{array}$} & \multicolumn{5}{|c|}{ SAXS } & \multirow{2}{*}{$\frac{\text { WAXS }}{\text { C }_{\mathrm{S}}(\mathrm{nm})}$} & \multirow{2}{*}{$\frac{\text { DCS }}{\mathrm{D}(\mathrm{nm})}$} \\
\hline & & $\mathrm{R}(\mathrm{nm})$ & $\sigma(\mathrm{nm})$ & $\mathrm{R}_{\mathrm{G}}(\mathrm{nm})$ & $\mathrm{R}_{\mathrm{HS}}(\mathrm{nm})$ & $\eta$ & & \\
\hline $\mathrm{Au}$ & 0:100 & $3,1(1)$ & $1,3(3)$ & $14,1(11)$ & $4,1(3)$ & $0,21(5)$ & $4,4(6)$ & $7(1)$ \\
\hline $\mathrm{AgAu} 2080$ & $20: 80$ & $5,0(1)$ & $3,7(3)$ & $25(2)$ & $7,85(4)$ & $0,441(4)$ & $5,5(2)$ & $14(1)$ \\
\hline $\mathrm{AgAu} 5050$ & $50: 50$ & $4,4(2)$ & $2,1(1)$ & $16,2(5)$ & $6,84(5)$ & $0,409(3)$ & $4,4(1)$ & $11(2)$ \\
\hline $\mathrm{AgAu} 8020$ & $80: 20$ & $2,5(1)$ & $1,8(1)$ & $15,1(5)$ & $6,72(2)$ & $0,426(5)$ & $4,9(1)$ & $13(1)$ \\
\hline $\mathrm{Ag}$ & 100:0 & $5,0(5)$ & $1,1(2)$ & $\begin{array}{l}7,8(7) \\
19(4)\end{array}$ & $4,0(5)$ & $0,187(3)$ & $10(1)$ & - \\
\hline
\end{tabular}

$C_{S}$ é o tamanho de cristalito e $D$ é o diâmetro médio.

Os dados de WAXS revelaram tamanhos de cristalito de cerca de $5 \mathrm{~nm}$ para todas as amostras, exceto para amostra de prata pura, cujo tamanho de cristalito é $10 \mathrm{~nm}$. Os valores de $C_{S}$ são parecidos com os valores dos raios $(R)$, exceto para as amostras $\mathrm{Ag}$ e AgAu8020. Os tamanhos determinados por DCS são todos maiores que os tamanhos médios de cristalitos, o que é uma indicação de que as nanopartículas são policristalinas. A comparação entre os dados de SAXS e DCS revela uma boa concordância.

\section{Conclusões parciais}

Os dados adquiridos a partir de medições simultâneas SAXS e WAXS em equipamentos de laboratório de nanopartículas de prata e ouro com diferentes características forneceram informações úteis sobre os sistemas estudados, como revelou a comparação com dados de outras técnicas estruturais. Neste estudo, foram obtidas informações sobre polidispersidade, tamanhos, forma e grau de cristalinidade. Essas informações são cruciais para otimização e aplicação adicionais desses sistemas.

\subsection{Estudo ex situ de nanopartículas de prata}

Nesta seção é apresentado um estudo sobre a influência do tempo de reação de nanopartículas de prata na morfologia final. Os experimentos foram realizados durante o 
estágio do autor desta tese no Departamento de Química Inorgânica da Universidade de Duisburg-Essen, Alemanha, descrito na seção 7.14.

Para este estudo, nove amostras de nanopartículas de prata foram sintetizadas com diferentes tempos de reação. Essas amostras foram caracterizadas usando várias técnicas: SAXS, WAXS, DLS, DCS e espectroscopia Uv-vis. As medidas de SWAXS foram realizadas usando o equipamento Xeuss com distância amostra-detector para SAXS de 0,7 m. Na ocasião, as amostras foram trazidas ao IFUSP pelo Dr. Oleg Prymak durante missão científica.

O principal objetivo deste estudo foi a investigação da evolução temporal das características estruturais do sistema, bem como o aprendizado e possível otimização da rota de síntese utilizada.

As nanopartículas de prata foram preparadas seguindo a rota de síntese descrita na seção 7.1. Nove alíquotas de $8 \mathrm{~mL}$ foram coletadas com diferentes tempos de reação: Ag2, Ag10, Ag15, Ag19, Ag30, Ag35, Ag50, Ag120 e Ag210. O número nos nomes indica o tempo de reação em minutos (Ag2 é a alíquota coletada em 2 minutos de reação, Ag10 em 10 minutos e assim por diante). As alíquotas são mostradas na figura 39.

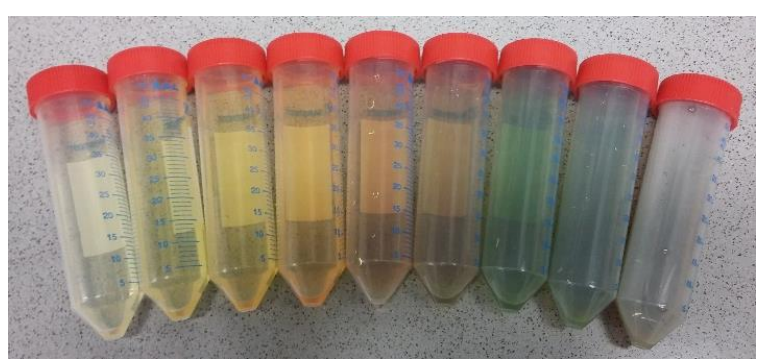

Figura 39 - Amostras de nanopartículas de prata (da esquerda para direita): Ag2, Ag10, Ag15, Ag19, Ag30, Ag35, Ag50, Ag120 e Ag210.

Uma característica importante vista nesta figura é o gradiente de cores exibido pelas amostras. Esse notável efeito de cor está relacionado aos efeitos de ressonância plasmônica na superfície das nanopartículas, caracterizada pelas curvas de absorbância mostradas na figura 40a, que varia de acordo com a evolução de tamanho médio das partículas.

As curvas de espectroscopia Uv-vis têm um pico de absorbância bastante pronunciado centrado em valores que variam de 401 a $425 \mathrm{~nm}$, isto é, as alíquotas absorvem comprimentos de onda de luz correspondentes ao violeta e azul. 
As alíquotas com tempo de reação até 35 minutos têm cores que variam de amarelo a laranja escuro. De fato, as curvas de absorbância dessas alíquotas têm baixa absorbância nos comprimentos de onda de 550 a $800 \mathrm{~nm}$, região que inclui cores como verde, amarelo e vermelho.

Interessantemente, a alíquota de 50 minutos é verde. A curva de absorbância desta amostra possui um vale cujo mínimo se situa no comprimento de onda de $540 \mathrm{~nm}$, que é a região correspondente ao verde no espectro visível. Esse vale é deslocado para maiores comprimentos de onda e se torna mais largo com o tempo de síntese, como observado para as amostras de 120 e 210 minutos. Como resultado, o intervalo de comprimentos de onda da radiação transmitida é aumentado, o que contribui para uma cor acinzentada. Além disso, todas as amostras exibem uma diminuição gradual em comprimentos de onda próximos a $400 \mathrm{~nm}$, causada pelo deslocamento do pico principal para comprimentos de onda maiores.

A tabela 5 mostra os valores de raio médio e polidispersidade calculados usando DCS, DLS e SAXS, bem como os valores de tamanho de cristal calculados por WAXS. Não foi possível coletar dados de DLS da amostra Ag2 e dados de DCS da amostra Ag15 devido à baixa concentração de nanopartículas, resultando em intensidade de espalhamento insuficiente. O raio médio das partículas determinado pelos dados do DCS aumentou de 4,5 para 17,5 nm com o tempo de reação. Esses valores estão de acordo com os resultados reportados na literatura (BANERJEE et al., 2014).

Para a análise dos dados SAXS foi utilizado um modelo de esferas polidispersas. Para as alíquotas coletadas até 35 minutos de tempo de reação foi necessário usar um modelo de SAXS bimodal. Conforme mostrado na equação 77, a intensidade de espalhamento é proporcional ao volume ao quadrado e, portanto, ao $\mathrm{R}^{6}$. Portanto, a intensidade de espalhamento de SAXS de alíquotas com tempo de reação maior que 35 minutos é dominada por partículas grandes, superando a intensidade de espalhamento devido à população de partículas pequenas, fazendo com que um modelo monomodal seja suficiente para descrever os dados SAXS dessas alíquotas.

Como pode ser visto na figura 40d, as intensidades de espalhamento integradas das amostras Ag2, Ag10 e Ag19 são muito baixas se comparadas às outras. Isso torna o processo de modelagem dos dados dessas alíquotas usando dois fatores de forma de esferas instável. Como alternativa, o fator de estrutura de Guinier (equação 49) foi utilizado para a descrição da intensidade de espalhamento da população de nanopartículas grandes. Isso 
tornou o procedimento de ajuste mais estável já que esse fator de estrutura descreve o espalhamento das nanopartículas grandes por meio de apenas dois parâmetros $\left(S c^{G}\right.$ e $\left.R G\right)$. O raio médio dessa população foi obtido através do raio de giro (equação 50).

Os dados de SAXS mostram que, já aos dois minutos, existem grandes partículas ou agregados presentes no sistema em um número relativamente pequeno ${ }^{2}$. O raio médio calculado por DCS dessas partículas é próximo ao raio médio da população de nanopartículas pequenas obtidas por SAXS. Isso mostra que a caracterização por DCS dessa amostra mostra informações principalmente das nanopartículas menores, o que indica que essas nanopartículas são muito mais numerosas que as nanopartículas grandes nesse estágio da síntese.

O raio hidrodinâmico médio $\left(R_{H}\right)$ calculado por DLS varia de 13 a $20 \mathrm{~nm}$ para tempos de reação de até 19 minutos. Esses resultados não são comparáveis aos obtidos pelas outras técnicas e nem estão de acordo com resultados reportados na literatura para esta amostra. Esta imprecisão dos resultados de DLS provavelmente está relacionada à baixa concentração de partículas dessas amostras e, consequentemente, a uma baixa estatística desses dados.

A figura 40c mostra as curvas WAXS de alíquotas a partir de 35 minutos. As curvas das alíquotas com reações de tempo de até 30 minutos não apresentam pico de difração no intervalo coberto pela técnica. Mas a partir de 35 minutos pode-se visualizar a formação de um pico em cerca de $2 \theta=37,7^{\circ}$. Esse pico de difração ocorre devido à reflexão dos planos (111) da estrutura cristalina da prata em uma rede FCC (BANERJEE et al., 2014). Essa reflexão não está visível no difratograma das outras amostras provavelmente devido à baixa concentração de partículas, produzindo intensidade devido à reflexão (111) insuficiente para a visualização do pico de difração.

A distância interplanar obtida para todas as amostras é $2,4 \AA$, o que significa que esse parâmetro é independente do tempo de reação. Os tamanhos dos domínios cristalinos exibem valores que variam de 10 a $14 \mathrm{~nm}$. O fato desses valores serem menores que os diâmetros médios sugere que as nanopartículas são policristalinas.

2 Comparado ao número total de partículas no sistema. 

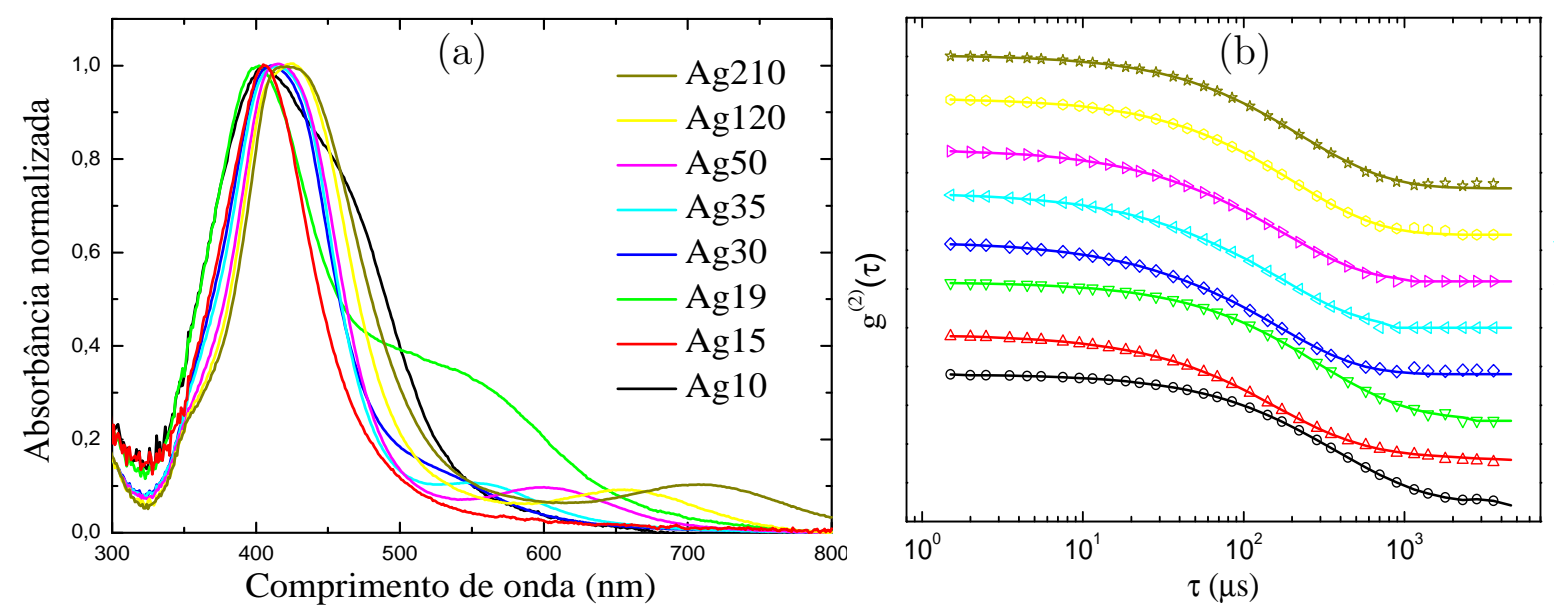

$\operatorname{Ag} 210$

Ag120

Ag50

Ag35

Ag30

Ag19

Ag15

- $\operatorname{Ag} 10$
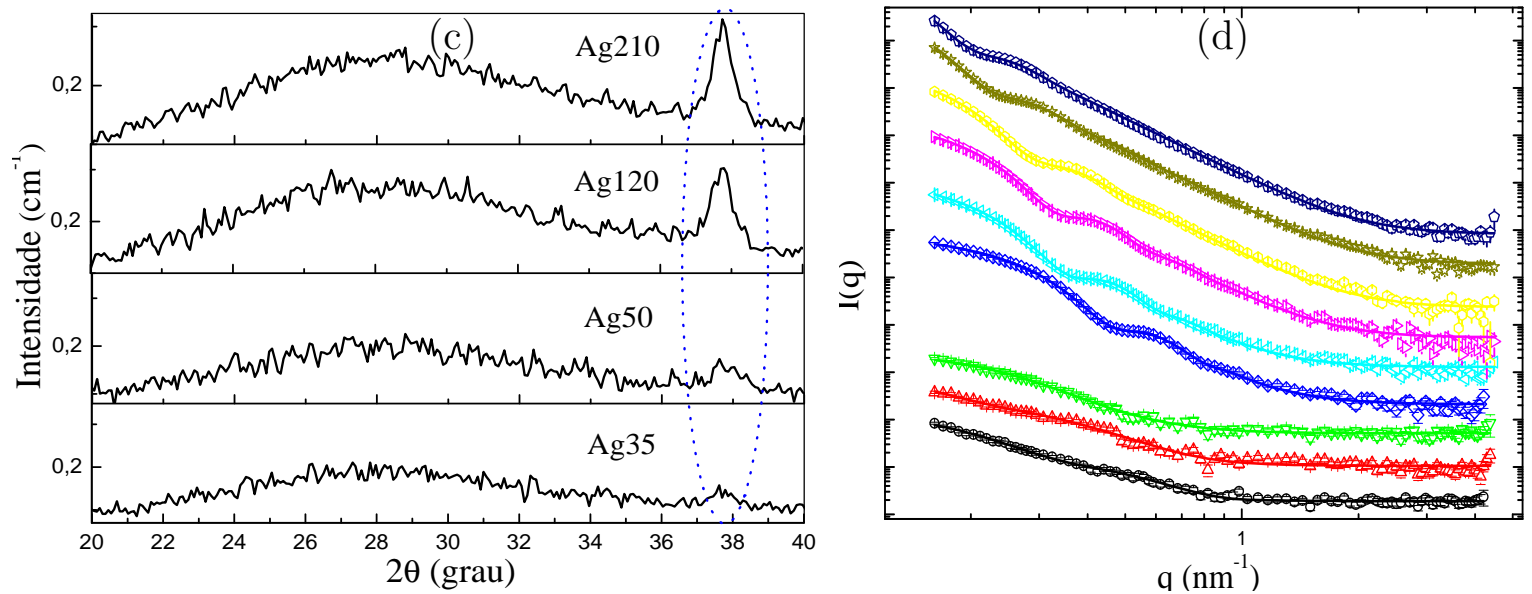

Ag210

Ag120

Ag50

Ag35

Ag30

Ag19

Ag15

Ag10

Ag2

Figura 40 - Caracterizações estruturais de alíquotas de nanopartículas de prata com diferentes tempos de reação: (a) espectroscopia Uv-vis (a absorbância está normalizada pelo valor máximo da curva), (b) DLS, (c) WAXS e (d) SAXS. 
Tabela 5 - Parâmetros estruturais de nanopartículas de prata sintetizadas com diferentes tempos de reação.

\begin{tabular}{|c|c|c|c|c|c|c|c|}
\hline \multirow{2}{*}{ Sample } & \multicolumn{2}{|c|}{ DCS } & \multicolumn{2}{|c|}{ DLS } & \multicolumn{2}{|c|}{ SAXS } & \multirow{2}{*}{$\frac{\text { WAXS }}{\mathrm{C}_{\mathrm{S}}(\mathrm{nm})}$} \\
\hline & $\mathrm{R}(\mathrm{nm})$ & $\sigma(\mathrm{nm})$ & $\mathrm{R}_{\mathrm{H}}(\mathrm{nm})$ & $\sigma(\mathrm{nm})$ & $\mathrm{R}(\mathrm{nm})$ & $\sigma(\mathrm{nm})$ & \\
\hline \multirow{2}{*}{ Ag2 } & \multirow{2}{*}{4,5} & \multirow{2}{*}{1,5} & \multirow{2}{*}{ - } & \multirow{2}{*}{ - } & $3,8(1)$ & $0,8($ fix $)$ & \multirow{2}{*}{-} \\
\hline & & & & & $12,96(4)$ & - & \\
\hline \multirow{2}{*}{ Ag10 } & \multirow{2}{*}{6,5} & \multirow{2}{*}{7,5} & \multirow{2}{*}{22} & \multirow{2}{*}{9} & $2,3(12)$ & $1,4($ fix $)$ & \\
\hline & & & & & 12,9 (fix) & - & \\
\hline \multirow{2}{*}{ Ag15 } & \multirow{2}{*}{ - } & \multirow{2}{*}{ - } & \multirow{2}{*}{13} & \multirow{2}{*}{4} & $1,1(5)$ & $1,2(\mathrm{fix})$ & \multirow{2}{*}{ - } \\
\hline & & & & & $9,3(5)$ & - & \\
\hline \multirow{2}{*}{ Ag19 } & \multirow{2}{*}{8,5} & \multirow{2}{*}{1,5} & \multirow{2}{*}{20} & \multirow{2}{*}{8} & $3,3(6)$ & $1,5(\mathrm{fix})$ & \multirow{2}{*}{ - } \\
\hline & & & & & $9,3(1)$ & $1,3(1)$ & \\
\hline \multirow{2}{*}{ Ag30 } & \multirow{2}{*}{9,5} & \multirow{2}{*}{1,0} & \multirow{2}{*}{3,1} & \multirow{2}{*}{0,7} & $2,3(6)$ & $5,0(1)$ & \multirow{2}{*}{ - } \\
\hline & & & & & $12,21(3)$ & $1,61(4)$ & \\
\hline \multirow{2}{*}{ Ag35 } & \multirow{2}{*}{10,0} & 15 & 2 & 08 & $4,8(5)$ & $3,5(2)$ & 12 \\
\hline & & 1,0 & 0,2 & 0,0 & $13,00(2)$ & $1,83(3)$ & $12(0)$ \\
\hline Ag50 & 12,0 & 1,5 & 4 & 1 & $14,34(2)$ & $2,67(4)$ & $10(2)$ \\
\hline Ag120 & 15,5 & 2,5 & 5 & 1 & $18,35(4)$ & $3,49(3)$ & $14(1)$ \\
\hline Ag210 & 17,5 & 3,0 & 9 & 3 & $20,7(1)$ & $4,01(5)$ & $14(1)$ \\
\hline
\end{tabular}

Todas as alíquotas possuem distância interplanar $d_{(111)}=2.38(2) \AA$ determinada pelos dados de WAXS.

Os dados de SAXS das amostras Ag2, Ag10, Ag15 e Ag19 foram modelados usando a equação 77 com $S_{H S}\left(q, \eta, R_{H S}\right)=1$. Nesses casos, o raio médio da população de partículas grandes foi calculado através do raio de giro RG (equação 50) assumindo que elas são esféricas.

Os dados de SAXS das amostras Ag30, Ag35, Ag50, Ag120 and Ag210 foram modelados usando a equação $77 \operatorname{com} S_{H S}\left(q, \eta, R_{H S}\right)=S_{G}\left(q, S c^{G}, R G\right)=1$ e dois fatores de forma de esferas.

\section{Conclusões parciais}

Uma investigação detalhada sobre nanopartículas de prata foi realizada. As análises revelaram que uma parte das amostras são compostas por duas populações de nanopartículas. Os resultados de SWAXS estão de acordo com os resultados obtidos pelo uso de outras técnicas. As análises estruturais mostraram que uma população possui um raio 
médio de partícula variando de 2 a $5 \mathrm{~nm}$, enquanto a outra população possui um raio médio de partícula variando de 9 a $20 \mathrm{~nm}$ aproximadamente.

Os espectros Uv-vis são típicos de nanopartículas de prata globulares. A mudança na posição da absorbância máxima está relacionada ao tamanho crescente das nanopartículas.

Os dados WAXS mostram um pico de difração crescente (111) para amostras com tempo de reação a partir de 35 minutos. Os tamanhos médios de cristalito são menores que os valores de raio médio, o que é uma evidência de nanopartículas policristalinas.

\subsection{Estudo in situ de nanopartículas de paládio-ouro}

Nanopartículas de paládio-ouro foram investigadas devido à potencial aplicação em catálise heterogênea (ROSTEK et al., 2018). Em julho de 2017, durante o estágio do autor desta tese na Universidade de Duisburg-Essen, foi realizada uma experiência in situ com nanopartículas de paládio-ouro encapadas com PVP no IFUSP na ocasião da visita da Dra. Kateryna Loza ao grupo brasileiro, incluída no projeto CAPES-DAAD mencionado anteriormente. A rota de síntese dessas nanopartículas segue um método mediado por sementes.

Esse experimento foi peculiar porque investigou as duas etapas distintas dessa rota de síntese: as sementes de paládio e a formação das cascas de ouro. A amostra do experimento relatado nesta seção foi sintetizada pela Dra. Loza e os dados foram analisados pelos autores desta tese. Este estudo foi publicado no artigo de Rostek et al. (2018). Os dados de SAXS foram obtidos usando equipamento Xeuss e a distância amostra-detector foi $0,84 \mathrm{~m}$. O aparato in situ utilizado é descrito na seção 7.7.

Primeiro, as sementes foram formadas seguindo o procedimento descrito na seção 7.3 e medidas por 50 minutos. Logo em seguida, na segunda etapa do experimento, o precursor de ouro foi adicionado à mistura desencadeando a formação das cascas de ouro. A amostra então foi medida por mais 50 minutos.

Os dados de SAXS foram analisados usando um modelo de esferas polidispersas e agregados com dois tamanhos característicos [equação $77 \operatorname{com} S_{H S}\left(q, \eta, R_{H S}\right)=1 \mathrm{e}$ equação 49 para $\mathrm{N}=2$ ]. Esse modelo de esferas foi utilizado também na segunda etapa do experimento, onde as nanopartículas possuem estruturas núcleo-casca. As informações contidas nas curvas de SAXS não fazem distinção entre o núcleo e a casca das nanopartículas. 
O modelo de esferas homogêneas descreveu satisfatoriamente os dados experimentais não sendo necessário utilizar o fator de forma, mais complicado, para núcleo-casca ${ }^{3}$.

A figura 41 mostra a imagem de HAADF-STEM e o mapa elementar de EDX das nanopartículas. Essas imagens, produzidas pelo grupo alemão e publicadas no artigo de Rostek et al. (2018), revelam nanopartículas com tamanho variando de 5 a $8 \mathrm{~nm}$. A estrutura núcleo-casca das nanopartículas pode ser vista no mapa elementar, onde o núcleo de paládio e a casca de ouro são evidenciados.
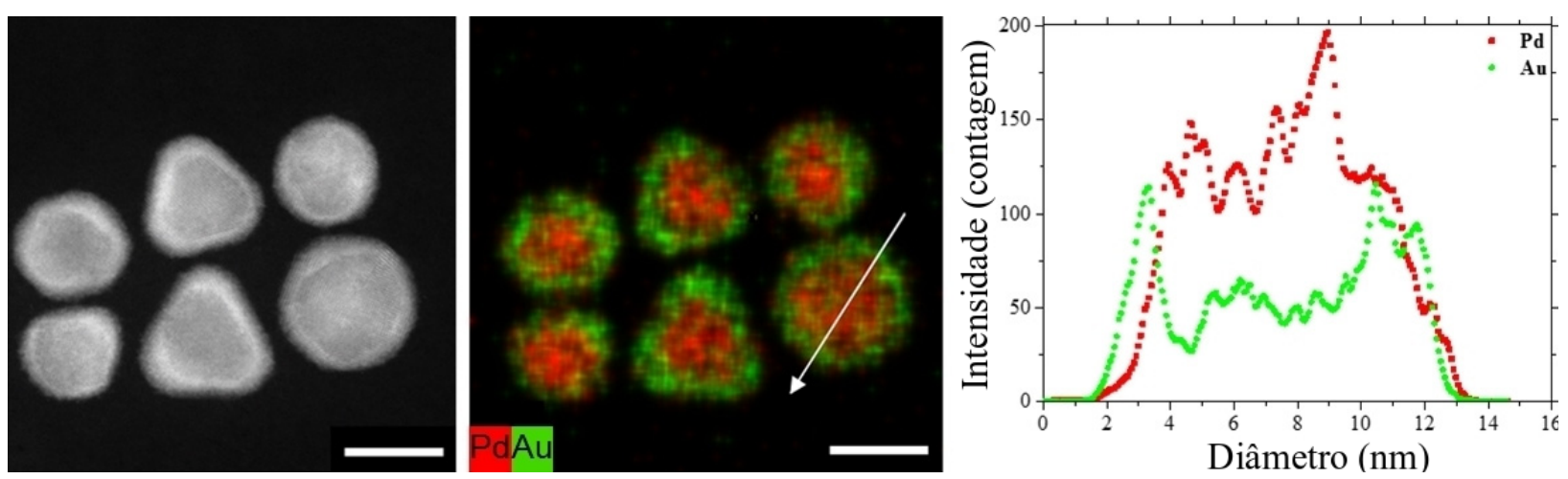

Figura 41 - Imagem de HAADF-STEM e mapa de EDX das nanopartículas núcleo-casca de paládio-ouro. Barras de escala são $7 \mathrm{~nm}$. Fonte: Adaptado de (ROSTEK et al., 2018).

Os dados in situ de SAXS são mostrados na figura 42a. A polidispersidade relativa $(\sigma / R)$ foi fixada em 0,53 para a modelagem dos dados das sementes e em 0,69 para a modelagem dos dados das sementes + cascas. Esses valores foram escolhidos porque foram os valores que tornaram os procedimentos de ajuste mais estáveis. Além disso, outros experimentos in situ realizados mostraram resultados de polidispersão relativa de $\approx 0,5$ (como os estudos reportados nas seções 8.4 e 8.6).

Como pode ser visto na figura 42a, a intensidade integrada das curvas de espalhamento das sementes (tempo < 50 minutos) aumenta levemente com o tempo de síntese. Porém, imediatamente após a adição de ouro (tempo $\geq 50$ minutos), a intensidade de espalhamento integrada aumenta abruptamente. Esse deslocamento da intensidade de espalhamento é causado principalmente pelo aumento no raio médio (figura 42b) como resultado da formação da casca. Como o primeiro quadro medido já possui o padrão de 3 Aqui o principio da parcimônia, descrito na seção 6.1 .3 , foi aplicado. 
espalhamento observado em medidas posteriores, os dados sugerem que as sementes de $\mathrm{Pd}$ sejam imediatamente formadas no início da síntese, antes de 1 minuto de síntese.

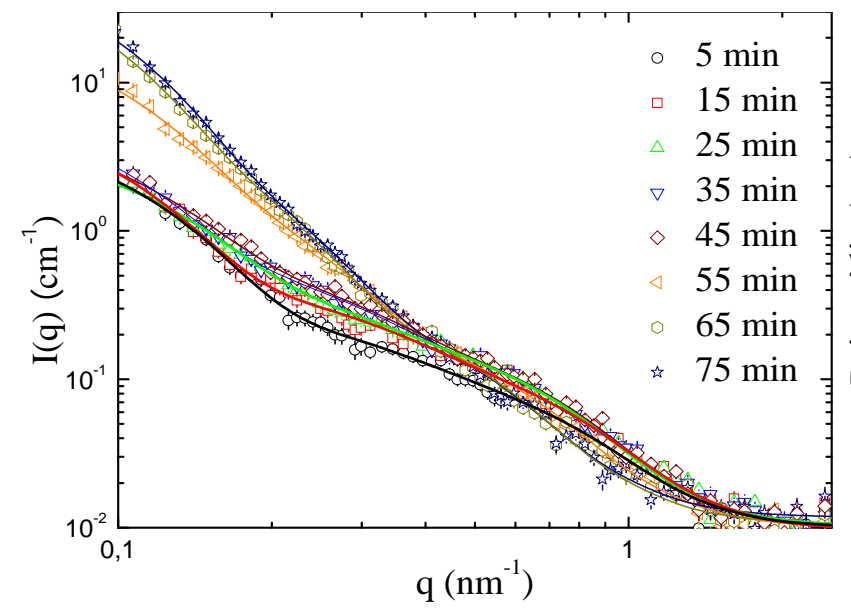

(a)

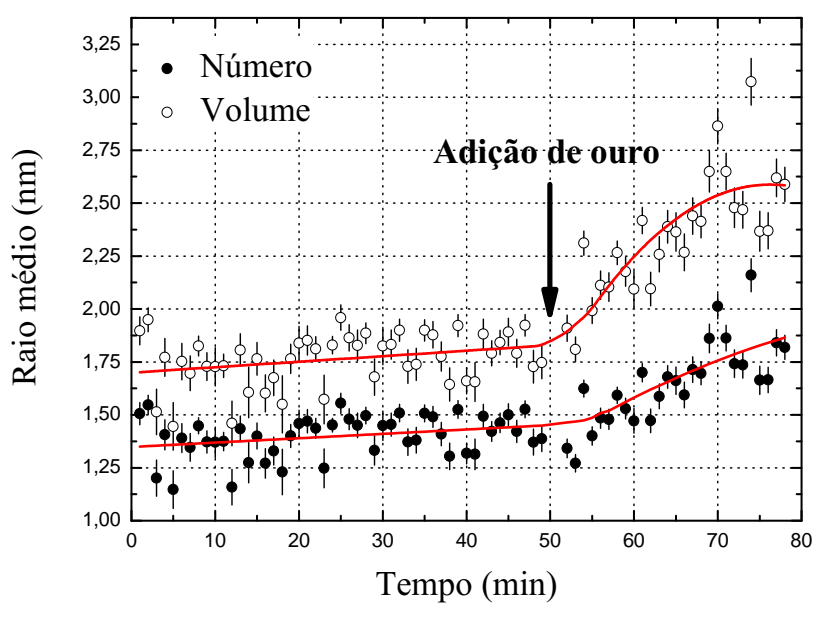

(b)

Figura 42 - Dados de SAXS in situ: Evolução temporal da (a) intensidade de espalhamento e (b) raio médio do sistema de nanopartículas núcleo-casca de $\mathrm{Pd}-\mathrm{Au}$. Para maior clareza, nem todas as curvas de intensidade são exibidas. Fonte: Adaptado de (ROSTEK et al., 2018).

Se consideradas as incertezas, os valores de raio médio mostrados na figura 42b são comparáveis, embora menores, aos resultados obtidos por DLS, DCS e TEM, publicados no artigo de Rostek et al. (2018). Como esperado, as sementes não cresceram significativamente e permaneceram estáveis, uma vez que o raio médio aumentou muito pouco.

O raio médio pesado por volume das sementes de paládio variou de $\approx 1,7$ a $1,8 \mathrm{~nm}$. Se a espessura média da casca ao final da síntese for considerada como a diferença entre o raio médio pesado por volume das últimas curvas antes e após a adição de ouro $[\mathrm{R}(\mathrm{t}=78$ $\min )$ - $\mathrm{R}(\mathrm{t}=49 \mathrm{~min})]$, a espessura média da casca das nanopartículas atingiu $\approx 0,9 \mathrm{~nm}$.

Como mencionado anteriormente, os dados SAXS também revelaram a presença de agregados. O modelo teórico usado para descrever o espalhamento desses agregados é uma função de dois fatores de escala e dois raios de giro.

Embora as contribuições dos agregados para a intensidade de espalhamento medida sejam evidentes e indispensáveis, o fator de estrutura de Guinier não fornece nenhuma informação sobre forma e polidispersão. Não é possível saber se os agregados são compostos por duas populações distintas ou, na verdade, os dois raios de giro são necessários para 
descrever uma única população ampla. De qualquer forma, o modelo permite quantificar os tamanhos e as frações características desses agregados. Uma população de agregados exibiu um raio de giro que variou de $\approx 15$ a $25 \mathrm{~nm}$, enquanto que a outra população exibiu raio de giro de $\approx 5$ a $10 \mathrm{~nm}$.

A figura 43a mostra a evolução dos fatores de escala das nanopartículas esféricas $(S c)$ e as duas populações de agregados $\left(S c_{1}{ }^{G}\right.$ e $\left.S c_{2}{ }^{G}\right)$. Imediatamente após a adição de ouro, os fatores de escala exibem um "salto" seguido de um grande aumento na inclinação das curvas de evolução temporal. A curva dos dois raios de giro também apresentam o mesmo comportamento. Portanto, claramente, a adição de ouro aumentou o volume ocupado pelos agregados no sistema, tornando-os maiores e mais numerosos.

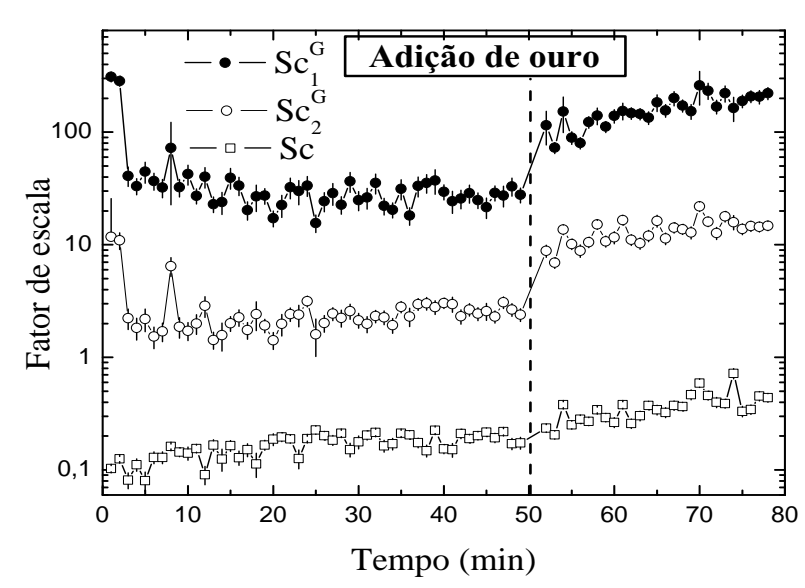

(a)

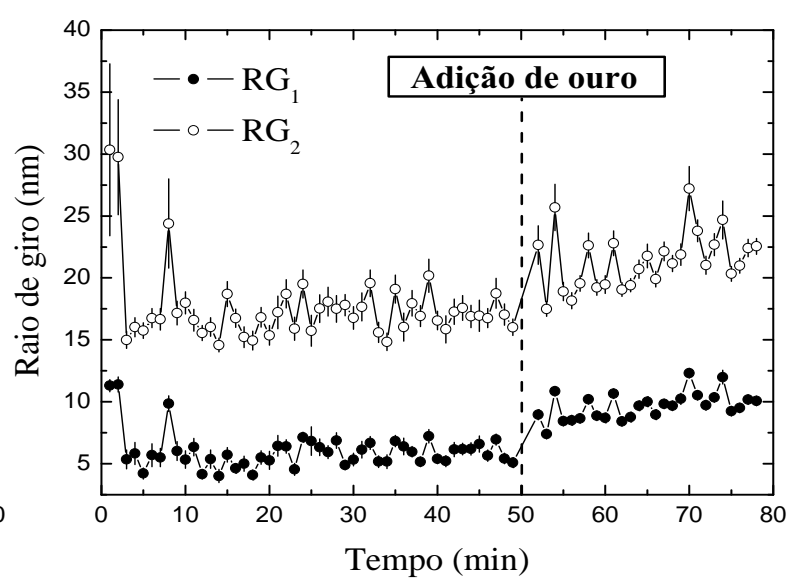

(b)

Figura 43 - Evolução temporal dos (a) fatores de escala e (b) raios de giro de agregados da amostra de nanopartículas de PdAu.

\section{Conclusões parciais}

Informações estruturais detalhadas foram obtidas durante a síntese de nanopartículas núcleo-casca de paládio-ouro. Uma característica inovadora desse experimento foi a habilidade em caracterizar as sementes e a formação das cascas separadamente.

Este estudo mostra que as sementes de paládio permaneceram estáveis durante a síntese, não apresentando grandes variações de tamanho ou forma. As sementes já estão presentes em 1 minuto de síntese. A formação da casca de ouro pôde ser rastreada e mostrou um valor de $\approx 0,9 \mathrm{~nm}$ no final do experimento. 
A amostra também possui agregados que também aumentaram em tamanho e número com a adição de ouro.

\subsection{Estudo in situ de nanopartículas de prata}

Nesta seção, é apresentado um estudo in situ sobre o crescimento de nanopartículas de prata. A formação das nanopartículas foi monitorada por medidas de SAXS em tempo real durante a síntese. Além disso, alíquotas foram coletadas para realizar caracterizações ex situ por TEM, Uv-vis e XRD, de modo a se obter informações adicionais. Este estudo foi publicado no artigo de Garcia et al. (2020).

O experimento in situ de SAXS foi realizado usando o equipamento de SAXS Xeuss com uma distância amostra-detector de 0,84 m. O aparelho Xeuss e o aparato in situ são descritos no capítulo 7.

Para este estudo, foram realizadas 64 medições de SAXS de 1 minuto cada durante o processo de síntese descrito na seção 7.1. O modelo de Monte Carlo, descrito na seção 7.13, foi utilizado para analisar os dados experimentais. A principal vantagem da abordagem de Monte Carlo é que ela não impõe restrições à forma da distribuição de raios. No entanto, precisamente por esse motivo, é importante ter dados com incerteza relativamente pequena e polidispersidade relativamente baixa (PAUW et al., 2013), o que provou ser o caso dos dados deste estudo.

A figura 44a mostra os dados de SAXS e a curva teórica de sete medidas selecionadas de forma que a evolução da intensidade de espalhamento seja visualizada com clareza. O gráfico revela um aumento na intensidade de espalhamento integrada com o tempo. Como ocorreu com estudos reportados nas seções anteriores, esse aumento ocorre devido ao aumento de número e tamanho das nanopartículas.

A análise da distribuição de raios sugere que o sistema de nanopartículas é bimodal. Experiências e testes anteriores usando diferentes modelos teóricos indicam a existência de nanopartículas menores com um raio médio variando entre, aproximadamente, 3 e $4 \mathrm{~nm}$. Já o raio médio das nanopartículas maiores aumenta continuamente ao longo do tempo de reação. Portanto, para análise dos dados e cálculo dos parâmetros, a população de nanopartículas pequenas, chamada distribuição 1, foi definida para raios de até 4,5 nm. Para raios superiores a 4,5 nm é definida a distribuição 2. Como exemplo, a figura 55 
no apêndice $B$ mostra histogramas das distribuições de raios calculadas para tempos de reação de 7 e 72 minutos com essas duas distribuições em destaque.

É importante mencionar que essas são as populações das quais foi possível obter informações dos dados de SAXS, mas isso não significa que estas sejam as únicas populações presentes na amostra. Podem haver outras partículas com tamanhos fora da escala de tamanhos observada pelas medições. Possivelmente, por exemplo, existem sementes (tamanho $<2 \mathrm{~nm}$ ) presentes no sistema cujos tamanhos são muito pequenos para serem observadas por SAXS e TEM.

A evolução temporal dos raios médios pesados por volume das distribuições 1 e 2 é mostrada na figura 44b. Os resultados revelam que o raio médio das nanopartículas da distribuição 1 permaneceu quase constante $(\approx 1,5-2 \mathrm{~nm})$ durante a síntese. As inclinações $A_{1}$ e $A_{2}$, raio crítico $R_{0}$ e tempo crítico $t_{0}$ foram determinados usando a equação de Carpena, descrita no apêndice A.1.

Como observado em outros experimentos in situ realizados anteriormente, o raio médio da distribuição 2 aumenta ao longo do tempo em dois diferentes estágios. No primeiro estágio, o raio médio aumenta a uma taxa de $0,59 \mathrm{~nm} \cdot \mathrm{min}^{-1}$ até cerca de $23 \mathrm{~nm}$ (em cerca de 51 minutos de síntese). Então, a evolução do raio fica mais lenta e a taxa diminui para 0,26 nm. $\mathrm{min}^{-1}$ no segundo estágio. Essa mudança da taxa de crescimento observada entre os dois estágios é provavelmente o resultado de um equilíbrio entre a redução dos íons de prata e os processos de oxidação na superfície das nanopartículas.

A figura 44c mostra os valores da polidispersidade relativa. A análise da polidispersidade para a distribuição 1 é complicada, pois o valor limite que separa as duas distribuições $(4,5 \mathrm{~nm})$ foi escolhido por inspeção visual e não é possível saber exatamente onde a distribuição 1 termina e a distribuição 2 começa nos histogramas de distribuição de raios. Além disso, o baixo número de barras da distribuição 1 (como mostrado na figura 55b) traz certa imprecisão aos cálculos da polidispersidade ${ }^{4}$. No entanto, outros experimentos realizados indicam que os valores obtidos fornecem uma boa aproximação desse parâmetro para ambas as distribuições.

4 Isso não é verdadeiro para a distribuição 2. Para essa população, o intervalo de valores em $R$ e o número de barras no histograma é maior que na distribuição 1, o que minimiza as imprecisões nos cálculos de polidispersão. 
Os resultados mostram que a distribuição 1 possui uma polidispersidade relativa de cerca de $50 \%$, enquanto a distribuição 2 apresenta uma polidispersidade relativa crescente, variando de $15 \%$ a $26 \%$.

A fração de volume ocupada pelas duas populações de nanopartículas foi calculada para cada medida e é exibida na figura 44d. Os dados da fração volumétrica mostram que, no início da síntese, o sistema de partículas espalhadoras é composto principalmente pela população de nanopartículas pequenas. O volume ocupado pelas partículas da distribuição 2 aumenta gradualmente, atingindo valores superiores a $80 \%$ do volume total de espalhamento aos 40 minutos, quando é observado um platô de saturação. Interessante observar que em cerca de 27 minutos as frações de volume têm valores iguais. Neste momento, as nanopartículas maiores têm um raio médio de cerca de $20 \mathrm{~nm}$.

A evolução temporal do raio médio carrega informações sobre o mecanismo de crescimento das nanopartículas. Alguns autores tem utilizado uma abordagem baseada na taxa de crescimento do raio médio pesado por número para determinar se o mecanismo de crescimento é limitado por difusão ou reação (HARADA; KATAGIRI, 2010). Este procedimento é explicado na seção 5.0 .3 em relação aos mecanismos de coalescência dinâmica e amadurecimento de Ostwald. Para fazer esta análise, as distribuições de volume foram convertidas em distribuições de número, conforme descrito na seção 7.13. Os raios médios pesados por número foram então obtidos calculado-se o raio médio de cada uma dessas distribuições.

A taxa de crescimento (equação 28, seção 5.0.3) foi determinada calculando-se as inclinações da curva do raio médio pesado por número em escala log-log, exibida na figura 45a. A taxa do primeiro estágio, calculada usando a equação de Carpena, resultou em 0,55, o que indica que a coalescência é o mecanismo dominante nesse estágio. No segundo estágio, a taxa é de 0,33, o que sugere a ocorrência do amadurecimento de Ostwald.

Entretanto, não há consenso na literatura sobre o amadurecimento de Ostwald como mecanismo de crescimento responsável pela formação de nanopartículas metálicas. Polte (2015), por exemplo, afirma que o amadurecimento de Ostwald é um processo improvável de crescimento, uma vez que as nanopartículas são termodinamicamente estáveis a temperatura de até $500 \mathrm{~K}$. Diversas rotas de síntese de nanopartículas são conduzidas em temperaturas mais baixas do que essa.

A figura 45b mostra micrografias de TEM (HR-TEM) de alta resolução nas quais podem ser vistas nanopartículas grandes e pequenas. As imagens permitiram a análise da 

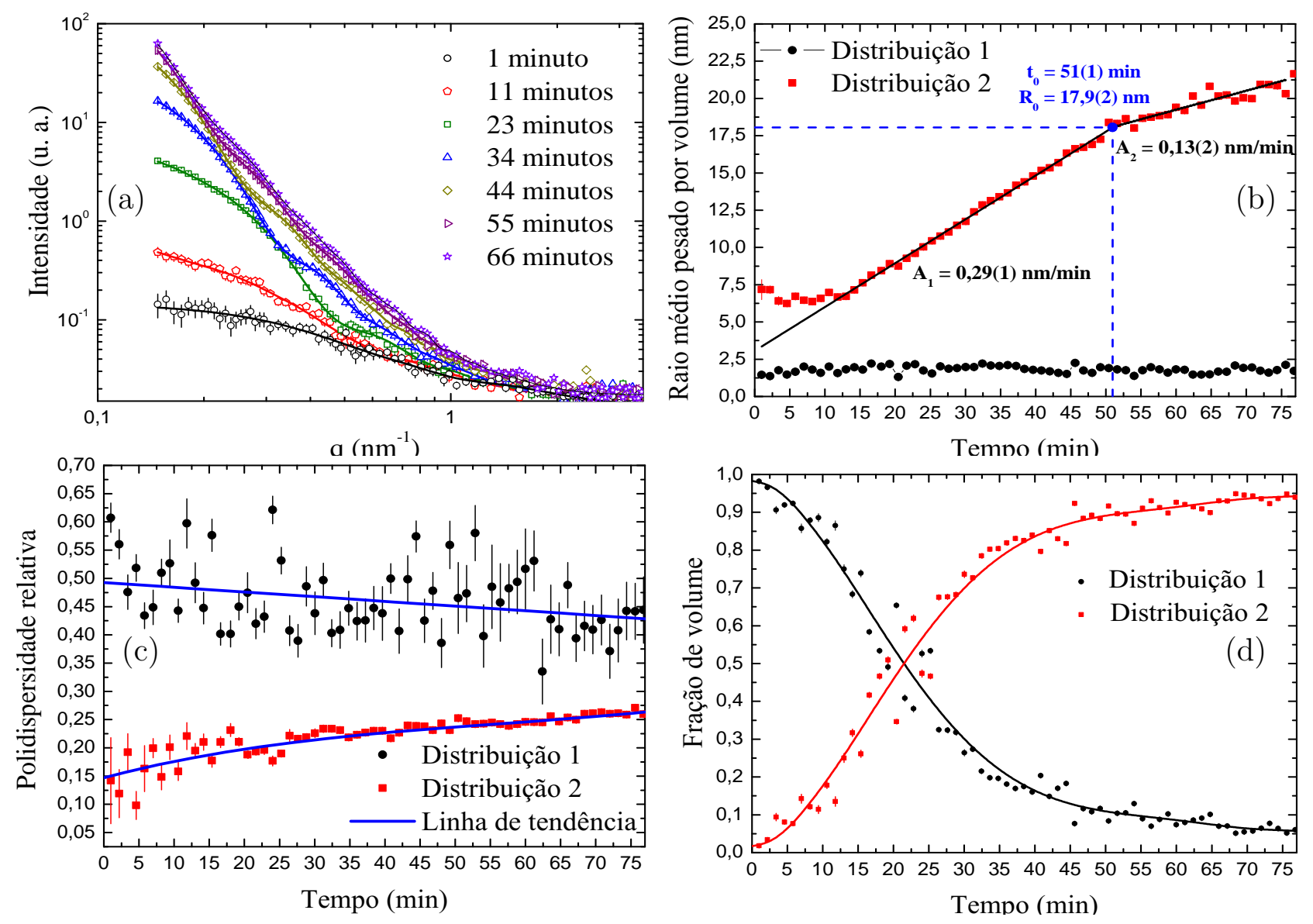

Figura 44 - Evolução temporal da (a) intensidade de espalhamento de SAXS, (b) raio médio pesado por volume, (c) polidispersidade relativa $(\sigma / R$, em que $\mathrm{R}$ e $\sigma$ são o raio médio pesado por volume e o desvio padrão da distribuição, respectivamente) e (d) frações de volume durante a síntese das nanopartículas de prata. Fonte: Figuras (a), (b) e (d) foram adaptadas de: (GARCIA et al., 2020).

estrutura interna das nanopartículas. A Transformada Rápida de Fourier (FFT), realizada pelo Dr. Wagner Wlysses, das imagens revelou uma distância interplanar do plano 111 de 2,34 $\AA$ em excelente concordância com o valor padrão para a estrutura da rede cúbica de face centrada da prata (cartão ICDD 04-0783). Foram encontradas nanopartículas policristalinas com raio de $\approx 15 \mathrm{~nm}$. Várias dessas nanopartículas têm uma simetria quíntupla e uma proporção de tamanho médio de cristalito:diâmetro de partículas de cerca de 1:3, em concordância com resultados anteriores (BANERJEE et al., 2014). A distribuição de tamanho das nanopartículas também foi calculada usando as micrografias TEM e são mostradas na figura 56 e na tabela 8, apêndice B. O raio médio determinado por TEM varia de $\approx 10$ a $30 \mathrm{~nm}$. Embora maiores que os tamanhos obtidos por SAXS, as 
nanopartículas observadas nas imagens de TEM estão dentro da faixa de comprimento típicas esperadas para as amostras com os tempos de reação dessas alíquotas.

As curvas de absorbância das quatro alíquotas podem ser vistas na figura 45c. As alíquotas mostram máximos de absorbância na região de comprimentos de onda de 410-445 nm, valores compatíveis com os valores característicos observados em outras amostras, incluindo as amostras estudadas na seção 8.2. O pico principal de absorbância é deslocado para maiores comprimentos de onda com o tempo de reação, ao mesmo tempo que se torna mais largo. Como já observado no estudo reportado na seção 8.2, esse comportamento das curvas de Uv-vis está relacionado ao aumento do tamanho médio e da polidispersidade. A absorbância em comprimentos de onda mais altos também aumenta provavelmente devido à presença de agregados e partículas maiores. A pequena banda localizada a $260 \mathrm{~nm}$ é formada pelo ligante de PVP.

A estrutura cristalográfica também foi investigada por meio de dados de XRD. O padrão de difração indica a presença de subprodutos de cloreto de prata (de 4 a $5 \%$ em peso, com um tamanho de cristalito de $143 \mathrm{~nm}$ de acordo com o resultado obtido por refinamento de Rietveld). Esses subprodutos já foram detectados em outras sínteses semelhantes. Como no caso ex situ, analisado na seção 8.2, o tamanho de cristalito é um pouco menor que o raio das nanopartículas. O tamanho de cristalito é de $22 \mathrm{~nm}$ e o raio médio ponderado pelo volume é de cerca de $25 \mathrm{~nm}$. Além disso, o parâmetro de rede calculado é a $=4.087(1) \AA$, próximo aos valores relatados no ICDD. É importante dizer que os dados de XRD se referem apenas a partículas grandes, uma vez que a intensidade devida às partículas ultra pequenas (sementes) não é suficiente para serem observadas. 


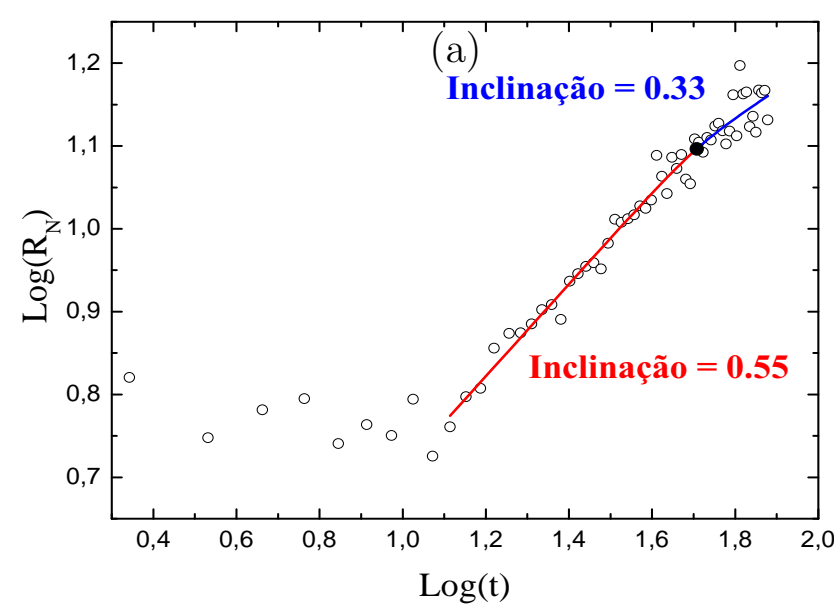

(b)
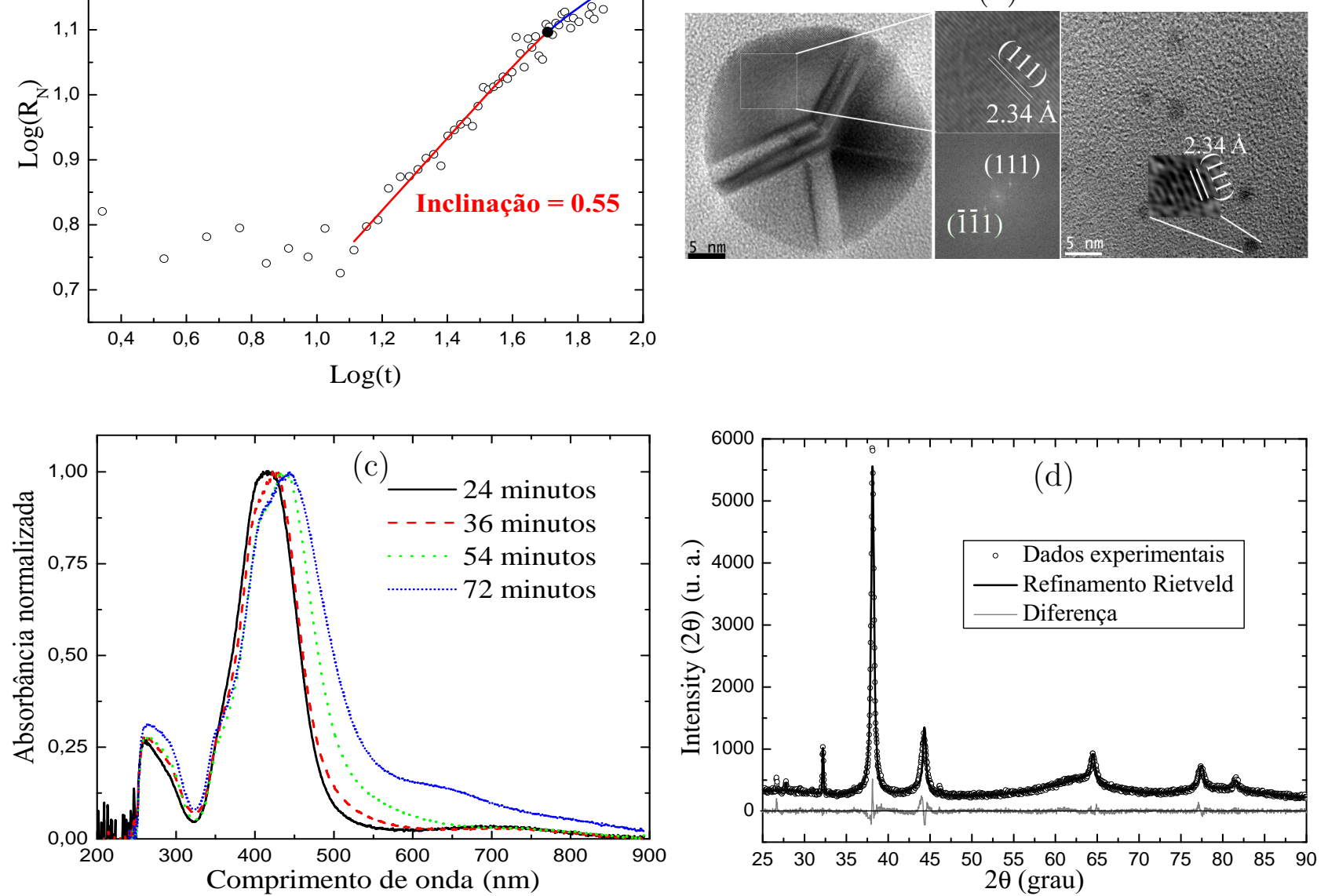

Figura 45 - (a) Gráfico log-log do raio médio pesado por número em função do tempo de síntese, (b) imagens de TEM mostrando nanopartículas grandes (esquerda) e pequenas (direita) com distâncias interplanares de 2,34 A, (c) espectros Uv-vis de alíquotas de nanopartículas de prata coletadas em 24, 36, 54 e 72 minutos de síntese; e (d) difratograma de XRD de uma alíquota obtida no final da síntese. Fonte: Adaptado de (GARCIA et al., 2020).

\section{Conclusões parciais}

Neste estudo o crescimento de nanopartículas de prata foi investigado. Os dados indicam que o sistema é composto por duas populações de nanopartículas. Uma população é composta por partículas com um raio médio pesado por volume de $\approx 1,3 \mathrm{~nm}$ que não crescem significativamente durante a síntese. A outra população é composta por 
nanopartículas com raio médio pesado por volume que aumentou de $\approx 6$ a $22 \mathrm{~nm}$. O crescimento das nanopartículas grandes com o tempo ocorre em dois estágios diferentes, nos quais a taxa de crescimento do primeiro estágio é superior à taxa de crescimento do segundo. A abordagem baseada em um modelo exponencial para a expressão do raio médio sugere que coalescência é o processo dominante no primeiro estágio e amadurecimento de Ostwald no segundo estágio.

No início da síntese, as curvas das frações de volume revelam que o sistema é composto principalmente pelas nanopartículas pequenas $(\approx 98 \%)$. As nanopartículas grandes aumentam e dominam gradualmente a fração de volume, atingindo mais de $90 \%$ em 55 minutos de síntese.

Uma análise cristalográfica foi realizada por meio de dados de TEM e XRD. As nanopartículas pequenas também foram observadas nas imagens de TEM. Os dados de XRD indicaram a presença de subprodutos de AgCl.

\subsection{Estudo in situ de nanopartículas de prata realizado no Labo- ratorio Nacional de Luz Síncotron}

Nesta seção um estudo in situ sobre nanopartículas de prata realizado no LNLS é apresentado. Este experimento foi feito durante a segunda visita da pesquisadora da Universidade de Duisburg-Essen, Kateryna Loza, em setembro de 2018.

A rota de síntese é idêntica à usada na seção anterior, descrita na seção 7.1. Os dados de SAXS foram modelados usando o método de Monte Carlo. As curvas de intensidade de espalhamento de SAXS, exibidas na figura 46a, são muito semelhantes às curvas obtidas anteriormente para essas amostras (seções 8.2 e 8.4), revelando um sistema bimodal de nanopartículas globulares. As duas populações são chamadas de distribuições 1 e 2, usando o mesmo critério descrito na seção 8.4. Como esperado, há um aumento na intensidade integrada como resultado do aumento na fração de volume ocupado pelas nanopartículas.

A figura 46b mostra a evolução do raio médio pesado por volume das nanopartículas das duas populações. A distribuição 1 exibiu o raio médio $<3,5 \mathrm{~nm}$ e diminui ligeiramente com o tempo. O raio médio da distribuição 2 pesado por volume cresceu a uma taxa praticamente constante de $\approx 0,16 \mathrm{~nm} / \mathrm{min}$, com uma clara descontinuidade em cerca de $41 \mathrm{~min}$. 
O desvio padrão da distribuição 1, mostrado na figura 46c, permaneceu oscilando em torno de um valor constante, enquanto o desvio padrão da distribuição 2 aumenta. As descontinuidades observadas nessa curva e nas curvas de fração de volume (figura 46d) são difíceis de avaliar, pois podem ser resultado de alguma imprecisão experimental, como um eventual deslocamento do porta-amostras durante as medições ou variações na ótica da linha uma vez que este equipamento estava instável durante as medidas.

Apesar das descontinuidades, pode-se observar que a evolução das frações de volume, exibida na figura 46d, ocorre mais rapidamente se comparada ao experimento in situ realizado no IFUSP (figura 44d). As formas dessas curvas de fração de volume parecem ser as mesmas observadas no outro experimento.
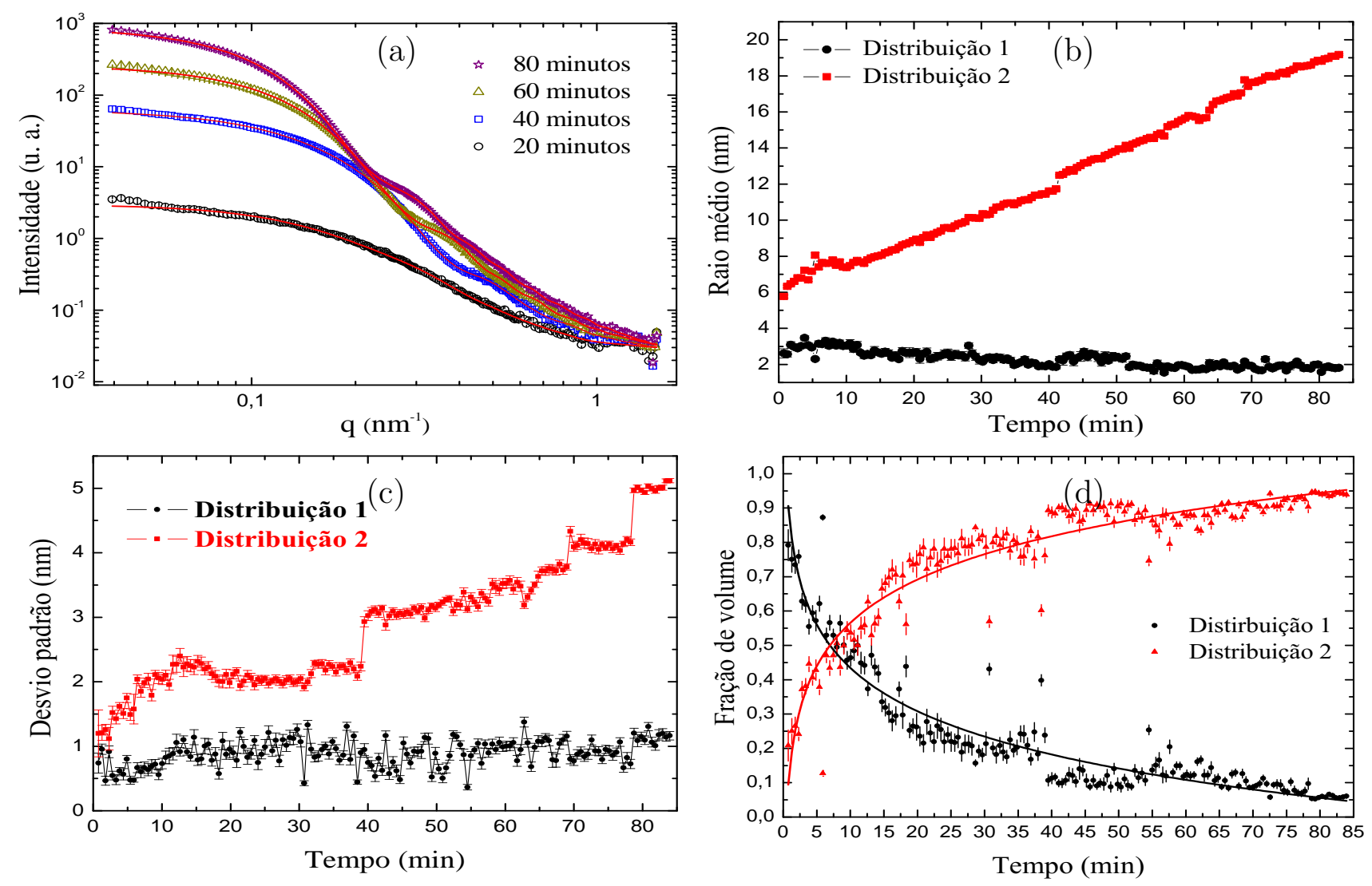

Figura 46 - Gráficos das caracterizações realizadas no Laboratorio Nacional de Luz Síncotron. Evolução temporal da (a) intensidade de espalhamento de SAXS, (b) raio médio pesado por volume, (c) polidispersidade $(\sigma)$ e (d) frações de volume durante a síntese das nanopartículas de prata. 
Diferentemente da amostra de nanopartículas de prata realizada no IFUSP (seção 44d), a curva de evolução do raio médio não apresenta dois estágios. O mesmo vale para o gráfico log-log da curva de raio médio pesado por número, mostrado na figura 47. A inclinação dessa curva é de $\approx 0,34$, que é mais próximo ao valor correspondente ao amadurecimento de Ostwald.

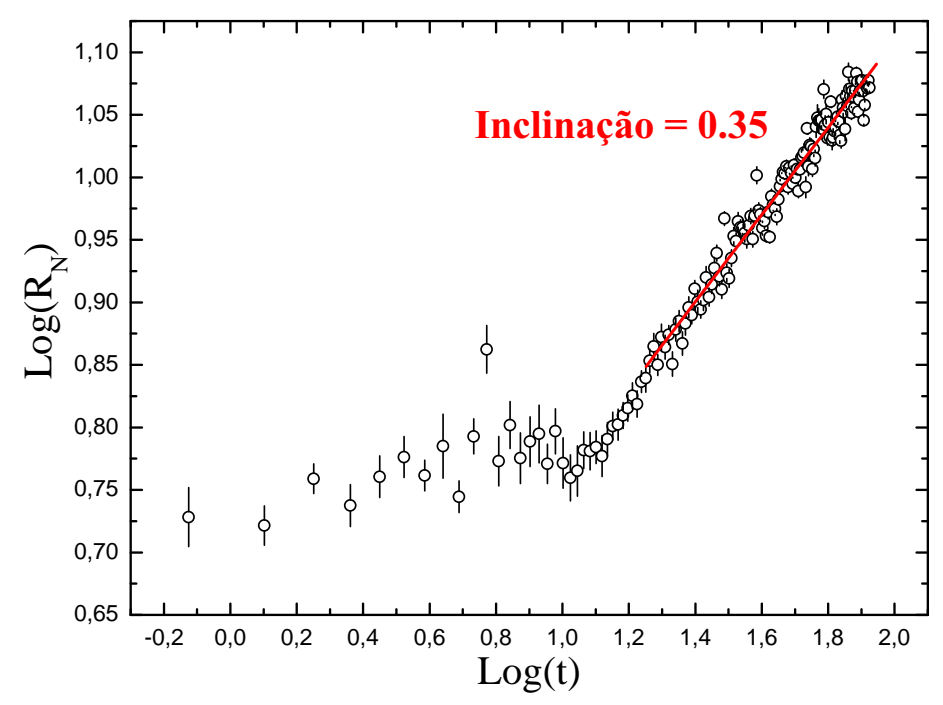

Figura 47 - Gráfico log-log do raio médio pesado por número em função do tempo de síntese de nanopartículas de prata. Síntese realizada no LNLS.

\section{Conclusões parciais}

O experimento realizado no LNLS proporcionou ao estudante a valiosa experiência de trabalho em uma instalação síncrotron. O síncrotron brasileiro é uma referência mundial no campo de pesquisa de materiais.

Como foi observado no experimento realizado no IFUSP, relatado na seção 8.4, a amostra de nanopartículas de prata revelou distribuição de raios bimodal, onde o raio médio da população de nanopartículas grandes cresceu continuamente enquanto que o raio médio da população de nanopartículas pequenas diminuiu ligeiramente. A inversão das curvas de fração de volume ocorreu mais cedo neste experimento. Também, a curva de evolução temporal do raio médio é bem diferente da curva obtida na experiência realizada no IFUSP. Descontinuidades nos dados indicam que podem ter ocorrido imprecisões experimentais. 


\subsection{Estudo in situ de nanopartículas de ouro-prata}

Nesta seção é apresentada uma investigação in situ sobre nanopartículas de ouroprata publicada no artigo de Garcia et al. (2020). O experimento foi conduzido em 2017 por Kevin Pappert e Viktoria Grasmik, estudantes da Universidade de Duisburg-Essen, e o autor desta tese. O equipamento de SAXS usado é o Nanostar, descrito na seção 7.5, com uma distância amostra-detector de 0,67 m. A rota de síntese é descrita na seção 7.2.

As nanopartículas sintetizadas são globulares e formam ligas de prata e ouro. Embora a maior parte do ouro esteja localizada na parte interna e a prata na região externa, a estrutura dessas nanopartículas não é classificada como núcleo-casca já que a interface entre esses dois elementos não é bem definida. De acordo com Ristig et al. (2015), essas partícula são classificadas como nanoligas.

Um modelo teórico de esferas polisdispersas foi utilizado para analisar os dados de SAXS e, como os perfis de intensidade de espalhamento de SAXS sugerem a presença de agregados, o fator de estrutura de Guinier foi incluso no modelo [equação 77 com $S_{H S}\left(q, \eta, R_{H S}\right)=1$ e equação 49 para $\left.\mathrm{N}=1\right]$. Para este estudo foi suficiente considerar uma população de agregados com raio de giro característico constante.

Curiosamente, a presença de agregados é indicada já no início da síntese. A curva de SAXS de 1 minuto tem uma inclinação pronunciada para valores baixos de $q(q<0,15$ $\left.\mathrm{nm}^{-1}\right)$. Como a formação de grandes nanopartículas de AuAg no início da síntese é muito improvável, esses agregados provavelmente são resultado de subprodutos de $\mathrm{AgCl}$, como demonstrado por Ristig et al. (2015). Apesar da predominância desses agregados nas curvas de espalhamento das primeiras medidas, as caracterizações por SAXS foram capazes de fornecer informações sobre as nanopartículas pequenas de ouro-prata.

A intensidade de espalhamento desses agregados não pode ser bem descrita pelo modelo de Monte Carlo devido à forma irregular. Além disso, o espalhamento desses agregados amortece as oscilações do fator de forma médio das nanopartículas esféricas de AuAg. Isso torna o processo de modelagem mais degenerado em relação às possíveis soluções de distribuições de raios. O modelo dependente dos fatores de forma e estrutura (descrito na seção 6.1.3) aborda muito bem essas limitações, pois impõe uma forma para a distribuição de raios, diminuindo o número de soluções de distribuições de raios. Além disso, o fator de estrutura de Guinier pode descrever satisfatoriamente a contribuição dos agregados. 
Por esses motivos, o modelo dos fatores de forma e estrutura foi usado para analisar os dados SAXS mostrados na figura 48. No apêndice B, a figura 58 exibe a evolução temporal da distribuição de raios.
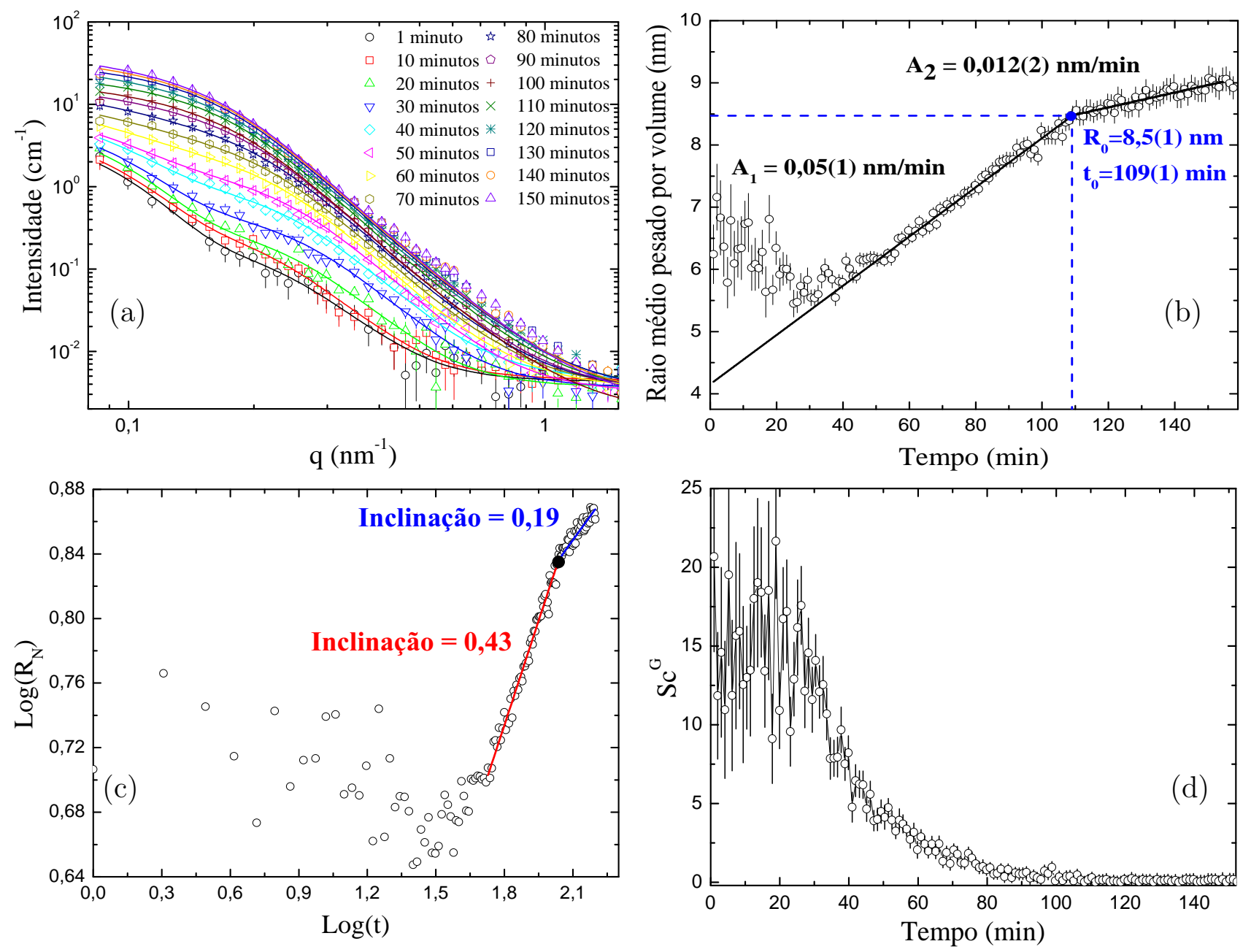

Figura 48 - Gráficos da evolução temporal da (a) intensidade de espalhamento de SAXS, raio médio pesado por volume em escalas linear e logarítmica (b, c) e (d) fator de escala de agregados. Fonte: Adaptado de (GARCIA et al., 2020)

O raio de giro dos agregados permaneceu $23 \mathrm{~nm}$ durante toda a síntese. Como será mostrado, o espalhamento das nanopartículas de AuAg dominam gradualmente a curva de intensidade à medida que crescem durante a síntese.

A evolução do raio médio pesado por número é mostrada na figura 48b. Como foi observado no experimento in situ com nanopartículas de prata reportado na seção 8.4, 
o crescimento das nanopartículas ocorre em dois estágios distintos. O primeiro estágio ocorre a uma taxa de $0,05 \mathrm{~nm} \cdot \mathrm{min}^{-1}$ e o segundo estágio ocorre a $0,012 \mathrm{~nm} \cdot \mathrm{min}^{-1}$.

Antes do início dos dois estágios, até 33 minutos, a curva de evolução do raio é bastante ruidosa e permanece oscilando em torno de $\approx 6 \mathrm{~nm}$. Isso acontece devido à baixa intensidade de espalhamento integrada das nanopartículas globulares de AuAg que nessa etapa inicial provavelmente ainda estão passando por alterações estruturais durante a formação das estruturas gradientes (RISTIG et al., 2015).

A análise da evolução temporal do raio médio usando a equação de Carpena (equação 84) revelou que o raio crítico é de $8,5 \mathrm{~nm}$ e ocorre em aproximadamente 109 minutos de tempo de síntese. Pode-se especular que a ocorrência do platô, que também ocorre na síntese de nanopartículas de prata relatadas na seção 8.4, talvez seja uma característica de rotas de síntese de redução química.

Os expoentes da equação 28 são exibidos na figura 48c. Para a primeira etapa, o expoente é de 0,43, valor compatível com coalescência. O valor de 0,19 para o segundo estágio está longe de 0,33, valor esperado para o amadurecimento de Ostwald. Na verdade, não é surpresa que o último estágio não possa estar associado ao amadurecimento de Ostwald, pois se trata um sistema complexo onde ocorrem a redução de dois precursores com diferentes taxas de decomposição. Portanto, o sistema passa por processos complexos de formação até que o equilíbrio termodinâmico seja alcançado.

Conforme demonstrado no apêndice A.2, o fator de escala de agregados $S c^{G}$ é equivalente à razão entre a intensidade de espalhamento dos agregados e a intensidade de espalhamento das nanopartículas na origem $(q=0)$. A evolução temporal deste parâmetro, mostrada na figura 48d, revela enormes oscilações até cerca de 33 minutos do tempo de síntese, como aconteceu com a curva do raio médio. A partir de 33 minutos, os valores de $S c^{G}$ diminuem para valores menores que 1 . Os valores iniciais ruidosos de $S c^{G}$ são muito maiores que 1 , o que significa que o espalhamento devido aos agregados é muito mais intenso que o espalhamento devido às nanopartículas de AuAg. Nesta fase, as nanopartículas ainda são, como mencionado anteriormente, muito pequenas ou não estão suficientemente formadas, resultando em uma baixa intensidade de espalhamento integrada. As nanopartículas permanecem crescendo durante a síntese até que, a partir de 33 minutos, o volume ocupado por elas é suficiente para dominar a intensidade total de espalhamento, causando a diminuição de $S c^{G}$. A tendência ruidosa da curva de $S c^{G}$ 
na parte inicial da síntese, como também observado na curva do raio médio, é também resultado da baixa intensidade integrada das nanopartículas de AuAg.

As figuras 49a e 49b mostram a imagem de TEM e o histograma da distribuição de tamanhos de uma alíquota coletada no final da síntese $(t \approx 157 \mathrm{~min}$ ), respectivamente. Esse histograma foi calculado pelo pesquisador Wagner Wlysses. Diferentemente das nanopartículas de prata estudadas na seção 8.4, esta amostra possui uma distribuição de tamanho monomodal. O tamanho médio determinado usando as imagens de TEM é 22 nm, valor próximo ao determinado por SAXS.

O espectro Uv-vis é mostrado na figura 49d. A localização da absorbância máxima está de acordo com a banda de ressonância plasmônica típica relatada na literatura (RISTIG et al., 2015). O fato de haver uma única banda de absorbância é uma indicação de ligas de ouro e prata. Caso contrário, se os precursores de prata e ouro formassem fases distintas (como, por exemplo, estruturas núcleo-casca), haveriam pelo menos dois máximos de absorbância como resultado da condição de ressonância plasmônica devida a cada uma das estruturas (RISTIG et al., 2015).

\section{Conclusões parciais}

Este estudo revelou que a amostra de nanopartículas de ouro-prata é composta por uma distribuição monomodal. O crescimento das nanopartículas ocorre em duas etapas, com diferentes taxas de crescimento. O raio médio ponderado por volume do primeiro estágio cresce a uma taxa de 0,56 nm.min-1 até atingir um valor crítico de 17,9 nm aos 51 minutos de tempo de síntese, quando a taxa de crescimento do raio diminui para 0,26 $\mathrm{nm} \cdot \mathrm{min}^{-1}$.

A análise baseada na taxa de crescimento indica que a coalescência é o mecanismo de crescimento dominante no primeiro estágio. Para o segundo estágio, essa abordagem não foi conclusiva, pois o valor da taxa de crescimento não pôde ser associado a nenhum mecanismo de crescimento.

Os resultados de SAXS estão de acordo com os dados de TEM. A estrutura cristalina e a composição química foram investigadas pela caracterização de XRD. O parâmetro da rede calculado é comparável ao valor calculado para as nanopartículas de prata. O difratograma também indica a presença de subprodutos de $\mathrm{AgCl}$. 
(a)

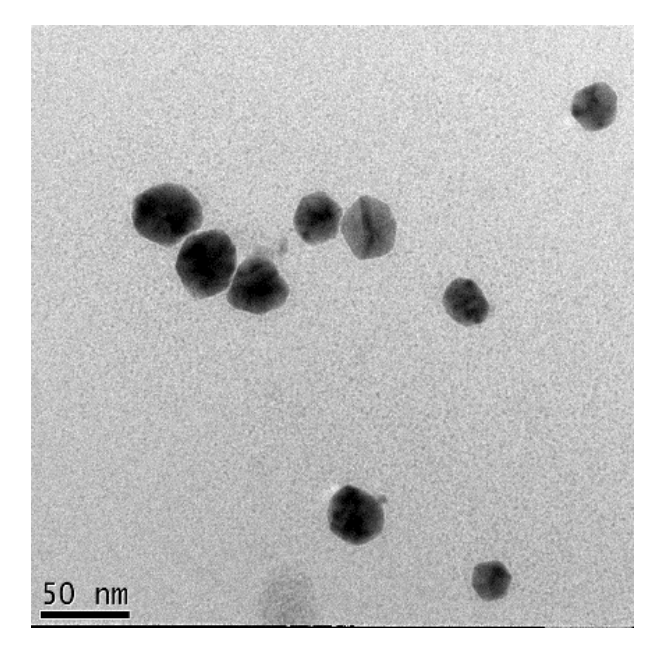

(b)
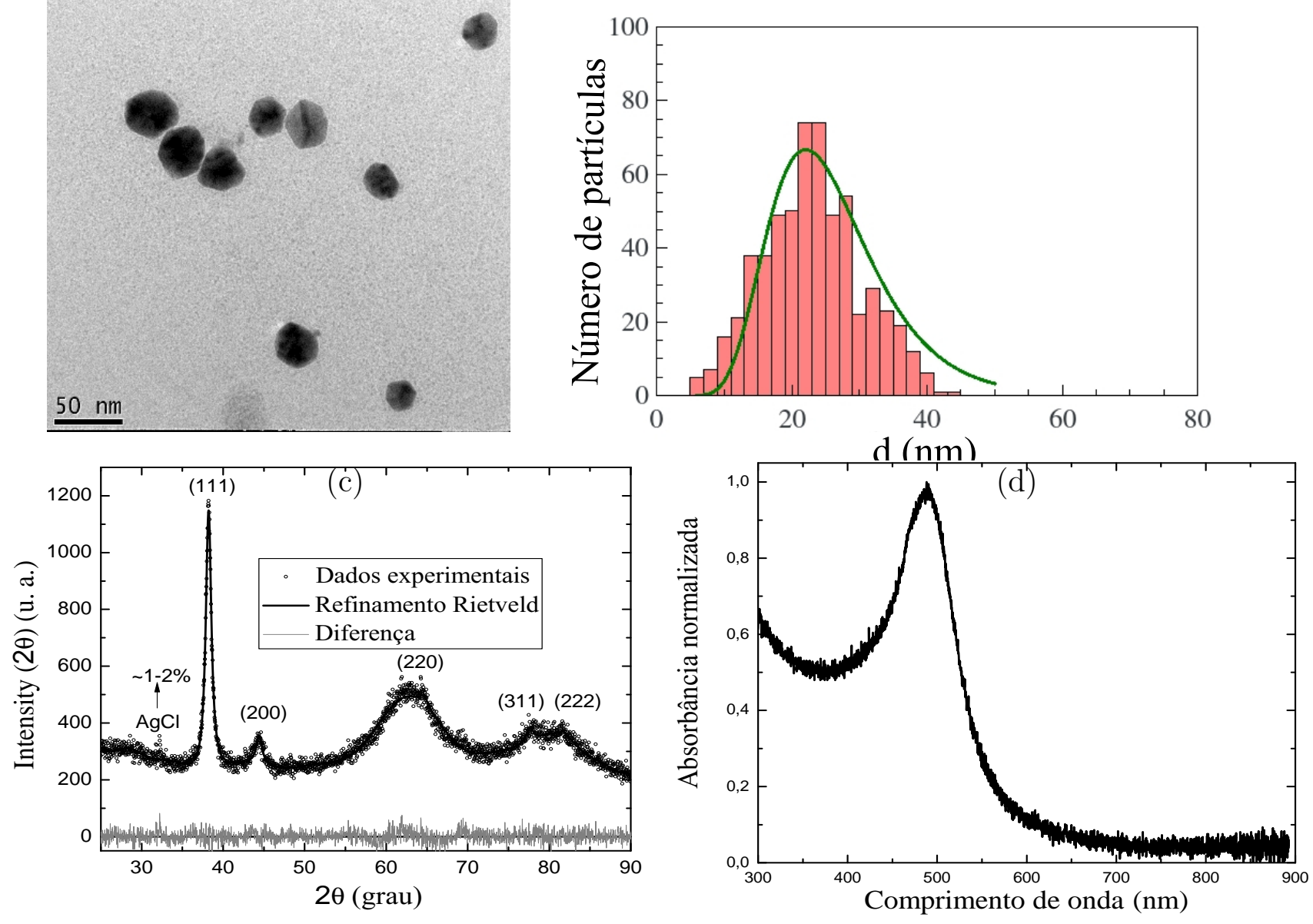

Figura 49 - Caracterizações da alíquota de nanopartículas de ouro-prata retirada ao final da síntese. (a) imagem de TEM, (b) histograma de distribuição de tamanhos calculado usando as imagens de TEM, (c) dados de XRD com refinamento de Rietveld e (d) espectros Uv-vis. O histograma foi produzido pelo pesquisador Dr. Wagner Wlysses. Fonte: Adaptado de (GARCIA et al., 2020).

A caracterização por espectroscopia Uv-vis revelou uma única banda de ressonância plasmônica, o que é uma evidência de que os precursores de ouro e prata formam ligas metálicas no interior das nanopartículas.

\subsection{Investigação estrutural de nanobastões de ouro}

Uma investigação estrutural ex situ de nanobastões de ouro foi realizada com o objetivo de avaliar o crescimento das nanopartículas durante o processo de crescimento. Uma alteração da rota de síntese foi feita tornando a evolução do sistema mais lenta. O 
atraso no crescimento de partículas foi importante, pois permitiu acompanhar a evolução dos nanobastões em tempo hábil.

Durante a síntese, descrita na seção 7.4, seis alíquotas de $8 \mathrm{ml}$ foram coletadas em diferentes tempos de reação: 12, 22, 30, 41, 50 e 60 minutos. Essas alíquotas foram caracterizadas por SAXS e os resultados foram correlacionados com dados de TEM e Uv-vis. As caracterizações por SAXS foram realizadas usando o instrumento Xeuss 10m, descrito na seção 7.5. A distância amostra-detector foi de $6,5 \mathrm{~m}$ e a fonte de cobre foi usada. O intervalo em $q$ das curvas de SAXS é de 0,03 a 0,6 $\mathrm{nm}^{-1}$.

A figura 50a mostra um gráfico de SAXS das curvas da intensidade de espalhamento. Os dados experimentais foram modelados usando a equação 77 com fator de forma de cilindros. As curvas possuem uma região Guinier muito bem definida, com a inclinação tendendo a zero para baixos valores do vetor transferência de momento (q). Em um gráfico log-log, este é um indicativo visual de que a região de Guinier foi alcançada para a partícula (GUINIER; FOURNET; YUDOWITCH, 1955). A oscilação proeminente do fator de forma em $q \approx 0,29 \mathrm{~nm}^{-1}$ é evidência de baixa polidispersidade. Além disso, a oscilação se torna mais pronunciada com o tempo de síntese, indicando uma diminuição da polidispersidade. Essas características serão verificadas quantitativamente a seguir.

A evolução temporal do raio e comprimento médios dos cilindros são mostrados nas figuras 50b e 50c, respectivamente. Como esperado, as partículas se alongam com o tempo, com a taxa crescimento diminuindo gradualmente. Ao mesmo tempo, o raio médio dos cilindros diminui. Como mencionado anteriormente, a polidispersidade relativa $(\sigma / R)$, mostrada na figura 50d, diminui com o tempo de aproximadamente 0,19 para cerca de 0,17. Os nanobastões podem ser vistos nas imagens de TEM mostradas na figura 51 . 

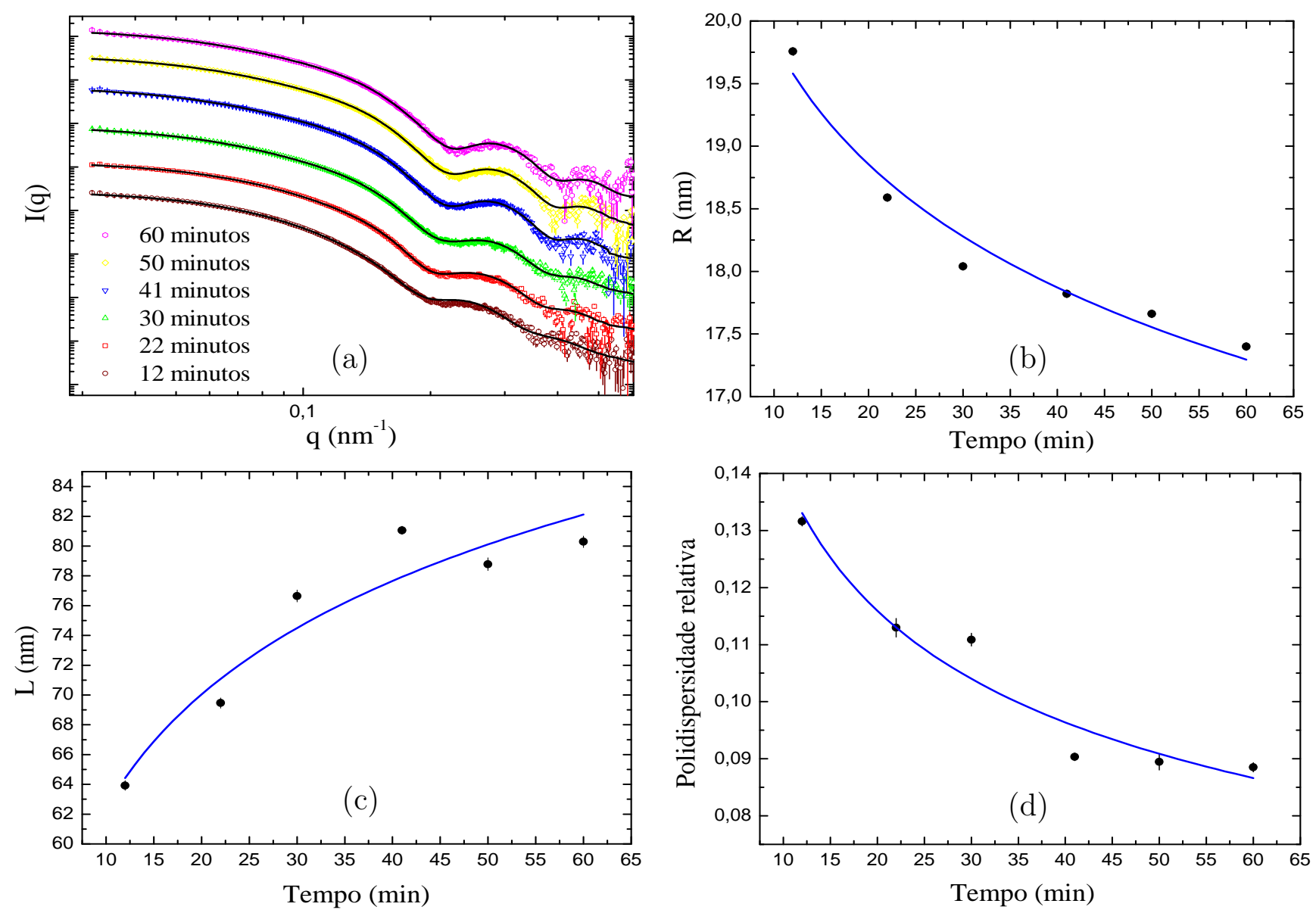

Figura 50 - Dados de SAXS de nanobastões de ouro. (a) Dados experimentais e curva teórica da intensidade de espalhamento, evolução temporal do (b) raio médio, (c) comprimento médio e $(\mathrm{d})$ polidispersidade relativa $(\sigma / R)$. Os símbolos são os dados experimentais e as linhas são linhas de tendência (b, c, d) ou curvas de ajuste (a). 
$12 \min$

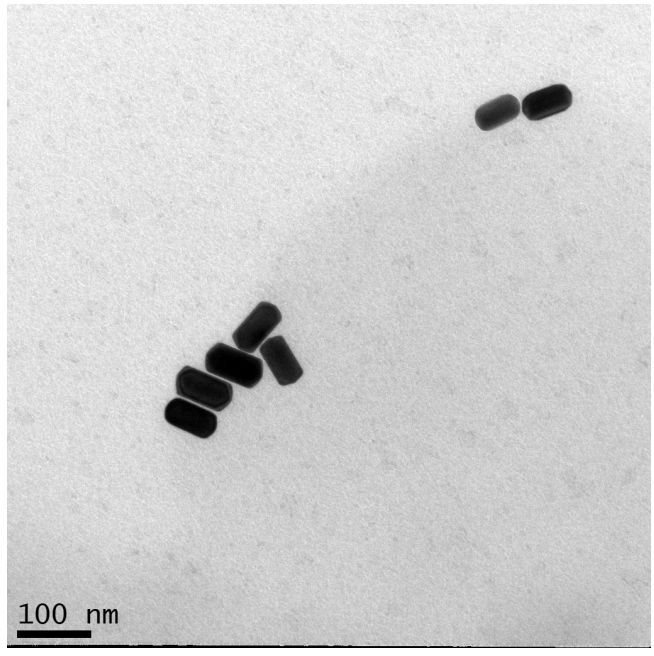

$30 \mathrm{~min}$

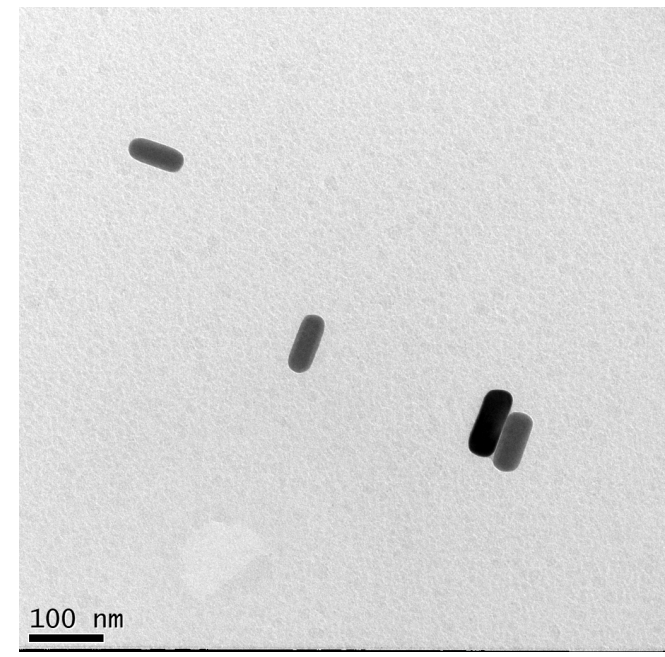

$50 \min$

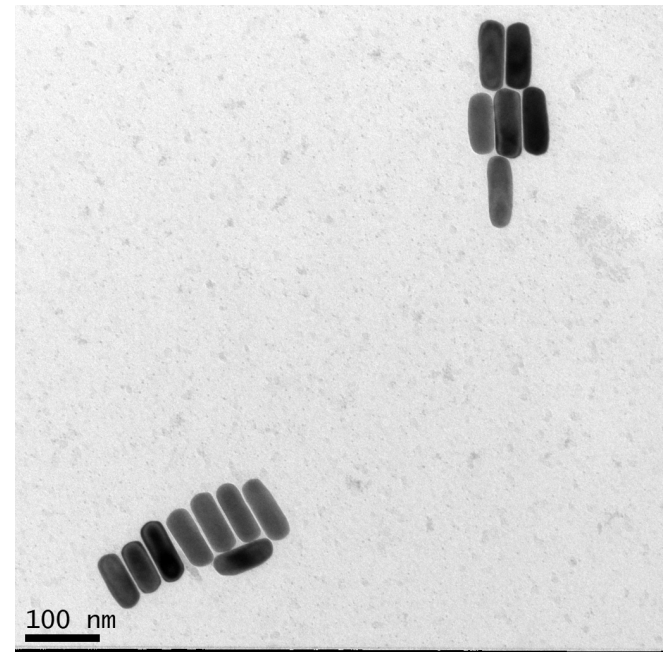

$22 \min$

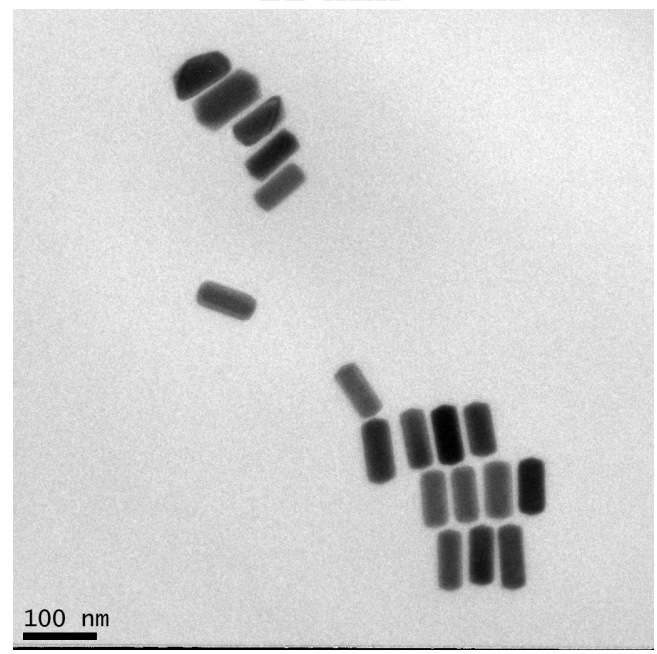

$41 \mathrm{~min}$

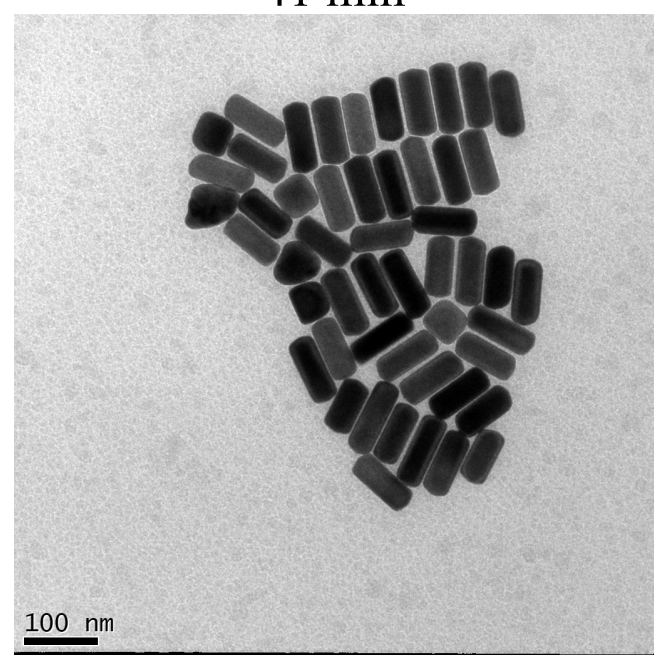

$60 \mathrm{~min}$

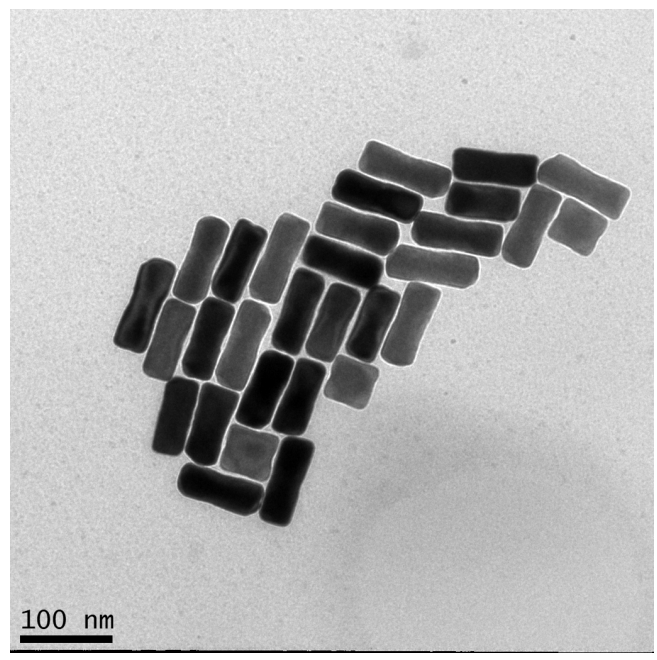

Figura 51 - Imagens de TEM de diferentes alíquotas de nanobastões de ouro. 
A razão de aspecto $(L / 2 R)$ é um parâmetro frequentemente analisado em publicações sobre nanobastões de ouro, uma vez que esse parâmetro está intimamente relacionado à ressonância plasmônica. A razão de aspecto é linearmente correlacionada com a posição da banda longitudinal de ressonância plasmônica de superfície (PÉREZ-JUSTE et al., 2005; EUSTIS; EL-SAYED, 2006a).

A rota de síntese usada geralmente produz nanobastões com razão de aspecto que varia entre $\approx 2$ e 3,5. As alíquotas mostram uma razão de aspecto crescente com o tempo. Esse aumento também é evidenciado pelas curvas de absorbância, exibidas na figura 52b. O espectro de absorbância de partículas cilíndricas geralmente têm duas bandas de ressonância plasmônica, relativas aos modos de oscilação eletrônica ao longo do comprimento e diâmetro das nanopartículas. As duas bandas características do espectro das alíquotas se distanciam com o tempo, efeito do alongamento (ou seja, do aumento da razão de aspecto) das nanopartículas.

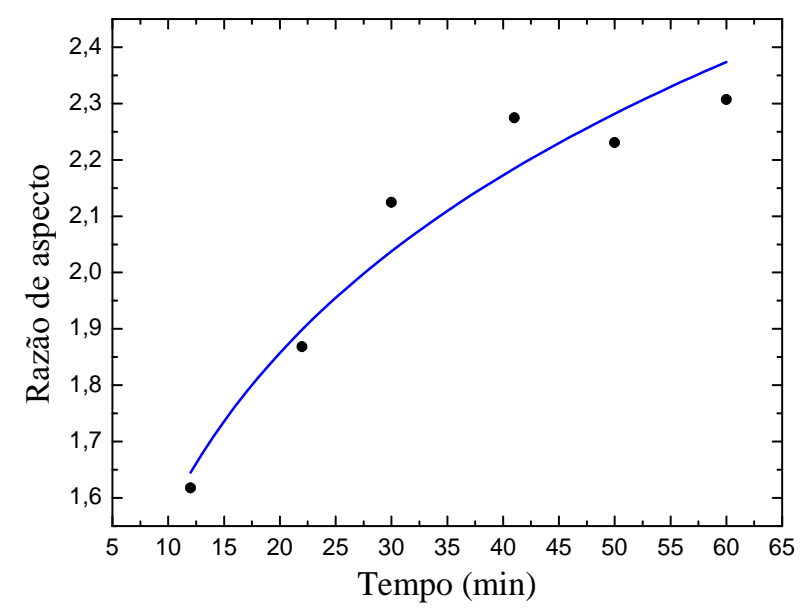

(a)

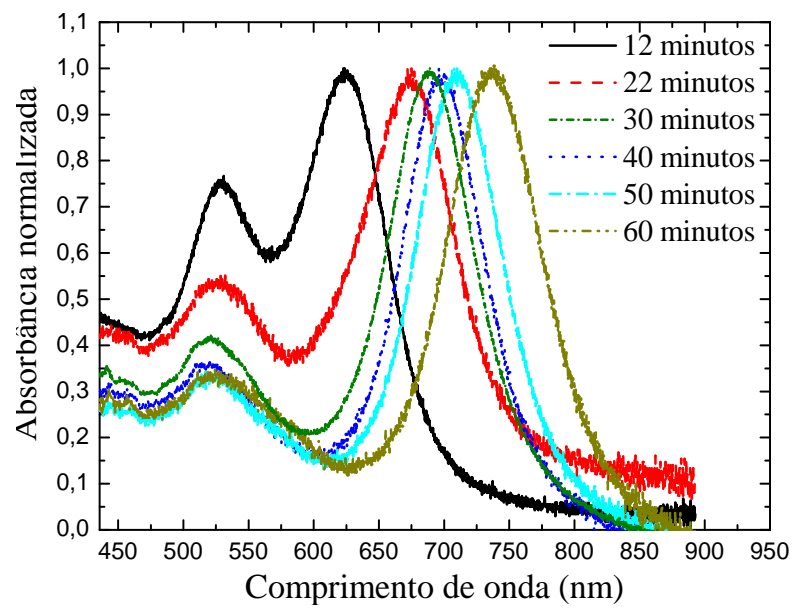

(b)

Figura 52 - Evolução temporal da (a) razão de aspecto e (b) espectro Uv-vis de nanobastões de ouro. A linha na figura (a) é uma linha de tendência.

As primeiras amostras de nanobastões de ouro sintetizadas pelo autor dessa tese foram feitas seguindo a rota de síntese padrão descrita na seção 7.4. As medidas de SAXS dessas amostras foram realizadas utilizando-se outra configuração de equipamento (distância amostra-detector de 0,84 m) resultando em valores de q variando de 0,12 a 4,5 $\mathrm{nm}^{-1}$. Portanto, essa configuração permitiu analisar a intensidade de espalhamento na 
região com valores de $q$ mais altos se comparados às medidas das amostras modificadas apresentadas nesta seção.

A seguir os dados de uma dessas amostras são apresentados. Este estudo revelou uma característica interessante: a presença de micelas de CTAB na amostra e sua influência nas medidas SAXS. O espalhamento devido às micelas de CTAB é evidente para $q>0.8$ $\mathrm{nm}^{-1}$. Como essa região não foi coberta nas medições de SAXS dos nanobastões modificados, o espalhamento das micelas de CTAB não é discernível nessas curvas.

Surpreendentemente, a curva de SAXS da amostra de nanobastões analisada na próxima seção revelou informações sobre as micelas de CTAB, apesar dessa micelas serem bastante menores que os nanobastões de ouro. Isso só foi possível porque o espalhamento dos nanobastões não sobrepôs o espalhamento das micelas de CTAB nas regiões finais das curvas.

\subsubsection{Estudo de micelas de CTAB}

Neste estudo amostras de nanobastões sintetizados seguindo a rota de síntese padrão (MORASSO et al., 2015) são analisados. Os dados foram coletados de uma alíquota centrifugada e outra não centrifugada. O objetivo é analisar a influência da quantidade de CTAB nas curvas de SAXS bem como o processo de centrifugação.

A amostra sintetizada possui um excesso de CTAB na solução e a remoção desse excesso de surfactante é um dos objetivos do processo de centrifugação. As caracterizações por SAXS feitas neste estudo foram realizadas utilizando o equipamento Xeuss. A distância amostra-detector foi de 0,84 m resultando em um intervalo de $q$ de 0,12-4,5 $\mathrm{nm}^{-1}$.

Os dados de espalhamento dessas amostras, mostrados na figura 53, exibem uma diferença acentuada na região compreendida entre 0,51 e 2,3 $\mathrm{nm}^{-1}$. Ambas as curvas mostram um "ombro" nessa região, mas a curva da alíquota não centrifugada mostra um "ombro" mais acentuado do que a curva da alíquota centrifugada.

Esse espalhamento adicional na parte final da curva é resultado da presença de micelas de CTAB no meio aquoso. Assim, um fator de forma de elipsoides de revolução núcleo-casca foi adicionado ao modelo para descrever o espalhamento dessas micelas. Como na seção anterior, os nanobastões de ouro foram descritos por um fator de forma de cilindros. O modelo completo é exibido na equação 81. 


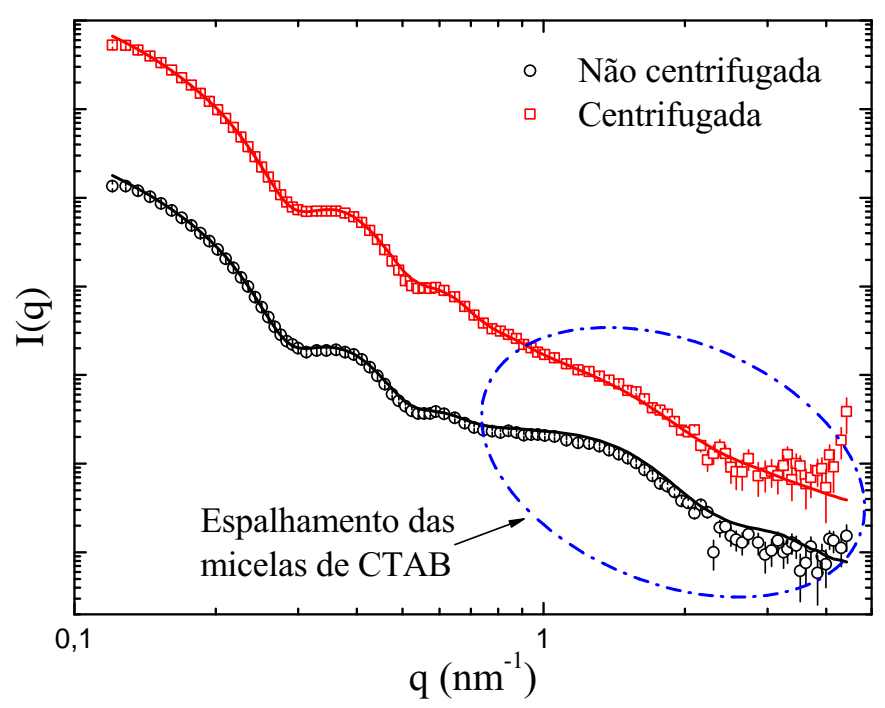

Figura 53 - Intensidade de espalhamento de SAXS de amostras de nanobastões centrifugada e não centrifugada.

Os parâmetros estruturais calculados são mostrados na tabela 7. Como esperado, o procedimento de centrifugação não afeta os nanobastões, já que os parâmetros do fator de forma de cilindros são praticamente iguais, com exceção do fator de escala $S c$. O maior valor desse parâmetro para a amostra centrifugada está diretamente relacionado à maior concentração de nanobastões promovida pelo processo de centrifugação.

A razão da concentração de nanobastões entre as duas amostras pode ser calculada pela razão dos fatores de escala $S c$, resultando em $S c_{\text {cent }} / S c_{N c e n t} \approx 4.5$. Esse resultado significa que a centrifugação causou um aumento de 4,5 vezes na concentração de nanobastões. Para as micelas $S c_{m i c}^{c e n t} / S c_{m i c}^{N c e n t} \approx 0,058$, o que significa que a concentração de micelas da amostra centrifugada é diminuiu cerca de 17 vezes.

Esses resultados motivaram a investigação de soluções de CTAB com diferentes concentrações. Três soluções aquosas com diferentes concentrações molares de CTAB foram preparadas de acordo com a publicação de Morasso et al. (2015): 20 mM, 50 mM e 200 mM. As soluções com concentrações de CTAB de 20 mM, 50 mM são usadas na síntese dos nanobastões, enquanto que a solução com concentração de 200 mM é usada na síntese das sementes. Essas soluções também possuem hidroquinona com concentração de $40 \mathrm{mM}$. Os dados de SAXS dessas soluções foram modelados considerando um sistema de elipsoides de revolução interagentes usando a equação 78.

As curvas da intensidade de espalhamento de SAXS dessas amostras, mostradas na figura 54, são muito peculiares. A intensidade de espalhamento é muito baixa no início e 
Tabela 6 - Parâmetros estruturais das amostras de nanobastões de ouro centrifugada e não centrifugada.

\begin{tabular}{ccc}
\hline & Centrifugada & Não centrifugada \\
\hline $\mathrm{Sc}$ & $322(3)$ & $71(1)$ \\
$\mathrm{R}(\mathrm{nm})$ & $13,07(2)$ & $12,96(3)$ \\
$\sigma(\mathrm{nm})$ & $1,518(1)$ & $1,56(2)$ \\
$\mathrm{L}(\mathrm{nm})$ & $44,9(5)$ & $47,8(7)$ \\
$\mathrm{Sc}_{\text {mic }}$ & $2,1(17) \times 10^{-4}$ & $3,6(5) \times 10^{-3}$ \\
$\mathrm{R}_{\text {mic }}(\mathrm{nm})$ & $1,75(4)$ & $1,93(7)$ \\
$\sigma_{\text {mic }}(\mathrm{nm})$ & $0,42(\mathrm{Fix})$ & $0,4(\mathrm{Fix})$ \\
$\epsilon_{\text {mic }}$ & $1,28(\mathrm{Fix})$ & $1,25(6)$ \\
$\mathrm{Th}_{\text {mic }}(\mathrm{nm})$ & $0,052(\mathrm{Fix})$ & $0,051(2)$ \\
$\rho_{\text {mic }}$ & $-10,205(\mathrm{Fix})$ & $-10,205(\mathrm{Fix})$ \\
$\left.\mathrm{Back}_{(\mathrm{cm}}{ }^{-1}\right)$ & $1 \times 10^{-8}(\mathrm{Fix})$ & $1 \times 10^{-8}(\mathrm{Fix})$ \\
\hline
\end{tabular}

$S c$ é o fator de escala, $\mathrm{R}$ é o raio médio, $\mathrm{L}$ é o comprimento médio e $\sigma$ é a polidispersidade dos nanobastões de ouro; $S c_{\text {mic }}$ é o fator de escala, $\mathrm{R}_{\text {mic }}$ é o raio médio do núcleo, $\sigma$ mic é a polidispersidade, $\epsilon$ mic é a excentricidade, $\mathrm{Th}_{\text {mic }}$ é a espessura da casca e $\rho$ mic é o contraste da densidade eletrônica da casca das micelas de CTAB; Back é a constante que descreve o fundo. O contraste da densidade eletrônica dos núcleos das micelas foi normalizado para 1.

no final das curvas, onde os dados experimentais exibem grandes flutuações. Essa é uma característica muito peculiar pois geralmente as curvas de SAXS de nanopartículas exibem alta intensidade para baixos valores de $q$. A baixa intensidade de espalhamento no início ocorre devido à forte interação entre as micelas do CTAB. Essa interação, descrita pelo fator de estrutura de esferas rígidas (equação 46), aumenta a ocorrência de interferência destrutiva do feixe espalhado, causando uma diminuição na intensidade de espalhamento no início da curva.

A tabela 7 mostra os parâmetros calculados. Pode-se ver que o raio médio diminui enquanto a excentricidade aumenta, indicando que as micelas se tornam mais finas e proporcionalmente mais alongadas à medida que a concentração aumenta. Além disso, o raio das esferas rígidas $\left(\mathrm{R}_{\mathrm{HS}}\right)$ diminui enquanto a fração de esferas rígidas $\eta$ aumenta, indicando que as micelas ficam mais compactadas e a interação entre elas fica mais intensa. Interessante observar que o fator de escala global $S c$ segue uma relação aproximadamente linear em relação à concentração de CTAB. 


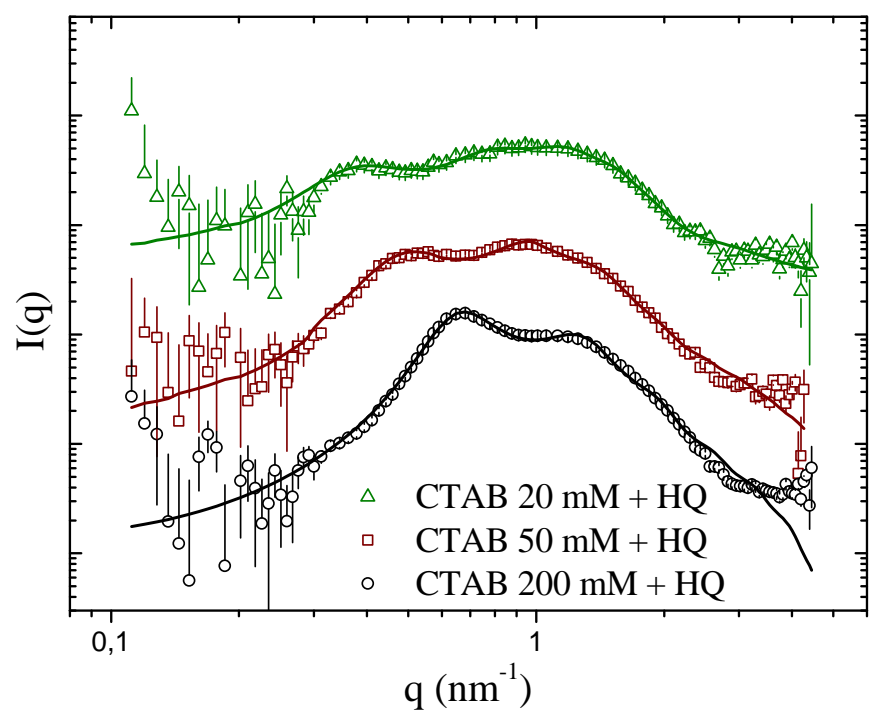

Figura 54 - Curvas de SAXS das amostras de CTAB.

Tabela 7 - Parâmetros estruturais calculados para soluções de CTAB com diferentes concentrações.

\begin{tabular}{cccc}
\hline & $20 \mathrm{mM}+\mathrm{HQ}$ & $50 \mathrm{mM}+\mathrm{HQ}$ & $200 \mathrm{mM}$ \\
\hline $\mathrm{Sc}_{\text {mic }}$ & $1,1(5) \times 10^{-10}$ & $2,5(1) \times 10^{-8}$ & $1,3(1) \times 10^{-7}$ \\
$\mathrm{R}_{\text {mic }}(\mathrm{nm})$ & $1,92(6)$ & $1,73(4)$ & $1,58(6)$ \\
$\sigma_{\text {mic }}(\mathrm{nm})$ & $4,19($ Fixo $)$ & $3,96($ Fixo $)$ & $4,01($ Fixo $)$ \\
$\epsilon_{\text {mic }}$ & $1,16(5)$ & $1,34(3)$ & $1,50(5)$ \\
$\mathrm{Th}_{\text {mic }}(\mathrm{nm})$ & $0,050(1)$ & $0,047(1)$ & $0,040(1)$ \\
$\rho_{\text {mic }}$ & $-10,2($ Fixo $)$ & $-10,2($ Fixo $)$ & $-10,2($ Fixo $)$ \\
$\mathrm{R}_{\mathrm{HS}}(\mathrm{nm})$ & $8,0(1)$ & $5,97(4)$ & $4,81(2)$ \\
$\eta$ & $0,21($ Fixo $)$ & $0,26($ Fixo $)$ & $0,32($ Fixo $)$ \\
Back $_{\left(\mathrm{cm}^{-1}\right)}$ & $2,2(2) \times 10^{-9}$ & $-1,9(5) \times 10^{-9}$ & $-1,1(2) \times 10^{-8}$ \\
\hline
\end{tabular}

$\mathrm{Sc}_{\text {mic }}$ é o fator de escala, $\mathrm{R}_{\text {mic }}$ é o raio médio do núcleo das micelas de CTAB, $\sigma$ mic é a polidispersidade, $\epsilon_{\text {mic }}$ é a excentricidade, $T h_{\text {mic }}$ é a espessura média da casca, $\rho$ mic é o contraste de densidade eletrônica da casca, $R_{H S}$ é o raio de interação de esferas rígidas, $\eta$ é a fração de volume de esferas rígidas e Back é a constante que descreve o fundo. O contraste da densidade eletrônica do núcleo foi considerado como 1 . 


\section{Conclusões parciais}

A análise estrutural dos nanobastões modificados revelou que as nanopartículas possuem formato cilíndrico bem definido. A polidispersidade é relativamente baixa e diminui com o tempo de síntese, enquanto que a razão de aspecto aumenta, conforme indicado por SAXS e pelos espectros de Uv-vis.

A análise dos nanobastões sintetizados usando a rota de síntese padrão mostrou que as caracterizações por SAXS foram capazes de fornecer informações sobre as micelas de CTAB presentes nas amostras. A caracterização dos nanobastões não foi afetada pelas micelas de $\mathrm{CTAB}$ e nem pelo processo de centrifugação, como revelou a comparação entre os parâmetros da amostra centrifugada e não centrifugada. Como esperado, a amostra centrifugada apresentou maior concentração de nanobastões e menor concentração de micelas de CTAB.

O estudo das micelas de CTAB revelou que as micelas se tornam mais alongadas e mais finas com a concentração. Além disso, a interação entre elas se torna mais intensa com a concentração. O estudo destes nanobastões somente foi possível pelo fato de termos o novo equipamento de SAXS (Xeuss 10m) disponível para os experimentos. 


\section{Conclusão}

Foi apresentada neste trabalho a complementaridade das técnicas de espalhamento e difração (SAXS, DLS e WAXS) com a técnica de imagem TEM. Os dados de SAXS forneceram dados adicionais extremamente pertinentes para os sistemas estudados. Esses dados forneceram informações sobre médias feitas em um grande número de partículas e uma ampla gama de escalas de comprimento.

Os dados de difração (XRD e WAXS) revelaram informações importantes sobre a estrutura cristalina dos sistemas estudados. Tamanhos médios de cristalito e parâmetros de rede determinados neste trabalho estão de acordo com valores relatados na literatura.

O estudo de nanopartículas de prata e ouro com diferentes composições e formas demonstrou a qualidade dos dados produzidos em equipamentos de laboratório. Além disso, foram obtidas informações estruturais importantes que podem ser usadas para a síntese de nanopartículas com características específicas de acordo com a aplicação desejada. A experiência adquirida na modelagem e análise dos dados de SAXS foi crucial para outros estudos realizados durante o projeto.

O estudo de nanopartículas globulares com diferentes concentrações de prata:ouro mostrou que quanto maior a quantidade de ouro, menor a nanopartícula. Além disso, a análise do fator de estrutura nos dados de SAXS indica que as correlações entre partículas são mais intensas para as nanopartículas de ouro e prata do que para as nanopartículas de prata pura ou ouro puro.

Os experimentos ex situ e in situ solidificaram o aprendizado em rotas de síntese e métodos de análise de nanopartículas metálicas adquiridas durante o estágio na Universidade de Duisburg-Essen. No experimento in situ de SAXS com nanopartículas núcleo-casca de paládio-ouro, a evolução do núcleo e a formação das cascas foram investigadas separadamente. Esse estudo demonstrou a estabilidade dos núcleos de paládio e proveu informações quantitativas sobre a evolução da espessura das cascas de ouro.

Uma segunda população de nanopartículas foi observada para uma amostra de nanopartículas de prata sintetizada usando uma rota de síntese específica reportada por Banerjee et al. (2014). As investigações foram capazes de revelar como o raio médio do sistema de nanopartículas evolui durante o processo de síntese, mostrando que o tamanho médio da população de nanopartículas pequenas permanece quase constante enquanto as nanopartículas grandes crescem em dois estágios diferentes. Além disso, uma hipótese sobre 
o mecanismo de formação de nanopartículas de prata, já observada em outras publicações, pôde ser formulada com base nos dados in situ de SAXS. A hipótese de que a coalescência é o principal mecanismo de crescimento do primeiro estágio e o amadurecimento de Ostwald pode ser o principal mecanismo do segundo estágio ainda não havia sido feita para nanopartículas de prata sintetizadas usando essa rota de síntese.

Os dados in situ das nanopartículas de ouro e prata confirmaram que as nanopartículas possuem uma interface difusa entre as regiões de concentração do ouro e da prata. Assim, essas nanopartículas estão em um estado intermediário entre uma liga e uma estrutura núcleo-casca. Como observado para as nanopartículas de prata, as nanopartículas de ouro e prata crescem em dois estágios. A distribuição das nanopartículas é, neste caso, monomodal. A presença de agregados foi sugerida pela análise dos dados. Esses agregados estão provavelmente relacionados a subprodutos de $\mathrm{AgCl}$ indicados pelos dados de XRD.

Usando a experiência em síntese adquirida durante o estágio na Alemanha, o autor da tese reproduziu com sucesso a síntese de nanobastões de ouro relatada no artigo de Morasso et al. (2015). De fato, uma modificação foi feita na rota de síntese para desacelerar o crescimento dos nanobastões. Os dados revelaram nanobastões muito bem definidos, com baixa polidispersidade de tamanho e forma. Os nanobastões tornaram-se mais alongados com o tempo de síntese, enquanto a polidispersidade do sistema diminuiu.

Os dados de SAXS dos nanobastões de ouro forneceram indicações de micelas de CTAB nas amostras. Assim, foi realizado um estudo das micelas e a influência do processo de centrifugação na amostra. O estudo mostrou que quanto maior a concentração de CTAB, mais alongadas são as micelas. Além disso, os dados de SAXS revelaram fortes interações entre as micelas. Como esperado, essas interações se tornaram mais intensas com o aumento da concentração de CTAB.

A comparação entre os dados de SAXS das amostras centrifugada e não centrifugada demonstrou quantitativamente que o processo de centrifugação removeu a maioria das micelas de CTAB da amostra, mas uma pequena porção ainda permaneceu. Foi confirmado que os nanobastões de ouro não foram afetados pela centrifugação.

Os resultados obtidos nesta tese permitem que seja possível ajustar o tamanho desejado de nanopartículas em uma síntese. Isso é muito importante pois partículas com tamanhos diferentes podem ter aplicações diferentes. Além disso, toda a metodologia de síntese e análise de dados pode ser aplicada para outros sistemas de nanopartículas. 


\section{Referências $^{1}$}

BANERJEE, S. et al. Structural evolution of silver nanoparticles during wet-chemical synthesis. Chemistry of Materials, ACS Publications, v. 26, n. 2, p. 951-957, 2014. Citado 6 vezes nas páginas 18, 67, 95, 96, 106 e 126.

BEVINGTON, P. R.; ROBINSON, D. K. Data Reduction and Error Analysis for the Physical Sciences. New York: McGraw-Hill, 2003. Citado 3 vezes nas páginas 23, 24 e 25.

BLEEKER, E. A. et al. Considerations on the eu definition of a nanomaterial: science to support policy making. Regulatory toxicology and pharmacology, Elsevier, v. 65, n. 1, p. 119-125, 2013. Citado na página 30.

BORCHERT, H. et al. Determination of nanocrystal sizes: a comparison of tem, saxs, and xrd studies of highly monodisperse copt3 particles. Langmuir, ACS Publications, v. 21, n. 5, p. 1931-1936, 2005. Citado na página 19.

BRAUN, A. et al. Validation of dynamic light scattering and centrifugal liquid sedimentation methods for nanoparticle characterisation. Advanced Powder Technology, Elsevier, v. 22, n. 6, p. 766-770, 2011. Citado na página 66.

CARPENA, P. et al. Problems associated with the treatment of conductivityconcentration data in surfactant solutions: simulations and experiments. Langmuir, ACS Publications, v. 18, n. 16, p. 6054-6058, 2002. Citado na página 136.

CAVALCANTI, L. et al. Two new sealed sample cells for small angle x-ray scattering from macromolecules in solution and complex fluids using synchrotron radiation. Review of scientific instruments, AIP, v. 75, n. 11, p. 4541-4546, 2004. Citado na página 76.

CHEON, J. M. et al. Synthesis of ag nanoparticles using an electrolysis method and application to inkjet printing. Colloids and Surfaces A-physicochemical and Engineering Aspects - COLLOID SURFACE A, v. 389, p. 175-179, 09 2011. Citado na página 35.

CONTI, M. et al. Phase ordering with a global conservation law: Ostwald ripening and coalescence. Physical Review E, American Physical Society (APS), v. 65, n. 4, abr. 2002. Citado na página 39.

CPS INSTRUMENTS EUROPE. Disc Centrifuge. 2019. Disponível em: 〈https: //www.uni-due.de/chemie/xrd/englisch/equipment). Acesso em: 18 nov. 2019. Citado 4 vezes nas páginas 10, 11, 65 e 83.

CULliTY, B. Elements of X-ray Diffraction. [S.l.]: Addison-Wesley Publishing Company, 1956. Citado na página 53.

EALIAS, A. M.; SARAVANAKUMAR, M. A review on the classification, characterisation, synthesis of nanoparticles and their application. In: IOP Conf. Ser. Mater. Sci. Eng. [S.l.: s.n.], 2017. v. 263, p. 032019. Citado 2 vezes nas páginas 30 e 32.

EDINGTON, J. W. Electron diffraction in the electron microscope. In: Electron Diffraction in the Electron Microscope. [S.1.]: Springer, 1975. p. 1-77. Citado na página 55.

1 De acordo com a Associação Brasileira de Normas Técnicas. NBR 6023. 
EINSTEIN, A. Über die von der molekularkinetischen theorie der wärme geforderte bewegung von in ruhenden flüssigkeiten suspendierten teilchen. Annalen der physik, Wiley Online Library, v. 322, n. 8, p. 549-560, 1905. Citado na página 58.

ESCALANTE, C.; SIERRA, E. Fundamentals of transmission electron microscopy, the technique with the best resolution in the world. 02 2019. Citado na página 62.

EUSTIS, S.; EL-SAYED, M. A. Determination of the aspect ratio statistical distribution of gold nanorods in solution from a theoretical fit of the observed inhomogeneously broadened longitudinal plasmon resonance absorption spectrum. Journal of Applied Physics, AIP, v. 100, n. 4, p. 044324, 2006. Citado na página 120.

EUSTIS, S.; EL-SAYED, M. A. Why gold nanoparticles are more precious than pretty gold: noble metal surface plasmon resonance and its enhancement of the radiative and nonradiative properties of nanocrystals of different shapes. Chemical society reviews, Royal Society of Chemistry, v. 35, n. 3, p. 209-217, 2006. Citado na página 18.

EVERETT, D. Manual of symbols and terminology for physicochemical quantities and units, appendix ii: Definitions, terminology and symbols in colloid and surface chemistry. Pure and Applied Chemistry, De Gruyter, v. 31, n. 4, p. 577-638, 1972. Citado na página 38.

FEIGIN, L.; SVERGUN, D. Structure Analysis by Small-Angle X-Ray and Neutron Scattering. [S.l.]: Plenum Press, New York, 1987. Citado 6 vezes nas páginas 42, 43, 44, 45,46 e 47.

FREESTONE, I. et al. The lycurgus cup - a roman nanotechnology. Gold bulletin, Springer, v. 40, n. 4, p. 270-277, 2007. Citado 3 vezes nas páginas 9, 30 e 31.

GARCIA, C. Modelagem e Simulação de Processos Industriais e de Sistemas Eletromecânicos Vol. 1. [S.l.]: EdUSP, 2005. Citado na página 23.

GARCIA, P. R. A. F. et al. Combining small-angle x-ray scattering and x-ray powder diffraction to investigate size, shape and crystallinity of silver, gold and alloyed silver-gold nanoparticles. Brazilian Journal of Physics, v. 49, n. 2, p. 183-190, 2019. Citado 4 vezes nas páginas 11, 89, 90 e 92 .

GARCIA, P. R. A. F. et al. An in situ saxs investigation of the formation of silver nanoparticles and bimetallic silver-gold nanoparticles in controlled wet-chemical reduction synthesis. Nanoscale Adv., RSC, v. 2, p. 225, 2020. Citado 8 vezes nas páginas 12, 13, 103, 106, 108, 112, 113 e 116.

GARRISON, J. An alternative to von glasersfeld's subjectivism in science education: Deweyan social constructivism. Science $\&$ Education, Springer, v. 6, n. 6, p. 543-554, 1997. Citado na página 52.

GLATTER, O.; KRATKY, O. Small-Angle X-ray Scattering. [S.l.]: New York: Academic Press, 1982. Citado na página 48.

GUINIER, A.; FOURNET, G.; YUDOWITCH, K. L. Small-angle scattering of x-rays. Wiley New York, 1955. Citado na página 117. 
HABIBA, K. et al. Fabrication of nanomaterials by pulsed laser synthesis. Manufacturing Nanostructures, One Central Press, Manchester, UK, 2014. Citado 2 vezes nas páginas 9 e 32 .

HAN, Y.-J.; KIM, J. M.; STUCKY, G. D. Preparation of noble metal nanowires using hexagonal mesoporous silica sba-15. Chemistry of Materials, American Chemical Society, v. 12, n. 8, p. 2068-2069, 2000. Citado na página 18.

HARADA, M.; IKEGAMI, R. In situ quick x-ray absorption fine structure and small-angle x-ray scattering study of metal nanoparticle growth in water-in-oil microemulsions during photoreduction. Crystal Growth \& Design, v. 16, n. 5, p. 2860-2873, 2016. Citado na página 38.

HARADA, M.; KATAGIRI, E. Mechanism of silver particle formation during photoreduction using in situ time-resolved saxs analysis. Langmuir, v. 26, n. 23, p. 17896-17905, 2010. Citado 2 vezes nas páginas 38 e 105.

INGHAM, B.; TONEY, M. X-ray diffraction for characterizing metallic films. In: Metallic Films for Electronic, Optical and Magnetic Applications. [S.1.]: Elsevier, 2014. p. 3-38. Citado na página 55.

IPEN - INSTITUTO DE PESQUISAS ENERGÉTICAS E NUCLEARES. Laboratório de Microscopia e Microanálise - LMM. 2019. Disponível em: 〈https: //www.ipen.br/portal_por/portal/interna.php?secao_id=523\&campo=2147 $\rangle$. Acesso em: 18 nov. 2019. Citado 2 vezes nas páginas 11 e 82.

ISO13318-1. Determination of Particle Size Distribution by Centrifugal Liquid Sedimentation Methods-Part 1: General Principles and Guidelines. [S.1.]: International Organization for Standardization Geneva, 2001. Citado na página 66.

ISO13318-2. Determination of Particle Size Distribution by Centrifugal Liquid Sedimentation Methods-Part 2: Photocentrifuge method. [S.l.]: International Organization for Standardization Geneva, 2007. Citado na página 66.

JEEVANANDAM, J. et al. Review on nanoparticles and nanostructured materials: history, sources, toxicity and regulations. Beilstein journal of nanotechnology, Beilstein-Institut, v. 9, n. 1, p. 1050-1074, 2018. Citado na página 30.

KNOLL, M.; RUSKA, E. Das elektronenmikroskop. Zeitschrift für physik, Springer, v. 78, n. 5-6, p. 318-339, 1932. Citado na página 63.

LAMER, V. K.; DINEGAR, R. H. Theory, production and mechanism of formation of monodispersed hydrosols. Journal of the American Chemical Society, ACS Publications, v. 72 , n. 11, p. 4847-4854, 1950. Citado na página 37.

LEA, M. C. Allotropic forms of silver. American Journal of Science, American Journal of Science (AJS), s3-37, n. 222, p. 476-491, jun. 1889. Citado na página 33.

LEVENBERG, K. A method for the solution of certain non-linear problems in least squares. Quarterly of applied mathematics, v. 2, n. 2, p. 164-168, 1944. Citado 2 vezes nas páginas 23 e 25 . 
LIFSHITZ, I. M.; SLYOZOV, V. V. The kinetics of precipitation from supersaturated solid solutions. Journal of physics and chemistry of solids, Elsevier, v. 19, n. 1-2, p. 35-50, 1961. Citado na página 38.

MARQUARDT, D. W. An algorithm for least-squares estimation of nonlinear parameters. Journal of the society for Industrial and Applied Mathematics, SIAM, v. 11, n. 2, p. 431-441, 1963. Citado 3 vezes nas páginas 23, 25 e 28.

MARTIN, E.; HINE, R. A dictionary of biology. [S.l.]: Oxford University Press, USA, 2015. Citado na página 51.

MAYER, K. M.; HAFNER, J. H. Localized surface plasmon resonance sensors. Chemical reviews, ACS Publications, v. 111, n. 6, p. 3828-3857, 2011. Citado 2 vezes nas páginas 61 e 62.

MERCURI, L. P. et al. Ordered mesoporous silica sba-15: A new effective adjuvant to induce antibody response. Small, Wiley Online Library, v. 2, n. 2, p. 254-256, 2006. Citado na página 18.

MORASSO, C. et al. Control of size and aspect ratio in hydroquinone-based synthesis of gold nanorods. Journal of Nanoparticle Research, Springer, v. 17, n. 8, p. 330, 2015. Citado 4 vezes nas páginas 70, 121, 122 e 127.

MORELHÃO, S. L. Computer simulation tools for x-ray analysis. Cham: Springer International Publishing, Springer, 2016. Citado 2 vezes nas páginas 53 e 54.

NGUYEN, T.-D. From formation mechanisms to synthetic methods toward shapecontrolled oxide nanoparticles. Nanoscale, The Royal Society of Chemistry, v. 5, p. 9455-9482, 2013. Citado na página 33.

OCEAN OPTICS. Ocean Optics. 2019. Disponível em: 〈https://blog.oceanoptics.com/ 5-great-things-favorite-spectrometers $\rangle$. Acesso em: 12 nov. 2019. Citado 2 vezes nas páginas 10 e 60.

OLIVEIRA, C. et al. Discovering new features of protein complexes structures by small-angle x-ray scattering. In: Applications of Synchrotron Light to Scattering and Diffraction in Materials and Life Sciences. [S.1.]: Springer, 2009. p. 231-244. Citado na página 75 .

OLIVEIRA, C. L. P. Investigating macromolecular complexes in solution by small angle x-ray scattering. Current trends in X-ray Crystallography, p. 367-392, 2011. Citado 4 vezes nas páginas 19, 46, 47 e 75 .

OLIVEIRA, C. L. P.; MONTEIRO, A. M.; NETO, A. M. F. Structural modifications and clustering of low-density lipoproteins in solution induced by heating. Brazilian Journal of Physics, v. 44, n. 6, p. 753-764, 2014. Citado 2 vezes nas páginas 50 e 136.

OSTWALD, W. Über die vermeintliche isomerie des roten und gelben quecksilberoxyds und die oberflächenspannung fester körper. Zeitschrift für physikalische Chemie, De Gruyter Oldenbourg, v. 34, n. 1, p. 495-503, 1900. Citado na página 38. 
PAUW, B. R. et al. Improvements and considerations for size distribution retrieval from small-angle scattering data by monte carlo methods. Journal of applied crystallography, International Union of Crystallography, v. 46, n. 2, p. 365-371, 2013. Citado 3 vezes nas páginas 85, 87 e 103.

PERCUS, J. K.; YEVICK, G. J. Analysis of classical statistical mechanics by means of collective coordinates. Physical Review, APS, v. 110, n. 1, p. 1, 1958. Citado na página 50 .

PÉREZ-JUSTE, J. et al. Gold nanorods: synthesis, characterization and applications. Coordination chemistry reviews, Elsevier, v. 249, n. 17-18, p. 1870-1901, 2005. Citado na página 120.

POLTE, J. Fundamental growth principles of colloidal metal nanoparticles-a new perspective. CrystEngComm, Royal Society of Chemistry, v. 17, n. 36, p. 6809-6830, 2015. Citado 4 vezes nas páginas 35, 36, 37 e 105.

PRESS, W. H. et al. Numerical recipes in C. [S.l.]: Cambridge university press Cambridge, 1996. Citado 6 vezes nas páginas 23, 25, 26, 27, 28 e 29.

PROVENCHER, S. W. Contin: a general purpose constrained regularization program for inverting noisy linear algebraic and integral equations. Computer Physics Communications, North-Holland, v. 27, n. 3, p. 229-242, 1982. Citado na página 59.

RAMACHANDRAN, V. S.; BEAUDOIN, J. J. Handbook of analytical techniques in concrete science and technology: principles, techniques and applications. [S.l.]: Elsevier, 2000. Citado na página 52.

Reibold M. et al. Carbon nanotubes in an ancient Damascus sabre. Nature, Nature Publishing Group, v. 444, p. 286, nov 2006. Disponível em: 〈https: //www.nature.com/articles/444286a\\#supplementary-information〉. Citado 2 vezes nas páginas 9 e 31.

RISTIG, S. et al. Nanostructure of wet-chemically prepared, polymer-stabilized silver-gold nanoalloys $(6 \mathrm{~nm})$ over the entire composition range. Journal of Materials Chemistry B, Royal Society of Chemistry, v. 3, n. 23, p. 4654-4662, 2015. Citado 4 vezes nas páginas $18,112,114$ e 115 .

ROSTEK, A. et al. Wet-chemical synthesis of pd-au core-shell nanoparticles $(8 \mathrm{~nm})$ : From nanostructure to biological properties. ChemistrySelect, Wiley Online Library, v. 3, n. 17, p. 4994-5001, 2018. Citado 6 vezes nas páginas 11, 12, 69, 99, 100 e 101.

SAKURAI, J. J.; NAPOLITANO, J. Modern quantum mechanics. [S.l.]: Addison-Wesley, 2011. Citado 4 vezes nas páginas 42, 43, 44 e 45.

SANCHEZ, F.; SOBOLEV, K. Nanotechnology in concrete-a review. Construction and building materials, Elsevier, v. 24, n. 11, p. 2060-2071, 2010. Citado 2 vezes nas páginas 30 e 32 .

SCOTTI, A. et al. The contin algorithm and its application to determine the size distribution of microgel suspensions. The Journal of chemical physics, AIP Publishing, v. 142, n. 23, p. 234905, 2015. Citado 2 vezes nas páginas 59 e 60. 
SHAH, M. et al. Gold nanoparticles: various methods of synthesis and antibacterial applications. Frontiers in bioscience (Landmark edition), v. 19, p. 1320-1344, 062014. Citado na página 33.

SPECTROSCOPY. 2019. Disponível em: 〈https://www.slideshare.net/MUBOSScz/ microscopy-fin $\rangle$. Acesso em: 31 jul. 2019. Citado 2 vezes nas páginas 10 e 63.

STOKES, S. G. G. et al. Mathematical and physical papers. [S.l.: s.n.], 1901. Citado na página 65.

SUN, Y.; XIA, Y. Large-scale synthesis of uniform silver nanowires through a soft, self-seeding, polyol process. Nature, v. 353, n. 1991, p. 737, 1991. Citado na página 35.

THANH, N. T.; MACLEAN, N.; MAHIDDINE, S. Mechanisms of nucleation and growth of nanoparticles in solution. Chemical reviews, ACS Publications, v. 114, n. 15, p. 7610-7630, 2014. Citado 2 vezes nas páginas 35 e 36.

TURKEVICH, J.; STEVENSON, P. C.; HILliER, J. A study of the nucleation and growth processes in the synthesis of colloidal gold. Discussions of the Faraday Society, Royal Society of Chemistry, v. 11, p. 55-75, 1951. Citado na página 33.

UNIVERSITY OF DUISBURG-ESSEN. X-RAY STRUCTURE ANALYSIS. 2019.

Disponível em: 〈https://www.uni-due.de/chemie/xrd/englisch/equipment〉. Acesso em: 18 nov. 2019. Citado 2 vezes nas páginas 11 e 80.

WAGNER, C. Theorie der alterung von niederschlägen durch umlösen (ostwald-reifung). Zeitschrift für Elektrochemie, Berichte der Bunsengesellschaft für physikalische Chemie, v. 65, n. 78, p. 581-591, 1961. Citado na página 38.

WANG, H. et al. Preparation of silver nanoparticles by chemical reduction method. Colloids and Surfaces A: Physicochemical and Engineering Aspects, Elsevier, v. 256, n. 2, p. 111-115, 2005. Citado 2 vezes nas páginas 34 e 67.

WIEDERRECHT, G. Handbook of nanoscale optics and electronics. [S.l.]: Academic Press, 2010. Citado 2 vezes nas páginas 61 e 62.

WILL, G. The Rietveld Method and the Two Stage Method to Determine and Refine Crystal Structures from Powder Diffraction Data. [S.l.]: Springer, 2006. Citado na página 55.

WILliAMS, D. B.; CARTER, C. B. Transmission Electron Microscopy. [S.1.]: Springer US, 2009. Citado 3 vezes nas páginas 10, 63 e 64 .

WILLIAMS, T.; KELLEY, C.; many others. Gnuplot 4.4: an interactive plotting program. 2010. 〈http://gnuplot.sourceforge.net/〉. Citado na página 83.

WRIEDT, T. Mie theory: A review. The Mie Theory: Basics and Applications, v. 169, p. 53-, 06 2012. Citado na página 31.

WU, C.-G.; BEIN, T. Conducting carbon wires in ordered, nanometer-sized channels. Science, p. 1013-1015, 1994. Citado na página 18.

XIA, Y. et al. Shape-controlled synthesis of metal nanocrystals: Simple chemistry meets complex physics? Angewandte Chemie International Edition, Wiley Online Library, v. 48, n. 1, p. 60-103, 2009. Citado 6 vezes nas páginas 9, 33, 35, 38, 39 e 40. 
ZEMB, T.; LINDNER, P. Neutrons, X-rays and light: scattering methods applied to soft condensed matter. [S.1.]: North-Holland, 2002. Citado 9 vezes nas páginas 14, 47, 48, 49, $50,51,56,57$ e 58 .

ZHAO, P.; LI, N.; ASTRUC, D. State of the art in gold nanoparticle synthesis.

Coordination Chemistry Reviews, v. 257, n. 3, p. $638-665,2013$. Citado 3 vezes nas páginas 9,33 e 34 . 
Apêndices 


\section{Apêndice A - Conteúdo complementar}

\section{A.1 A equação de Carpena}

A metodologia proposta por Carpena et al. (2002) foi utilizada para ajustar os dados de evolução temporal do raio médio das nanopartículas estudadas no experimentos in situ. Este método, desenvolvido para analisar dados de condutividade, assume que os dados que possuem o perfil típico dos dados de condutividade e podem ser descritos pela integral da equação sigmóide de Boltzmann:

$$
F(x)=F_{0}+A_{1} x+\Delta x\left(A_{2}-A_{1}\right) \ln \left(\frac{1+e^{\frac{x-x_{0}}{\Delta x}}}{1-e^{\frac{-x_{0}}{\Delta x}}}\right)
$$

aqui $F_{0}$ é o valor de $F(x)$ em $x=0, A_{1}$ é a inclinação do primeiro estágio, $A_{2}$ é a inclinação do segundo estágio, $\Delta x$ é a largura da região de transição entre os dois estágios e $x_{0}$ é o valor central da transição.

\section{A.2 O fator de escala de agregados $\mathrm{Sc}^{\mathrm{G}}$}

Considere-se um sistema composto por uma população de nanopartículas e N populações de agregados. Se o espalhamento devido às nanopartículas e aos agregados puderem ser desacoplados, a intensidade total de espalhamento será igual à soma da intensidade de espalhamento das populações de $\mathrm{N}$ agregados $\left[I^{A g g}(q)\right]$ com a intensidade de espalhamento das nanopartículas $\left[I_{N P}(q)\right]$ (OLIVEIRA; MONTEIRO; NETO, 2014):

$$
\begin{aligned}
& I(0)=c_{N P} \Delta \rho_{N P}^{2} V_{N P}^{2}+\sum_{i=1}^{N} c_{i} \Delta \rho_{i}^{2}\left(V_{i}^{A g g}\right)^{2}=c_{N P} \Delta \rho_{N P}^{2} V_{N P}^{2} \cdot\left[1+\frac{\sum_{i=1}^{N} c_{i} \Delta \rho_{i}^{2}\left(V_{i}^{A g g}\right)^{2}}{c_{N P} \Delta \rho_{N P}^{2} V_{N P}^{2}}\right] \\
& =I_{N P}(0) \cdot\left[1+\frac{\sum_{i=1}^{N} I_{i}^{A g g}(0)}{I_{N P}(0)}\right]
\end{aligned}
$$

onde foi assumido que o contraste de densidade eletrônica das nanopartículas e dos agregados são iguais. 
Comparando esta expressão com a expressão de intensidade e usando o fator de estrutura de agregados $\left[I(q)=c_{N P} \Delta \rho_{N P}^{2} V_{N P}^{2} P_{N P}(q) S^{G}(q)\right]$ para $q=0$ tem-se ${ }^{1}$ :

$$
c_{N P} \Delta \rho_{N P}^{2} V_{N P}^{2}\left(1+\sum_{i=1}^{N} S c_{i}^{G}\right)=I_{N P}(0)\left(1+\sum_{i=1}^{N} S c_{i}^{G}\right)=I_{N P}(0) \cdot\left[1+\frac{\sum_{i=1}^{N} I_{i}^{A g g}(0)}{I_{N P}(0)}\right]
$$

o que implica:

$$
S c_{i}^{G}=\frac{I_{i}^{A g g}(0)}{I_{N P}(0)}
$$

$1 \quad P(0)=1$ 


\section{Apêndice B - Dados complementares}

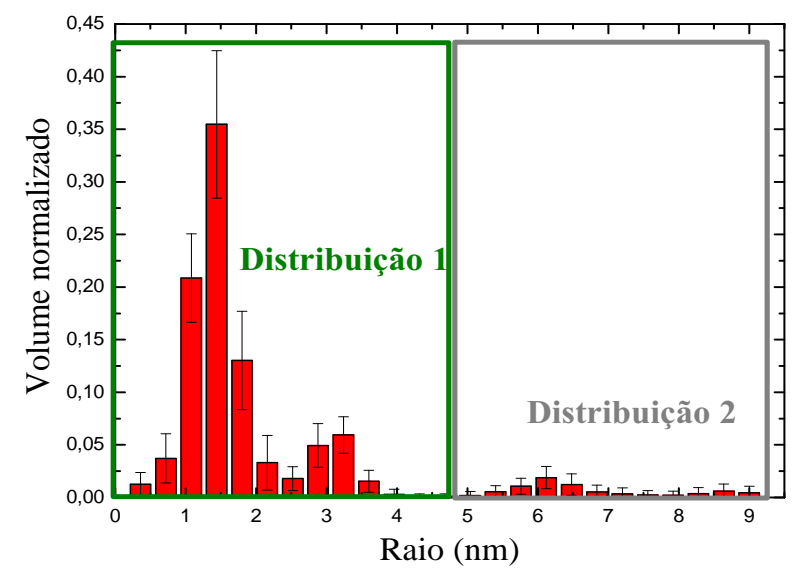

(a)

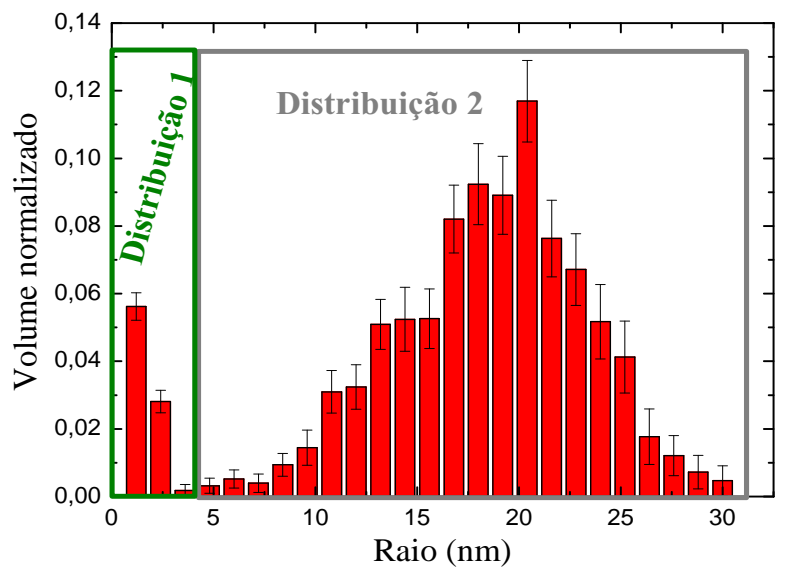

(b)

Figura 55 - Histogramas das distribuições de raio de alíquotas de nanopartículas de prata obtidas em (a) 7 e (b) 72 minutos de síntese.

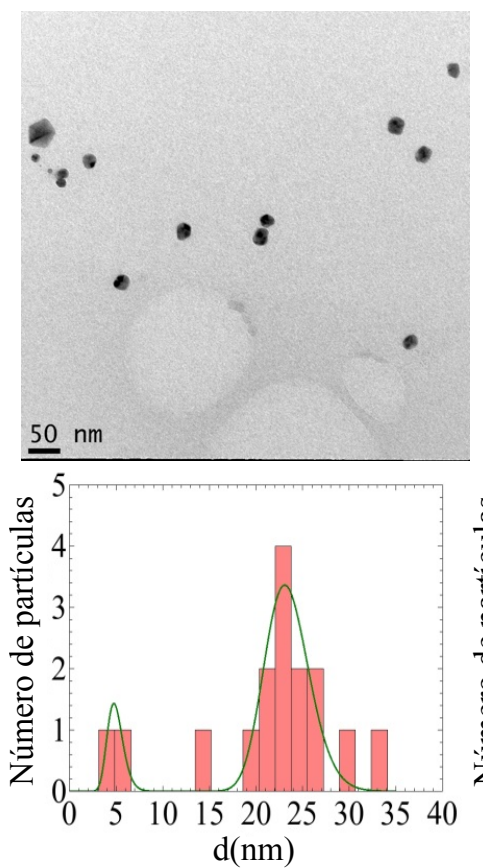

(a)

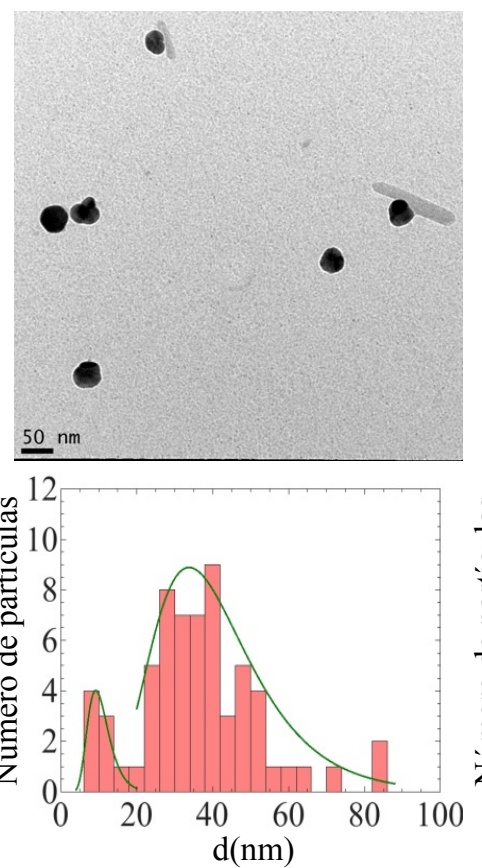

(b)

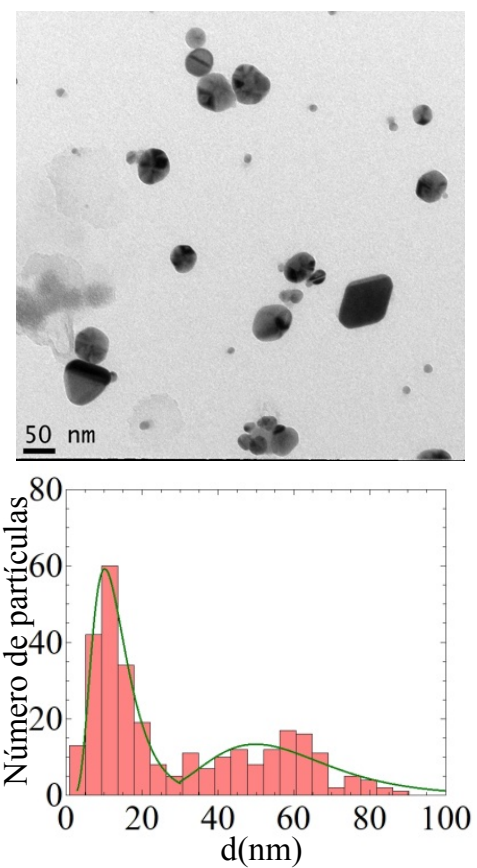

(c)

Figura 56 - Micrografias de TEM e distribuição de tamanhos de alíquotas de nanopartículas de prata obtidas em (a) 24 minutos, (b) 36 minutos e (c) 72 minutos de síntese. 
Tabela 8 - Parâmetros estruturais de nanopartículas de prata calculados usando as micrografias TEM.

\begin{tabular}{ccc}
\hline Tempo de síntese (min) & $\mathrm{R}(\mathrm{nm})$ & $\sigma(\mathrm{nm})$ \\
\hline 24 & 11,7 & 1,2 \\
36 & 21,0 & 8,8 \\
72 & 28,8 & 8,9 \\
\hline
\end{tabular}

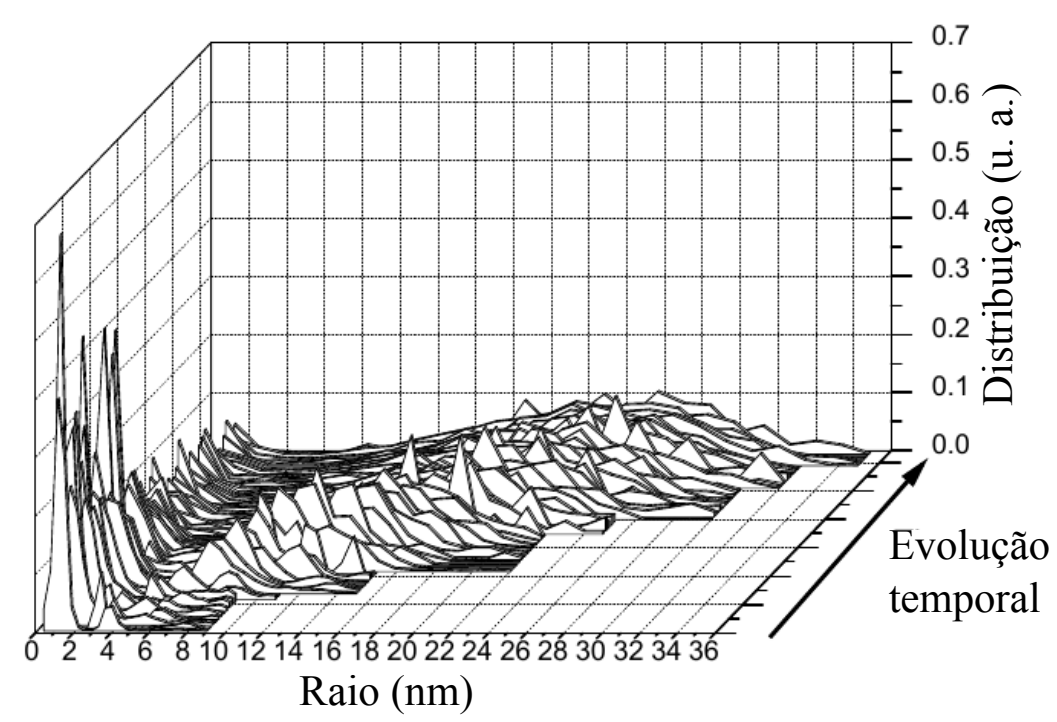

Figura 57 - Evolução temporal da distribuição de raios de nanopartículas de prata durante experimento in situ.

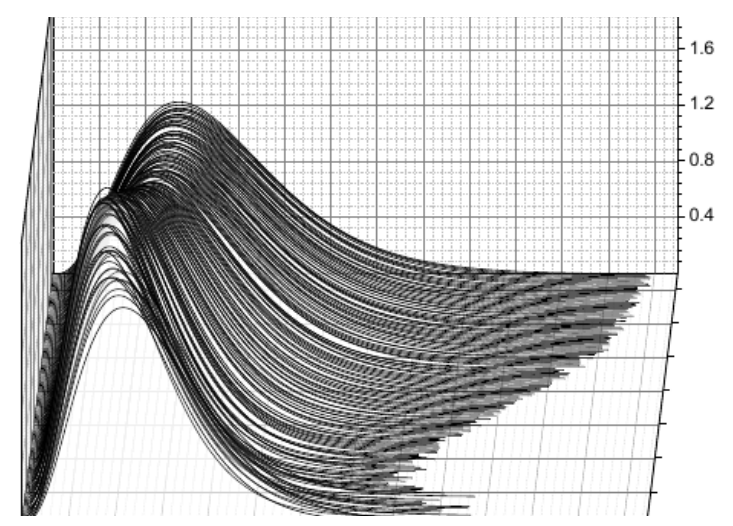

Figura 58 - Evolução temporal da distribuição de raios de nanopartículas de ouro-prata durante experimento in situ. 
Tabela 9 - Parâmetros estruturais das alíquotas de nanobastões de ouro obtidas em diferentes tempos de reação.

\begin{tabular}{ccccc}
\hline $\begin{array}{c}\text { Tempo de } \\
\text { síntese (min) }\end{array}$ & $\mathrm{Sc}$ & $\mathrm{R}(\mathrm{nm})$ & $\sigma(\mathrm{nm})$ & $\mathrm{L}(\mathrm{nm})$ \\
\hline 12 & $29,1(1)$ & $19,76(3)$ & $2,60(2)$ & $63,9(3)$ \\
22 & $23,0(1)$ & $18,60(2)$ & $2,10(3)$ & $69,5(3)$ \\
30 & $25,2(1)$ & $18,04(2)$ & $1,99(2)$ & $76,6(4)$ \\
40 & $33,8(1)$ & $17,82(1)$ & $1,61(1)$ & $81,1(3)$ \\
50 & $29,79(1)$ & $17,66(2)$ & $1,58(2)$ & $78,8(4)$ \\
60 & $19,91(8)$ & $17,45(2)$ & $1,54(1)$ & $80,3(4)$ \\
\hline
\end{tabular}

O fundo foi fixado em $1,3 \times 10^{-3} \mathrm{~cm}^{-1}$ para todas as alíquotas. 
Anexos 


\section{Nanoscale Advances}

Check for updates

Cite this: DOI: 10.1039/c9na00569b

Received 6th September 2019 Accepted 11th November 2019

DOI: 10.1039/c9na00569b

rsc.li/nanoscale-advances

\section{An in situ SAXS investigation of the formation of silver nanoparticles and bimetallic silver-gold nanoparticles in controlled wet-chemical reduction synthesis $\uparrow$}

\begin{abstract}
Paulo R. A. F. Garcia, ${ }^{a}$ Oleg Prymak, ${ }^{\text {b }}$ Viktoria Grasmik, ${ }^{\text {b }}$ Kevin Pappert, ${ }^{\text {b }}$ Wagner Wlysses, ${ }^{a}$ Larissa Otubo, ${ }^{c}$ Matthias Epple (D) *b and Cristiano L. P. Oliveira (D)*a

We present a study on the formation of silver (Ag) and bimetallic silver-gold (AgAu) nanoparticles monitored by in situ SAXS as well as by ex situ TEM, XRD and UV-vis analysis in a flow reactor at controlled reaction temperature. The formation mechanism of the nanoparticles is derived from the structural parameters obtained from the experimental data. The evolution of the average particle size of pure and alloyed nanoparticles shows that the particle growth occurs initially by a coalescence mechanism. The later growth of pure silver nanoparticles is well described by Ostwald ripening and for the alloyed nanoparticles by a process with a significantly slower growth rate. Additionally, the SAXS data of pure silver nanoparticles revealed two major populations of nanoparticles, the first one with a continuous crystal growth to a saturation plateau, and the second one probably with a continuous emergence of small new crystals. The particle sizes obtained by SAXS agree well with the results from transmission electron microscopy and X-ray diffraction. The present study demonstrates the capability of an in situ investigation of synthesis processes using a laboratory based SAXS instrument. Online monitoring of the synthesis permitted a detailed investigation of the structural evolution of the system.
\end{abstract}

\section{Introduction}

There is increasing interest in nanoparticles because of their remarkable properties and synergetic effects depending on their size, shape and chemical composition. One can find several studies in the literature on promising applications and advances in this field. ${ }^{1-3}$ Silver nanoparticles can be used to control the antibacterial and cytotoxic properties of colloids, and gold nanoparticles have unique optical properties, chemical stability and catalytic reactivity., ${ }^{\mathbf{4} 5}$ Alloyed silver-gold nanoparticles can potentially combine these properties in a controllable way. ${ }^{6}$

An understanding of the mechanism of nanoparticle formation is fundamental for proper control of the final morphology of the nanoparticle system. In addition, since the

${ }^{a}$ Institute of Physics, University of São Paulo, Rua do Matão 1371, São Paulo, 05508-090, Brazil

${ }^{b}$ Inorganic Chemistry and Center for Nanointegration Duisburg-Essen (CeNIDE), University of Duisburg-Essen, Universitaetsstr. 5-7, 45117 Essen, Germany. E-mail: matthias.epple@uni-due.de

${ }^{\circ}$ Laboratório de Microscopia e Microanálises (LMM), Instituto de Pesquisas Energéticas e Nucleares, IPEN-CNEN/SP, 05508-000, São Paulo-SP, Brazil. E-mail: crislpo@if. usp.br

$\dagger$ Electronic supplementary information (ESI) available. See DOI: $10.1039 / \mathrm{c} 9 \mathrm{na00569b}$ initial particle nucleation represents the very first stage of any crystallization process, it is very important to correctly characterize the nucleation process. ${ }^{7}$ Therefore, it is necessary to use experimental methods that allow in-depth structural characterization of the system.

By scanning and transmission electron microscopy (SEM/ TEM) and X-ray powder diffraction (XRD), Banerjee et al. ${ }^{8}$ investigated the formation of silver nanoparticles during the reduction with glucose, together with a colloidal stabilization with poly( $N$-vinylpyrrolidone) (PVP). They monitored the evolution of the particles and their internal crystallites for 3500 minutes of synthesis, resulting in particle sizes up to $75 \mathrm{~nm}$. In addition, electron microscopy provided information on the shape, size and inner structure of the produced nanoparticles. The synthesis of bimetallic nanoparticles offers new options to tune the properties of metallic nanoparticles, e.g. for plasmonic or biomedical applications..$^{9-18}$

Small angle X-ray scattering (SAXS) is a very useful technique for the investigation of the formation and growth mechanisms of nanoparticles, in situ, under realistic synthesis conditions. ${ }^{\mathbf{1 9 2 0}}$ The unique feature of SAXS is the possibility of online monitoring of the system during the measurements ${ }^{21}$ and it is demonstrated in a number of publications in the literature. Harada and Katagiri ${ }^{22}$ have reported an in situ SAXS study on the formation of silver nanoparticles by photoreduction. The 
average particle size was followed during the synthesis process, and a model for the growth mechanism was formulated based on Ostwald ripening and Lifshitz-Slyozov-Wagner (LSW) theory. This approach was extended to palladium systems where a similar behavior in aggregative particle growth and Ostwald ripening was also found by Harada and Ikegami. ${ }^{23}$ In both Ag and Pd nanoparticles synthesized by reduction in waterin-oil microemulsions, different stages in the metal nanoparticle formation were found, starting with a diameter of 8 $10 \mathrm{~nm}$ and followed by an initial fast crystal growth rate with a lower rate at later stages, where the particles almost double in size in the saturation region.

Polte et $a .^{24}$ studied the formation mechanism of silver nanoparticles using silver perchlorate as a precursor and sodium borohydride as a reducing agent. They also analyzed the influence of the steric stabilizing agent poly $(N$-vinylpyrrolidone), PVP. Using SAXS and ultra-violet visible spectroscopy (UV-vis), the authors concluded that coalescence is the main growth process during the synthesis of metallic nanoparticles in which the monomer-supplying chemical reaction is faster than the particle growth. The authors also made a comparison between the growth process of silver and gold nanoparticles, ${ }^{21}$ where a step-like formation mechanism was deduced, with coalescence being the main growth process. Similar results for the particle aggregation into regular assemblies were also reported by Chen et al. ${ }^{5}$ and Koerner et al. ${ }^{25}$ who investigated the formation of gold nanoparticles by in situ SAXS/ WAXS and UV-vis spectroscopy in the size range of about 2$6 \mathrm{~nm}$.

Singh et al. studied the formation and growth of bimetallic $\mathrm{Ag}-\mathrm{Cu}$ nanoparticles by co-reduction of silver nitrate and copper nitrate in water. ${ }^{26}$ Using SAXS, localized surface plasmon resonance (LSPR) and TEM, the authors showed a bimodal size distribution describing the formed spherical particles as a mixture of smaller (15-18 $\mathrm{nm}$ ) and larger particles (56-59 $\mathrm{nm}$ ), pointing to a cluster aggregation and their restructuring. $\mathrm{Wu}$ et al. investigated the formation of bimetallic PtSn nanoparticles by seed-mediated synthesis at elevated temperature. ${ }^{27}$ By in situ synchrotron X-ray scattering (SAXS) supported by WAXS and HRTEM, the authors showed the transformation of the initially formed Pt nanoparticles (fcc), reduced from Pt(II), to hexagonal PtSn nanocrystals by a fast diffusion of $\mathrm{Sn}$ into the Pt lattice. A volume increase of the nanocrystals to a saturation plateau as a function of the reaction time was also found.

Based on the available information from the literature, it can be concluded that the knowledge about the crystal formation and growth of metallic and bimetallic nanoparticles is of high interest, but the growth process is still not well understood. Some authors have observed a step-like development in the crystal growth of the formed particles via variable growth rates starting from small crystal seeds, ${ }^{24,28}$ but have neither focused on nor provided evidence for the co-existence of the smaller seeds during the whole synthesis. Furthermore, such a reduction synthesis is typically carried out at elevated temperature and therefore temperature fluctuations must be minimized in the system.

In our work, the synthesis routes are based on the so-called 'wet chemical process' which is a bottom-up strategy. ${ }^{4}$ A detailed study of the synthesis of pure silver and alloyed silvergold nanoparticles, followed by in situ SAXS and ex situ TEM, $\mathrm{XRD}$ and UV-vis, is presented. Special care was given to the temperature control in the reaction vessel using thermally isolated tubes in order to have fully isothermal conditions in the sample holder of the SAXS device. The investigation of the early crystal growth stages of mono- and bimetallic nanoparticles in a wide size range during a well-controlled and reproducible synthesis is the main focus of this article. Besides the detailed structural characterization of the investigated systems, the current work demonstrates the possibility of a careful online monitoring of synthesis processes using a laboratory-based SAXS system.

\section{Experimental conditions}

The experimental setup used for the in situ SAXS experiments is shown in Fig. 1. The synthesis was performed in a doublewalled glass reactor (volume about $500 \mathrm{~mL}$ ) which was held at the desired temperature by means of a circulating silicon oil bath. The sample holder was also thermally controlled with the same circulating line and consisted of a quartz capillary glued into a stainless-steel case which allowed a direct connection between the inlet and outlet tubes. The reaction solution in the glass reactor was vigorously stirred with a magnetic bar and continuously pumped through the sample holder with a peristaltic pump in a closed loop. All connecting tubes were thermally well isolated to minimize temperature gradients. The total volume in the tubes was about $20 \mathrm{~mL}$. The glass reactor was closed with a PTFE cover with a good fixation of the inlet and outlet tubes to avoid the evaporation of water.

The silver nanoparticle samples were synthesized following a procedure described by Banerjee et al. ${ }^{8}$ The SAXS measurements were performed during the synthesis: first, $16 \mathrm{~g}$ of glucose and $8 \mathrm{~g}$ of poly( $N$-vinylpyrrolidone), PVP, were dissolved in $320 \mathrm{~mL}$ water at $90{ }^{\circ} \mathrm{C}$. Then, $4 \mathrm{~g} \mathrm{AgNO}_{3}$, dissolved in $8 \mathrm{~mL}$ water, was quickly added. The temperature in the solution and in the sample holder was controlled at $90{ }^{\circ} \mathrm{C}$. After the mixing, the SAXS measurements were immediately started by taking frames at intervals of 1 min for up to 70 minutes up to a particle size of $\sim 40 \mathrm{~nm}$. Four aliquots for ex situ investigations (i.e. TEM, $\mathrm{UV} / \mathrm{vis}$ and XRD) were taken by quickly opening and closing a small lid in the cover of the glass reactor. For each aliquot, $15 \mathrm{~mL}$ of sample was taken using a glass pipet and immediately quenched by immersion in an ice bath. The aliquots were then centrifuged at $29400 \mathrm{~g}$ for 30 minutes and redispersed in pure water. This centrifugation procedure was repeated three times.

At the end of the stated observation period, no further significant changes in the SAXS curves were detected. It is notable that silver nanoparticles still continue to grow, as shown in previous works,${ }^{8}$ but the larger sizes were not accessible by our SAXS device.

The synthesis of the AgAu particles was adapted from Ristig et al. ${ }^{6} 300 \mathrm{~mL}$ ultra-pure water was heated to $100^{\circ} \mathrm{C}$. Then, silver nitrate $(1.5 \mathrm{~mL} ; 10 \mathrm{mM} ; 15 \mu \mathrm{mol})$ and gold(III) chloride trihydrate $(1.5 \mathrm{~mL} ; 10 \mathrm{mM} ; 15 \mu \mathrm{mol})$ were added under vigorous stirring, followed by a quick addition of a trisodium citrate 


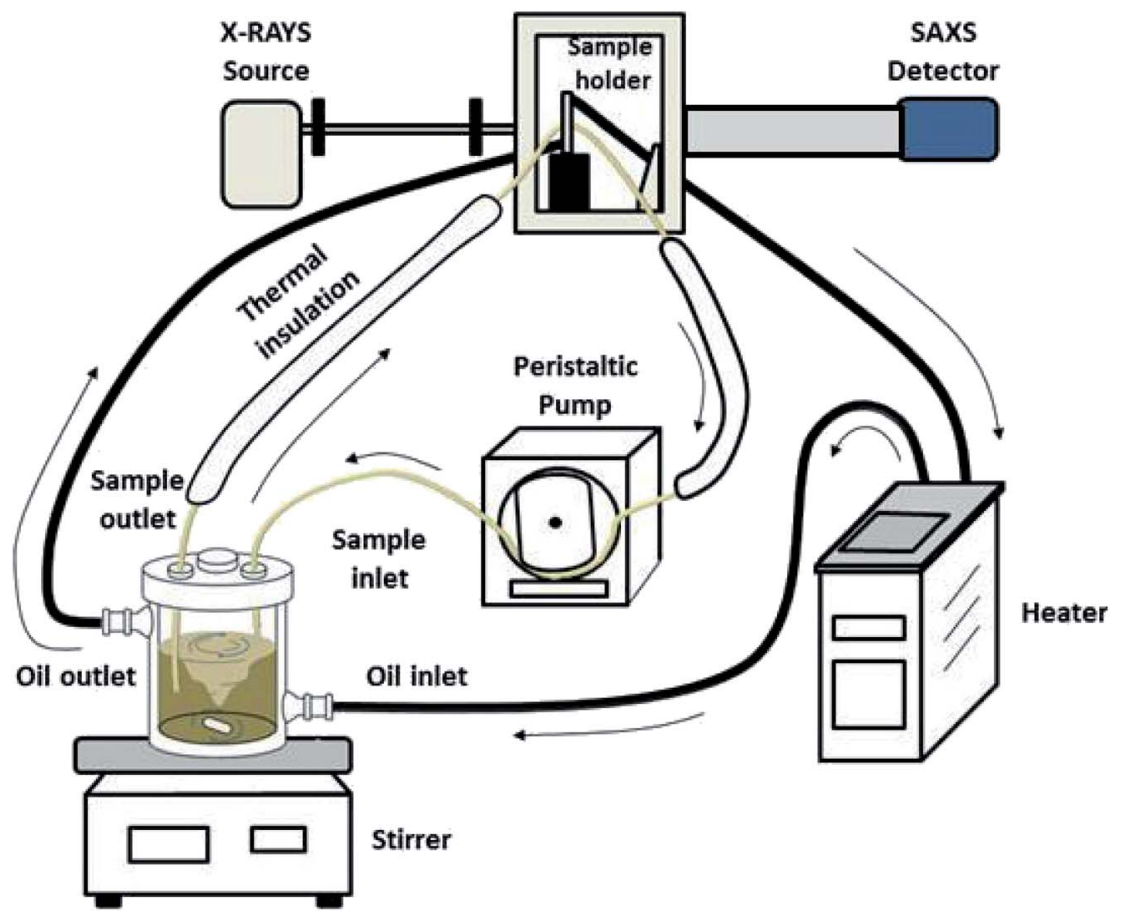

Fig. 1 Schematic representation of the experimental setup for the in situ SAXS experiments.

dihydrate solution ( $3 \mathrm{~mL} ; 58 \mathrm{mM} ; 174 \mu \mathrm{mol})$. This enabled the synthesis of bimetallic nanoparticles with the nominal molar composition $\mathrm{Ag}: \mathrm{Au}=50: 50$. At first, the SAXS experiments were carried out at $100{ }^{\circ} \mathrm{C}$, but the early stages of the crystal growth turned out to occur too fast to be followed in detail (data not shown). Therefore, the temperature was lowered to $70{ }^{\circ} \mathrm{C}$ in order to slow down the crystal growth and to precisely study the development of the alloyed particles. The in situ SAXS measurements were carried out for up to 157 minutes at $1 \mathrm{~min}$ intervals, resulting in final particle diameters of $\sim 20 \mathrm{~nm}$.

All chemicals were purchased from Sigma-Aldrich. Ultrapure water was obtained from a Milli-Q system from Millipore $₫$.

Small angle X-ray scattering data collection was performed on the laboratory-based SAXS equipment Xenocs XEUSS ${ }^{\mathrm{TM}}$ at the Institute of Physics, University of São Paulo. The scattering intensity is expressed as a function of the reciprocal space momentum transfer modulus $q=4 \pi \sin (\theta) / \lambda$, where $2 \theta$ is the scattering angle and $\lambda$ the radiation wavelength. The radiation was generated by a GENIX ${ }^{\mathrm{TM}}$ source ( $\mathrm{Cu} \mathrm{K} \alpha$ edge, $\lambda=1.54 \AA$ ) with the beam focused by FOX2 $\mathrm{D}^{\mathrm{TM}}$ optics. The beam collimation was performed using two sets of scatterless slits (Xenocs 2.0). In the high flux mode, the flux was $\sim 1 \times 10^{8}$ photons s $^{-1}$ with a beam size of $1 \times 1 \mathrm{~mm}^{2}$. The 2D SAXS data were collected with a Dectris Pilatus ${ }^{\mathrm{TM}} 300 \mathrm{k}$ detector. The sample-to-detector distance was approximately $0.90 \mathrm{~m}$, resulting in a range of $0.015<q<0.4 \AA^{-1}$. The scattering data were normalized to an absolute scale with water as the primary standard. A measurement of a quartz capillary filled with water heated to the temperature of the experiments was used as the background in the data correction procedure. The data treatment was performed using standard procedures. ${ }^{29}$
The transmission electron microscopy investigation was performed using a JEOL 2100 instrument equipped with a $\mathrm{LaB}_{6}$ filament, a high-resolution (HR) pole piece, and an energy dispersive X-ray spectroscopy (EDS) system (Thermo EDS detector). The microscope was operated at $200 \mathrm{kV}$ to achieve high-resolution imaging $(0.23 \mathrm{~nm})$. The samples were dispersed in water, and a few droplets of the suspension were transferred onto a carbon-coated collodion film copper grid. In order to obtain the particle size distribution from TEM micrographs (considering $\sim 150$ particles), the images were pre-treated with Image $^{30,31}$ for noise reduction with a smoothing filter and finally analyzed by Huang's thresholding method. ${ }^{32}$ Sizehistograms were fitted to a log-normal distribution given by eqn (1)

$$
p(D) \mathrm{d} D=\frac{1}{D s \sqrt{2 \pi}} \mathrm{e}^{\left(-\frac{\ln \left(\frac{D}{D_{\mathrm{m}}}\right)^{2}}{2 s^{2}}\right)}
$$

where $D_{\mathrm{m}}$ and $s$ are optimized values obtained from the fit. The mean diameter $D$ and the standard deviation of particle size $\sigma$ were determined from eqn (2) and (3):

$$
\begin{aligned}
& \langle D\rangle=D_{\mathrm{m}} \mathrm{e}^{\left(-\frac{s^{2}}{2}\right)} \\
& \sigma=\langle D\rangle \sqrt{\mathrm{e}^{s^{2}}-1}
\end{aligned}
$$

For the crystallographic characterization of the formed $\mathrm{Ag}$ and AgAu nanoparticles, an X-ray powder diffractometer (XRD, 
Bruker D8 Advance) with $\mathrm{Cu} \mathrm{K} \alpha$ radiation $(\lambda=1.54 \AA$; $40 \mathrm{kV}, 40$ $\mathrm{mA}$; Bragg-Brentano geometry) was used. ${ }^{33}$ The colloidal samples were placed and dried on a silicon single crystal to minimize scattering and investigated up to $90{ }^{\circ} 2 \theta$ with a step size of $0.03^{\circ}$ and a counting time of 6 seconds at each step. The qualitative phase analysis was performed with software Diffrac Suite EVA V1.2 (Bruker). The patterns of silver (Ag, \#04-0783) and silver chloride ( $\mathrm{AgCl}, \# 31-1238)$ from the ICDD database were used as references. Software TOPAS 4.2 (Bruker) was used for quantitative analysis by Rietveld refinement to calculate the lattice parameters and the average crystallite size from diffraction peak broadening (using the Scherrer equation): ${ }^{34}$

$$
\mathrm{CS}=\frac{K \lambda}{\mathrm{FWHM} \cos \theta}
$$

where CS is the crystallite size, $K$ is a form factor set to 0.89 (for spheres), FWHM is the full width at half maximum of each peak (in radians), and $\theta$ is the diffraction angle. For each Rietveld refinement, the instrumental correction was determined with a $\mathrm{LaB}_{6}$ standard powder sample obtained from NIST (SRM $660 \mathrm{~b})$.

Ultraviolet-visible spectroscopy (UV-vis) was used to measure the plasmonic properties of the nanoparticles. The measurements were performed using a Mikropack DH-2000-BAL light source and two Ocean Optics diffractometers USB4000. Plastic cuvettes with a sample volume of about $1 \mathrm{~mL}$ were used.

\section{Theoretical SAXS model}

In spite of some similarities, the two nanoparticle samples studied constitute systems with important structural differences. Therefore, two different approaches were necessary to fit the SAXS data. In both cases, a system of polydisperse spheres was assumed, which is a good approximation for the shape of the formed nanoparticles as confirmed by TEM.

\section{Monte Carlo (MC) model}

In this approach, a Monte Carlo optimization method was used to obtain the particle size distribution of spheres that provided the best fit of the experimental data. Mathematical and computational details can be found in Martelli and Di Nunzio ${ }^{35}$ and Pauw et al. ${ }^{36}$ In general, the method provides a histogramlike size distribution and uncertainties for each histogram bar. The quality of the fit is evaluated using the chi-square test. From the obtained particle size distributions, further analyses can be performed, e.g. the identification of different particle populations and the calculation of volume fractions, average sizes and standard deviations.

The overall equation of the MC model is ${ }^{36}$

$$
I(q)=B+S_{\mathrm{C}}\left(\frac{4}{3} \pi\right)^{2} \sum_{i=1}^{N_{\mathrm{S}}} P_{i}^{\mathrm{sph}}\left(q, R_{i}\right) R_{i}^{(6-p c)}
$$

where $B$ is a constant describing the background, $S_{\mathrm{c}}$ is an overall scale factor, $N_{\mathrm{s}}$ is the number of spheres considered by the model, $P_{i}^{\mathrm{sph}}\left(q, R_{i}\right)$ is the form factor of a sphere with radius $R_{i}$, and $p c$ is a stabilization parameter.
The form factor $P^{\mathrm{sph}}(q, R)$ of a sphere with radius $R$ is given $\mathrm{by}^{37}$

$$
P^{\mathrm{sph}}(q, R)=F^{\mathrm{sph}}(q)^{2}=\left[3 \frac{\sin (q R)-q R \cos (q R)}{(q R)^{3}}\right]^{2}
$$

The parameter $p c$ has typical values in the range $2<p c<3.3$ in order to ensure the stability of the fitting procedure. ${ }^{36}$ One of the main features of this approach is the fact that the obtained distribution is model-free, i.e. it can adopt any shape, similar to standard Indirect Fourier Transformation (IFT) approaches, ${ }^{38,39}$ but with the advantage of an easy inclusion of additional contributions to the theoretical intensity.

\section{Model of aggregated polydisperse spheres (APSs)}

In this approach it is assumed that we have a polydisperse system of spheres which can form large aggregates. The scattering intensity is described as ${ }^{40}$

$$
I(q)=S_{\mathrm{C}}\left(\int_{0}^{\infty} V^{2}(R) D(R, \sigma) P^{\mathrm{sph}}(q, R) \mathrm{d} R\right) S_{\mathrm{G}}(q, \mathrm{RG})+B
$$

where $S_{\mathrm{C}}$ is a global scale factor, $R$ is the radius of the spheres, $V(R)$ is the volume of the spheres, $\sigma$ is the size polydispersity, $S_{\mathrm{G}}(q, \mathrm{RG})$ is the structure factor of the aggregates having an overall radius of gyration (RG), and $B$ is a constant for the background.

The form factor of the spheres $P^{\mathrm{sph}}(q, R)$ is the same as in eqn (6), and the number distribution is given by a Schulz-Zimm function $D(x, z)$ which is useful due to its ability to describe asymmetric distributions: ${ }^{40}$

$$
D(x, z)=\left(\frac{z+1}{x_{\mathrm{c}}}\right)^{z+1} \frac{x^{z}}{\Gamma(z+1)} \mathrm{e}^{-(z+1) \frac{x}{x_{\mathrm{c}}}}
$$

where $x_{\mathrm{c}}$ is the central value of the distribution, $\Gamma(x)$ is the gamma function, and $z$ is defined as $z=1 /(\sigma / R)^{2}-1$. $\sigma$ is the polydispersity of the spheres in the system.

The presence of large aggregates is included in the model by a Guinier Structure Factor $\left(S_{\mathrm{G}}\right)$ :

$$
S_{\mathrm{G}}(q, \mathrm{RG})=1+S_{\mathrm{C}}^{\mathrm{G}} \mathrm{e}^{-\frac{q^{2} \mathrm{RG}^{2}}{3}}
$$

where the scale factor $S_{\mathrm{C}}^{\mathrm{G}}$ is related to the fraction of aggregates. ${ }^{41,42}$ In this case, we consider that at low $q$ values, the scattering intensity is given by the Guinier law. ${ }^{43}$ If the aggregates are assumed to be spherical, their average radius is related to the obtained RG as follows:

$$
\left\langle R_{\mathrm{AGG}}\right\rangle=\sqrt{\frac{5}{3}} \mathrm{RG}
$$

It can be shown that the scale factor $S_{\mathrm{C}}^{\mathrm{G}}$ is given by the ratio of the number concentration $c$ times the squared volume $V$ of the particles of the two populations: ${ }^{\mathbf{4 2}}$

$$
S_{\mathrm{C}}^{\mathrm{G}}=\frac{c_{\mathrm{AGG}} V_{\mathrm{AGG}}^{2}}{c V^{2}}
$$


Finally, the average radius was calculated using the equation $^{40}$

$$
\left\langle R_{j}\right\rangle=\left(\frac{\int_{0}^{\infty} D(R . \sigma) R^{i} \mathrm{~d} r}{\int_{0}^{\infty} D(R . \sigma) \mathrm{d} r}\right)^{\frac{1}{i}}
$$

If $i=1$ the average is weighted by number $(j=$ number) and if $i=3$ the average is weighted by volume $(j=$ volume). For the evolution of the particle sizes, a model proposed by Carpena et $a l .{ }^{44}$ was used, where the function is described by the integral of the Boltzmann sigmoidal equation:

$$
F(x)=F_{0}+A_{1} x+\Delta x\left(A_{2}-A_{1}\right) \ln \left(\frac{1+\mathrm{e}^{\frac{x-x_{0}}{\Delta X}}}{1+\mathrm{e}^{\frac{-x_{0}}{\Delta X}}}\right)
$$

where $F_{0}$ is the value of $F(x)$ at $x=0, A_{1}$ is the slope of the first stage, $A_{2}$ is the slope of the second stage, $\Delta x$ is the width of the transition between the two stages and $x_{0}$ is the central value of the transition. This equation enables a precise description of the growth of $\mathrm{Ag}$ and $\mathrm{AgAu}$ nanoparticles as a function of time as well as the determination of rates and transition points.

\section{Coalescence and Ostwald ripening}

In order to gain further insights into the growth mechanism of the nanoparticles, one can investigate the evolution of the number-average size as a function of time. Several authors have proposed a hypothesis on the growth mechanism (coarsening processes) in terms of the diffusion-limited Ostwald ripening and dynamic coalescence. This approach is based on the temporal evolution rate of the average radius, which follows a power-law function of time: $R \propto t^{x} .^{22}$ If exponent $x$ has a value of 0.50 the growth is dominated by dynamic coalescence. ${ }^{45}$ On the other hand, if $x$ is 0.33 , then the growth is controlled by Ostwald ripening (diffusion-limited ripening), as stated by Lifshitz-Slyozov-Wagner (LSW) theory. ${ }^{22,46}$ There are other models based on the average radius growth rate and the socalled dynamic cluster coalescence (see Sholl \& Skodje $(1996)^{47}$ and Woehl et al. $\left.(2014)^{48}\right)$. However, since other authors used LSW theory to describe silver and silver-gold nanoparticles, ${ }^{21,24}$ the same approach was used in the current work.

\section{Silver nanoparticles}

In Fig. 2a the experimental in situ SAXS data acquired during the synthesis of silver nanoparticles are shown together with the MC model fits. For a better visualization of the time evolution of the scattering intensity, only selected frames are presented. In Fig. S1a, $\uparrow$ the full dataset and MC model fits are shown. The proposed model provides a very good fit for the full dataset. The forward scattering increases over time, indicating a continuous increase in particle sizes and concentration.

The data analysis indicates that the system of silver nanoparticles can be described as consisting of two major populations. The size distributions determined after 7 and 72 min of synthesis are shown in Fig. S2a and b. $\dagger$ From a visual inspection of these distributions, two different particle populations can be clearly distinguished. One consists of smaller nanoparticles with a diameter of $\sim 3 \mathrm{~nm}$ (distribution 1) and another one consists of larger nanoparticles with a diameter from 10 to $40 \mathrm{~nm}$ (distribution 2). This behavior is clearly seen in the full series of the MC distributions shown in Fig. S1b. $\dagger$ Therefore, for the calculations of average sizes, volume fractions and polydispersity, the following criterion was used to distinguish these two different distributions: distribution 1: particle size smaller than or equal to $9 \mathrm{~nm}$, distribution 2: particle size larger than $9 \mathrm{~nm}$.

From the fitting of all SAXS curves the evolution of the average particle sizes for both large and small populations were obtained and are shown as a function of the synthesis time (Fig. 2b). Interestingly, the results indicate that the average size of the small particles remains almost constant $(\sim 3-4 \mathrm{~nm})$ during the whole synthesis. It is necessary to stress that there must be ultrasmall nanoparticles or seeds $(<2 \mathrm{~nm})$ in the system as well, but their contribution to the total scattering is masked by the constant background. This background results from the scattering intensity of the dissolved reactants in the solution, including ultrasmall nanoparticles and seeds.

At the same time, the evolution of larger particles from 10 to $40 \mathrm{~nm}$ is observed. The growth happens in different states, as clearly indicated for the volume-weighted average diameter curve in Fig. 2b. The results indicate two major kinetic rates: faster at the beginning $\left(0.59 \mathrm{~nm} \mathrm{~min}^{-1}\right)$ and slower at the end $\left(0.26 \mathrm{~nm} \mathrm{~min}^{-1}\right)$. This behavior can be described by the Carpena model in eqn (13) that provides the identification of the critical particle size $(\sim 36 \mathrm{~nm})$ at a synthesis time of about $51 \mathrm{~min}$. After this time, the particle growth seems to reach a saturation level, probably caused by a different crystal growth mechanism or by a balance between the reduction of the silver ions in the solution and the oxidation processes on the surface of the nanoparticles. ${ }^{49}$ Banerjee et $a{ }^{8}{ }^{8}$ and Ahlberg et al. ${ }^{49}$ found a plateaulike behavior for the crystal growth and the dissolution of silver nanoparticles as a function of time, respectively.

The volume fraction occupied by the two nanoparticle populations is shown in Fig. 2c. At the beginning of the synthesis, the system is dominated by smaller nanoparticles (distribution 1) which continuously grow to larger particles (distribution 2) and contribute to the volume fraction change. It is interesting to see that at a synthesis time of about $27 \mathrm{~min}$, the volume fractions for the two distributions are similar, corresponding to a diameter of $\sim 20 \mathrm{~nm}$ for the larger nanoparticles. Furthermore, a saturation plateau is also observed at around $40 \mathrm{~min}$ in the volume fraction plot.

Fig. 2d shows a log-log plot of the number weighted radius as a function of time. From 15-51 minutes, an exponent $x$ of about 0.55 was obtained and after this point, an exponent of 0.33 . Therefore, the initial growth has the predominance of coalescence which is then followed by Ostwald ripening. Coalescence has been found to be the main growth mechanism of several nanoparticle systems..$^{21,22,50}$ Even though the obtained results strongly suggest Ostwald ripening as the growth mechanism for 

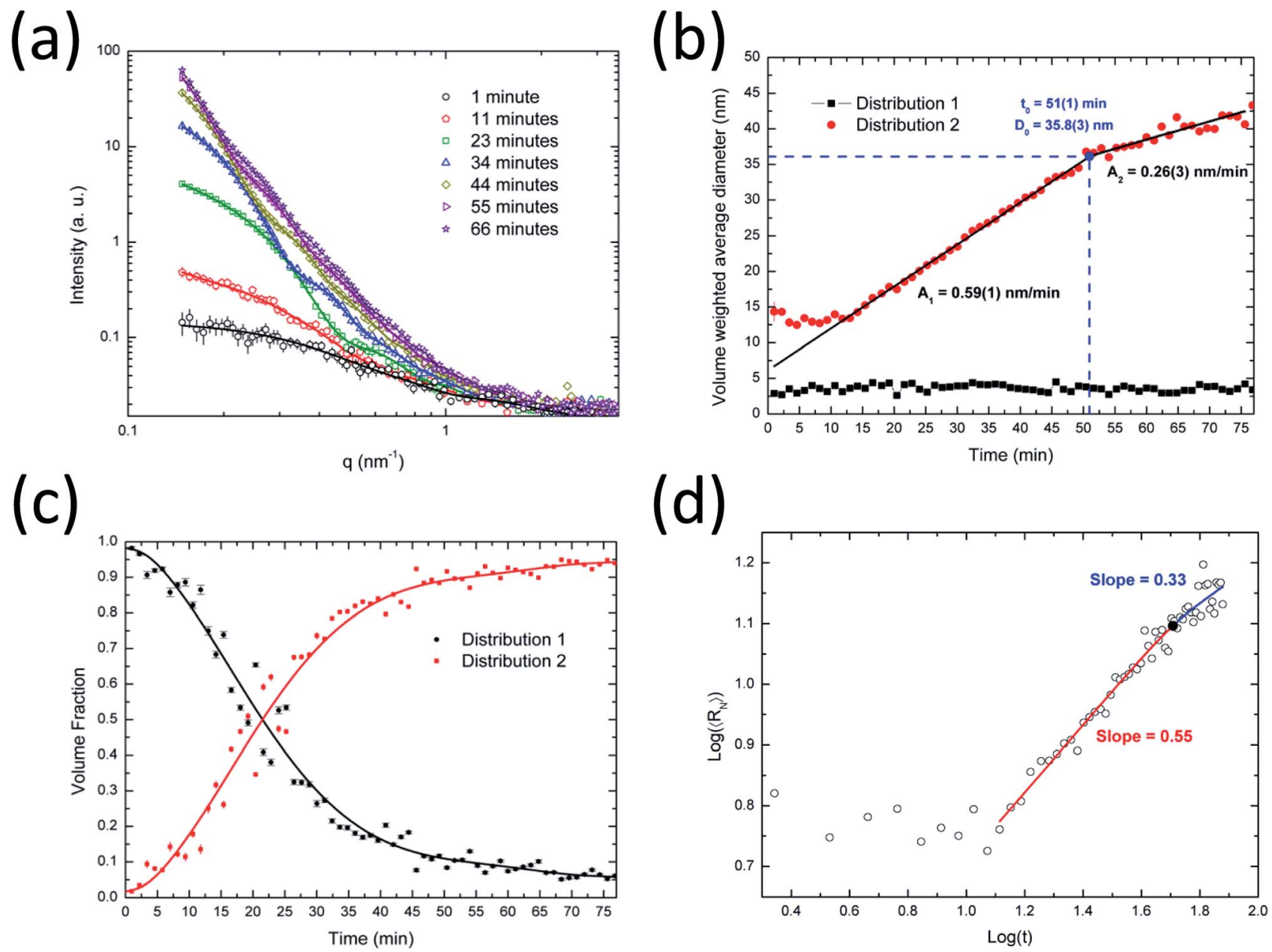

Fig. 2 SAXS results for Ag nanoparticle synthesis. (a) Experimental in situ SAXS data (symbols) and theoretical curves (lines) recorded during the synthesis of silver nanoparticles at $90^{\circ} \mathrm{C}$, (b) volume weighted average diameter of distributions 1 and 2, (c) temporal evolution of the volume fractions and (d) log-log plot of the number weighted average radius as a function of time.

the late stage of the nucleation of the silver nanoparticles, there is no general agreement about this in the literature. Polte ${ }^{28}$ states that Ostwald ripening is an unlikely process because metallic clusters and nanoparticles are thermodynamically stable even at high temperatures. However, several authors show results that support the assumption of Ostwald ripening. In any case, we found a decrease in the exponent value and the inclination close to $1 / 3$ suggests that Ostwald ripening may be dominant in this stage of the synthesis.

Since the synthesis is initially dominated by coalescence it can be concluded that the smaller particles found in the system are coalescing to form the larger ones. However, since the presence of smaller nanoparticles is observed throughout the synthesis they may be continuously formed and replaced by newly formed crystals that have reached the size required to be detectable by SAXS.

Fig. 3a-f show the TEM images of silver nanoparticles taken from the reaction mixture at different times together with the obtained size distributions. In good agreement with SAXS results, there are both small and large nanoparticles in the system. This confirms the crystal growth of particles from $\sim 20 \mathrm{~nm}$ up to $\sim 60 \mathrm{~nm}$ with increasing synthesis time while the size of the small particles remains at about $5 \mathrm{~nm}$.

In order to investigate the inner structure of the nanoparticles, high-resolution TEM (HR-TEM) experiments and fast Fourier transform (FFT) of the micrographs were performed (Fig. 4a and b). Large silver nanoparticles with a diameter of $\sim 30 \mathrm{~nm}$ consisting of several crystallites or domains with a size of $\sim 10 \mathrm{~nm}$ were found. This polycrystallinity with a fivefold symmetry and a ratio of crystallite size : particle diameter of $1: 3$ is in excellent agreement with earlier studies. ${ }^{\mathbf{8}, 51,52}$

A detailed analysis of the HRTEM micrograph and the corresponding FFT analysis show the presence of (111) crystallographic planes inside one domain with an interplanar distance $\left(d_{\mathrm{hkl}}\right)$ of $2.34 \AA$ (ICDD card 04-0783). ${ }^{6,53}$ The smaller nanoparticles with a diameter of $2-3 \mathrm{~nm}$ are also crystalline with the same interplanar distance $(2.34 \AA$ ) , which corresponds to the (111) plane. The determined interplanar distances were also in agreement with the values ( $c a$. 2.4 $\AA$ ) found in HRTEM investigations for the (111) planes of silver ${ }^{54}$ and gold. ${ }^{55}$ The presented dominance of the (111) crystallographic planes in the twinned $\mathrm{Ag}$ nanoparticles also agrees well with the tetrahedral 
(a)

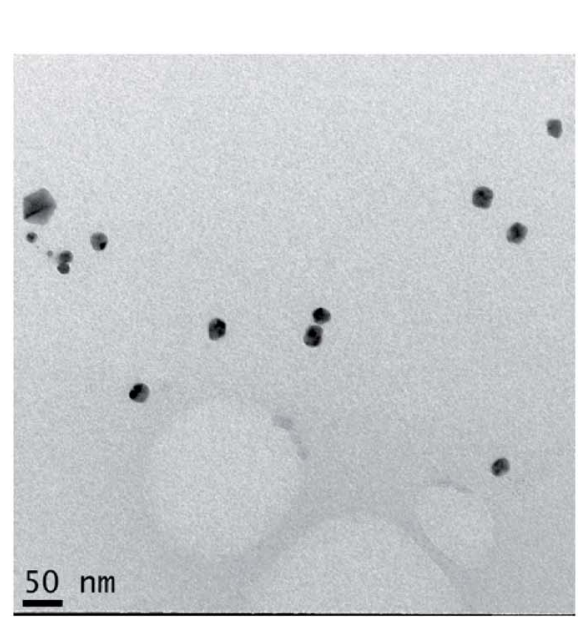

(c)

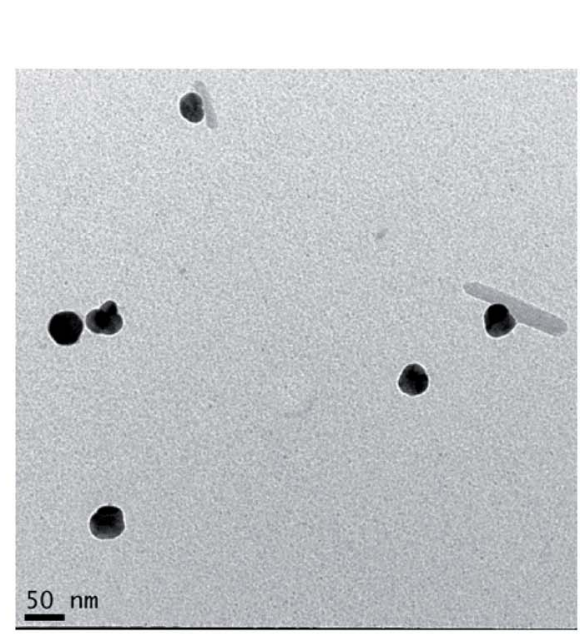

(d)

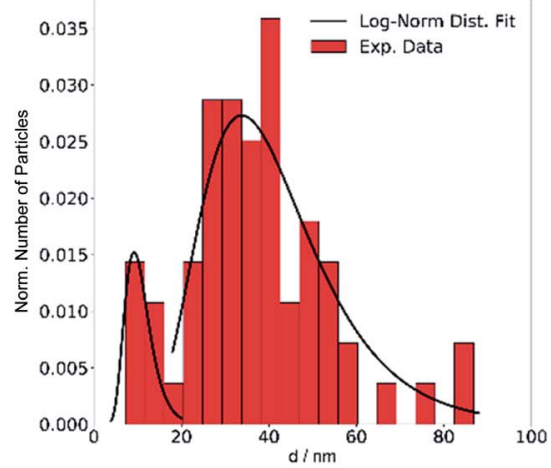

(f)

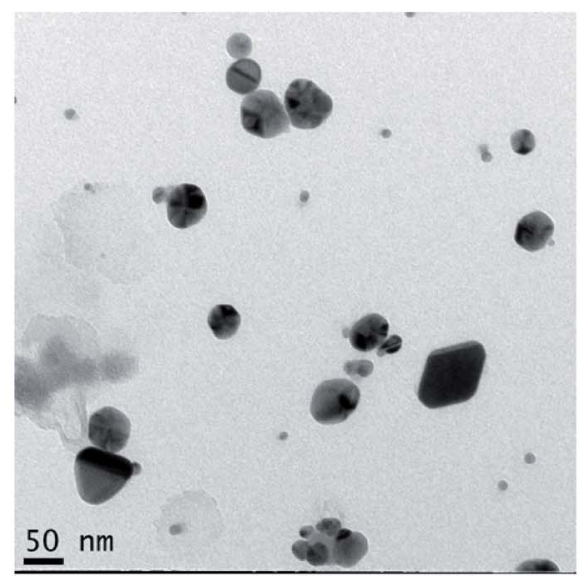

(b)

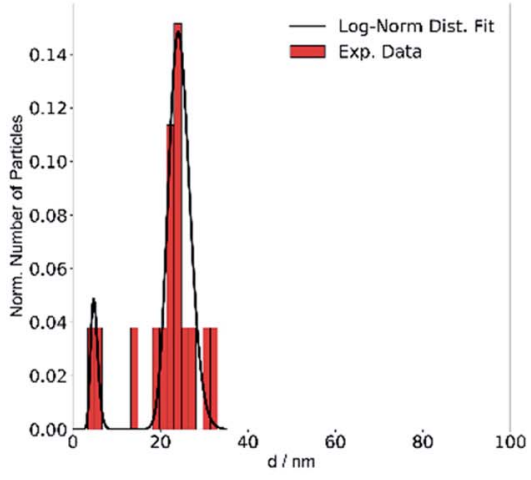

(e)

Fig. 3 Ex situ TEM investigation of the synthesis of silver nanoparticles at $90{ }^{\circ} \mathrm{C}$. TEM micrographs and particle size distribution of silver nanoparticles obtained after $24 \mathrm{~min}(\mathrm{a}$ and b), $36 \mathrm{~min}$ ( $c$ and $\mathrm{d}$ ) and $72 \mathrm{~min}$ ( $\mathrm{e}$ and f) reaction time.

configuration of each individual domain in fcc silver as shown by Helmlinger et al. ${ }^{\mathbf{8} 51,52}$ Furthermore, a preferred orientation of (111) was also detected by XRD (see Fig. 4c), where the intensity ratio of the planes was found with $I(111): I(200)=100: 17$ compared to untextured silver $I(111): I(200)=100: 41$, as from ICDD card 04-0783. 

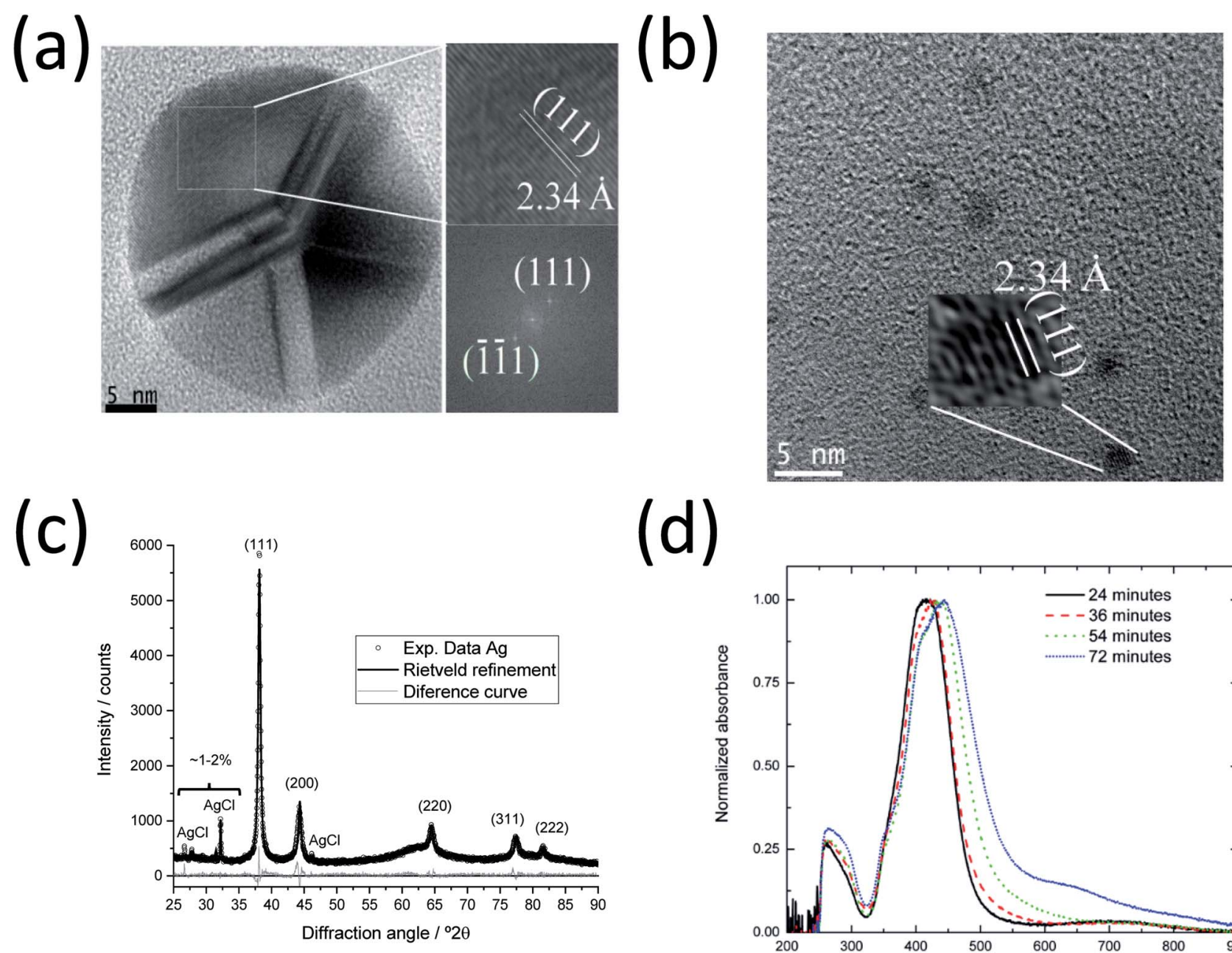

(d)

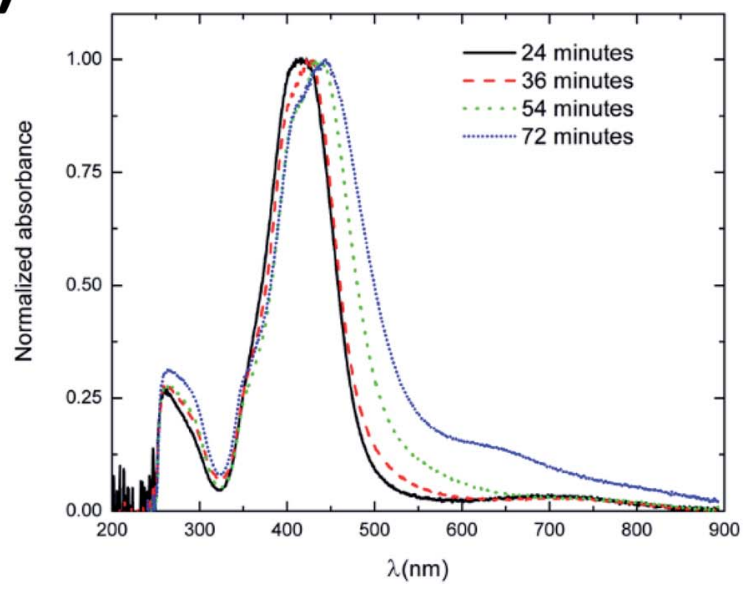

Fig. 4 HRTEM, XRD and UV/Vis investigations of the synthesis of silver nanoparticles at $90^{\circ} \mathrm{C}$. (a) Micrographs for larger (left) and smaller (right) silver nanoparticles, showing an interplanar distance of $2.34 \AA$. (b) FFT analysis results indicating the (111) planes. (c) XRD data with Rietveld refinement of silver nanoparticles obtained after $70 \mathrm{~min}$. Peaks and Miller indices of silver and byproduct AgCl are indicated. (d) UV/Vis spectra of silver nanoparticles taken after 24, 36, 54 and 72 min during SAXS experiments.

Fig. 4c shows an X-ray powder diffractogram with Rietveld refinement for the silver nanoparticles taken during the SAXS experiments after $70 \mathrm{~min}$. The computed lattice parameter of silver $a(\mathrm{Ag})=4.087(1) \AA$ agrees well with the ICDD database. Trace amounts of the synthesis byproduct AgCl (about 4-5 wt\% and crystallite size $143 \mathrm{~nm}$ according to Rietveld refinement) are detectable, as reported earlier for a similar synthesis. ${ }^{6}$ The crystallite size for the silver nanoparticles of 22(1) $\mathrm{nm}$ is about half the particle size $(50 \mathrm{~nm})$ determined by SAXS and TEM, indicating that the silver nanoparticles are polycrystalline (twinned), again in good agreement with the TEM data reported here and earlier. ${ }^{\mathbf{8} 52}$ It is important to note that the XRD results only represent the larger particles because the ultra-small silver nanoparticles and seeds $(2-3 \mathrm{~nm})$ are too small to contribute to the diffraction signal.

Fig. 4d shows the UV-vis spectra of silver nanoparticles from the aliquots taken during the SAXS synthesis. The absorption maxima for all samples are in the characteristic range for silver nanoparticles with a spherical shape. ${ }^{6,56}$ They become broader and shift from 410 to $440 \mathrm{~nm}$ with increasing synthesis time. This indicates an increasing particle size and polydispersity in the system, supporting the SAXS and HRTEM results. The absorbance at higher wavelengths $(\lambda>550 \mathrm{~nm})$ also increases with time, indicating the formation of larger particles or aggregates. The bands at $260 \mathrm{~nm}$ are due to the PVP ligand.

\section{Silver-gold nanoalloys}

Fig. 5a shows the in situ SAXS results for the synthesis of alloyed silver-gold nanoparticles. In Fig. S3a $\uparrow$ the full dataset of SAXS intensities is shown. The proposed model provides a very good fit for the full dataset. Interestingly, there is a clear upturn on the SAXS intensity at low angles $\left(q<0.15 \mathrm{~nm}^{-1}\right)$ already after one minute, which suggests the presence of large aggregates. Since it is not realistically possible to have large AgAu nanoparticles at the beginning of the reaction, the presence of such 
(a)

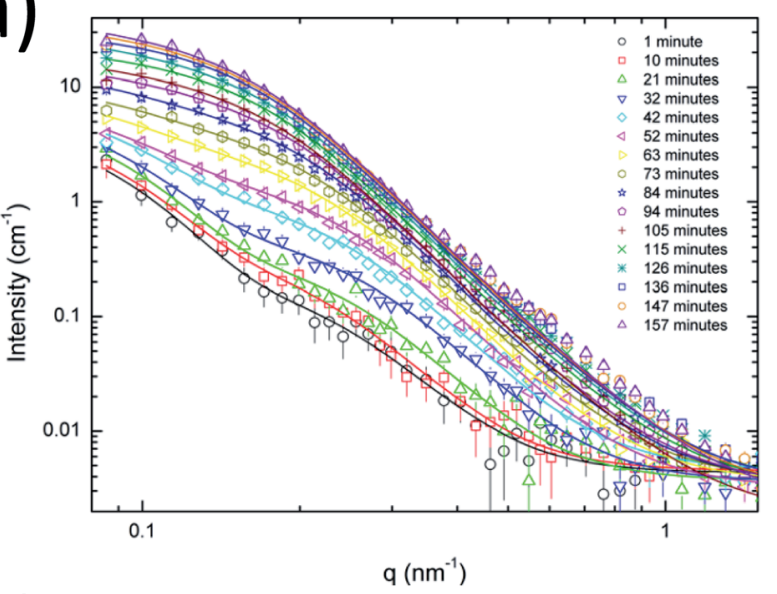

(b)

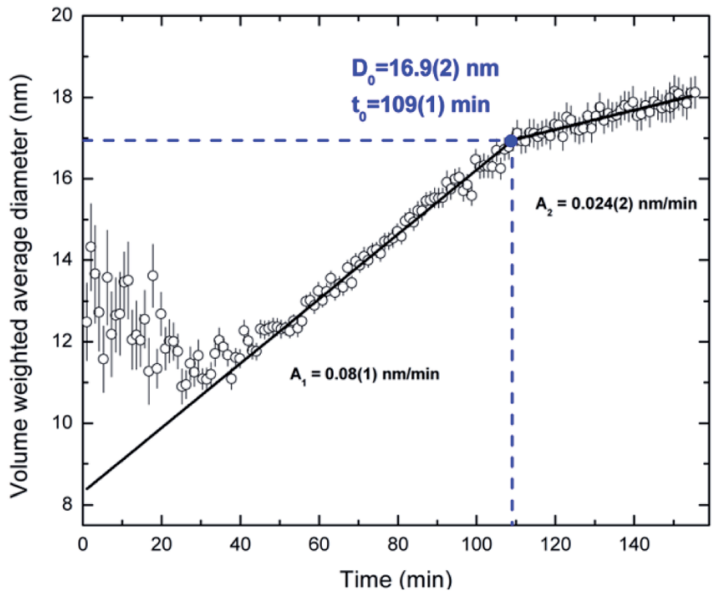

(c)

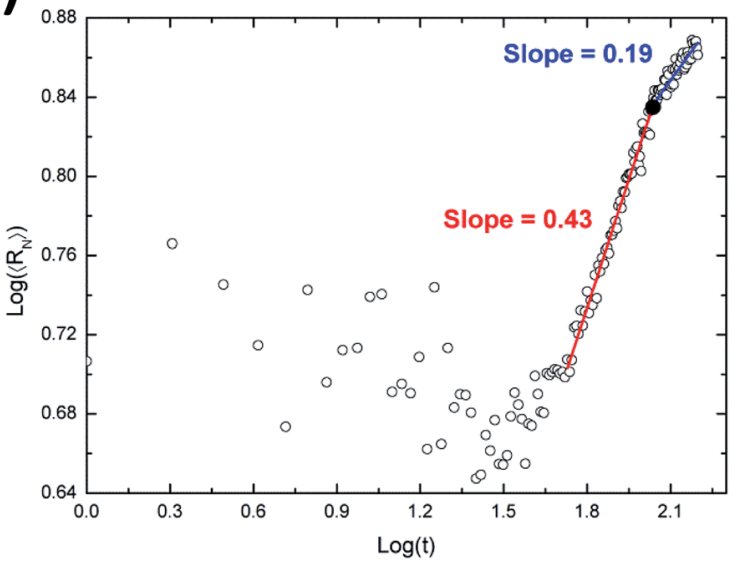

Fig. 5 In situ investigations of the synthesis of alloyed silver-gold nanoparticles. (a) Recorded experimental in situ SAXS data. The experimental data points (symbols) and theoretical curves (lines) of a few frames are shown for clarity. (b) Evolution of the volume weighted average diameter. (c) log-log plot of the number weighted average radius of the silver-gold nanoalloys as a function of time.

aggregates in small amounts is probably due to the byproduct $\mathrm{AgCl}$ from $\mathrm{AgNO}_{3}$ and $\mathrm{HAuCl}_{4}$ as was shown by Ristig et al. ${ }^{6}$ The further evolution of the SAXS scattering intensity confirms that these initial byproducts do not influence the detection of the slowly growing AgAu nanoparticles. After $\sim 60 \mathrm{~min}$, the evolution of the SAXS curves is dominated by the formation and further growth of AgAu nanoparticles.

The presence of the byproducts makes the MC analysis difficult because they strongly affect the particle size distribution. Therefore, the APS analysis was more suitable for the detection of the time-dependent growth of AgAu nanoparticles because it can explicitly include the presence of byproducts in a very easy way. The size distributions obtained from the APS fitting are shown in Fig. S3b. $\dagger$

The APS analysis indicated that the average radius of gyration of the byproducts was about $23 \mathrm{~nm}$, which corresponds to a particle size of about $60 \mathrm{~nm}$ (see eqn (10)). As shown later in the text (Fig. 6e), the effect of these aggregates is superseded by the formation of AgAu nanoparticles.

Fig. $5 \mathrm{~b}$ shows the time evolution of the volume-weighted average diameter of the growing AgAu nanoparticles. During the first 20 minutes of the synthesis, nanoparticles with a constant diameter of about $12 \mathrm{~nm}$ are observed which then start to increase their size continuously. One can speculate that this may be due to some kind of electrochemical equilibration between the more noble gold and the less noble silver. During this reduction process the formed particles seem to undergo a structural change (e.g. building of the gradient structures ${ }^{\mathbf{6 , 5 6}}$ caused by the possible electron exchange between $\mathrm{Au}$ and $\mathrm{Ag}$ ) which seems to keep the size nearly constant before the systematic crystal growth. By using the Carpena model (eqn (13)) we obtained an initially faster growth rate of $\sim 0.08$ $\mathrm{nm} \mathrm{min}^{-1}$ followed by a slower rate of $\sim 0.024 \mathrm{~nm} \mathrm{~min}{ }^{-1}$. It can be clearly seen that the saturation plateau for AgAu nanoparticles starts at $\sim 107$ min with a critical diameter of $\sim 17 \mathrm{~nm}$. Interestingly, the presence of a plateau seems to be characteristic for the investigated wet-chemical synthesis (reduction), pure Ag and alloyed AgAu.

Fig. $5 c$ shows the evolution of the number-average radius as a function of time in logarithmic scales. Following the previous comparison with LSW theory, the estimation of exponent $x$ as an indicator for the growth process was $\sim 0.43$ for the fastgrowth region, strongly suggesting the occurrence of coalescence in this stage. The $x$ value for the slow-growth region is 0.19 which is reasonably smaller than the value expected for Ostwald ripening (1/3). Therefore, the late stage of the growth evolution for the silver-gold sample cannot be directly described by coarsening mechanisms, probably due to the complex equilibrium and the consumption of precursors at the end of the synthesis. These nanoparticles are expected to be spherical with a more or less defined state between an alloy and a core-shell. Therefore, the growth mechanism of the nanoparticles may follow a complex mechanism that cannot be uniquely associated with a specific process.

Fig. 6a and b show a TEM image of AgAu nanoparticles taken at the end of the observation period (157 $\mathrm{min})$, together with the particle size distribution. The average size of the AgAu nanoparticles is $\sim 22 \mathrm{~nm}$, in good agreement with the final size determined by SAXS analysis $(\sim 18 \mathrm{~nm})$. A monomodal 
(a)

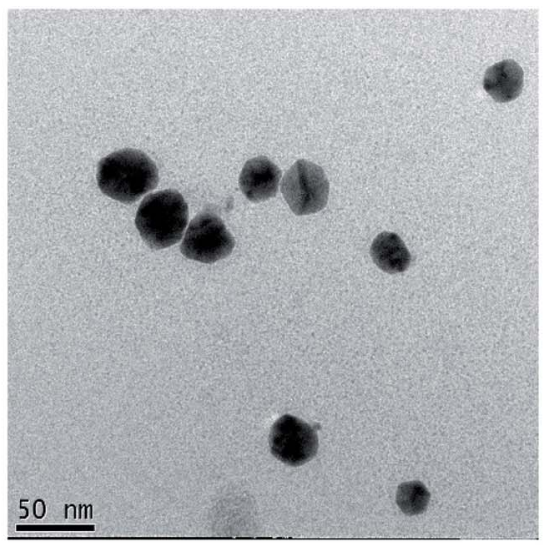

(b)

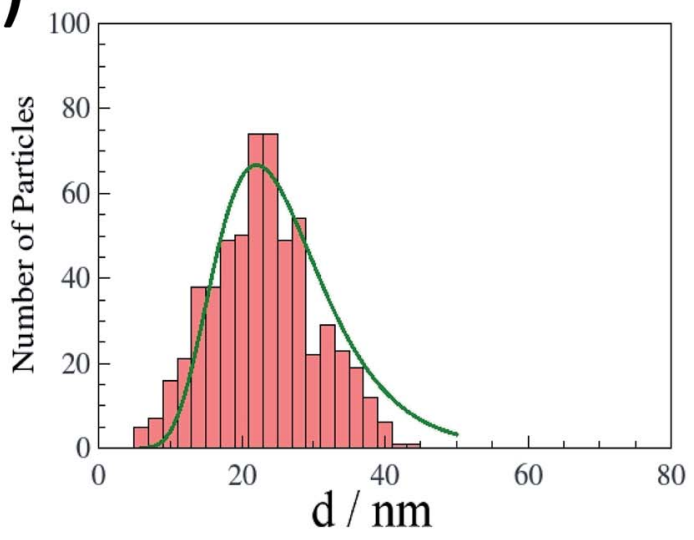

(c)

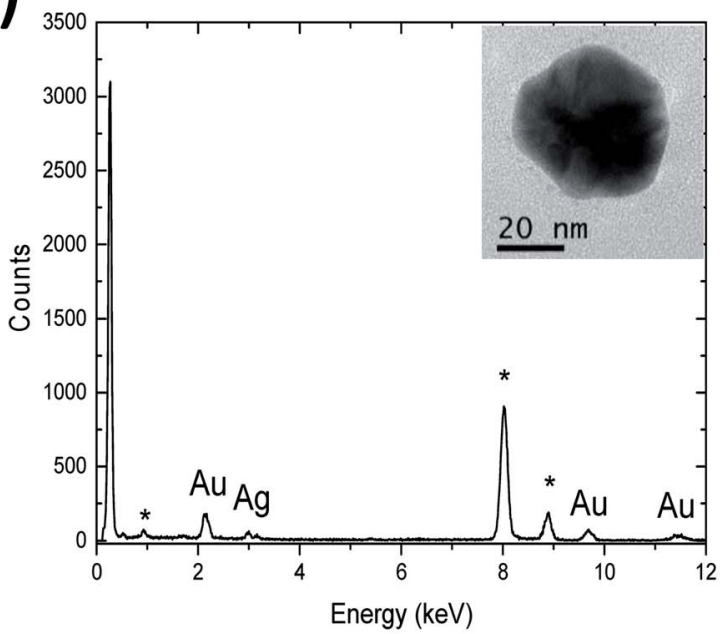

(d)

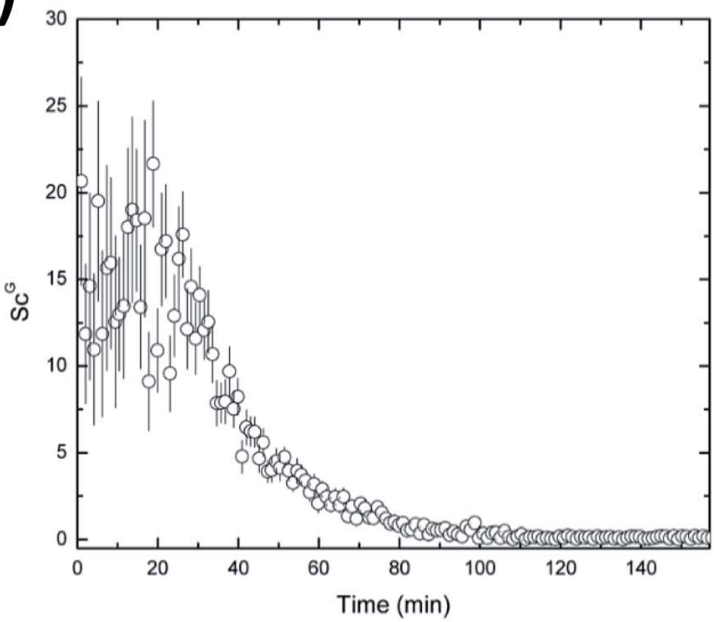

(f)

(e)
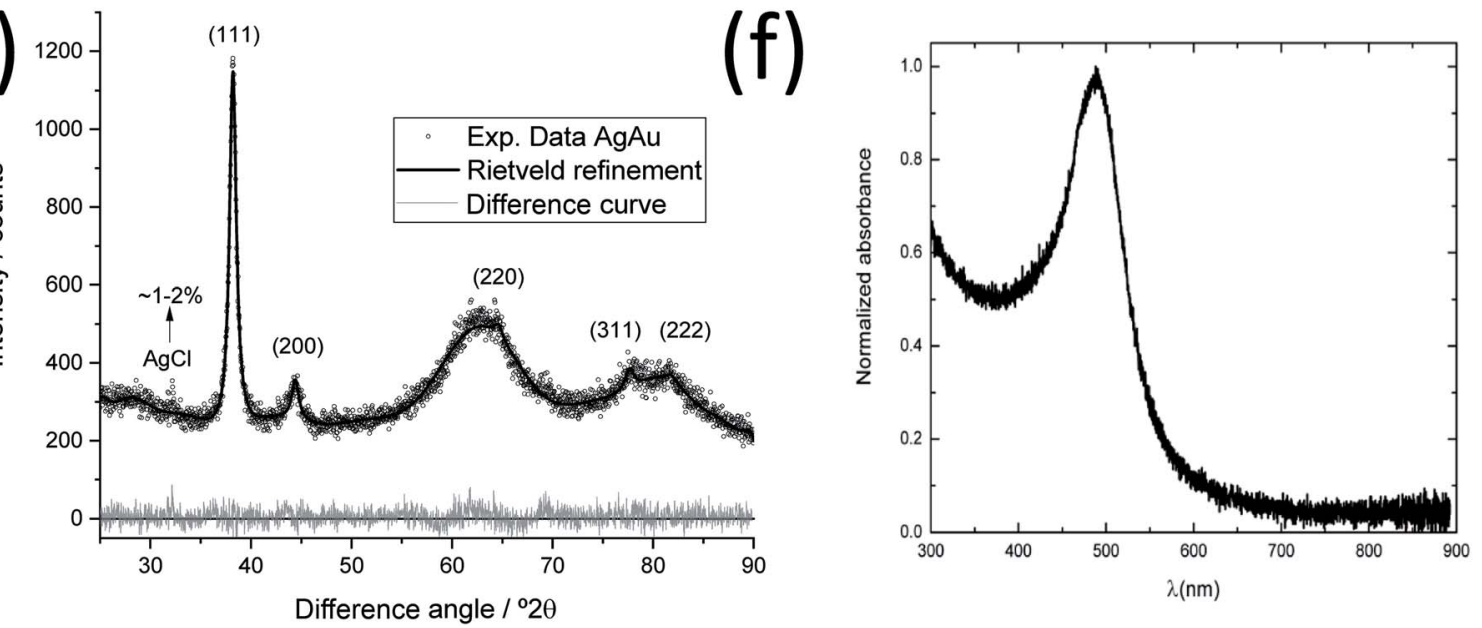

Fig. 6 Ex situ investigations of the silver-gold nanoparticles. (a) Representative TEM image and (b) size distribution of the alloyed silver-gold nanoparticles. An aliquot was taken at the end of the experiment (157 min). (c) EDS spectrum of the inset area, containing a single silver-gold nanoparticle, taken after 157 min synthesis time. In this plot, * denotes peaks of Cu from the copper TEM grid. (d) Time evolution of the aggregation parameter $S_{C}^{G}$ during the synthesis of silver-gold nanoparticles, showing that the amount of AgAu nanoparticles is increasing in the system while the byproduct phase is constant. (e) XRD data and representative Rietveld refinement of AgAu nanoparticles after 157 min during SAXS synthesis. Miller indices of the AgAu phase and a small peak of the synthesis byproduct AgCl are indicated. (f) UV/Vis spectrum of AgAu nanoparticles, taken after 157 min synthesis time. 
distribution was observed (no small nanoparticles), which is different from the synthesis of pure Ag nanoparticles (Fig. 3).

To ensure the bimetallic composition of the nanoparticles, EDS analyses were performed on aliquots taken at the end of the synthesis (157 min) and ten different AgAu nanoparticles were analysed. Fig. $6 \mathrm{c}$ shows a spectrum of the inset area, containing a single nanoparticle with a diameter of $\sim 46 \mathrm{~nm}$. This spectrum is representative of the spectra recorded for other nanoparticles, indicating the presence of both metals, silver and gold, in the same nanoparticle. This supports the formation of the silvergold alloy.

Fig. 6d shows the time evolution of the scale factor $S_{\mathrm{C}}^{\mathrm{G}}$. As explained above, this factor provides a direct indication of the ratio between the scattering power (product of concentration and squared volume) of the aggregated species and the smaller particles. During the first $20 \mathrm{~min}$ the values of the scale factor varies with high uncertainty, with a tendency to increase. In this region it was also possible to see unclear effects on the average diameter (Fig. 5b) which can be associated with some sort of equilibration in the system. After this period, one can see a systematic decrease in the scale factor $S_{\mathrm{C}}^{\mathrm{G}}$. According to eqn (11) this may be a result of an increase in the concentration of growing AgAu nanoparticles, while the amount of the initial byproducts remains constant in the system. This behavior of $S_{\mathrm{C}}^{\mathrm{G}}$ can also indicate an increase in the electronic contrast due to the incorporation of the gold and silver atoms during the formation of the gradient structures.

Fig. 6e shows an X-ray powder diffractogram with Rietveld refinement for the AgAu nanoparticles, taken after $157 \mathrm{~min}$. The lattice parameter $a(\mathrm{AgAu})=4.082(8) \AA$ indicates the formation of an alloy. ${ }^{57}$ As in the synthesis of silver nanoparticles, a small amount of the synthesis byproduct $\mathrm{AgCl}(1-2 \%)$ was found. The computed crystallite size of AgAu nanoparticles of 10(1) nm is again about half the particle size $(22 \mathrm{~nm})$ as determined by SAXS and TEM. This indicates the formation of polycrystalline (twinned) AgAu nanoparticles, in good agreement with earlier results. ${ }^{56}$ Notably, the crystallite size of AgAu nanoparticles (CS $=10 \mathrm{~nm})$ is smaller than in the case of silver nanoparticles $(22$ $\mathrm{nm}$ ) but has the same ratio to the particle diameter (about $1: 2$ ).

Fig. $6 f$ shows the UV-vis curves for the AgAu nanoparticles taken after $157 \mathrm{~min}$. The absorption maximum at $480 \mathrm{~nm}$ indicates the formation of nanoparticles, typical of alloyed spherical AgAu nanoparticles of a comparable size, in good agreement with the EDS measurements and earlier results. ${ }^{6,56} \mathrm{In}$ the case of two independent $\mathrm{Ag}$ and Au phases or the formation of a core-shell structure, two separate plasmon resonance bands would be detected. ${ }^{58}$

\section{Conclusions}

In situ SAXS investigations of the nucleation process of pure silver and alloyed silver-gold nanoparticles were performed. The analysis of the data indicates that silver nanoparticles develop into two characteristic size fractions, i.e. smaller and larger nanoparticles. For the silver-gold nanoparticles, only one growing fraction was found with simultaneous detection of the remaining byproduct $(\mathrm{AgCl})$. The crystal growth of both $\mathrm{Ag}$ and
AgAu nanoparticles can be described by two main features: faster growth at the beginning and slower at the end, reaching a saturation plateau. By modeling the number weighted radius as a function of time with the expression $R \propto t^{x}$ one could associate the dynamic coalescence as the growth mechanism for the beginning of both $\mathrm{Ag}$ and AgAu nanoparticle syntheses. At the end of the Ag synthesis, the results indicated that Ostwald ripening could be the possible mechanism. On the other hand, at the end stage of the AgAu synthesis there is a strong decrease in the exponent, making difficult its association with LSW predicted growth mechanism.

The in situ SAXS results were confirmed by ex situ TEM images, giving the particle size distributions. HRTEM, FFT, EDX and XRD analyses revealed the crystal structure and the chemical composition of the formed nanoparticles. By combination of these in situ and ex situ analyses it was possible to investigate the continuous growth of the metallic nanoparticles in detail during the wet-chemical reduction synthesis, starting at the early nucleation stage.

For $\mathrm{Ag}$ nanoparticles it was possible to detect two particle fractions (distributions) during the synthesis, one with smaller size, almost constant throughout the synthesis and another one, which grows over time. Both distributions were also visible in the TEM micrographs. Dynamic coalescence was found in previous investigations of Ag nanoparticle synthesis, ${ }^{22,28}$ and the results shown in this work suggest that the smaller particles visible in the system are coalescing to form the larger particles. Therefore, the initial nanoparticles in the system grow up to $\sim 3 \mathrm{~nm}$ in diameter before being absorbed in the larger particles. This process evolves up to an aggregate size of $\sim 36 \mathrm{~nm}$. At this point, there is a decrease in the growth rate which, based on the LSW analysis, suggested a change in the coarsening process from coalescence to Ostwald ripening. This change may be attributed to variations in the free-energy of the system since after a certain radius one growth process is more favorable. ${ }^{59,60}$ For the AgAu alloy nanoparticle synthesis, a dynamic coalescence was also observed as the main growth process but only one distribution was found in the SAXS data. This suggests that the small particles coalescing into larger ones have sizes smaller than the minimum detectable size in our experiments. In this case, for particles larger than $\sim 17 \mathrm{~nm}$, a change in the growth mechanism was found, with an important decrease of the growth rate. The obtained exponent could not be easily explained by any of the usual coarsening processes. This suggests a complex equilibrium in the system, either by the variations of the free energy or by the exhausting of the components for the particle formation in the system.

Overall, the investigation strategy proposed in this article provides a systematic description of the in situ growth process for $\mathrm{Ag}$ and $\mathrm{AgAu}$ systems, which allowed a detailed and precise determination of structural parameters with comprehensive comparisons among several experimental techniques. The results also demonstrate the high quality of the obtained SAXS data on a laboratory based SAXS instrument, coupled with advanced modeling tools and a careful experimental setup for temperature control and in situ investigations. 


\section{Author contributions}

Author contributions: PRAFG carried out in situ SAXS experiments, fit the SAXS data and wrote the manuscript draft. VG and KP contributed to the synthesis. LO collected HRTEM and EDX data. WW evaluated the particle size distribution by TEM. OP performed X-ray powder diffraction analysis and Rietveld refinement. OP, ME, and CLPO supervised the experiments, interpreted the results and critically reviewed the manuscript.

\section{Funding sources}

C. L. P. Oliveira was supported by CAPES (grant 431/15), CNPq (grant 304861/2015-4) and the São Paulo Research Foundation (FAPESP - grants 2016/24531-3, 2018/16092-5). P. R. A. F. Garcia was supported by CAPES, under CAPES-DAAD project no. 431/ 15. Matthias Epple thanks the DFG for funding (project Ep 22/ 44-1) and DAAD/CAPES (2015-2018, No 57139595). We are grateful to the Deutscher Akademischer Austauschdienst for generous funding within the joint DAAD-PROBRAL exchange programme. This study was financed in part by the Coordenação de Aperfeiçoamento de Pessoal de Nível Superior Brasil (CAPES) - Finance Code 001.

\section{Conflicts of interest}

The authors state that there are no conflicts to declare.

\section{Acknowledgements}

We would like to thank all the technicians of the Complex Fluid Group involved in the realization of the experiments, especially Dennys Reis, whose assistance was fundamental to the success of the experiments.

\section{References}

1 P. K. Jain, X. Huang, I. H. El-Sayed and M. A. El-Sayed, Review of Some Interesting Surface Plasmon Resonance-enhanced Properties of Noble Metal Nanoparticles and Their Applications to Biosystems, Plasmonics, 2007, 2(3), 107-118.

2 M. C. Daniel and D. Astruc, Gold nanoparticles: assembly, supramolecular chemistry, quantum-size-related properties, and applications toward biology, catalysis, and nanotechnology, Chem. Rev., 2004, 104, 293-346.

$3 \mathrm{~N}$. Sozer and J. L. Kokini, Nanotechnology and its applications in the food sector, Trends Biotechnol., 2009, 27(2), 82-89.

4 S. Banerjee, K. Loza, W. Meyer-Zaika, O. Prymak and M. Epple, Structural Evolution of Silver Nanoparticles during Wet-Chemical Synthesis, Chem. Mater., 2014, 26(2), 951-957.

5 X. Chen, J. Schröder, S. Hauschild, S. Rosenfeldt, M. Dulle and S. Förster, Simultaneous SAXS/WAXS/UV-Vis Study of the Nucleation and Growth of Nanoparticles: A Test of Classical Nucleation Theory, Langmuir, 2015, 31(42), 11678-11691.
6 S. Ristig, O. Prymak, K. Loza, M. Gocyla, W. Meyer-Zaika, M. Heggen, D. Raabe and M. Epple, Nanostructure of wetchemically prepared, polymer-stabilized silver-gold nanoalloys $(6 \mathrm{~nm})$ over the entire composition range, $J$. Mater. Chem. B, 2015, 3(23), 4654-4662.

7 M. Harada, N. Tamura and M. Takenaka, Nucleation and Growth of Metal Nanoparticles during Photoreduction Using In Situ Time-Resolved SAXS Analysis, J. Phys. Chem. C, 2011, 115(29), 14081-14092.

8 S. Banerjee, K. Loza, W. Meyer-Zaika, O. Prymak and M. Epple, Structural evolution of silver nanoparticles during wet-chemical synthesis, Chem. Mater., 2014, 26, 951-957.

9 E. N. Saw, V. Grasmik, C. Rurainsky, M. Epple and K. Tschulik, Electrochemistry at single bimetallic nanoparticles - using nano impacts for sizing and compositional analysis of individual AgAu alloy nanoparticles, Faraday Discuss., 2016, 193(Single Entity Electrochemistry), 327-338.

10 G. Guisbiers, R. Mendoza-Cruz, L. Bazán-Díaz, J. J. Velázquez-Salazar, R. Mendoza-Perez, J. A. RobledoTorres, J. L. Rodriguez-Lopez, J. M. Montejano-Carrizales, R. L. Whetten and M. José-Yacamán, Electrum, the goldsilver alloy, from the bulk scale to the nanoscale: synthesis, properties, and segregation rules, ACS Nano, 2016, 10, 188-198.

11 Y. Xu, L. Chen, X. Wang, W. Yao and Q. Zhang, Recent advances in noble metal based composite nanocatalysts: colloidal synthesis, properties, and catalytic applications, Nanoscale, 2015, 7, 10559-10583.

12 K. McNamara and S. A. Tofail, Nanosystems: the use of nanoalloys, metallic, bimetallic, and magnetic nanoparticles in biomedical applications, Phys. Chem. Chem. Phys., 2015, 17, 27981-27995.

13 F. Calvo, Thermodynamics of nanoalloys, Phys. Chem. Chem. Phys., 2015, 17, 27922-27939.

14 S. Ristig, D. Kozlova, W. Meyer-Zaika and M. Epple, An easy synthesis of autofluorescent alloyed silver-gold nanoparticles, J. Mater. Chem. B, 2014, 2, 7887-7895.

15 R. Intartaglia, G. Das, K. Bagga, A. Gopalakrishnan, A. Genovese, M. Povia, E. Di Fabrizio, R. Cingolani, A. Diaspro and F. Brandi, Laser synthesis of ligand-free bimetallic nanoparticles for plasmonic applications, Phys. Chem. Chem. Phys., 2013, 15, 3075-3082.

16 X. Liu, D. Wang and Y. Li, Synthesis and catalytic properties of bimetallic nanomaterials with various architectures, Nano Today, 2012, 7(5), 448-466.

17 C. J. DeSantis, A. C. Sue, M. M. Bower and S. E. Skrabalak, Seed-mediated co-reduction: A versatile route to architecturally controlled bimetallic nanostructures, ACS Nano, 2012, 6, 2617-2628.

18 S. J. Guo and E. K. Wang, Functional micro/nanostructures: simple synthesis and application in sensors, fuel cells, and gene delivery, Acc. Chem. Res., 2011, 44, 491-500.

19 S. Mourdikoudis, R. M. Pallares and N. T. K. Thanh, Characterization techniques for nanoparticles: comparison 
and complementarity upon studying nanoparticle properties, Nanoscale, 2018, 10(27), 12871-12934.

$20 \mathrm{~T}$. Li, A. J. Senesi and B. Lee, Small Angle X-ray Scattering for Nanoparticle Research, Chem. Rev., 2016, 116(18), 1112811180.

21 J. Polte, T. T. Ahner, F. Delissen, S. Sokolov, F. Emmerling, A. F. Thünemann and R. Kraehnert, Mechanism of Gold Nanoparticle Formation in the Classical Citrate Synthesis Method Derived from Coupled In Situ XANES and SAXS Evaluation, J. Am. Chem. Soc., 2010, 132(4), 1296-1301.

22 M. Harada and E. Katagiri, Mechanism of Silver Particle Formation during Photoreduction Using In Situ TimeResolved SAXS Analysis, Langmuir, 2010, 26(23), 1789617905.

23 M. Harada and R. Ikegami, In Situ Quick X-ray Absorption Fine Structure and Small-Angle X-ray Scattering Study of Metal Nanoparticle Growth in Water-in-Oil Microemulsions during Photoreduction, Cryst. Growth Des., 2016, 16(5), 2860-2873.

24 J. Polte, X. Tuaev, M. Wuithschick, A. Fischer, A. F. Thuenemann, K. Rademann, R. Kraehnert and F. Emmerling, Formation Mechanism of Colloidal Silver Nanoparticles: Analogies and Differences to the Growth of Gold Nanoparticles, ACS Nano, 2012, 6(7), 5791-5802.

25 H. Koerner, R. I. MacCuspie, K. Park and R. A. Vaia, In Situ UV/Vis, SAXS, and TEM Study of Single-Phase Gold Nanoparticle Growth, Chem. Mater., 2012, 24(6), 981-995.

26 M. Singh, I. Sinha, A. K. Singh and R. K. Mandal, LSPR and SAXS studies of starch stabilized Ag-Cu alloy nanoparticles, Colloids Surf., A, 2011, 384, 668-674.

27 L. Wu, A. P. Fournier, J. J. Willis, M. Cargnello and C. J. Tassone, In Situ X-ray Scattering Guides the Synthesis of Uniform PtSn Nanocrystals, Nano Lett., 2018, 18(6), 4053-4057.

28 J. Polte, Fundamental growth principles of colloidal metal nanoparticles - a new perspective, CrystEngComm, 2015, 17(36), 6809-6830.

29 C. L. P. Oliveira, T. Vorup-Jensen, C. B. F. Andersen, G. R. Andersen and J. S. Pedersen, Discovering New Features of Protein Complexes Structures by Small-Angle XRay Scattering, in Applications of Synchrotron Light to Scattering and Diffraction in Materials and Life Sciences, 2009, pp 231-244.

30 C. T. Rueden, J. Schindelin, M. C. Hiner, B. E. DeZonia, A. E. Walter, E. T. Arena and K. W. Eliceiri, ImageJ2: Image J for the next generation of scientific image data, BMC Bioinf., 2017, 18(1), 529.

31 J. Baumgard, M.-M. Pohl, U. Kragl and N. Steinfeldt, Preparation of tailor-made supported catalysts using asymmetric flow field flow fractionation and their application in hydrogenation, In Nanotechnology Reviews, 2014, Vol. 3, p. 87.

32 L.-K. Huang and M.-J. J. Wang, Image thresholding by minimizing the measures of fuzziness, Pattern Recognit., 1995, 28(1), 41-51.

33 O. Prymak, S. Ristig, V. Meyer-Zaika, A. Rostek, L. Ruiz, J. M. Gonzalez-Calbet, M. Vallet-Regi and M. Epple, X-Ray powder diffraction as a tool to investigate the ultrastructure of nanoparticles, Russ. Phys. J., 2014, 56, 1111-1115.

34 P. Scherrer, Bestimmung der Größe und der inneren Struktur von Kolloidteilchen mittels Röntgenstrahlen, Nachr. Ges. Wiss. Goettingen, Math.-Phys. Kl., 1918, 2, 98-100.

35 S. Martelli and P. E. Di Nunzio, Particle size distribution of nanospheres by Monte Carlo fitting of small angle X-ray scattering curves, Part. Part. Syst. Charact., 2002, 19(4), 247-255.

36 B. R. Pauw, J. S. Pedersen, S. Tardif, M. Takata and B. B. Iversen, Improvements and considerations for size distribution retrieval from small-angle scattering data by Monte Carlo methods, J. Appl. Crystallogr., 2013, 46, 365371.

37 D. I. Svergun, L. A. Feigin and G. W. Taylor., Structure analysis by small-angle X-ray and neutron scattering, Springer, 1987.

38 O. Glatter, Determination of Particle-Size DistributionFunctions From Small-Angle Scattering Data by Means of the Indirect Transformation Method, J. Appl. Crystallogr., 1980, 13(FEB), 7-11.

39 A. V. Semenyuk and D. I. Svergun, GNOM - A Program Package for Small-Angle Scattering Data-Processing, J. Appl. Crystallogr., 1991, 24, 537-540.

40 P. Lindner and T. Zemb, Neutron, X-ray and light scattering: introduction to an investigative tool for colloidal and polymeric systems, 1991.

41 C. L. P. Oliveira, P. R. Santos, A. M. Monteiro and A. M. F. Neto, Effect of oxidation on the structure of human low- and high-density lipoproteins, Biophys. J., 2014, 106, 2595-2605.

42 C. L. P. Oliveira, A. M. Monteiro and A. M. Figueiredo Neto, Structural modifications and clustering of low-density lipoproteins in solution induced by heating, Braz. J. Phys., 2014, 44, 753-764.

43 A. Guinier, X-ray diffraction in crystals, imperfect crystals, and amorphous bodies, Courier Corporation, 1994.

44 P. Carpena, J. Aguiar, P. Bernaola-Galvan and C. C. Ruiz, Problems associated with the treatment of conductivityconcentration data in surfactant solutions: Simulations and experiments, Langmuir, 2002, 18(16), 6054-6058.

45 M. Conti, B. Meerson, A. Peleg and P. V. Sasorov, Phase ordering with a global conservation law: Ostwald ripening and coalescence, Phys. Rev. E: Stat., Nonlinear, Soft Matter Phys., 2002, 65(4), 0461171-04611713.

46 I. M. Lifshitz and V. V. Slyozov, The Kinetics of Precipitation From Supersaturated Solid Solutions, J. Phys. Chem. Solids, 1961, 19(1-2), 35-50.

47 D. S. Sholl and R. T. Skodje, Late-stage coarsening of adlayers by dynamic cluster coalescence, Phys. A, 1996, 231(4), 631-647.

48 T. J. Woehl, C. Park, J. E. Evans, I. Arslan, W. D. Ristenpart and N. D. Browning, Direct Observation of Aggregative Nanoparticle Growth: Kinetic Modeling of the Size Distribution and Growth Rate, Nano Lett., 2014, 14(1), 373378. 
49 S. Ahlberg, A. Antonopulos, J. Diendorf, R. Dringen, M. Epple, R. Flöck, W. Goedecke, C. Graf, N. Haberl, J. Helmlinger, F. Herzog, F. Heuer, S. Hirn, C. Johannes, S. Kittler, M. Köller, K. Korn, W. G. Kreyling, F. Krombach, J. Lademann, K. Loza, E. M. Luther, M. Malissek, M. C. Meinke, D. Nordmeyer, A. Pailliart, J. Raabe, F. Rancan, B. Rothen-Rutishauser, E. Rühl, C. Schleh, A. Seibel, C. Sengstock, L. Treuel, A. Vogt, K. Weber and R. Zellner, PVP-coated, negatively charged silver nanoparticles: A multi-center study of their physicochemical characteristics, cell culture and in vivo experiments, Beilstein J. Nanotechnol., 2014, 5, 1944-1965.

50 S. P. Shields, V. N. Richards and W. E. Buhro, Nucleation Control of Size and Dispersity in Aggregative Nanoparticle Growth. A Study of the Coarsening Kinetics of ThiolateCapped Gold Nanocrystals, Chem. Mater., 2010, 22(10), 3212-3225.

51 S. Banerjee, C. H. Liu, J. D. Lee, A. Kovyakh, V. Grasmik, O. Prymak, C. Koenigsmann, H. Liu, L. Wang, A. M. M. Abeykoon, S. S. Wong, M. Epple, C. B. Murray and S. J. L. Billinge, Improved models for metallic nanoparticle cores from atomic pair distribution function (PDF) analysis, J. Phys. Chem. C, 2018, 122, 29498-29506.

52 J. Helmlinger, O. Prymak, K. Loza, M. Gocyla, M. Heggen and M. Epple, On the crystallography of silver nanoparticles with different shapes, Cryst. Growth Des., 2016, 16, 3677-3687.

53 E. Rodríguez-León, R. Iñiguez-Palomares, R. E. Navarro, R. Herrera-Urbina, J. Tánori, C. Iñiguez-Palomares and A. Maldonado, Synthesis of silver nanoparticles using reducing agents obtained from natural sources (Rumex hymenosepalus extracts), Nanoscale Res. Lett., 2013, 8, 318.

$54 \mathrm{H}$. Liu and J. Yang, Bimetallic Ag-hollow Pt heterodimers via inside-out migration of $\mathrm{Ag}$ in core-shell $\mathrm{Ag}-\mathrm{Pt}$ nanoparticles at elevated temperature, J. Mater. Chem. A, 2014, 2(19), 70757081.

55 D. Chen, C. Li, H. Liu, F. Ye and J. Yang, Core-shell Au@Pd nanoparticles with enhanced catalytic activity for oxygen reduction reaction via core-shell Au@Ag/Pd constructions, Sci. Rep., 2015, 5, 11949.

56 V. Grasmik, C. Rurainsky, K. Loza, M. V. Evers, O. Prymak, M. Heggen, K. Tschulik and M. Epple, Deciphering the surface composition and the internal structure of alloyed silver-gold nanoparticles, Chem. - Eur. J., 2018, 24, 90519060.

57 O. Prymak, J. Jakobi, C. Rehbock, M. Epple and S. Barcikowski, Crystallographic characterization of lasergenerated, polymer-stabilized $4 \mathrm{~nm}$ silver-gold alloyed nanoparticles, Mater. Chem. Phys., 2018, 207, 442-450.

58 M. S. Shore, J. Wang, A. C. Johnston-Peck, A. L. Oldenburg and J. B. Tracy, Synthesis of $\mathrm{Au}($ core $) / \mathrm{Ag}$ (shell) nanoparticles and their conversion to $\mathrm{AuAg}$ alloy nanoparticles, Small, 2011, 7, 230-234.

59 D. V. Talapin, A. L. Rogach, M. Haase and H. Weller, Evolution of an ensemble of nanoparticles in a colloidal solution: theoretical study, J. Phys. Chem. B, 2001, 105(49), 12278-12285.

60 R. A. L. Jones., Soft condensed matter, Oxford University Press, Oxford, 2002. 


\title{
Combining Small-Angle X-ray Scattering and X-ray Powder Diffraction to Investigate Size, Shape and Crystallinity of Silver, Gold and Alloyed Silver-Gold Nanoparticles
}

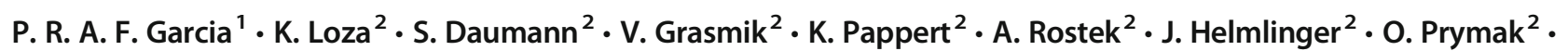 \\ M. Heggen ${ }^{3} \cdot$ M. Epple ${ }^{2} \cdot$ C. L. P. Oliveira ${ }^{1}$ (D)
}

Received: 1 August 2018 / Published online: 20 February 2019

(C) Sociedade Brasileira de Física 2019

\begin{abstract}
The combination of simultaneous measurements of small and wide angle X-ray scattering (SAXS/WAXS-SWAXS) to investigate the overall size, shape, and crystallinity of silver nanoparticles and alloyed silver-gold nanoparticles in the size range of 8 to $80 \mathrm{~nm}$ is shown. The obtained results for overall size are in agreement with the particle size obtained by differential centrifugal sedimentation (DCS) and transmission electron microscopy (TEM). In addition to the overall size, SWAXS provided precise information about the crystallographic internal structure of the particles, providing a powerful multi-scale tool for structural characterization of the studied systems.
\end{abstract}

Keywords SAXS $\cdot$ WAXS $\cdot$ XRD $\cdot$ Nanoparticles $\cdot$ Structure

\section{Introduction}

Nanoscale systems $(<100 \mathrm{~nm})$ are of considerable scientific interest due to their special physical properties which may be very different from the ones in larger length scales [1, 2]. A very important aspect is the proper control and tuning of the electronic, optical, and magnetic properties of these systems that enables a broad range of applications. Examples can be found in many areas such as nanomedicine, catalysis, photonics, information storage, sensing, imaging, photography, as well as generation, conversion and energy storage devices [3-5]. In order to understand the formation of nanoparticles in dispersion, it is necessary to perform a structural investiga-

M. Epple

Matthias.Epple@uni-due.de

$\triangle$ C. L. P. Oliveira

crislpo@if.usp.br

1 Institute of Physics, University of São Paulo, Rua do Matão 1371, São Paulo, SP 05508-090, Brazil

2 Inorganic Chemistry and Center for Nanointegration Duisburg-Essen (CeNIDE), Universitaetsstr. 5-7, 45117 Essen, Germany

3 Ernst Ruska-Centre and Peter Grünberg Institute, Forschungszentrum Jülich GmbH, 52425 Jülich, Germany tion of the system not only for the final products but also during the synthesis process. In the case of metallic nanoparticles, the particle formation is divided into nucleation, evolution of nuclei to clusters and growth of nanocrystals clusters [6]. Although there are several characterization techniques, the particle shape at each stage of the synthesis is usually probed by electron microscopy methods (EM). One of the main advantages of EM is the retrieval of structural information in the real space. However, due to the special conditions required for the measurements, it cannot be used to investigate the structural evolution in situ during the synthesis unless very special equipment is used [7]. Moreover, electron microscopy methods permit the visualization of the nanostructures at very high resolution (in some cases, close to atomic scale), but there is always a question whether the analyzed particles (usually restricted to a few hundred or thousand) are a good representation for the whole system [8].

An alternative to microscopic techniques are scattering/ diffraction techniques. In these techniques, a radiation beam strikes the sample and, due to the interaction of the radiation with the matter, a fraction of the incoming beam is scattered into a particular direction. From the analysis of the scattering data it is possible to retrieve structural information for the studied system. For example, one can obtain the average particle shape and size, polydispersity levels, interparticle 
Table 1 Several structural parameters for all studied nanoparticles. $W$ is the width, $T$ is the thickness and $L$ is the length

\begin{tabular}{|c|c|c|c|c|c|c|}
\hline Sample & Shape & TEM diameter $(\mathrm{nm})$ & DCS diameter (nm) & DLS diameter (nm) & XRD crystallite size $(\mathrm{nm})$ & Reference \\
\hline Ag10 & Spheres & $8(1)$ & $7(1)$ & $11(3)$ & $7(1)$ & this manuscript \\
\hline Ag15 & Spheres & $15(2)$ & - & - & $6(1)$ & {$[12]$} \\
\hline Ag30 & Spheres & $30(4)$ & - & - & 11(1) & {$[12]$} \\
\hline $\mathrm{Ag} 42$ & Spheres & $42(6)$ & - & - & $14(1)$ & {$[12]$} \\
\hline Ag83 & Spheres & $83(8)$ & - & - & $21(1)$ & {$[12]$} \\
\hline Ag platelets & Platelets & $\begin{array}{l}W=40(20) \\
* T=16\end{array}$ & $30(4)$ & $48(6)$ & $15(1)$ & {$[2,14]$} \\
\hline Ag rods & Rods & $\begin{array}{l}W=100(50) \\
L \approx 20.10^{3}\end{array}$ & - & $558(50)$ & $117(2)$ & {$[2]$} \\
\hline $\operatorname{AgAu}(80: 20)$ & Spheres & - & $13(1)$ & - & $* *$ & [16] \\
\hline $\operatorname{AgAu}(50: 50)$ & Spheres & - & $11(2)$ & - & $* *$ & [16] \\
\hline $\operatorname{AgAu}(20: 80)$ & Spheres & - & $14(1)$ & - & $* *$ & [16] \\
\hline $\mathrm{Au}(7 \mathrm{~nm})$ & Spheres & $6(1)$ & $7(1)$ & $5(1)$ & $2.5(2)$ & [16] \\
\hline
\end{tabular}

-No data available

*The thickness was determined by atomic force microscopy

**The crystallite size of these samples was determined using data from the WAXS measurements. The values are given in the following sections

interactions and clustering [9-11]. One of the main advantage of these applications is the possibility of characterizing the studied samples (powder, gels or solution dispersions) in a reasonably fast experiment. Also, since the scattering data is given by the ensemble average on a very large number of particles, the structural information is a trustful representation of the system. On the other hand, differently from microscopic techniques, scattering methods provide information in reciprocal space (Fourier space) which may demand the use of appropriate experimental procedures and analysis methods. Microscopy, scattering and diffraction techniques are highly complementary and together deliver a very comprehensive description of the studied system.

Here, a systematic structural characterization of different sets of metallic nanoparticles in solution and dry state (powder) is presented. Multiscale information is obtained from the analysis of the experimental data providing interesting structural features.

Fig. 1 Representative TEM images of Ag-sphere (a), Agplatelets (b), and Ag-rod (c)
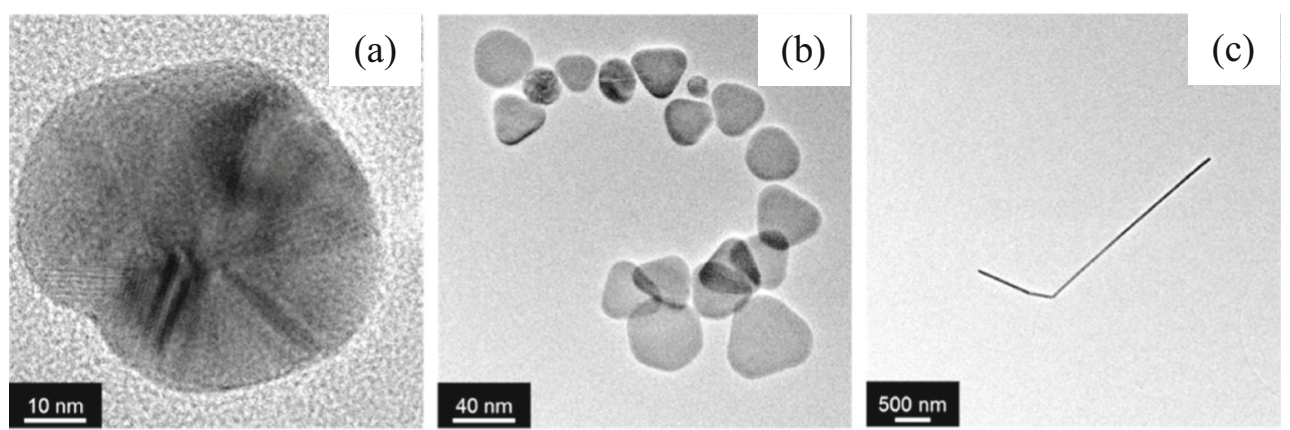

\section{Materials and Methods}

All metallic nanoparticles (NPs) were synthesized in aqueous media by reduction with different chemicals, depending on the specific synthesis routes of each nanoparticle, stabilized as colloids with poly(N-vinylpyrrolidone) (PVP) and purified by ultracentrifugation. Silver nanoparticles with a diameter of $10 \mathrm{~nm}$ were prepared by dissolving $18 \mathrm{mg}$ of silver nitrate ( $\geq 99.9 \%$, Carl-Roth) and $26 \mathrm{mg}$ sodium citrate in $250 \mathrm{~mL}$ ultra-pure water [12]. The whole reaction mixture was cooled down in an ice bath and treated with $10 \mathrm{~mL}$ of a $10-\mathrm{mM}$ sodium borohydride solution while the mixture was vigorously stirred. After $1 \mathrm{~min}, 150 \mathrm{mg}$ PVP $\left(\mathrm{MW} \approx 40.000 \mathrm{~g} \mathrm{~mol}^{-1}\right.$, Sigma-Aldrich) dissolved in $10 \mathrm{~mL}$ water was added to the resulting yellow dispersion. The solution was further stirred for $2 \mathrm{~h}$. The nanoparticles were purified and collected by ultracentrifugation (66.000 g, 2.30 min) and redispersed in ultrapure water. In preparation for the SAXS and X-ray powder 
(a)

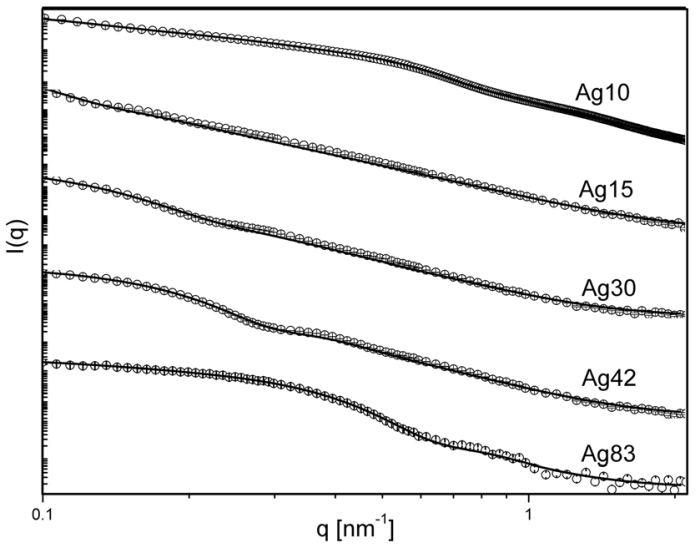

(b)

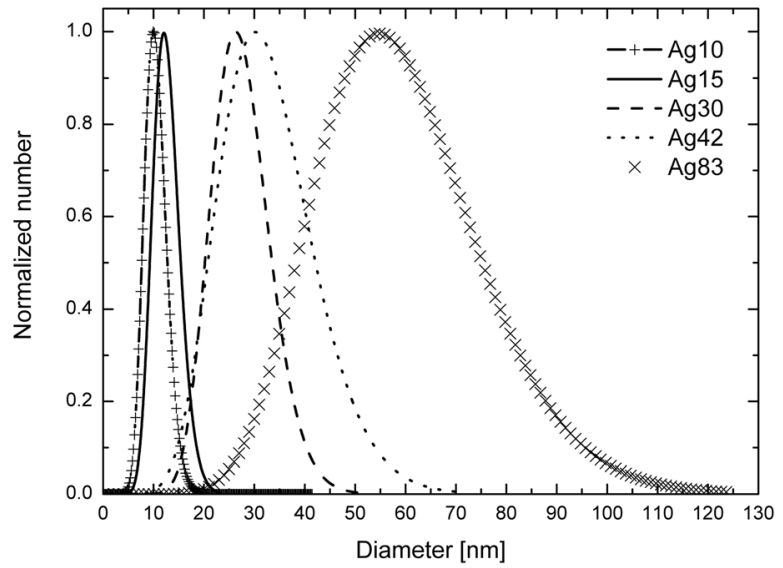

Fig. 2 SAXS results for spherical silver nanoparticles of different size, measured in aqueous dispersion. (a) SAXS data (symbols) and model fits (solid lines). The curves were shifted for clarity. (b) Number size distributions obtained from the SAXS analyses

diffraction (XRD) measurements, the samples were freezedried.

The synthesis of silver (Ag) nanospheres was done according to Wang et al. [13] by reduction of $\mathrm{AgNO}_{3}$ with glucose as described in Banerjee et al. [12] Sample aliquots were taken after 30,100, 200, and $1200 \mathrm{~min}$ of synthesis, and the average particle size was determined by several techniques (Table 1). Ag nanoplatelets were synthesized by microwave-assisted reduction of silver nitrate with ethylene glycol monoethyl ether in the presence of PVP as described by Helmlinger et al. [14]. Ag nanorods were obtained by a modified polyol process according to Schuette and Buhro $[14,15]$. Alloyed Ag:Au nanoparticles with a molar composition 20:80, 50:50, and 80:20 were obtained by simultaneous reduction of $\mathrm{HAuCl}_{4}$ and $\mathrm{AgNO}_{3}$ with a mixture of sodium citrate and tannic acid according to Mahl et al. [16]. In that article the preparation of gold nanoparticles by the reduction of $\mathrm{HAuCl}_{4}$ with a mixture of sodium citrate and tannic acid is also described. The particles were characterized by dynamic light scattering (DLS), differential centrifugal sedimentation (DCS), scanning electron microscopy (SEM), and X-ray powder diffraction (PXRD) as described in the references stated above.

Small/wide angle X-ray scattering experiments (SAXS/WAXS) data collection was performed on the laboratory-based SAXS equipment Xenocs XEUSSTM, at the Institute of Physics, University of São Paulo. The radiation was generated by a GENIX' ${ }^{\mathrm{TM}}$ source $(\mathrm{Cu} \mathrm{K} \alpha$ edge, $\lambda=1.54 \AA$ ) with the beam focused by a FOX2D ${ }^{\mathrm{TM}}$ optics. The beam collimation was performed by two sets of scatterless slits (Xenocs 2.0 ). In the high flux mode, the flux was $\sim 1 \cdot 10^{8}{\text { photons } \mathrm{s}^{-1}}^{-1}$ with a beam size of $1 \cdot 1 \mathrm{~mm}^{2}$. The 2D SAXS data were collected with a Dectris Pilatus ${ }^{\mathrm{TM}} 300 \mathrm{k}$ detector. The 2D WAXS data were collected on a Dectris Pilatus ${ }^{\mathrm{TM}}$ 100k detector, placed inside the vacuum chamber, allowing simultaneous SAXS/ WAXS measurements. Powder samples were placed between two mica windows and measured in vacuum. Liquid dispersion samples were placed into reusable quartz capillaries with $1.5 \mathrm{~mm}$ in diameter, mounted on stainless steel cases. The capillaries can be washed and rinsed, thus permitting the measurements of the sample and buffer in exactly same conditions. For SAXS measurements, the distance from sample to detector was $0.7 \mathrm{~m}$, giving a $q$ range of $0.15<q<4.5 \mathrm{~nm}^{-1}$ where $q$ is the reciprocal space momentum transfer modulus defined as $q=(4 \pi \sin \theta) / \lambda$ with $2 \theta$ the scattering angle and $\lambda$ the radiation wavelength. For WAXS measurements, the distance from sample to detector was $0.169 \mathrm{~m}$ with a $q$ range of $11<q<31 \mathrm{~nm}^{-1}$ $\left(16^{\circ}<2 \theta<44^{\circ}\right)$. In all cases, we measured several frames for $600 \mathrm{~s}$ each. These frames were compared and averaged in order to increase the signal to noise ratio. The SAXS data was modeled using several semi-analytical factors (see Appendix) and the parameters were optimized by using least squares methods. The average crystallite sizes can be estimated from the peak broadening reflections using the Scherrer equation [17]. Rietveld refinement was performed with the Bruker software TOPAS 4.22 using a Pseudo-Voigt function to describe the diffraction profile. For each Rietveld refinement the

Table 2 SAXS results for the spherical silver nanoparticles, measured in aqueous dispersion. The symbol $\sigma$ is the polydispersity

\begin{tabular}{lrr}
\hline Sample & Averaged diameter $(\mathrm{nm})$ & $\sigma(\mathrm{nm})$ \\
\hline Ag10 & $10.4(5)$ & $2.2(4)$ \\
Ag15 & $16.0(3)$ & $2.6(2)$ \\
Ag30 & $35.0(3)$ & $5.8(2)$ \\
Ag42 & $50(1)$ & $9.4(2)$ \\
Ag83 & $86(2)$ & $16.2(8)$ \\
\hline
\end{tabular}


(a)

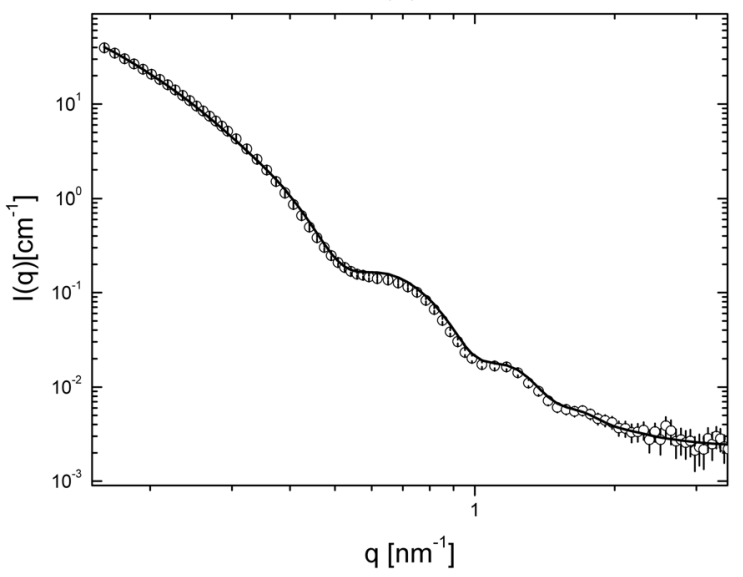

(b)

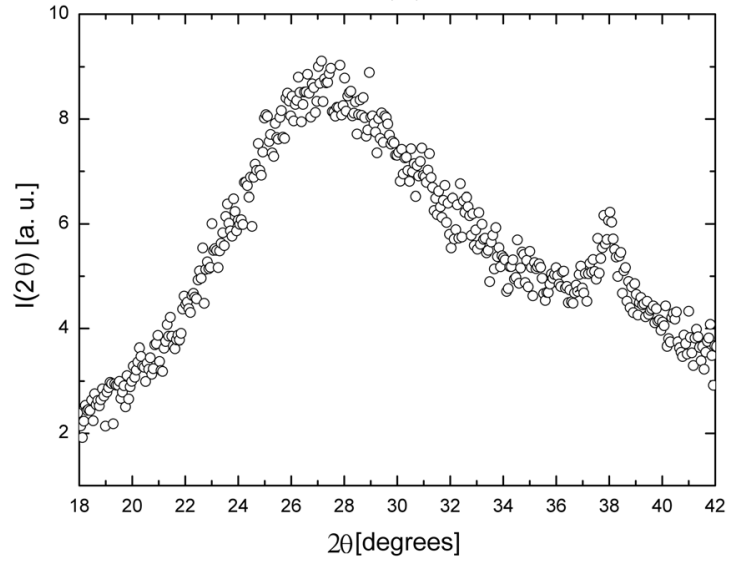

Fig. 3 SAXS/WAXS data for Ag nanoplatelets. (a) SAXS experimental data (symbols) and fitting curve (solid curve). (b) WAXS experimental data

instrumental correction was included as determined with a standard powder sample Al2O3 (NIST SRM 676a) for WAXS.

\section{Results and Discussion}

The physicochemical characterization data of all studied samples is given in Table 1. The average diameters determined using SEM data were calculated using images containing at least 100 particles. The standard deviation of the size distribution is displayed in parenthesis for the DCS and TEM data. Some representative images for the studied systems are shown in Fig. 1.

\section{Spherical Silver Nanoparticles with Different Sizes}

The SAXS-WAXS data for spherical silver nanoparticles are shown in Fig. 2. From the model fits, we obtained structural information (Table 2) that may be compared with the results in Table 1 . The average size obtained from SAXS is very similar

(a)

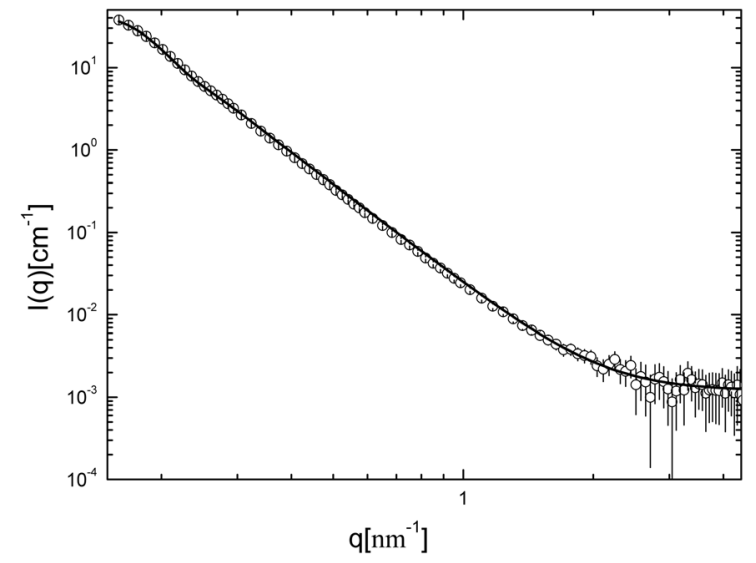

to the one estimated from the TEM images. However, as mentioned above, the results from SAXS correspond to an average from a much larger number of particles, providing a better representation for the ensemble average. From the data analysis it is possible to obtain the polydispersity levels, which is defined as the standard deviation of the radius distribution. Table 2 shows that the polydispersity varied from $\sim 20 \%$ for $\mathrm{Ag}(15 \mathrm{~nm})$ up to $\sim 27 \%$ for $\mathrm{Ag}(83 \mathrm{~nm})$.

\section{Rod and Platelet-Shaped Nanoparticles}

For the non-spherical silver nanoparticles, i.e., nanoplatelets and nanorods, the measured SAXS data are shown in Figs. $3 \mathrm{a}$ and $4 \mathrm{a}$. It was possible to determine the overall dimensions in each case. The SAXS data for Ag platelets were described using a theoretical model of a cylinder with elliptical cross section (length $L$, cross-section axes A and B). The SAXS data for Ag nanorods was modeled as long polydisperse cylinders, with size $D$ and length $L$. The structural parameters obtained from the model fits are shown in

(b)

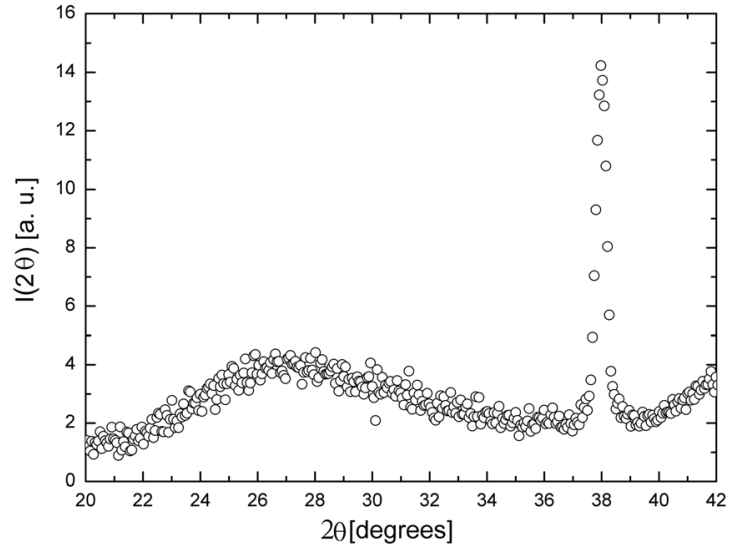

Fig. 4 SAXS/WAXS data for Ag nanorods. (a) SAXS experimental data (symbols) and fitting curve (solid curve). (b) WAXS experimental data 
Table 3 SAXS and WAXS results for Ag nanoplatelets and Ag nanorods, measured in aqueous dispersion. Parameters: $D$ is the diameter, $\sigma_{\mathrm{D}}$ is the polydispersity in the diameter, $L$ is the length of the cylinders, $\mathrm{A}$ and $\mathrm{B}$ are the major and the minor axis of the elliptical cylinders respectively, $\sigma_{\mathrm{A}}$ and $\sigma_{\mathrm{B}}$ are the polydispersity of the axis A and $\mathrm{B}$ respectively, $d$ is the interplanar distance and $C_{\mathrm{S}}$ is the crystallite size

\begin{tabular}{|c|c|c|c|}
\hline \multirow[b]{2}{*}{ Sample } & \multicolumn{2}{|l|}{ SAXS } & \multirow{2}{*}{$\begin{array}{l}\text { WAXS } \\
\text { Parameters (nm) }\end{array}$} \\
\hline & Form factor & Parameters (nm) & \\
\hline AgPlates & Elliptical cylinders & $\begin{array}{l}A=46(5) \\
B=26(2) \\
\sigma_{A}=4(2) \\
\sigma_{B}=2(1) \\
L=12.3(4)\end{array}$ & $\begin{array}{l}d=0.2368(1) \\
C_{S}=12(2)\end{array}$ \\
\hline AgRod & Long cylinders & $\begin{array}{l}D=96(7) \\
\sigma_{D}=13(4) \\
L=20(2) \cdot 10^{3}\end{array}$ & $\begin{array}{l}d=0.2369(2) \\
C_{S}=30(2)\end{array}$ \\
\hline
\end{tabular}

Table 3. The overall sizes are in reasonable agreement with the results from electron microscopy (Table 1), but from the modeling of the SAXS data, further details could be obtained. For the Ag platelets, the SAXS results gave an average thickness of $\sim 12 \mathrm{~nm}$, which is a parameter not available from SEM images. For the Ag nanorods, the SAXS analyses provided the average sizes for the cylinders, which was slightly larger than the values from electron microscopy. However, as mentioned in the previous section, the SAXS data correspond to an average from a much larger number of particles than the ones visible on the TEM images. From the WAXS data (Figs. 3b and 4b), the (111) peak of fcc silver crystallographic structure at about $37.5^{\circ}$ can be analyzed to estimate the average crystallite size. We found $12 \mathrm{~nm}$ for the nanoplatelets, which is in reasonable agreement with the data obtained earlier from X-ray powder diffraction $(\sim 15 \mathrm{~nm})$ [2]. For the nanorods, the estimated crystallite size obtained from the WAXS data was $\sim 30 \mathrm{~nm}$. Interestingly, this value is smaller than the one previously obtained from XRD analysis $(\sim 117 \mathrm{~nm})$. Since the WAXS data and the XRD were measured on different batches, this may indicate that this parameter varies in each sample preparation. In any (a)

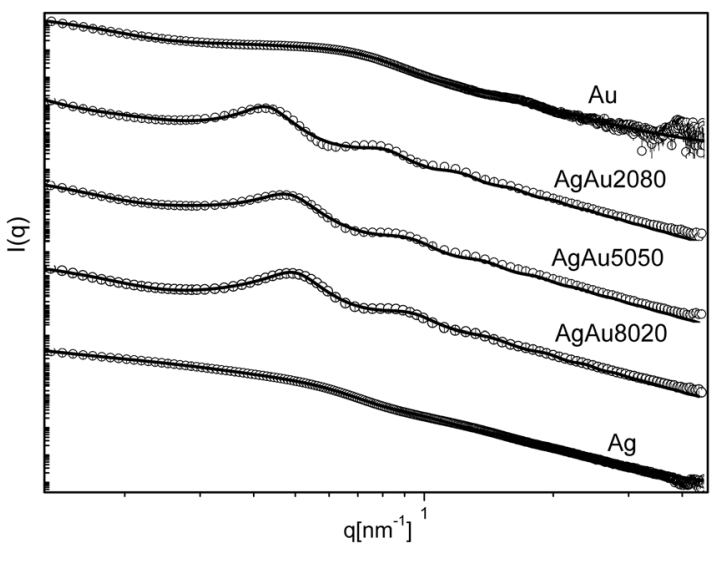

(b)

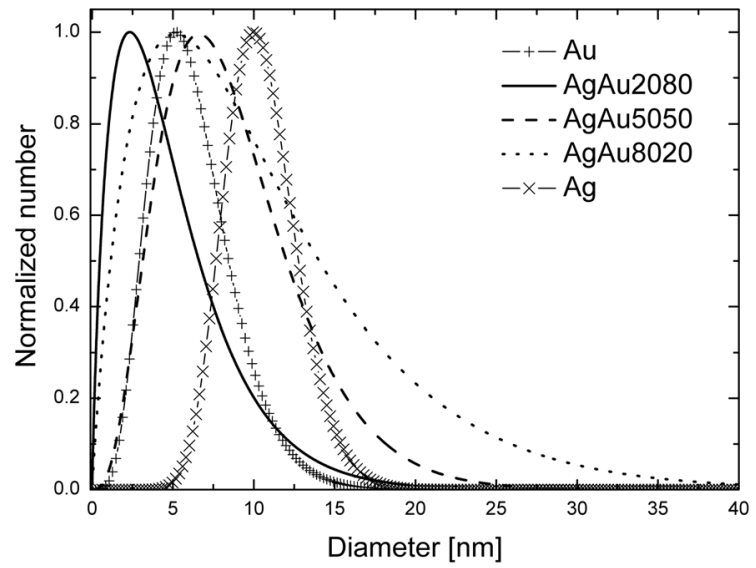

(c)

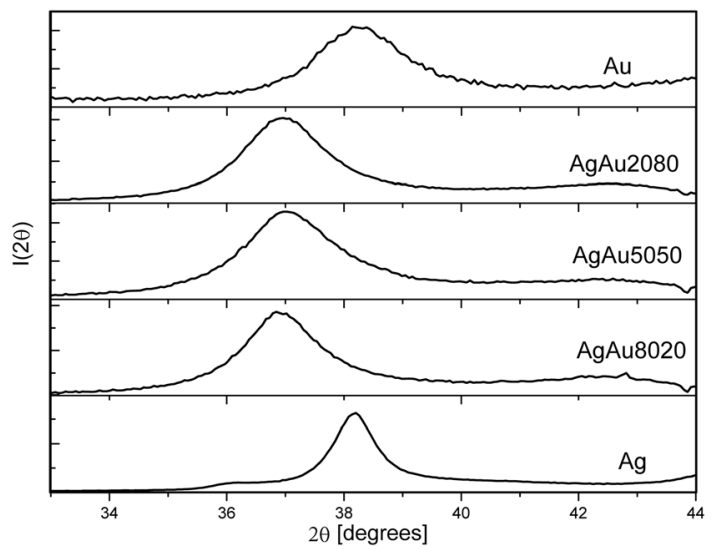

Fig. 5 SAXS/WAXS data for alloyed AgAu nanoparticles, measured as powder. (a) SAXS data (symbol, experimental data; solid lines: model fit), (b) Number size distributions obtained from the SAXS analyses and (c) WAXS experimental data 
Table 4 SAXS and WAXS results for Ag-Au nanoparticles, measured as powder. Parameters: $D$ is the number-weighted average diameter, $D_{V}$ is the volume-weighted average diameter, $\sigma$ is the polydispersity, $R_{G}$ is the gyration radius of the aggregates, $R_{H S}$ is the interaction radius, and $\eta$ is the hard sphere volume fraction

\begin{tabular}{|c|c|c|c|c|c|c|c|}
\hline \multirow[b]{2}{*}{ Sample } & \multicolumn{6}{|l|}{ SAXS } & \multirow{2}{*}{$\begin{array}{l}\text { WAXS } \\
\text { Crystallite size (nm }\end{array}$} \\
\hline & $D(\mathrm{~nm})$ & $D_{v}(\mathrm{~nm})$ & $\sigma(\mathrm{nm})$ & $R_{G}(\mathrm{~nm})$ & $R_{H S}(\mathrm{~nm})$ & $\eta$ & \\
\hline $\mathrm{Au}$ & $6.2(1)$ & $7.2(1)$ & $2.6(6)$ & 14.1(11) & 4.1(3) & $0.21(5)$ & $4.4(6)$ \\
\hline AgAu2080 & $10(2)$ & $15(3)$ & $7.4(6)$ & $25(2)$ & $7.85(4)$ & $0.441(4)$ & $5.5(2)$ \\
\hline AgAu5050 & $8.8(4)$ & 11(1) & $4.2(2)$ & $16.2(5)$ & $6.84(5)$ & $0.409(3)$ & $4.4(1)$ \\
\hline AgAu8020 & $5.0(2)$ & $7(1)$ & $3.6(2)$ & 15.1(5) & $6.72(2)$ & $0.426(5)$ & $4.9(1)$ \\
\hline $\mathrm{Ag}$ & $10(1)$ & 11(1) & $2.2(4)$ & $\begin{array}{c}7.8(7) \\
19(4)\end{array}$ & $4.0(5)$ & $0.187(3)$ & $10(1)$ \\
\hline
\end{tabular}

case, the comparison between the WAXS and XRD data is still useful in order to show that the interplanar periodicity $(d=(2.365(1) \AA)$ is similar in both cases, indicating the crystalline structure of silver.

\section{Alloyed Silver-Gold Nanoparticles Samples in Powder Form}

The SAXS-WAXS data obtained for alloyed silver-gold nanoparticles from solid (powder) samples are shown in Fig. 5. By using the proposed model (polydisperse system of aggregating hard spheres), it was possible to obtain good fits for the experimental data. The results are shown in Table 4.

For these samples it was necessary to consider the interaction between the particles, as well as agglomerates. The interaction was considered through the addition of the PercusYevick structure factor (see Appendix) [18]. This factor is a function of the average interaction distance represented by the $R_{H S}$ radius and the volume fraction $\eta$ associated with fraction of the interacting particles in the system.

The scattering due to agglomerates was considered by the use of a Guinier structure factor. In this case it is assumed that the agglomerates have an overall size, represented by an average radius of gyration [11]. One of the main advantages of this method is the possibility of describing characteristic sizes of the aggregates, without assuming a specific shape for them.

The results of the SAXS measurements displayed in Table 4 show good agreement with the results of others characterizations displayed in Table 1. The volume weighted average diameter calculated using the SAXS data are in good agreement with the values obtained from DCS experiments. Also, the radius of interaction among the particles ranges from 4 to about $8 \mathrm{~nm}$. The volume fraction of interacting particles $(\eta)$ is larger for the alloyed silver-gold nanoparticles samples than for the silver and gold samples.
The resolution of the SAXS technique is related to the minimum $q$ value available on the scattering curve by the estimation Dmax $\sim \pi / \mathrm{q}_{\min }$ [19]. However, up to this limit, SAXS data give information on the overall size and polydispersity for the particles in the system, independently of its degree of crystallinity. The XRD data provide information about the crystallinity of the system, permitting the characterization of the lattice parameters and overall crystallographic domain size of the nanoparticles. Therefore, the combination of XRD and SAXS data may provide direct indications on the formation of crystalline domains inside the metallic nanoparticles and also the information whether they are mono or polycrystalline.

\section{Conclusions}

Here, a large number of experimental results applied to different kinds of metallic nanoparticles with different sizes and shapes are presented. As demonstrated, the combination and correlation of the obtained experimental results for each sample provided a detailed structural description, on a multiscale level. The particular combination of simultaneous SAXS and WAXS measurements on a lab-based system provides a powerful characterization tool for the metallic nanoparticles since one can obtain information about the particle sizes, shapes, polydispersity and crystallinity degree. This type of information is crucial for the proper characterization of the particles, design, optimization and tuning of the synthesis routes and further technological applications.

Funding information C.L.P. Oliveira was supported by the CAPES (grant 431/15), CNPq (grant 304861/2015-4), and grant \#2015/017320, São Paulo Research Foundation (FAPESP). P.R.A.F. Garcia was supported by CAPES, under the CAPES-DAAD project (grant 431/15). M. Epple was supported by the Deutsche Forschungsgemeinschaft (DFG) under the grant number EP 22/44-1. We are grateful to the Deutscher Akademischer Austauschdienst for generous funding within the joint DAAD-PROBRAL exchange programme. This study was financed in 
part by the Coordenação de Aperfeiçoamento de Pessoal de Nível Superior - Brasil (CAPES) - Finance Code 001.

\section{Appendix}

In the following the theoretical models used to fit the experimental SAXS data are described. Detailed information about these models can be found in the book of Lindner (1991) [20]. The non-linear least squares method was used to determine the optimal values of the parameters. The uncertainties of these parameters were determined from the correlation matrix.

\section{Long Cylinders}

For a system composed of long cylinders with polydispersity in radius as used, the scattering intensity is given by:

$I_{\text {rod }}(q)=\operatorname{Sc} . P_{M O D}(q) P_{R O D}(q)+$ Back

where $S_{C}$ is an overall constant factor, Back a constant background, $P_{R O D}(\mathrm{q})$ is the form factor for an infinitely thin rod with length $L$ [21] and e $P_{M O D}(\mathrm{q})$ is the form factor of a polydisperse circular cross section given by:

$P_{M O D}(q)=\frac{\int_{0}^{\infty} D(r) m(r)^{2} F_{S}(q, r) d r}{\int_{0}^{\infty} D(r) m(r)^{2} d r}$

$\mathrm{m}(\mathrm{r})$ is the area of the circular cross section $\left(\pi r^{2}\right)$ and $F_{S}(q, R)$ is the intensity form factor for a circular cross section of radius $\mathrm{R}$ given by,

$F_{S}(q, R)=\left(\frac{J_{1}(q R)}{q R}\right)^{2}$

The polydispersity in radius $D\left(R, R_{0}, \sigma\right)$ is described as a Schulz-Zimm function [20]:

$D\left(R, R_{0}, \sigma\right)=\left(\frac{z+1}{R_{0}}\right)^{z+1} \frac{R^{z}}{\Gamma(z+1)} \exp \left(-(z+1) \frac{R}{R_{0}}\right)$

where $R_{0}$ is the central value of the distribution, $\Gamma$ is the gamma function and $z=1 /\left(\sigma / R_{0}\right)^{2}-1$ ( $\sigma$ is the polidispersity). This distribution is very useful because it allows asymmetric distributions.

\section{Cylinder with elliptical cross section}

For Ag Plates a model composed of cylinders with elliptical cross section was used. The scattering intensity is given by:

$I_{\text {ell }}(q)=\operatorname{Sc} \cdot P(q)+$ Back

where $\mathrm{S}_{\mathrm{C}}$ is an overall scale factor, Back a constant background and $\mathrm{P}(\mathrm{q})$ is the form factor of cylinders with elliptical cross section given by:
$P(q)=\frac{2}{\pi} \int_{0}^{\pi / 2} \int_{0}^{\pi / 2}\left[\frac{2 \mathrm{~B}_{1}(q r(A, B, \varphi, \alpha))}{q r(A, B, \varphi, \alpha)} \frac{\sin ((q L \cos \alpha) / 2)}{(q L \cos \alpha) / 2}\right] \mathrm{d} \varphi \sin \alpha d \alpha$

with $r(A, B, \varphi, \alpha)=0.5\left(\sqrt{A^{2} \sin ^{2} \varphi+B^{2} \cos ^{2} \varphi}\right) \sin \alpha$. In this equation, $\mathrm{L}$ is the length of the cylinders, $\mathrm{B}_{1}$ is the Bessel function of first order and $A$ and $B$ are the major and minor axis of the elliptical cross section respectively.

\section{Polydisperse system of spheres with aggregates}

In this case, the scattering intensity is given by:

$I(q)=S c\left(\int_{0}^{\infty} V^{2}(R) D(R, \sigma) F_{\text {sphere }}(q, R)^{2} d R\right) S_{P Y}\left(q, R_{H S}\right) \cdot S_{G}\left(q, R G_{1}\right)+$ Back

where Sc is the global scale factor, $\mathrm{R}$ is the radius of the sphere, $\mathrm{V}(\mathrm{R})$ is sphere volume, $\sigma$ is the size polydispersity, $R G$ is the average radius of gyration of the aggregates, $S_{G}$ is the Guinier structure factor, $\mathrm{R}_{\mathrm{HS}}$ is the hard sphere interaction radius and Back is a constant background.

The polydispersity in radius $\mathrm{D}(\mathrm{R}, \sigma)$ is described as a Schulz-Zimm function shown previously in Eq. 4.

In order to take into account the interaction among the spherical particles (repulsion), the hard-sphere PercusYevick structure factor $\mathrm{S}_{\mathrm{PY}}\left(\mathrm{q}, \mathrm{R}_{\mathrm{HS}}\right)$ was used [18]:

$S_{P Y}\left(q, R_{H S}\right)=\frac{1}{1+24 \eta G\left(2 R_{H S} q\right) /\left(2 R_{H S} q\right)}$

Where $\mathrm{R}_{\mathrm{HS}}$ is the hard sphere radius, $\eta$ is volume fraction of hard spheres and $G$ is given by:

$$
\begin{aligned}
G(A)= & \frac{a(\sin A-A \cos A)}{A^{2}}+\frac{\beta\left(2 A \sin A+\left(2-A^{2}\right) \cos A-2\right)}{A^{3}}+ \\
& \frac{\gamma\left[-A^{4} \operatorname{cps} A+4\left\{\left(3 A^{2}-6\right) \cos A+\left(A^{3}-6 A\right) \sin A+6\right\}\right]}{A^{5}}
\end{aligned}
$$

with,

$\alpha=\frac{(1+2 \eta)^{2}}{(1-\eta)^{4}}, \beta=\frac{-6 \eta(1+\eta / 2)^{2}}{(1-\eta)^{4}}, \gamma=\frac{\eta \alpha}{2}$

The contribution of aggregates and/or large particles is described in terms of their average gyration radius $\mathrm{RG}$ and the scale factors $\mathrm{Sc}^{\mathrm{G}}$ [10]. The expression for this structure factor $\mathrm{SG}$ is given by:

$S_{G}(q, R G)=1+S c e^{G} e^{\frac{-q^{2} R G^{2}}{3}}$

where $\mathrm{RG}_{\mathrm{sph}}=R_{\mathrm{sph}}(3 / 5)^{1 / 2}$.

Publisher's Note Springer Nature remains neutral with regard to jurisdictional claims in published maps and institutional affiliations. 


\section{References}

1. R.A.L. Jones, Soft condensed matter (Oxford University Press, Oxford, 2002)

2. J. Helmlinger, O. Prymak, K. Loza, M. Gocyla, M. Heggen, M. Epple, On the crystallography of silver nanoparticles with different shapes. Cryst. Growth Des. 16, 3677-3687, 2016/05/24 (2016)

3. L.X. Wang, Y. Li, M.R. Xia, Z.P. Li, Z.H. Chen, Z.P. Ma, X.J. Qin, G.J. Shao, Ni nanoparticles supported on graphene layers: an excellent 3D electrode for hydrogen evolution reaction in alkaline solution. J. Power Sources 347, 220-228 (2017)

4. Y. Xu, W.G. Tu, B.W. Zhang, S.M. Yin, Y.Z. Huang, M. Kraft, R. $\mathrm{Xu}$, Nickel nanoparticles encapsulated in few-layer nitrogen-doped graphene derived from metal-organic frameworks as efficient bifunctional electrocatalysts for overall. Adv. Mater. 29(11) (2017)

5. R.W. Huang, Y.S. Wei, X.Y. Dong, X.H. Wu, C.X. Du, S.Q. Zang, T.C.W. Mak, Hypersensitive dual-function luminescence switching of a silver-chalcogenolate cluster-based metal-organic framework. Nat. Chem. 9(7), 689-697 (2017)

6. Y.N. Xia, Y. Xiong, B. Lim, S.E. Skrabalak, Shape-controlled synthesis of metal nanocrystals: simple chemistry meets complex physics? Angew. Chem. Int. Ed. 48, 60-103 (2009)

7. M.H. Nielsen, S. Aloni, J.J. De Yoreo, In situ TEM imaging of $\mathrm{CaCO} 3$ nucleation reveals coexistence of direct and indirect pathways. Science 345(6201), 1158-1162 (2014)

8. C.L.P. Oliveira, S. Juul, H.L. Jorgensen, B. Knudsen, D. Tordrup, F. Oteri, M. Falconi, J. Koch, A. Desideri, J.S. Pedersen, F.F. Andersen, B.R. Knudsen, Structure of nanoscale truncated octahedral DNA cages: variation of single-stranded linker regions and influence on assembly yields. ACS Nano 4, 1367-1376 (2010)

9. C.L.P. Oliveira, in Investigating macromolecular complexes in solution by small angle $x$-ray scattering, Current trends in $x$-ray crystallography, ed. by D. A. Chandrasekaran. (InTech, London, 2011), pp. 367-392
10. C.L.P. Oliveira, P.R. Santos, A.M. Monteiro, A.M. Figueiredo Neto, Effect of oxidation on the structure of human low- and high-density lipoproteins. Biophys. J. 106(12), 2595-2605 (2014)

11. C.L.P. Oliveira, A.M. Monteiro, A.M. Figueiredo Neto, Structural modifications and clustering of low-density lipoproteins in solution induced by heating. Braz. J. Phys. 44(6), 753-764 (2014)

12. S. Banerjee, K. Loza, W. Meyer-Zaika, O. Prymak, M. Epple, Structural evolution of silver nanoparticles during wet-chemical synthesis. Chem. Mater. 26, 951-957, 2014/01/28 (2014)

13. H.S. Wang, X.L. Qiao, J.G. Chen, S.Y. Ding, Preparation of silver nanoparticles by chemical reduction method. Colloids Surf. A Physicochem. Eng. Asp. 256, 111-115 (2005)

14. J. Helmlinger, C. Sengstock, C. Gross-Heitfeld, C. Mayer, T.A. Schildhauer, M. Koller, M. Epple, Silver nanoparticles with different size and shape: equal cytotoxicity, but different antibacterial effects. RSC Adv. 6, 18490-18501 (2016)

15. W.M. Schuette, W.E. Buhro, Silver chloride as a heterogeneous nucleant for the growth of silver nanowires. ACS Nano 7, 3844 3853, 2013/05/28 (2013)

16. D. Mahl, J. Diendorf, S. Ristig, C. Greulich, Z.A. Li, M. Farle, M. Koeller, M. Epple, Silver, gold, and alloyed silver-gold nanoparticles: characterization and comparative cell-biologic action. J. Nanopart. Res. 14, 1153 (2012)

17. H.P. Klug, L.E. Alexander, X-ray Diffraction Procedures for Polycrystalline and Amorphous Materials (Wiley-Interscience, New York, 1974)

18. J.K.A.Y. Percus, J. George, Analysis of classical statistical mechanics by means of collective coordinates. Phys. Rev. 110, 1 (1958)

19. O. Glatter, O. Kratky, Small angle x-ray scattering (Academic, London, 1982)

20. P.A.Z. Lindner, Th, neutron, $\mathrm{x}$-ray and light scattering: introduction to an investigative tool for colloidal and polymeric systems (1991)

21. T. Neugebauer, Calculation of the light diffusion of filament chain solutions. Ann. Phys. 42(7/8), 509-533 (1942) 1942 
Materials Science inc. Nanomaterials \& Polymers

\title{
Wet-Chemical Synthesis of Pd-Au Core-Shell Nanoparticles $(8 \mathrm{~nm})$ : From Nanostructure to Biological Properties
}

\author{
Alexander Rostek, ${ }^{[\mathrm{a}]}$ Marina Breisch, ${ }^{[\mathrm{b}]}$ Kateryna Loza, ${ }^{[\mathrm{a}]}$ Paulo R. A. F. Garcia, \\ Cristiano L. P. Oliveira, ${ }^{[c]}$ Oleg Prymak, ${ }^{[a]}$ Marc Heggen, ${ }^{[\mathrm{d}]}$ Manfred Köller, ${ }^{[\mathrm{b}]}$ \\ Christina Sengstock, ${ }^{[b]}$ and Matthias Epple*[a]
}

\begin{abstract}
$\mathrm{Pd}$-Au core-shell nanoparticles with a palladium core (diameter about $5.5 \mathrm{~nm}$ ) and a gold shell (thickness about $1.7 \mathrm{~nm}$ ) were wet-chemically synthesized in an easy water-based one-pot synthesis by sequential reduction of $\mathrm{Pd}^{2+}$ and $\mathrm{Au}^{3+}$ with glucose in the presence of poly(N-vinylpyrrolidone) (PVP). The metals are present in about equal amounts (molar ratio Pd:Au about 2:1) with a clear separation between core and shell. The reaction was monitored in-situ by small-angle X-ray scattering (SAXS), showing the initial growth of the palladium seeds, followed by the epitactic formation of the gold shell. The core-
\end{abstract}

shell character of the particles was confirmed by highresolution scanning transmission electron microscopy (STEM) and energy-dispersive X-ray spectroscopy (EDX). However, Xray powder diffraction with Rietveld analysis indicated a partial alloying, i.e. a gradual border between the two metals. Cell culture experiments showed no adverse effects on human mesenchymal stem cells ( $\mathrm{hMSCs}$ ) with a $\mathrm{Pd}-\mathrm{Au}$ nanoparticle concentration (computed as total metal) up to $50 \mu \mathrm{g} \mathrm{mL}^{-1}$ after $24 \mathrm{~h}$ incubation, i.e. the particles can be considered as biologically harmless, even after unintended human exposure.

\section{Introduction}

Inorganic and metallic nanoparticles represent a well-established field of nanoscience, medicine, catalysis, and industry. ${ }^{[1]}$ Noble metals like rhodium, palladium, platinum, silver, and gold are of special interest. ${ }^{[2]}$ Core-shell nanostructures and nanoalloys play important roles and open up new possibilities due to their tuneable properties, e.g. in heterogeneous catalysis, electrocatalysis, magnetism, and biomedical applications. ${ }^{[3]}$ In particular, palladium-gold nanoparticles $(\mathrm{Pd}-\mathrm{Au})$ are of considerable interest in heterogeneous catalysis, e.g. for various redox reactions. ${ }^{[4]}$ This is mainly ascribed to the modulation of the properties of palladium by alloying it with gold, both electronically and structurally. ${ }^{[4]}$ Zhang et al. have published a comprehensive review about the synthesis and the properties of $\mathrm{Pd}-\mathrm{Au}$ bimetallic nanoparticles, in core-shell form ( $\mathrm{Pd}-\mathrm{Au}$ and $\mathrm{Au}-\mathrm{Pd}$ ) and in alloyed form, including non-spherical nanoparticles. $^{[4]}$

[a] A. Rostek, Dr. K. Loza, Dr. O. Prymak, Prof. Dr. M. Epple

Inorganic Chemistry and Center for Nanointegration Duisburg-Essen (CeNIDE), University of Duisburg-Essen, Universitaetsstr. 7, 45141 Essen Germany

E-mail: matthias.epple@uni-due.de

[b] M. Breisch, Prof. Dr. M. Köller, Prof. Dr. C. Sengstock Bergmannsheil University Hospital/Surgical Research, Ruhr-University of Bochum, Bürkle-de-la-Camp-Platz 1, 44789 Bochum, Germany

[c] P. R. A. F. Garcia, Prof. Dr. C. L. P. Oliveira

Institute of Physics, University of São Paulo, Rua do Matão 1371, São Paulo, São Paulo, 05314-970, Brazil

[d] Dr. M. Heggen

Ernst Ruska-Centre for Microscopy and Spectroscopy with Electrons, Forschungszentrum Jülich $\mathrm{GmbH}, 52425$ Jülich, Germany

Supporting information for this article is available on the WWW under https://doi.org/10.1002/slct.201800638

A number of experimental and theoretical reports has been published about the $\mathrm{Pd}-\mathrm{Au}$ system, ranging from alloyed nanoparticles to physically prepared thin films. Zhang et al. have prepared alloyed $\mathrm{Pd}-\mathrm{Au}$ nanoparticles with a diameter of about 50 to $60 \mathrm{~nm}$ by co-reduction in the presence of $\mathrm{Cu}^{2+}$, also in porous form. ${ }^{[5]}$ Kunal et al. have reported a microwavebased synthesis of alloyed $\mathrm{Pd}-\mathrm{Au}$ nanoparticles (polyol process) with about $2.5 \mathrm{~nm}$ diameter with variable composition and tested them in the catalytic hydrogenation of alkenes. ${ }^{[6]}$ Hahn et al. have prepared thin films of $\mathrm{Pd}-\mathrm{Au}$ (thickness about 100 $150 \mathrm{~nm}$ ) for the electrocatalytic reduction of $\mathrm{CO}_{2} \cdot{ }^{[7]}$ Prevot et al. have investigated the thermal behaviour of carbon-supported $\mathrm{Pd}-\mathrm{Au}$ nanoparticles ( $3.4 \mathrm{~nm}$; about 40 at\% Pd). They found that dealloying occurred after $10 \mathrm{~h}$ at $600^{\circ} \mathrm{C}$, including an Ostwald-ripening of large particles on the expense of small particles. ${ }^{[8]}$

Two kinds of core-shell particles can be prepared: Gold core/palladium shell (Au-Pd) and palladium core/gold shell $(\mathrm{Pd}-\mathrm{Au})$. The first system is easier to prepare as there is no galvanic replacement when adding palladium ions to a metallic gold core. ${ }^{[4]}$ It is also of direct interest for palladium-based heterogeneous catalysis. Gold nanocubes were coated with a layer of palladium by Li et al. (full diameter down to $12 \mathrm{~nm}$ ) by a seed-mediated synthesis. ${ }^{[9]}$ Spitale et al. have prepared Au-Pd core-shell nanoparticles ( $6 \mathrm{~nm}$ Au core, $2 \mathrm{~nm}$ Pd shell thickness) and carried out atomistic simulations on this system. ${ }^{[10]}$ de Santis et al. have studied the formation of $\mathrm{Au}-\mathrm{Pd}$ core-shell nanoparticles of various diameters (around $100 \mathrm{~nm}$ ) and shapes by an extensive variation of the seeded-growth method paramaters. ${ }^{[11]}$

For the preparation of core-shell structures with a palladium core and a gold shell, a galvanic replacement of palladium 
metal by gold ions (oxidative etching) must be avoided. Here, the reducing agent must be properly chosen. Gopalan et al. have studied the catalytic performance of $\mathrm{Pd}-\mathrm{Au}$ core-shell nanoparticles ( $5 \mathrm{~nm}$ Pd core, $5 \mathrm{~nm}$ Au shell thickness). ${ }^{[12]} \mathrm{Lim}$ et al. have prepared palladium nanocubes (about $5 \mathrm{~nm}$ edge length) and coated them with a thin layer of gold (about 2 $3 \mathrm{~nm}$ thickness). ${ }^{[13]}$ Mazumder et al. have prepared core-shell nanoparticles with a palladium core $(5 \mathrm{~nm})$ and a gold shell (1 to $2 \mathrm{~nm}$ thickness, depending on the reaction conditions) in non-aqueous solvents. ${ }^{[14]}$

Theoretical reports deal with the stability and internal element distribution inside gold-palladium nanoparticles. Fernandez-Navarro et al. have simulated the stability of $\mathrm{Pd}-\mathrm{Au}$ core-shell nanoparticles $(3 \mathrm{~nm})$ by density functional theory (DFT) and predicted atom diffusion rates and melting temperatures. ${ }^{[15]}$ Zhu et al. computed the structure and the elemental distribution of quasi-spherical $\mathrm{Au}-\mathrm{Pd}$ nanoparticles with up to 405 atoms (corresponding to a diameter of about $2-3 \mathrm{~nm}$ ) by Monte-Carlo simulations. ${ }^{[16]}$

The challenge in the aqueous preparation of nanoparticles with a palladium core and a gold shell is to avoid the galvanic replacement of the palladium seed by the more noble gold during application of the outer shell. ${ }^{[4]}$ Furthermore, a synthesis in an organic solvent (including the polyol synthesis) ${ }^{[1 a, 17]}$ makes it difficult to transfer the particles into an aqueous dispersion. Finally, almost nothing is known about the biological effect of alloyed $\mathrm{Pd}-\mathrm{Au}$ nanoparticles.

Here, we report an easy synthesis of $\mathrm{Pd}-\mathrm{Au}$ core-shell nanoparticles by a water-based one-pot synthesis, followed by a stabilization with poly(N-vinyl pyrrolidone) (PVP), and an extensive characterization with different colloid-chemically and spectroscopic methods, including in-situ small-angle X-ray scattering (SAXS) during the palladium seed formation and the ongrowth of the gold shell. We have performed high-resolution transmission electron microscopy including energy-dispersive $X$-ray spectroscopy (EDX) to investigate the core-shell structure. $\mathrm{X}$-ray powder diffraction with an extensive Rietveld refinement was carried out to elucidate the ultra- and microstructure of the nanoparticles. We have furthermore studied the biological effect of such well-defined nanoparticles in colloidal dispersion with human mesenchymal stem cells in order to assess a potential risk for human health after non-intended exposure.

\section{Results and discussion}

The core-shell Pd-Au nanoparticles were prepared by sequential reduction in water, based on a seeded growth approach to bimetallic nanoparticles. ${ }^{[4,18]}$ First, a palladium seed was prepared as core to which a shell of gold was added in a one-pot synthesis. The presence of the reducing agent glucose prevented the galvanic replacement of the palladium seeds by the gold ions. Colloidal stabilization was accomplished by a shell of PVP. Both palladium core particles as well as Pd-Au core-shell nanoparticles were characterized by dynamic light scattering (DLS), analytical disc centrifugation (differential centrifugal sedimentation, DCS), UV-Vis spectroscopy (UV), high-resolution transmission electron microscopy (HRTEM) and scanning transmission electron microscopy (STEM). The nanostructure of the particles was studied by X-ray powder diffraction (XRD) and subsequent Rietveld refinement. Elemental analysis by atomic absorption spectroscopy after dissolution in aqua regia gave a weight ratio of palladium:gold of 53:47 (molar ratio 68:32). All characterization data are summarized in Table 1.

Table 1. Characterization data of PVP-stabilized Pd-Au core-shell nanoparticles after reduction with glucose (all nanoparticles were well dispersed in water and not agglomerated). Within the experimental error, DLS, DCS, and TEM gave the same size results for Pd seeds and Pd-Au nanoparticles.

\begin{tabular}{|llll|} 
& Method & $\begin{array}{l}\text { Pd-PVP } \\
\text { (seed/core only) }\end{array}$ & $\begin{array}{l}\text { Pd-Au-PVP } \\
\text { (core-shell) }\end{array}$ \\
\hline diameter / nm & DLS* & $6.7 \pm 1.2$ & $8.2 \pm 1.2$ \\
& DCS & $5.1 \pm 1.5$ & $7.4 \pm 1.2$ \\
& TEM & $5.4 \pm 1.1$ & $8.8 \pm 1.1$ \\
PDI (by DLS) & & 0.18 & 0.22 \\
zeta potential & $-6 \pm 5$ & $-6 \pm 4$ \\
(by DLS) / mV & & \\
Molar ratio of Pd:Au by AAS: 68:32; by EDX: 59:41. & \\
\hline * size distribution by number & \\
\hline
\end{tabular}

The nanoparticles had a slightly negative zeta potential due to the polyelectrolyte PVP and probably also to synthesis byproducts that were adsorbed on the nanoparticle surface. The hydrodynamic diameter of the water-dispersed nanoparticles represents the size of the solid metallic core together with the hydrated polymer layer of PVP. It was determined by differential centrifugal sedimentation and dynamic light scattering, with a good agreement between both methods (Table 1 and Figure 1). The fact that the hydrodynamic diameter is close to the diameter of the metallic core confirms the well-dispersed state of the nanoparticles in water (no agglomeration). Note that the hydrodynamic diameter determined by DCS is systematically underestimated due to the hydration shell. ${ }^{[19]}$

These results are in good agreement with the size determined by HRTEM (Figure 2). The high-resolution transmission electron micrographs of the initial Pd seeds and of the $\mathrm{Pd}-\mathrm{Au}$ core-shell nanoparticles showed crystals of almost spherical morphology with average diameters of $5.4 \pm 1.1 \mathrm{~nm}$ and $8.8 \pm 1.1 \mathrm{~nm}$, respectively. Thus, the thickness of the gold shell is about $1.7 \pm 0.6 \mathrm{~nm}$.

We performed high-angle annular dark field (HAADF) STEM to elucidate the nanoparticle ultrastructure. Under these conditions, $\mathrm{Au}(Z=79)$ shows a stronger brightness than $\mathrm{Pd}$ $(Z=46)$. The HAADF-STEM images and the EDX maps (Figures 3 and 4) confirmed the presence of a core-shell structure with a gold shell and a palladium core. The quantitative EDX evaluation gives an average molar Pd:Au ratio of 59 at\% to 41 at\%, which is slightly higher for palladium than expected from the stoichiometric synthesis where a 50:50 ratio was used. The thickness of the gold shell was about $1.5 \mathrm{~nm}$, in good agreement with the data given in Table 1 and Figure 2. Furthermore, the particles were mostly single crystalline, despite the coreshell structure and the presence of a few isolated twins and 

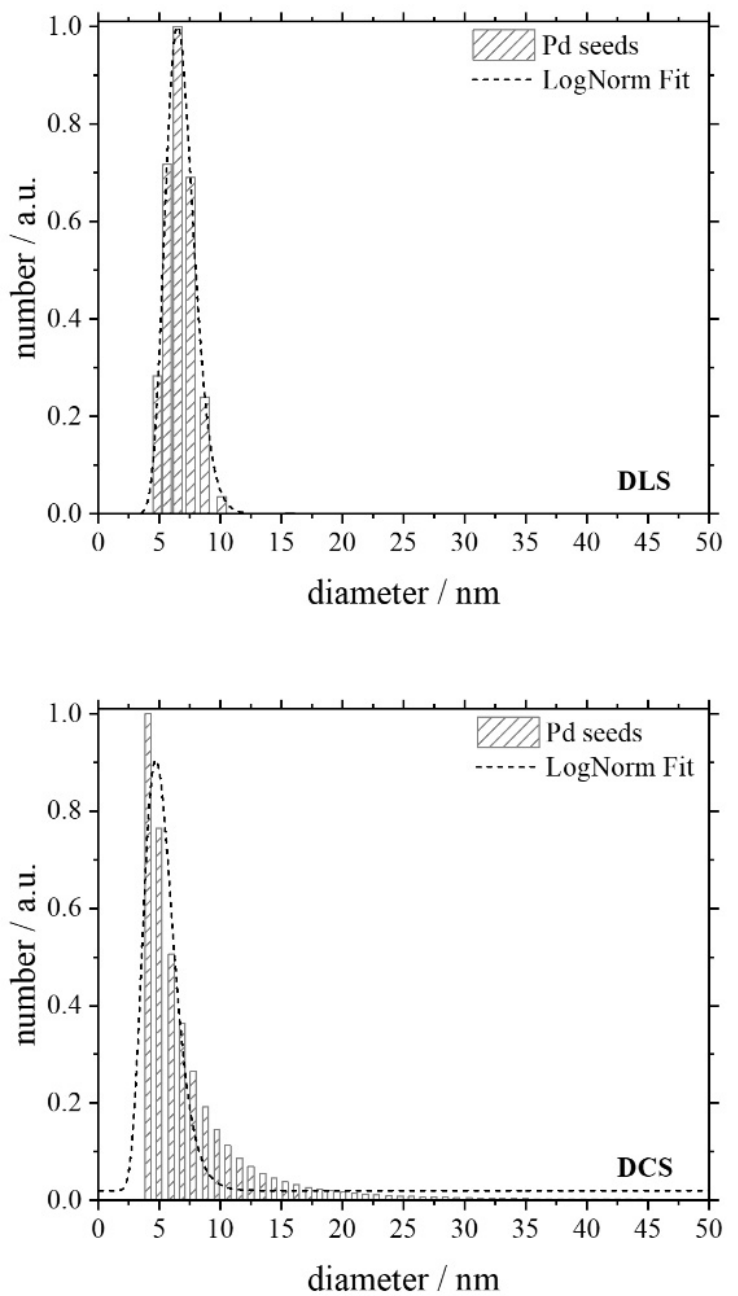
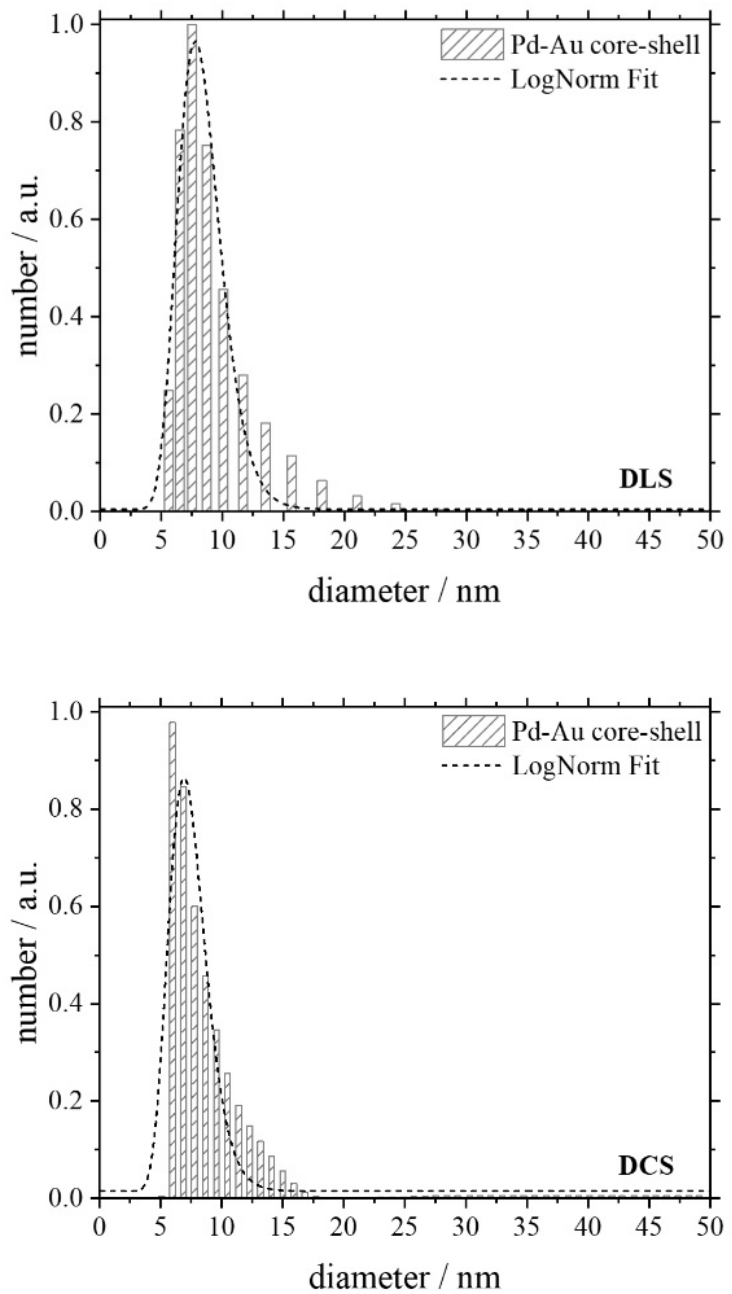

Figure 1. Size distributions by number determined by DLS (top row) and DCS (bottom row) of Pd-PVP seeds and Pd-Au-PVP core-shell nanoparticles.

grain boundaries (Figure 3), indicating an epitaxial growth of the gold shell onto the palladium core during the synthesis (Figure 4). Notably, some particles had a triangular instead of a spherical shape. The boundary between palladium and gold was rather sharp, indicating a sequential metal deposition, with some alloying at the interface. However, the obtained datasets did not allow an accurate quantification in order to prove the alloying of the shell and the core. An exact EDX analysis can only be realized by a partial cross section approach with single element calibration samples. ${ }^{[20]}$

Gold and palladium form an unlimited row of mixed crystals, with a perfect match to Vegard's rule concerning the lattice parameter $a$ (fcc crystal system) (Figure 5). ${ }^{[7,21]}$

X-ray powder diffraction of freeze-dried dispersions was carried out to study the internal structure on a larger number of particles (Figure 6). For the quantitative phase analysis, a Rietveld refinement was performed to determine the lattice parameters and the crystallite sizes. Despite the epitactic ongrowth of $\mathrm{Au}$, we were able to distinguish between the two metals in XRD due to their different lattice parameters. The results of the Rietveld refinement are summarized in Table 2 .

\begin{tabular}{|lll|}
\hline \multicolumn{3}{|c|}{$\begin{array}{c}\text { Table 2. Results of Rietveld refinement from X-ray powder diffraction } \\
\text { analysis of Pd-Au core-shell nanoparticles. }\end{array}$} \\
Parameter & $\mathrm{Au}$ (fcc) & $\mathrm{Pd}$ (fcc) \\
\hline Tabulated lattice parameter $a$ (bulk metals) / $\AA$ & 4.07860 & 3.89019 \\
Measured lattice parameter $a / \AA$ & $4.07 \pm 0.06$ & $3.97 \pm 0.06$ \\
Measured cell volume / $\AA^{3}$ & $68 \pm 3$ & $63 \pm 3$ \\
Measured crystallite size / $\mathrm{nm}$ & $2.5 \pm 0.4$ & $5.2 \pm 0.4$ \\
Computed crystal density / $\mathrm{g} \mathrm{cm}^{-3}$ & 19.4 & 11.3 \\
\hline
\end{tabular}

The reference values for $a$ were taken from PDF \#0784 (Au) and PDF \#1043 (Pd) of the ICDD database.

The EDX line scan as well as the calculated lattice parameter, especially for $\mathrm{Pd}$, indicate an alloying inside the particle. A partial alloying to a palladium-rich core and a goldrich shell is consistent with the TEM results. However, we must note that the calculated lattice parameters are associated with a comparatively large error due to the broad diffraction peaks. Therefore, a computation of the microstrain which also contributes to peak broadening was not possible. If we assume a spherical particle with $5.4 \mathrm{~nm} \mathrm{Pd}$ core and $1.7 \mathrm{~nm} \mathrm{Au}$ shell, 

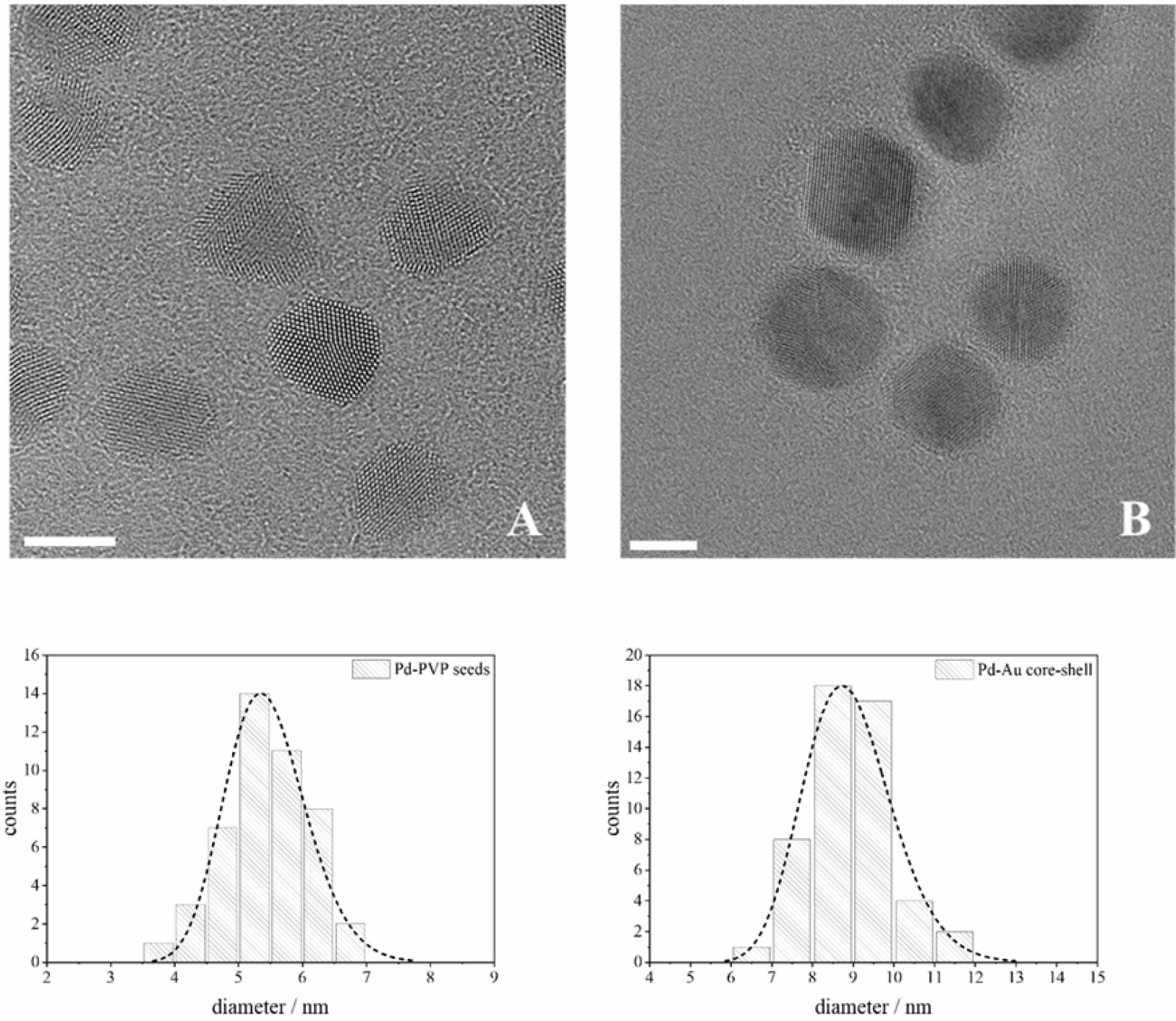

Figure 2. Representative HRTEM images (top) of Pd seeds (A) and Pd-Au core-shell nanoparticles (B) and the corresponding histograms for particle size analysis. The scale bars are $5 \mathrm{~nm}$.

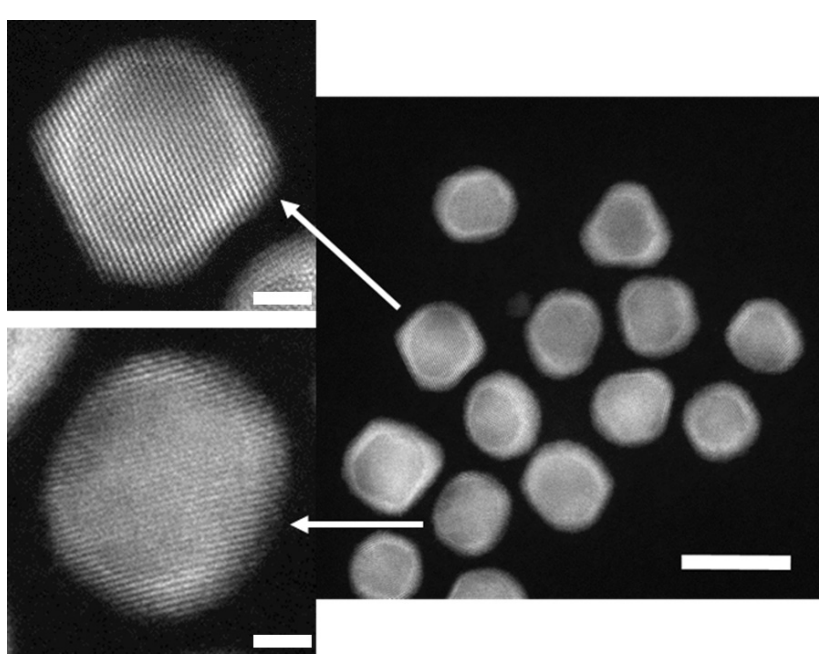

Figure 3. Right; HAADF-STEM image of Pd-Au core-shell nanoparticles (scale bar $10 \mathrm{~nm}$ ) with two particles in higher magnification (scale bar $2 \mathrm{~nm}$ ) (left). the relative volumes of core:shell are $82 \mathrm{~nm}^{3}: 275 \mathrm{~nm}^{3}$. Taking into account the densities and atomic weights of palladium and gold, we obtain a molar ratio of $\mathrm{Pd}: \mathrm{Au}=26: 74$. As a molar Pd:Au ratio of about 2:1 was experimentally determined by AAS and EDX (Table 1), there must be a substantial amount of palladium inside the gold shell.

In-situ small-angle X-ray scattering (SAXS) measurements were performed to monitor the core-shell formation during the synthesis. ${ }^{[22]}$ The time-resolved evolution of the average diameter (Figures 7 and 8) showed that the Pd seeds were almost immediately formed. A stepwise increase in size was observed after the gold precursor was added to the solution (at $t=50 \mathrm{~min}$ ). The particle diameter corresponds well to the data obtained for the palladium seeds and the final $\mathrm{Pd}-\mathrm{Au}$ core shell particles (Table 1). In addition to this result, we detected the evolution of agglomerates by SAXS (see Appendix A). Small fractions of aggregates with two characteristic sizes were retrieved from the data analysis. 

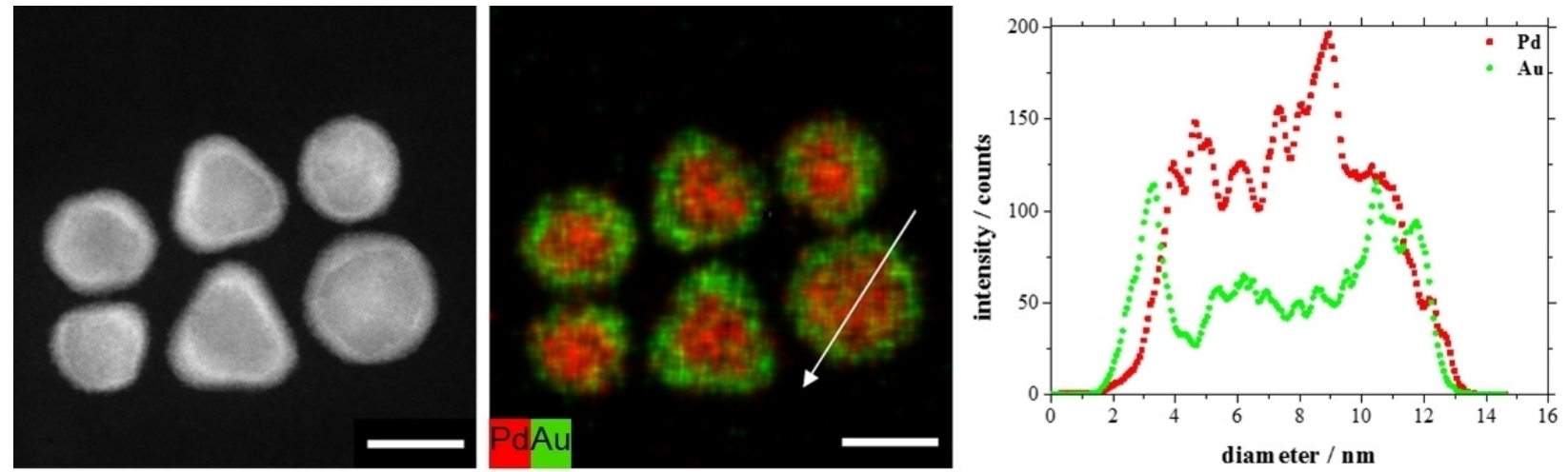

Figure 4. HAADF-STEM image and corresponding EDX map with an additional line scan (white arrow) of Pd-Au core-shell nanoparticles. The EDX maps and line scans clearly show the presence of a core-shell structure with a palladium core (red) and a gold shell (green). The scale bars are $7 \mathrm{~nm}$.
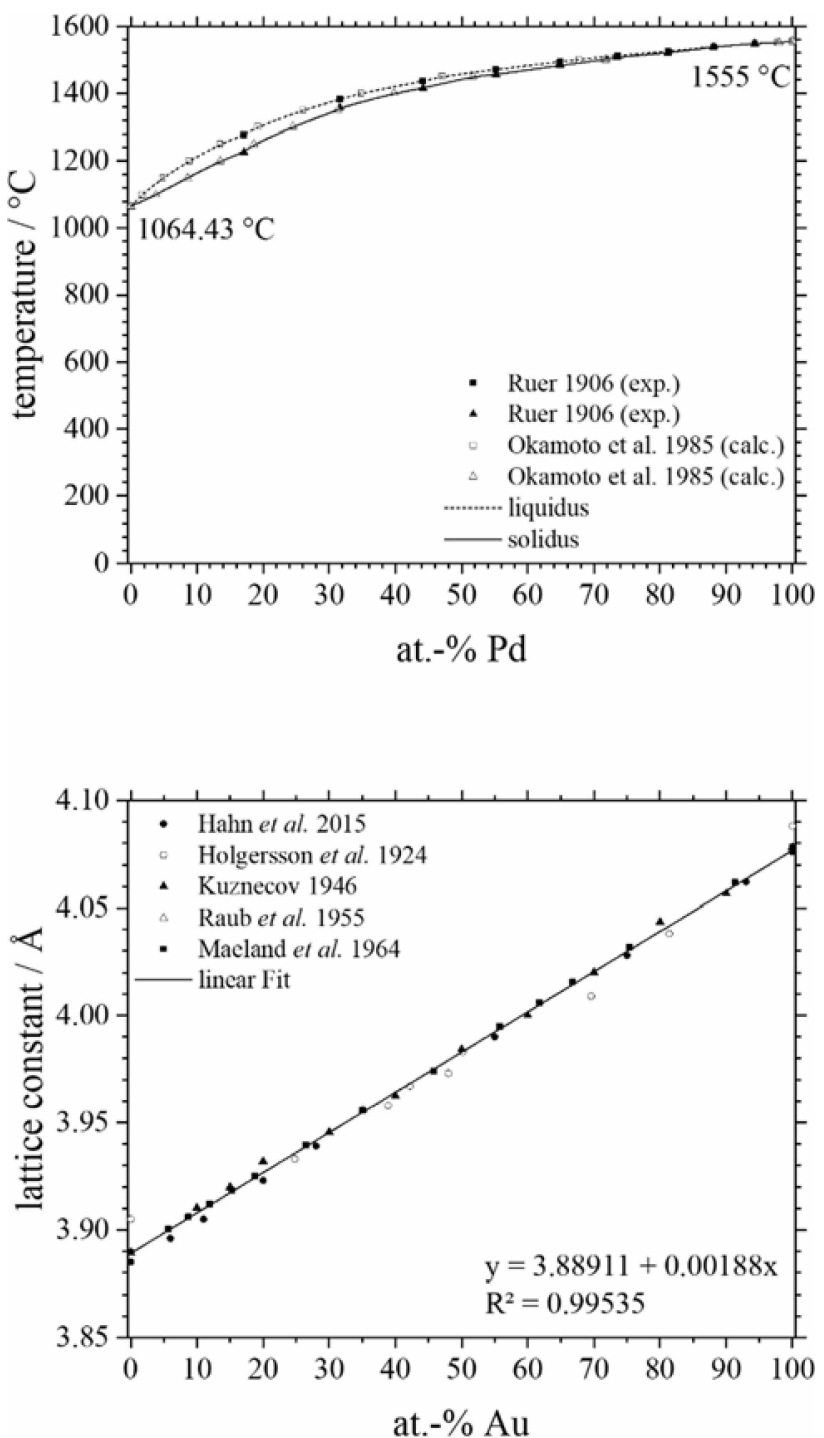

Figure 5. Phase diagram (top) and trend of lattice parameters in the Pd-Au system (bottom). Data points taken from the given references. ${ }^{[7,21 a-c, f]}$

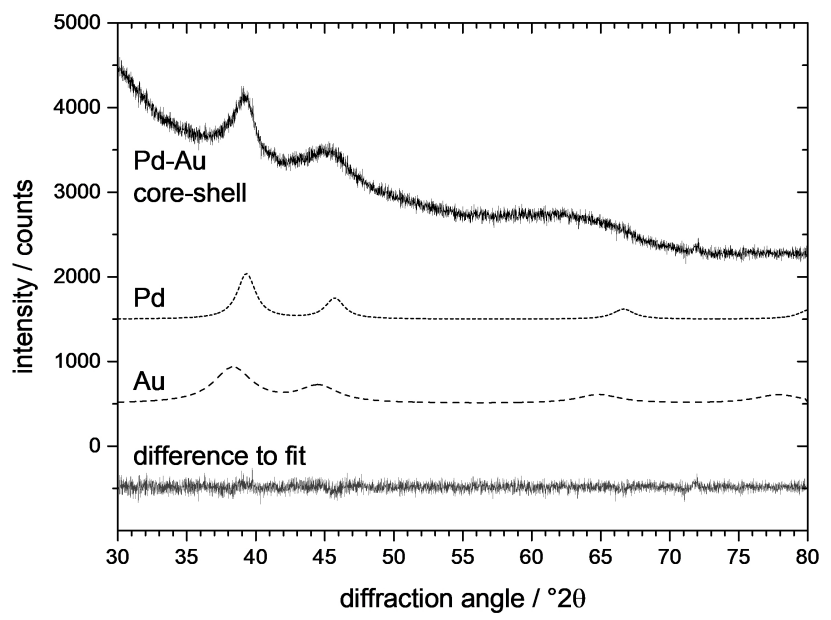

Figure 6. X-ray powder diffractogram including Rietveld refinement of Pd-Au core-shell nanoparticles.

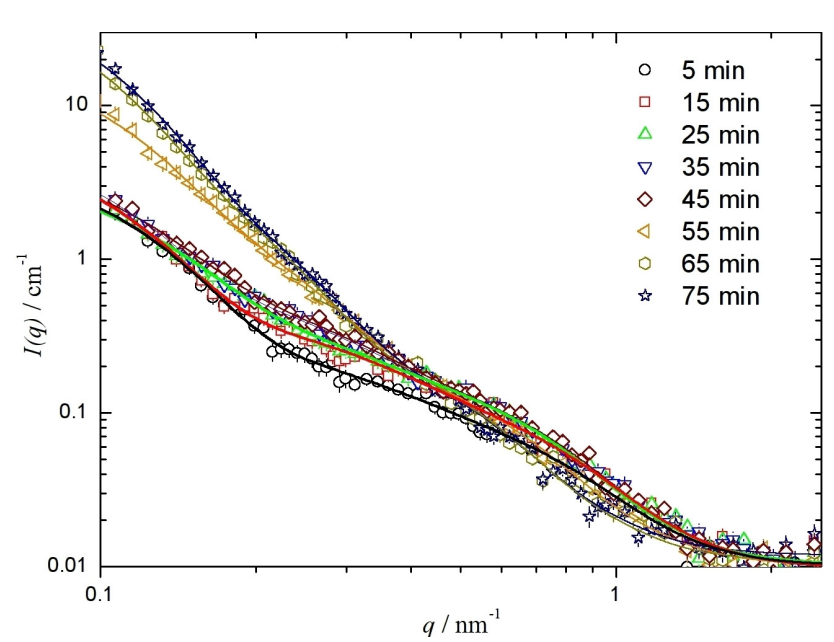

Figure 7. Scattering intensity data from in-situ SAXS measurements. The frames had $1 \mathrm{~min}$ of exposition time but for a better visualization, not all curves are shown. Symbols indicate experimental data points and solid lines indicate fitting curves. At $t=50 \mathrm{~min}$, the gold precursor was added. 


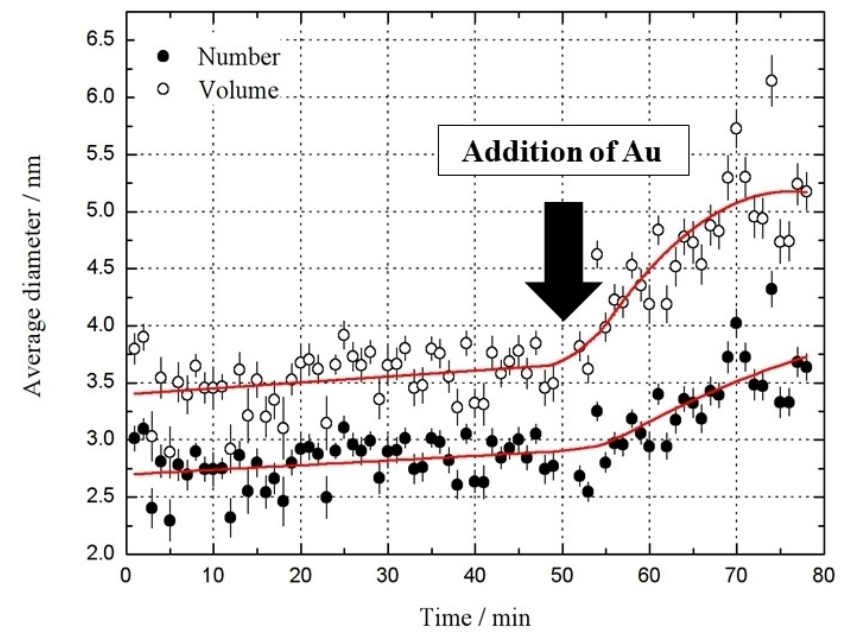

Figure 8. Time-resolved evolution of the average diameter during the synthesis of $\mathrm{Pd}-\mathrm{Au}$ core-shell nanoparticles determined by in-situ SAXS measurements. The trend lines are only for eye-guidance.

The UV-Vis spectra showed an absorption band after the addition of gold which corresponds to the absorption region of the surface plasmon resonance (SPR) of nanoparticulate gold (Figure 9). ${ }^{[23]}$ This observation confirms the presence of a dense gold layer around the palladium core.

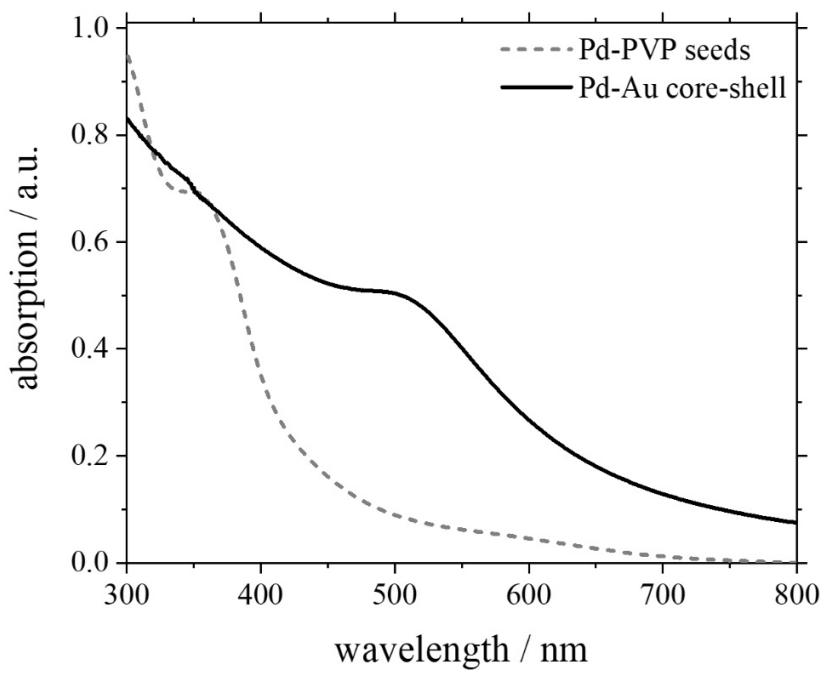

Figure 9. UV-Vis spectra of palladium seed crystals and of the Pd-Au coreshell nanoparticles.

The dispersed core-shell nanoparticles were also subjected to biological testing to assess a potential toxic effect after unintended exposure. Gold nanoparticles are usually considered as biologically inert, ${ }^{[24]}$ unless they are very small (up to a few $n m$, i.e. cluster size). ${ }^{[25]}$ For palladium nanoparticles, there are different reports in the literature where the potential risks have been identified, including catalytic effects and the formation of reactive oxygen species (ROS). ${ }^{[26]}$ In aquatic systems, the risk was assessed as low, probably due to a rapid agglomeration of unfunctionalized palladium nanoparticles in such environmental systems. ${ }^{[27]}$

There are no data available on the biological effects of bimetallic $\mathrm{Pd}-\mathrm{Au}$ nanoparticles. In this study, human mesenchymal stem cells (hMSC) as typical tissue-like cells were incubated with $\mathrm{Pd}-\mathrm{Au}$ core-shell nanoparticles at a total metal concentration of 2.5 to $50 \mu \mathrm{g} \mathrm{mL}^{-1}$ for $24 \mathrm{~h}$. The viability of the treated cells was analysed by fluorescence microscopy (calceinAM staining). As shown in Figure 10, $\mathrm{Pd}-\mathrm{Au}$ nanoparticles had no influence on the viability or the morphology of the treated cells. The quantitative analysis of these data is summarized in Figure 11. Previously, similar results were observed for PVPcoated gold nanoparticles with a particle size of $6 \mathrm{~nm}$ given to hMSC $^{[28]}$ or for pure palladium nanoparticles $(9 \mathrm{~nm})$ incubated with peripheral blood mononuclear cells as reported by Petrarca et al. ${ }^{[29]}$ In addition, Berry et al. showed that gold nanoparticles with a diameter of $5 \mathrm{~nm}$ achieved nuclear entry in fibroblasts, while particles larger than $9 \mathrm{~nm}$ remained in the cytoplasm, suggesting that the uptake into the nucleus is limited by the nuclear pore diameter. ${ }^{[30]}$ Given the size of the $\mathrm{Pd}-\mathrm{Au}$ core-shell nanoparticles in our study (7 to $8 \mathrm{~nm}$ ), it is unlikely that these nanoparticles will enter the cell nucleus to cause cellular damage. Therefore, the health risk after unintended exposure to such nanoparticles is probably low.

\section{Conclusions}

Palladium-gold core-shell particles can be easily prepared in a water-based synthesis by an initial formation of the palladium seed, followed by the addition of a gold shell. There is an epitactic overgrowth of the gold shell (thickness about $1.5 \mathrm{~nm}$ ) onto the palladium core (diameter about 5 to $6 \mathrm{~nm}$ ), leading to a molar ratio of $\mathrm{Pd}: \mathrm{Au}$ of about 2:1. A galvanic replacement of palladium by gold was not observed. The presence of palladium and gold in two separate (but partially alloyed) phases was confirmed by EDX and HAADF-STEM and by X-ray powder diffraction. These experimental results can provide valuable information for further molecular dynamic (MD) simulations because they can give important constraints for parameters like overall size, crystal structure, and number fractions. Concerning the biological activity, there was no significant effect on human mesenchymal stem cells, i.e. the potentially harmful palladium core is well shielded by the gold surface layer. Thus, the danger of a potential unintended exposure to such nanoparticles for humans is probably low. The extension of this synthesis to palladium-gold particles with a different ratio of the elements may be possible by variation of the synthesis conditions, in particular the ratio of the two metals.

\section{Supporting Information Summary}

In the supporting information, all experimental data of the synthesis and the characterization of the nanoparticles are given, including details of the cell-biological studies. Further- 

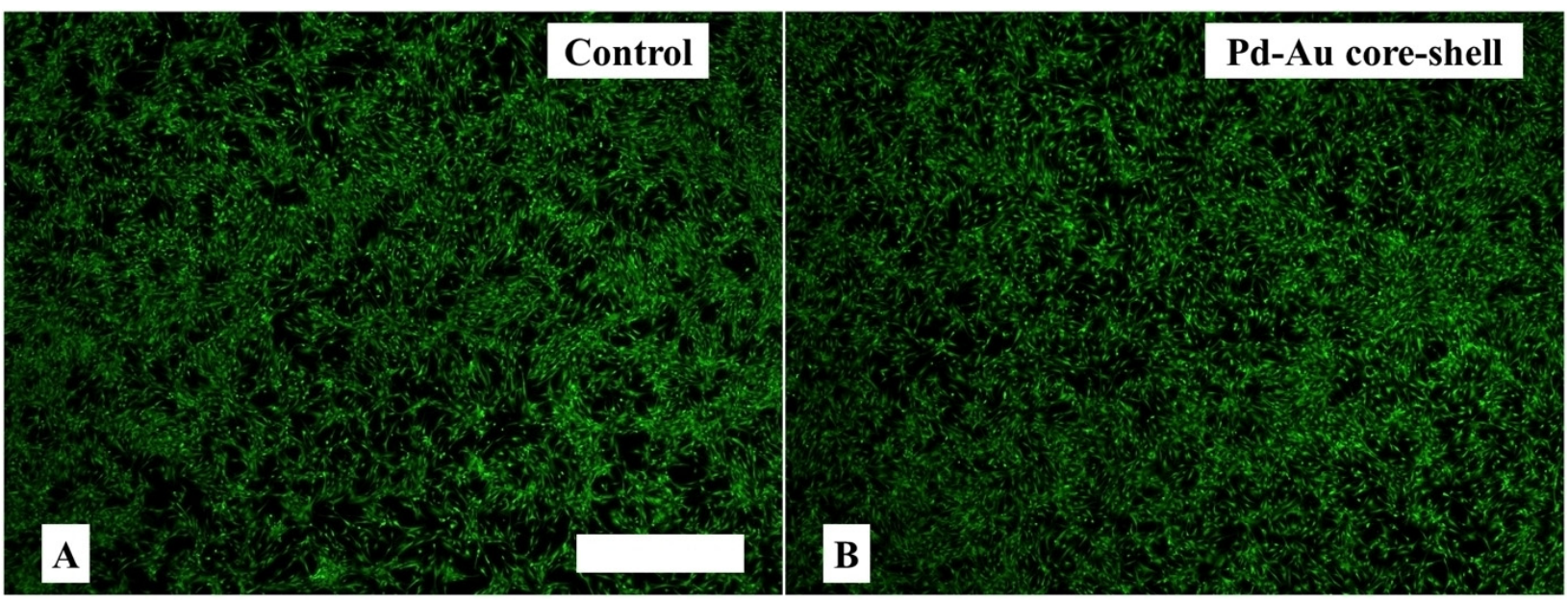

Figure 10. Effect of Pd-Au nanoparticles on the viability and morphology of human mesenchymal stem cells (hMSCs). Subconfluently growing hMSC in 24-well cell culture plates were incubated in the absence $\left(\mathbf{A}\right.$; control) or in the presence of nanoparticles $\left(\mathbf{B} ; 50 \mu \mathrm{g} \mathrm{mL}^{-1}\right)$ for $24 \mathrm{~h}$ under cell culture conditions and subsequently stained with calcein-AM. Viable cells are indicated by green fluorescence. Scale bar $500 \mu \mathrm{m}$.

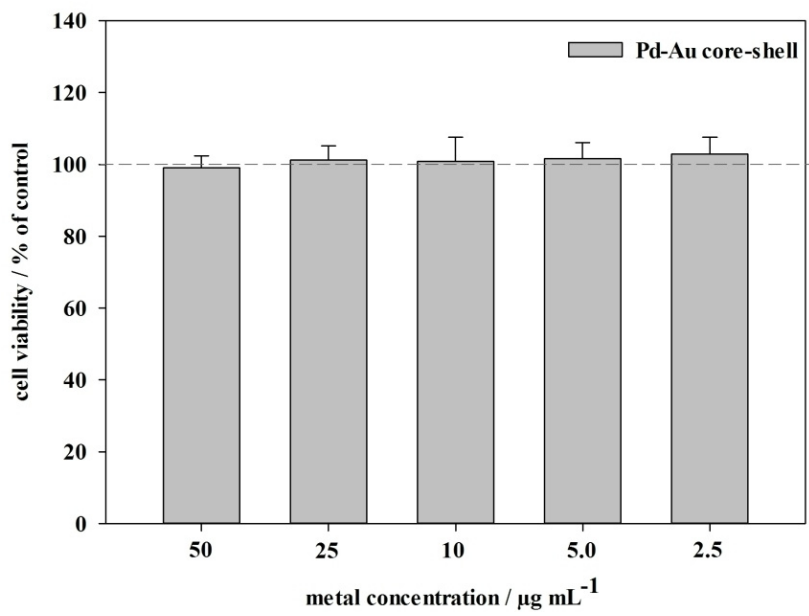

Figure 11. Effect of Pd-Au core-shell nanoparticles on the viability of human mesenchymal stem cells (hMSC). The cells were treated with Pd-Au-PVP nanoparticles ( 2.5 to $50 \mu \mathrm{g} \mathrm{mL}^{-1}$ ). for $24 \mathrm{~h}$ under cell culture conditions. Vital cells (green fluorescence) were quantified by digital image processing (phase analysis). The data are expressed as mean \pm SD ( $n=6$ independent experiments) given as the percentage of the control (cells cultured without nanoparticles).

more, the model that we used to analyse the SAXS data is described in detail.

\section{Acknowledgements}

The authors acknowledge financial support of this work by the Deutsche Forschungsgemeinschaft (DFG) in the projects EP 22/441, SE 2449/2-1, HE 7192/2-1, by the DAAD/CAPES PPP-project No 57139595 , and by the CAPES-PROBAL program for a fellowship within the process 99999.000298/2016-06 (to PRAFG). CLPO is supported by the National Council for Scientific and Technological Development, the Coordination for the Improvement of Higher
Education Personnel (CAPES), the National Institute of Science and Technology Complex Fluids (INCT-FCX), and the São Paulo Research Foundation.

\section{Conflict of Interest}

The authors declare no conflict of interest.

Keywords: core-shell nanoparticles - small-angle X-ray scattering $\cdot$ X-ray powder diffraction $\cdot$ alloys $\cdot$ palladium $\cdot$ gold . nanotoxicology

[1] a) H. Goesmann and C. Feldmann, Angew. Chem. Int. Ed. 2010, 49, 13621395; b) S. E. Lohse and C. J. Murphy, J. Am. Chem. Soc. 2012, 134, 15607-15620; c) W. J. Stark, P. R. Stoessel, W. Wohlleben and A. Hafner, Chem. Soc. Rev. 2015, 44, 5793-5805; d) Y. N. Xia, Y. Xiong, B. Lim and S. E. Skrabalak, Angew. Chem. Int. Ed. 2009, 48, 60-103; e) R. Yu, L. M. LizMarzán and F. J. García de Abajo, Chem. Soc. Rev. 2017, 46, 6710-6724; f) J. J. Giner-Casares, M. Henriksen-Lacey, M. Coronado-Puchau and L. M. Liz-Marzán, Mater. Today 2016, 19, 19-28; g) J. Broda, G. Schmid and U. Simon, Struct. Bond. 2014, 161, 189-242.

[2] a) P. K. Jain, X. Huang, I. H. El-Sayed and M. A. El-Sayed, Acc. Chem. Res. 2008, 41, 1578-1586; b) J. Li, T. Zhao, T. Chen, Y. Liu, C. N. Ong and J. Xie, Nanoscale 2015, 7, 7502-7519; c) Y. Xu, L. Chen, X. Wang, W. Yao and Q. Zhang, Nanoscale 2015, 7, 10559-10583; d) H. L. Liu, F. Nosheen and X. Wang, Chem. Soc. Rev. 2015, 44, 3056-3078; e) R. M. Wang, O. Dmitrieva, M. Farle, G. Dumpich, H. Q. Ye, H. Poppa, R. Kilaas and C. Kisielowski, Phys. Rev. Lett. 2008, 100, 017205.

[3] a) M. B. Gawande, A. Goswami, T. Asefa, H. Guo, A. V. Biradar, D. L. Peng, R. Zboril and R. S. Varma, Chem. Soc. Rev. 2015, 44, 7540-7590; b) K. McNamara and S. A. Tofail, Phys. Chem. Chem. Phys. 2015, 17, 2798127995; c) M. Spasova, T. Radetic, N. S. Sobal, M. Hilgendorff, U. Wiedwald, M. Farle, M. Giersig and U. Dahmen, Mat. Res. Soc. Symp. Proc. 2002, 721, 195-200; d) G. Guisbiers, R. Mendoza-Cruz, L. Bazán-Díaz, J. J. VelázquezSalazar, R. Mendoza-Perez, J. A. Robledo-Torres, J. L. Rodriguez-Lopez, J. M. Montejano-Carrizales, R. L. Whetten and M. José-Yacamán, ACS Nano 2016, 10, 188-198; e) L. Gan, M. Heggen, R. O'Malley, B. Theobald and P. Strasser, Nano Lett. 2013, 13, 1131-1138; f) V. Petkov, B. Prasai, Y. Ren, S. Y. Shan, J. Luo, P. Joseph and C. J. Zhong, Nanoscale 2014, 6, 10048-10061; g) C. K. Narula, X. Yang, C. Li, A. R. Lupini and S. J. Pennycook, J. Phys. Chem. C 2015, 119, 25114-25121; h) S. I. Sanchez, 
M. W. Small, J. M. Zuo and R. G. Nuzzo, J. Am. Chem. Soc. 2009, 131, 8683-8689.

[4] L. Zhang, Z. Xie and J. Gong, Chem. Soc. Rev. 2016, 45, 3916-3934.

[5] L. Zhang, J. W. Zhang, Q. Kuang, S. F. Xie, Z. Y. Jiang, Z. X. Xie and L. S. Zheng, J. Am. Chem. Soc. 2011, 133, 17114-17117.

[6] P. Kunal, H. Li, B. L. Dewing, L. Zhang, K. Jarvis, G. Henkelman and S. M. Humphrey, ACS Catalysis 2016, 6, 4882-4893.

[7] C. Hahn, D. N. Abram, H. A. Hansen, T. Hatsukade, A. Jackson, N. C. Johnson, T. R. Hellstern, K. P. Kuhl, E. R. Cave, J. T. Feaster and T. F. Jaramillo, J. Mater. Chem. A 2015, 3, 20185-20194.

[8] G. Prévot, N. T. Nguyen, D. Alloyeau, C. Ricolleau and J. Nelayah, ACS Nano 2016, 10, 4127-4133.

[9] J. Li, Y. Q. Zheng, J. Zeng and Y. N. Xia, Chem. Eur. J. 2012, 18, 8150-8156.

[10] A. Spitale, M. A. Perez, S. Mejía-Rosales, M. J. Yacamán and M. M. Mariscal, Phys. Chem. Chem. Phys. 2015, 17, 28060-28067.

[11] C. J. DeSantis, A. C. Sue, M. M. Bower and S. E. Skrabalak, ACS Nano 2012, 6, 2617-2628.

[12] A. Gopalan, D. Ragupathy, H. T. Kim, K. M. Manesh and K. P. Lee, Spectrochim. Acta A Mol. Biomol. Spectrosc. 2009, 74, 678-684.

[13] B. Lim, H. Kobayashi, T. Yu, J. G. Wang, M. J. Kim, Z. Y. Li, M. Rycenga and Y. N. Xia, J. Am. Chem. Soc. 2010, 132, 2506-2507.

[14] V. Mazumder, M. F. Chi, K. L. More and S. H. Sun, Angew. Chem. Int. Ed. 2010, 49, 9368-9372.

[15] C. Fernández-Navarro and S. Mejía-Rosales, J. Phys. Chem. C 2017, 121 21658-21664.

[16] B. Zhu, A. Front, H. Guesmi, J. Creuze, B. Legrand and C. Mottet, Comp. Theoret. Chem. 2017, 1107, 49-56.

[17] a) Y. Xia, X. Xia, Y. Wang and S. Xie, MRS Bull. 2013, 38, 335-344; b) B. Wiley, Y. Sun and Y. Xia, Acc. Chem. Res. 2007, 40, 1067-1076.

[18] a) P. Hou, H. Liu, J. Li and J. Yang, Cryst. Eng. Comm 2015, 17, 1826-1832; b) C. Gao, J. Goebl and Y. Yin, J. Mater. Chem. C 2013, 1, 3898-3909.

[19] a) S. Banerjee, K. Loza, W. Meyer-Zaika, O. Prymak and M. Epple, Chem. Mater. 2014, 26, 951-957; b) D. Mahl, J. Diendorf, W. Meyer-Zaika and M. Epple, Coll. Surf. A 2011, 377, 386-392.

[20] K. MacArthur, T. Slater, S. Haigh, D. Ozkaya, P. Nellist and S. Lozano-Perez, Microscopy Microanalysis 2016, 22, 71-81.

[21] a) R. Ruer, A. Anorg. Allg. Chem. 1906, 51, 391-396; b) S. Holgersson and E. Sedstrom, Ann. Phys. 1924, 75, 143-162; c) V. G. Kuznecov, Struct. Rep.
1946, 10, 54-55; d) E. Raub and G. Worwag, Z. Metallkde. 1955, 46, 513515; e) A. Maeland and T. B. Flanagan, Can. J. Phys. 1964, 42, 2364; f) H. Okamoto and T. B. Massalski, Bull. Alloy Phase Diagr. 1985, 6, 229-235.

[22] a) Y. G. Sun and Y. Ren, Part. Part. Syst. Charact. 2013, 30, 399-419; b) S. Yan, Z. H. Wu, H. Y. Yu, Y. Gong, Y. Y. Tan, R. Du, W. Chen, X. Q. Xing, G. Mo, Z. J. Chen, Q. Cai and D. B. Sun, J. Phys. Chem. C 2014, 118, 11454$11463 ;$ c) X. L. Chen, J. Schroder, S. Hauschild, S. Rosenfeldt, M. Dulle and S. Forster, Langmuir 2015, 31, 11678-11691.

[23] J. A. Creighton and D. G. Eadon, J. Chem. Soc. Faraday Trans. 1991, 87, 3881-3891.

[24] M. Homberger and U. Simon, Phil. Trans. R. Soc. A 2010, 368, 1405-1453.

[25] a) Y. Pan, S. Neuss, A. Leifert, M. Fischler, F. Wen, U. Simon, G. Schmid, W. Brandau and W. Jahnen-Dechent, Small 2007, 3, 1941-1949; b) S. K. Boda, J. Broda, F. Schiefer, J. Weber-Heynemann, M. Hoss, U. Simon, B. Basu and W. Jahnen-Dechent, Small 2015, 11, 3183-3193; c) A. Leifert, Y. Pan-Bartnek, U. Simon and W. Jahnen-Dechent, Nanoscale 2013, 5, 6224-6242.

[26] a) I. lavicoli, M. Farina, L. Fontana, D. Lucchetti, V. Leso, C. Fanali, V. Cufino, A. Boninsegna, K. Leopold, R. Schindl, D. Brucker and A. Sgambato, Toxicol. in vitro 2017, 42, 191-199; b) N. Neubauer, J. Palomaeki, P. Karisola, H. Alenius and G. Kasper, Nanotoxicology 2015, 9, 1059-1066; c) L. Fontana, V. Leso, A. Marinaccio, G. Cenacchi, V. Papa, K. Leopold, R. Schindl, B. Bocca, A. Alimonti and I. lavicoli, Nanotoxicology 2015, 9, 843-851.

[27] S. Luderwald, F. Seitz, G. A. Seisenbaeva, V. G. Kessler, R. Schulz and M. Bundschuh, Bull. Env. Contamin. Toxicol. 2016, 97, 153-158.

[28] D. Mahl, C. Greulich, W. Meyer-Zaika, M. Köller and M. Epple, J. Mater. Chem. 2010, 20, 6176-6181.

[29] C. Petrarca, E. Clemente, L. Di Giampaolo, R. Mariani-Costantini, K. Leopold, R. Schindl, L. V. Lotti, R. Mangifesta, E. Sabbioni, Q. Niu, G. Bernardini and M. Di Gioacchino, J. Immunol. Res. 2014, 2014, 295092.

[30] C. C. Berry, J. M. de la Fuente, M. Mullin, S. W. L. Chu and A. S. G. Curtis, NanoBioscience, IEEE Trans. 2007, 6, 262-269.

Submitted: March 2, 2018

Revised: March 31, 2018

Accepted: April 10, 2018 